Portland State University

PDXScholar

Spring 5-26-2016

\title{
The Effects of Phosphonic Acids in Dye-Sensitized Solar Cells
}

Keith Edward James

Portland State University

Follow this and additional works at: https://pdxscholar.library.pdx.edu/open_access_etds

Part of the Chemistry Commons, and the Power and Energy Commons Let us know how access to this document benefits you.

\section{Recommended Citation}

James, Keith Edward, "The Effects of Phosphonic Acids in Dye-Sensitized Solar Cells" (2016).

Dissertations and Theses. Paper 2951.

https://doi.org/10.15760/etd.2946

This Dissertation is brought to you for free and open access. It has been accepted for inclusion in Dissertations and Theses by an authorized administrator of PDXScholar. Please contact us if we can make this document more accessible: pdxscholar@pdx.edu. 
The Effects of Phosphonic Acids in Dye-Sensitized Solar Cells

by

Keith Edward James

A dissertation submitted in partial fulfillment of the requirements for the degree of

Doctor of Philosophy

in

Chemistry

Dissertation Committee:

Carl C. Wamser, Chair

Erik Johansson

Shankar B. Rananavare

Dean B. Atkinson

Rolf Könenkamp

Portland State University 2016 
(C) 2016 Keith Edward James 


\begin{abstract}
Novel methods for the construction of dye-sensitized solar cells (DSSCs) were developed. A thin dense underlayer of $\mathrm{TiO}_{2}$ was applied on fluorine-doped tin oxide (FTO) glass using as a precursor Tyzor AA-105. Subsequently a mesoporous film of P$25 \mathrm{TiO}_{2}$ was applied by spreading a suspension uniformly over the surface of the underlayer and allowing the plate to slowly dry while resting on a level surface. After sintering at $500^{\circ} \mathrm{C}$ slides were treated with TCPP as a sensitizing dye and assembled into DSSCs. A novel method was used to seal the cells; strips of Parafilm® were used as spacers between the electrodes and to secure the electrodes together. The cells were filled with a redox electrolyte and sealed by dipping into molten paraffin.
\end{abstract}

A series of phosphonic acids and one arsonic acid were employed as coadsorbates in DSSCs. The coadsorbates were found to compete for binding sites, resulting in lower levels of dye adsorption. The resulting loss of photocurrent was not linear with the reduction of dye loading, and in some cases photocurrent and efficiency were higher for cells with lower levels of dye loading.

Electrodes were treated with coadsorbates by procedures including pre-adsorption, simultaneous (sim-adsorption), and post-adsorption, using a range of concentrations and treatment times and a variety of solvents. Most cells were tested using an iodide-triiodide based electrolyte (I3I-1) but some cells were tested using electrolytes based on a 
$\mathrm{Co}(\mathrm{II}) / \mathrm{Co}(\mathrm{III})$ redox couple (CoBpy electrolytes). Phosphonic acid post-adsorbates increased the $\mathrm{V}_{\mathrm{oc}}$ of cells using CoBpy electrolytes but caused a decrease in the $\mathrm{V}_{\mathrm{oc}}$ of cells using I3I-1 electrolyte. Phosphonic acids as sim-adsorbates resulted in a significant increase in efficiency and $\mathrm{J}_{\mathrm{sc}}$, and they show promise as a treatment for TCPP DSSCs. 


\section{Dedication}

This dissertation is dedicated to my wife, Marsha Barnes. A patient woman.

She has given me encouragement when I needed it most and supported me in every

possible way. She has had faith in me when I lost faith in myself, and against all odds has continued to love me.

I am a lucky man. 


\section{Acknowledgements}

First and foremost I wish to thank my advisor, Dr. Carl C. Wamser, for the guidance and support he has given me as this project progressed. His knowledge and clear thinking were tremendously helpful, and his patience and generosity made it a pleasure to work in his lab. I could keep going, but I think the picture is clear enough.

I wish also to thank the other members of my committee; Dr. Erik Johansson, Dr. Rolf Könenkamp, Dr. Dean Atkinson, and Dr. Shankar Rananavare have been consistently gracious and helpful through all stages of my doctoral program, sharing ideas and encouragement.

I wish also to thank Dr. Mark Woods, who provided a helpful kick in the - you know that propelled the project forward when it needed it most. Thank you, Mark, for keeping your eye on the clock.

My hat is off to the PSU Chemistry Department for accepting me into their doctoral program and for seeing me through to the end. It has been a great pleasure to be in the company of chemists, including faculty and graduate students alike. There's not another group like 'em.

Life in the lab would not have been the same without Nick Day. Ever a source of good spirits, good ideas, and boundless energy, Nick made it a pleasure to be in the lab. And 
did I mention his optimism? A beacon of positive thinking. Thank you, Nick, for being who you are.

Cheryl Hodson has been my friend since we met, and more recently my guide through the final stages of this process. She has reassured me numerous times that my doubts, worries, and miscellaneous agonies are the same as experienced by every other chemistry graduate student who has ever struggled over the finish line. I thank you, Cheryl, for putting it all in perspective. You have saved my sanity more times than I can count.

Finally, I come to my wife, Marsha Barnes. I am having trouble finding words to express my appreciation for all that Marsha has done. But luckily, since she is my wife, I will have years to continue finding ways to thank her. Thank you, Marsha. There, that's a start. 


\section{TABLE OF CONTENTS}

Abstract.........................................................................

Dedication............................................................

Acknowledgements..................................................

List of Tables..............................................................

List of Figures.........................................................

List of Equations....................................................... xvi

List of Abbreviations and Symbols..................................... vvii

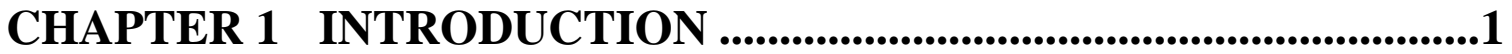

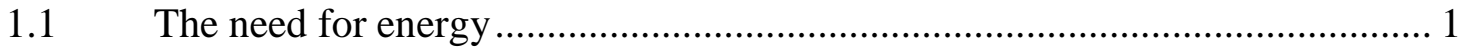

$1.2 \quad$ Fossil fuels ......................................................................................... 1

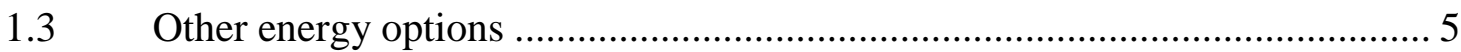

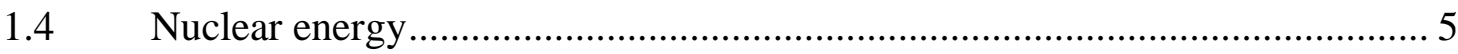

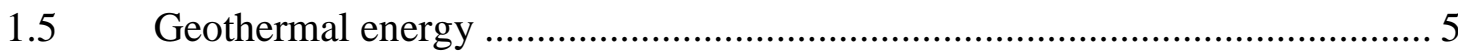

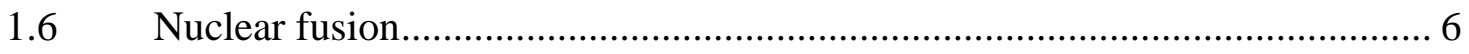

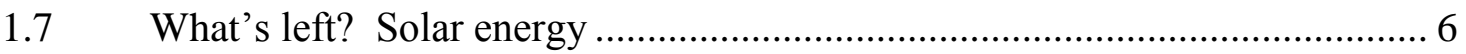

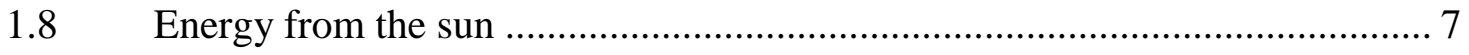

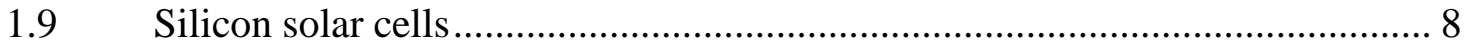

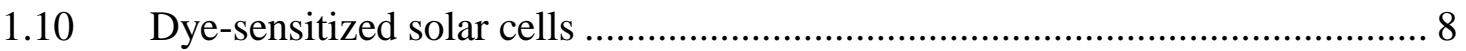

1.11 The atmosphere ...................................................................................... 10

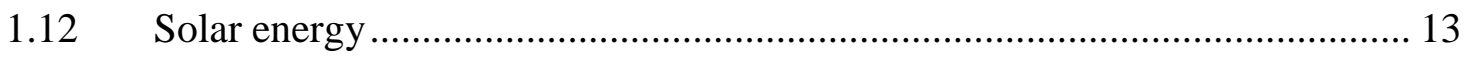

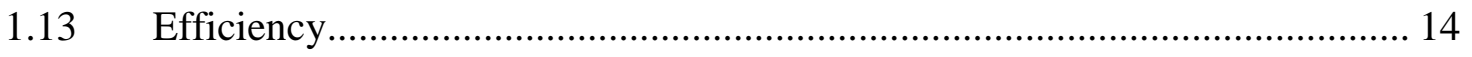




\section{CHAPTER 2 EXPERIMENTAL .......................................................16}

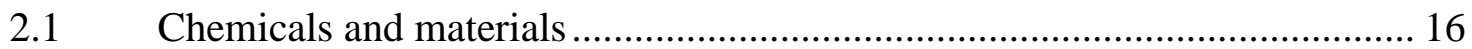

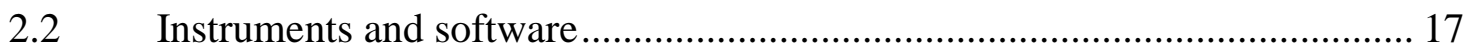

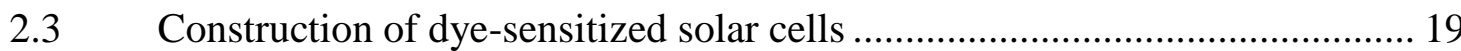

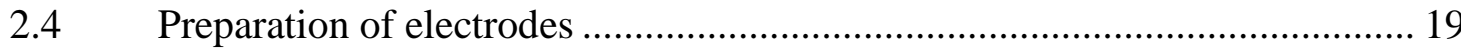

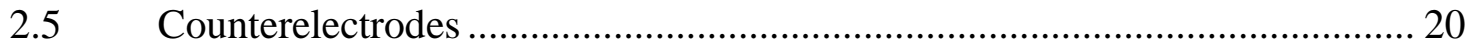

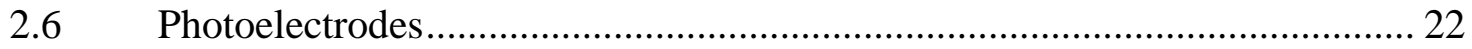

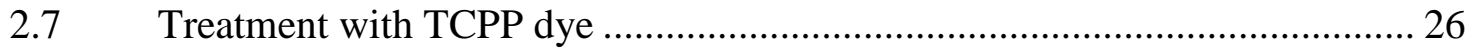

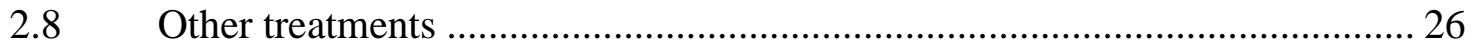

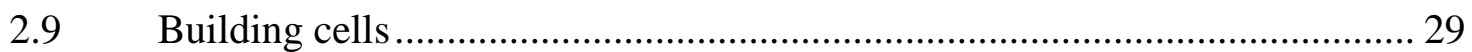

2.10 Light sources................................................................................ 30

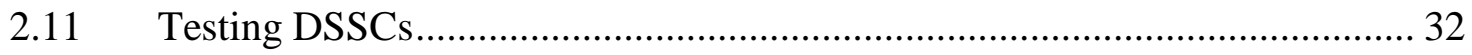

2.12 Preparation of I3I-1 electrolyte.............................................................. 36

2.13 Synthesis of Co tris-bipyridyl hexafluorophosphate ................................ 37

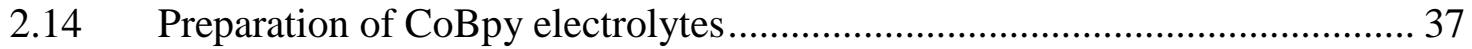

\section{CHAPTER 3 DYE-SENSITIZED SOLAR CELLS................................38}

History of dye-sensitized solar cells ..................................................... 38

3.2 Basis for the operation of a dye-sensitized solar cell ................................. 39

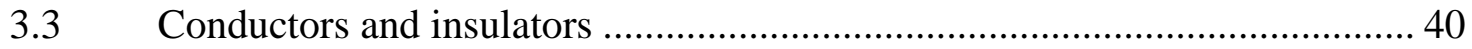

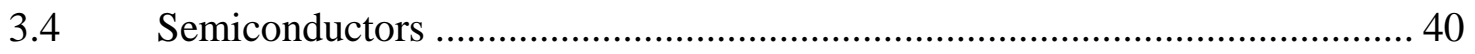

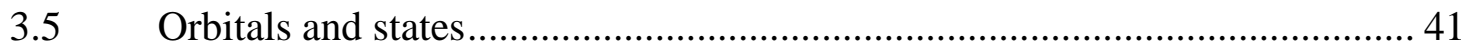

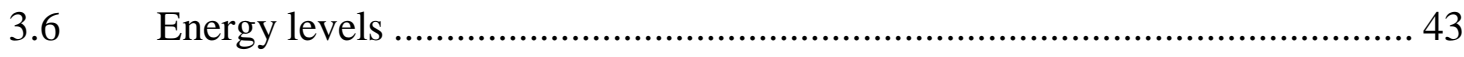

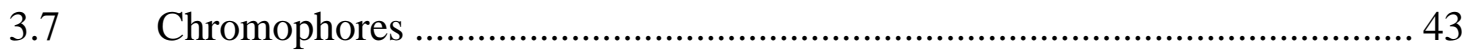


3.8 Light absorption by a semiconductor .............................................. 44

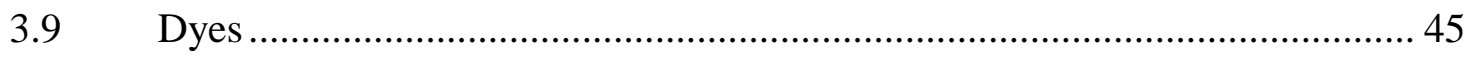

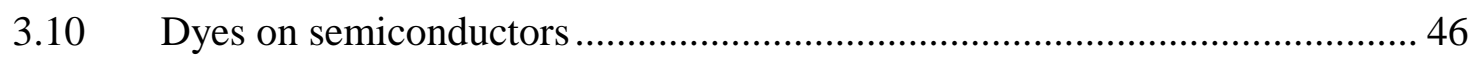

3.11 Holes and hole-transport media........................................................ 48

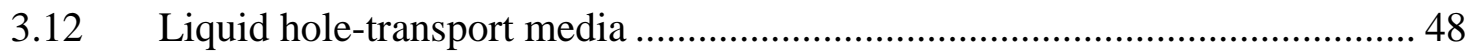

S.13 Strengths and weaknesses of I3I electrolytes ....................................... 50

Solid-state HTMs.............................................................................. 51

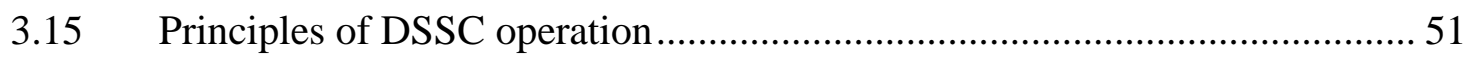

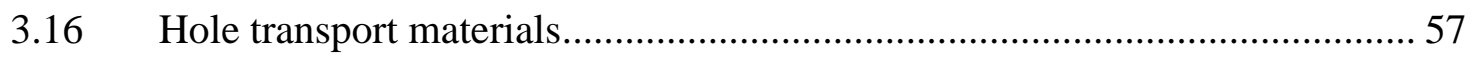

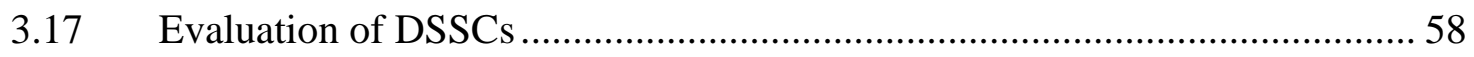

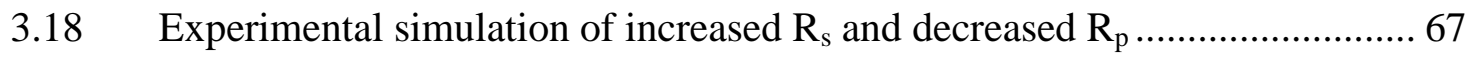

3.19 Preventing the type 2 back reaction.................................................. 70

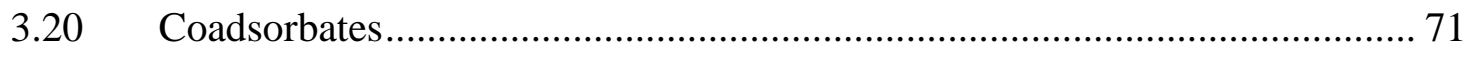

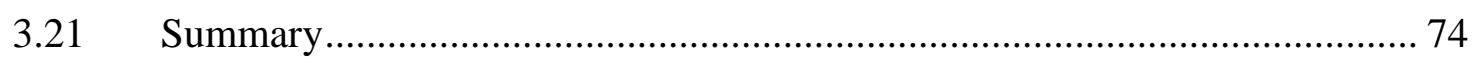

\section{CHAPTER 4 DEVELOPMENT OF METHODS .....................................76}

4.1 Philosophy of experimental practices ............................................... 76

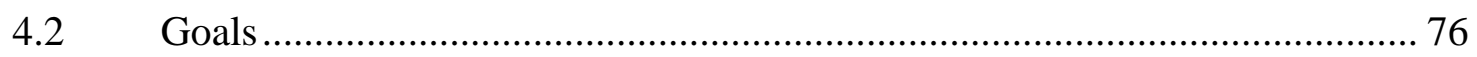

4.3 Methods to assemble and seal a DSSC ................................................. 77

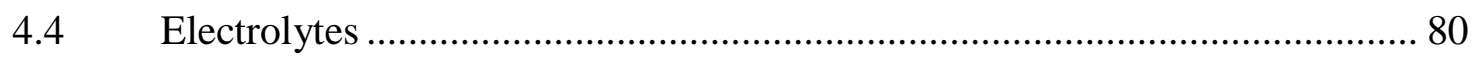

4.5 Methods used to apply a thin dense $\mathrm{TiO}_{2}$ underlayer................................ 81

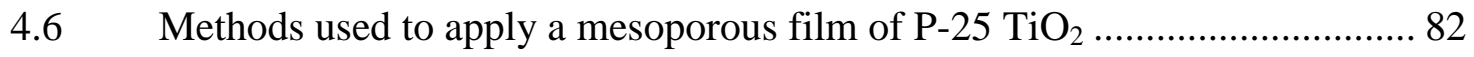

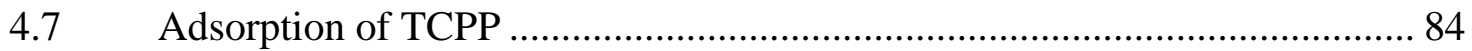

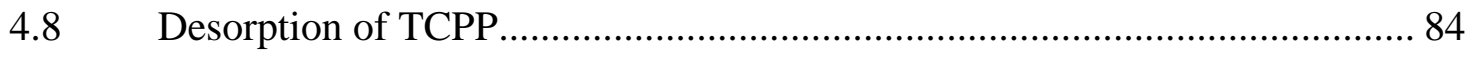


4.9 Treatment of TCPP slides with MeCN ................................................... 86

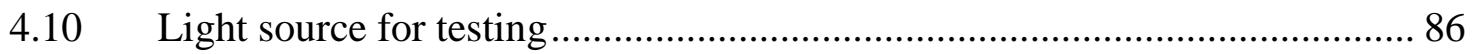

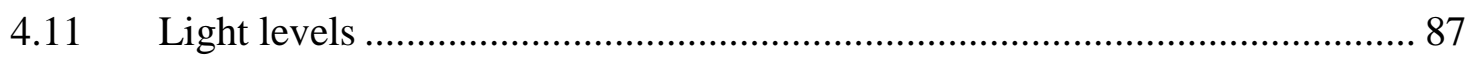

4.12 Using a mask for iV tests.............................................................. 88

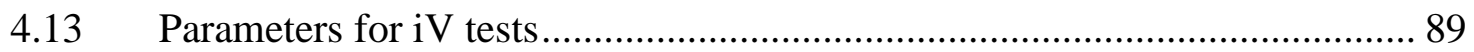

\section{CHAPTER 5 RESULTS AND DISCUSSION .......................................}

5.1 Reproducibility without coadsorbates .................................................. 93

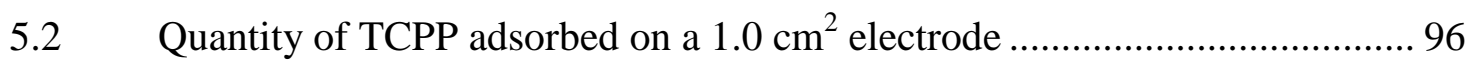

5.3 Performance of a DSSC as a function of excitation wavelength................... 99

5.4 Procedures for application of coadsorbates ......................................... 102

5.5 Effects of sintered phosphonate treatments ......................................... 105

5.6 Electrodes prepared with pre-adsorbed phosphonic acids with and without subsequent treatment with TCPP.......................................................... 107

5.7 Effect of pre-adsorbates on efficiency of TCPP-sensitized cells ................. 108

5.8 Effect of pre-adsorbates on $\mathrm{V}_{\mathrm{oc}}$ of TCPP-sensitized cells ........................ 110

5.9 Effect of pre-adsorbates on fill factor of TCPP-sensitized cells ................. 112

5.10 Effect of pre-adsorbates on $\mathrm{J}_{\mathrm{sc}}$ of TCPP-sensitized cells .......................... 114

5.11 Dye loading of cells treated with pre-adsorbates..................................... 116

5.12 Electrodes with pre-adsorbates and without TCPP ................................ 122

5.13 Efficiency of cells treated with pre-adsorbates but without TCPP............. 123

5.14 $\mathrm{V}_{\text {oc }}$ of cells treated with pre-adsorbates but without TCPP ....................... 125

5.15 Fill factor of cells with pre-adsorbates but without TCPP ….................... 127

$5.16 \mathrm{~J}_{\mathrm{sc}}$ of cells with pre-adsorbate but without TCPP .................................. 128

5.17 Summary of overall effects of pre-adsorbates without TCPP .................... 130 
5.18 Phosphonic acids as sim-adsorbates at $8 \mu \mathrm{M}$ concentration

5.19 Efficiencies of cells with sim-adsorbates at $8 \mu \mathrm{M}$ concentration

5.20 $\mathrm{V}_{\text {oc }}$ of cells with sim-adsorbates at $8 \mu \mathrm{M}$ concentration 134

5.21 Fill factors of cells with sim-adsorbates at $8 \mu \mathrm{M}$ concentration 136

5.22 $\mathrm{J}_{\mathrm{sc}}$ values of cells with sim-adsorbates at $8 \mu \mathrm{M}$ concentration 138

5.23 Summary of effects of sim-adsorbates at $8 \mu \mathrm{M}$ concentration 139

5.24 Determination of optimal sim-adsorbate concentration 140

5.25 Phosphonic acids as sim-adsorbates at $40 \mu \mathrm{M}$ concentration 142

5.26 Summary of effects of sim-adsorbates at $40 \mu \mathrm{M}$ concentration 146

5.27 Phosphonic acids as post-adsorbates

5.28 Results for cells using I3I-1 electrolyte

5.29 Summary of effects produced by post-adsorption treatment of TCPP cells using I3I-1 electrolyte

5.30 Results for cells using CoBpy-1 electrolyte

5.31 Summary of effects produced by post-adsorption treatment of TCPP cells using CoBpy-1 electrolyte 160

5.32 Results for cells using CoBpy-3 electrolyte 160

5.33 Summary of effects produced by post-adsorption treatment of TCPP cells using CoBpy-3 electrolyte. 165

CHAPTER 6 CONCLUSIONS 166

REFERENCES. 183 


\section{List of Tables}

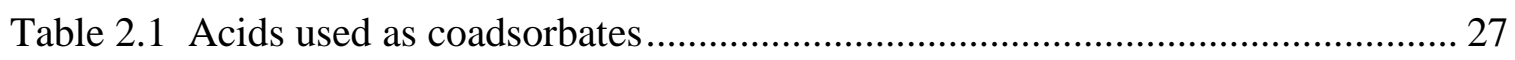

Table 5.1 Results of cell reproducibility test without coadsorbates .............................. 94

Table 5.2 Specific cases of electrodes with and without dye and/or coadsorbate ......... 108

Table 5.3 Efficiency of cells treated with pre-adsorbates, from 0 to 336 hours ............ 109

Table $5.4 \mathrm{~V}_{\text {oc }}$ of cells treated with pre-adsorbates from 0 hours to 336 hours .............. 111

Table 5.5 Effect of pre-adsorbates on fill factor from 0 to 336 hours .......................... 113

Table $5.6 \mathrm{~J}_{\mathrm{sc}}$ values of TCPP cells treated with pre-adsorbates ................................. 115

Table 5.7 Dye loading and $\mathrm{J}_{\mathrm{sc}}$ ratios of cells pre-treated with coadsorbates normalized to

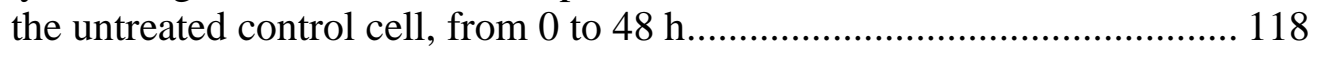

Table $5.8 \mathrm{~J}_{\text {sc }}$ per nanomole of adsorbed TCPP $(\mu \mathrm{A} / \mathrm{nmol})$. These data are presented graphically in Figure 5.10 ............................................................. 121

Table 5.9 Estimated efficiencies of cells with pre-adsorbates but without TCPP ......... 124

Table $5.10 \mathrm{~V}_{\mathrm{oc}}$ of cells with pre-adsorbates but without TCPP ................................. 126

Table 5.11 Fill factor of cells with pre-adsorbates but without TCPP......................... 127

Table $5.12 \mathrm{~J}_{\mathrm{sc}}$ of cells with pre-adsorbates but without TCPP.................................. 129

Table 5.13 Performance metrics at $0.1 \mathrm{~h}$ of cells treated with $8 \mu \mathrm{M}$ sim-adsorbates.... 132

Table 5.14 Average efficiency of cells with $8 \mu \mathrm{M}$ sim-adsorbates .............................. 133

Table 5.15 Average $\mathrm{V}_{\text {oc }}$ of cells treated with $8 \mu \mathrm{M}$ sim-adsorbates ............................ 135

Table 5.16 Average fill factor of cells treated with $8 \mu \mathrm{M}$ sim-adsorbates .................... 137

Table 5.17 Average $\mathrm{J}_{\mathrm{sc}}$ of cells treated with $8 \mu \mathrm{M}$ sim-adsorbates............................. 138

Table 5.18 Performance metrics at $0.1 \mathrm{~h}$ of cells treated with varying concentrations of decylphosphonic acid as a sim-adsorbate ............................................. 141

Table 5.19 Performance metrics at $0.1 \mathrm{~h}$ and $2.0 \mathrm{~h}$ of cells treated with $40 \mu \mathrm{M}$ phosphonic acid sim-adsorbates

Table 5.20 Performance data for cells treated with C10PA (2 mM) in MeCN for cells using I3I-1 electrolyte

Table 5.21 Performance data for cells treated with C10PA (2 mM) in MeCN for cells using CoBpy-1 electrolyte

Table 5.22 Performance data for cells treated with C10PA (2 mM) in MeCN for cells using CoBpy-3 electrolyte 161 


\section{List of Figures}

Figure 1.1 Atmospheric $\mathrm{CO}_{2}$ levels as measured by the National Oceanic and Atmospheric Administration at Mauna Loa Observatory

Source: http://www.esrl.noaa.gov/gmd/ccgg/trends

Figure 1.2 Solaronix' multicolored transparent photovoltaic façade at the SwissTech Convention Center, EPFL, Switzerland

Source: http://www.solaronix.com/documents/solaronix_solar_cells 9

Figure 1.3 A commercially available DSSC-powered backpack, from Gcell.com Source: http://gcell.com/product/gratzel-solar-backpack 10

Figure 1.4 The AM1.5 solar spectrum. The red curve is the solar spectrum before it enters the atmosphere. Absorptions by various components of the atmosphere attenuate the light reaching the surface of the Earth. These are most pronounced in the IR region. Source:

http://www.pveducation.org/pvcdrom/appendices/standard-solar-spectra, derived from data provided by NREL

Figure 2.1 Scoring and masking diagram for a plate of electrodes............................. 21

Figure 2.2 Fixture used to trim $\mathrm{TiO}_{2}$ from half-plates ............................................. 24

Figure 2.3 A typical electrode, with Parafilm ${ }^{\circledR}$ strips and a counterelectrode ............... 25

Figure 2.4 Structures of phosphonic and arsonic acids employed as coadsorbates....... 28

Figure 2.5 A typical cell, fully assembled and ready to be tested. The photoelectrode is on top, with its identifier $\mathrm{CH}-3725$ scribed into the back of the slide. The ends of the electrodes are not coated with paraffin to enable clean electrical connections.

Figure 2.6 Global tilt solar spectra with emission spectra of a white (5000 K) LED and a $50 \mathrm{~W}$ quartz-halogen lamp. Each spectrum was normalized to the wavelength of maximum power flux. Power flux units are arbitrary. Source of the solar spectrum:

http://www.pveducation.org/pvcdrom/appendices/standard-solar-spectra, derived from data provided by NREL

Figure 2.7 A cell in the iV test station, with the cover removed for clarity. In the foreground the back of the LED light source is seen, directed at a cell mounted on the test stage and connected with alligator clips. The cell is masked by an aluminum strip with a hole 0.25 inch in diameter ................. 33

Figure 2.8 Close-up of the test stage with cell to be tested mounted in position............ 34

Figure 2.9 Test station with the lid in place. During dark trials the black L-shaped piece resting on top is lowered to cover the light port. The Gamry potentiostat can be seen in the background.................................................................... 35 
Figure 3.1 Energy level diagram of the components and processes in a DSSC. Energy levels are reported vs. SCE.

Figure 3.2 Basic structure and processes of a DSSC. The parenthesized numbers in red correspond to the same steps depicted in Figure 3.1 ................................. 55

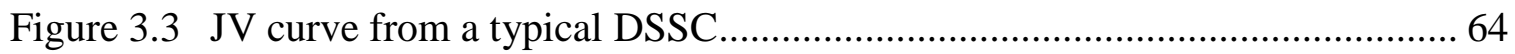

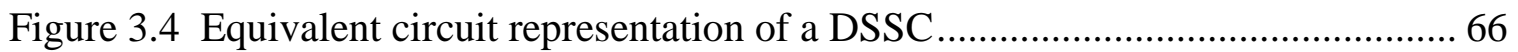

Figure 3.5 Equivalent circuit of a DSSC showing internal and external resistances ...... 68

Figure 3.6 Effect of artificially decreasing the shunt resistance of a DSSC by adding external resistance in parallel to the cell under test ..................................... 69

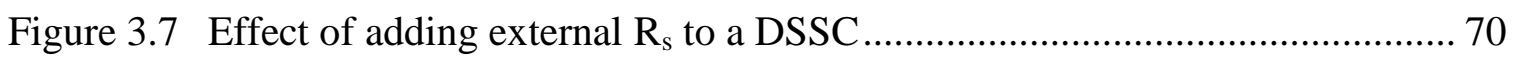

Figure 4.1 LSV scans, forward (+0.05 V to $-0.8 \mathrm{~V})$ and reverse $(-0.8 \mathrm{~V}$ to $+0.05 \mathrm{~V})$. The full scans extend to $-0.99 \mathrm{~V}$ but have been cropped at $-0.8 \mathrm{~V}$ for clarity ...... 90

Figure 4.2 LSV scans (forward) at scan rates from $5 \mathrm{mV} / \mathrm{sec}$ to $2560 \mathrm{mV} / \mathrm{sec}$. The full scans extend to $-0.99 \mathrm{~V}$ but have been cropped at $-0.8 \mathrm{~V}$ for clarity............ 92

Figure 5.1 Adsorption of TCPP from $100 \mu \mathrm{M}$ solution $(2.5 \mathrm{~mL})$ in absolute ethanol .... 97

Figure 5.2 Desorption of TCPP from $\mathrm{TiO}_{2}$ into absolute ethanol. The plot depicts the normalized quantity of TCPP remaining on the electrode during the

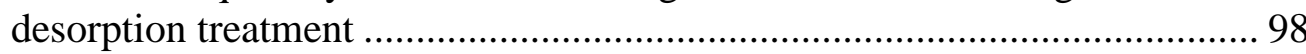

Figure 5.3 Performance of a TCPP DSSC as a function of excitation wavelength ........ 99

Figure 5.4 Effect of pre-adsorbates on efficiency of TCPP DSSCs ............................ 109

Figure 5.5 $\mathrm{V}_{\text {oc }}$ of TCPP cells with phosphonic acid pre-adsorbates ............................ 111

Figure 5.6 Effect of pre-adsorbates on fill factor....................................................... 113

Figure 5.7 Effect of pre-adsorbates on the $\mathrm{J}_{\mathrm{sc}}$ of cells sensitized with TCPP dye ........ 115

Figure 5.8 Dye loading ratio of cells treated with pre-adsorbates normalized to the

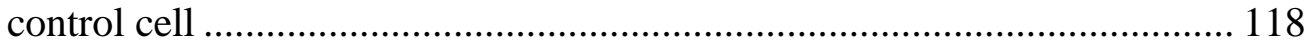

Figure 5.9 Ratio of the $\mathrm{J}_{\mathrm{sc}}$ of cells treated with pre-adsorbates, as photocurrent per mole of adsorbed TCPP, normalized to the control cell at ages from 0 to 336 hours

Figure 5.10 Effect of pre-adsorbates on the amount of photocurrent produced per nanomole of adsorbed TCPP in units of $\mu \mathrm{A} / \mathrm{nmol}$

Figure 5.11 Estimated efficiencies of cells treated with pre-adsorbates but without sensitizing TCPP. Irradiation (UV portion of Xe lamp spectrum) was estimated to be 0.2 sun, or about $10 \%$ of the total irradiation

Figure $5.12 \mathrm{~V}_{\text {oc }}$ of cells with pre-adsorbates but without TCPP ................................ 126

Figure 5.13 Fill factor of cells with pre-adsorbates but without TCPP ....................... 127

Figure $5.14 \mathrm{~J}_{\mathrm{sc}}$ of cells with pre-adsorbates but without TCPP ................................ 129 
Figure 5.15 Average efficiency of cells treated with $8 \mu \mathrm{M}$ sim-adsorbates 133

Figure 5.16 Average $\mathrm{V}_{\mathrm{oc}}$ of cells treated with $8 \mu \mathrm{M}$ sim-adsorbates........................... 135

Figure 5.17 Average fill factor of cells treated with $8 \mu \mathrm{M}$ sim-adsorbates .................. 137

Figure 5.18 Average $\mathrm{J}_{\mathrm{sc}}$ of cells treated with $8 \mu \mathrm{M}$ sim-adsorbates ............................ 138

Figure 5.19 Efficiencies of TCPP cells prepared with $40 \mu \mathrm{M}$ PA sim-adsorbates........ 143

Figure $5.20 \mathrm{~V}_{\mathrm{oc}}$ values of TCPP cells prepared with $40 \mu \mathrm{M}$ PA sim-adsorbates .......... 144

Figure 5.21 Fill factors of TCPP cells prepared with $40 \mu \mathrm{M}$ PA sim-adsorbates ......... 145

Figure 5.22 $\mathrm{J}_{\mathrm{sc}}$ values of TCPP cells prepared with $40 \mu \mathrm{M}$ PA sim-adsorbates............ 146

Figure 5.23 Efficiency of cells prepared using C10PA as a post-adsorbate and I3I-1 as electrolyte

Figure 5.24 $\mathrm{V}_{\mathrm{oc}}$ values of cells prepared using C10PA as a post-adsorbate and I3I-1 as electrolyte

Figure 5.25 Fill factor of cells prepared using C10PA as a post-adsorbate and I3I-1 as electrolyte

Figure 5.26 $\mathrm{J}_{\mathrm{sc}}$ values of cells prepared using C10PA as a post-adsorbate and I3I-1 as electrolyte

Figure 5.27 Efficiency of cells prepared using C10PA as a post-adsorbate and CoBpy-1 as electrolyte 156

Figure 5.28 $\mathrm{V}_{\text {oc }}$ of cells prepared using C10PA as a post-adsorbate and CoBpy-1 as electrolyte

Figure 5.29 Fill factor of cells prepared using C10PA as a post-adsorbate and CoBpy-1 as electrolyte

Figure 5.30 $\mathrm{J}_{\mathrm{sc}}$ of cells prepared using C10PA as a post-adsorbate and CoBpy-1 as electrolyte

Figure 5.31 Efficiency of cells prepared using C10PA as a post-adsorbate and CoBpy-3 as electrolyte

Figure 5.32 $\mathrm{V}_{\mathrm{oc}}$ of cells prepared using C10PA as a post-adsorbate and CoBpy-3 as electrolyte

Figure 5.33 Fill factor of cells prepared using C10PA as a post-adsorbate and CoBpy-3 as electrolyte

Figure 5.34 $\mathrm{J}_{\mathrm{sc}}$ of cells prepared using C10PA as a post-adsorbate and CoBpy-3 as electrolyte

Figure 6.1 Performance metrics of cells prepared using linear alkyl phosphonic acids as sim-adsorbates 173

Figure 6.2 Performance metrics of cells prepared using linear alkyl phosphonic acids as pre-adsorbates 
Figure 6.3 Above: Singly anchored $\mathrm{TiO}_{2}$ with several linear alkyl phosphonic acids and phenylphosphonic acid. Below: Doubly anchored $\mathrm{TiO}_{2}$ with the same acids, except phenylphosphonic acid is not depicted........................................ 179 


\section{List of Equations}

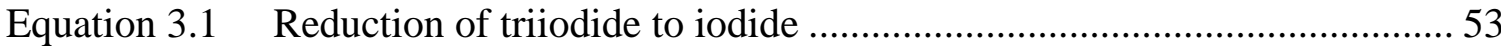

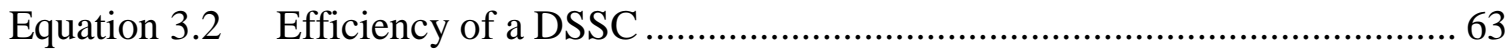

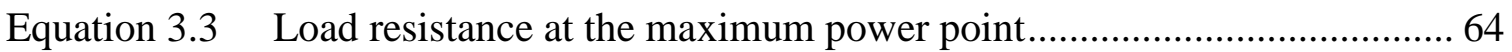

Equation 3.4 Approximate effective $R_{s}$ and $R_{p}$ for the circuit in Figure 3.5 .............. 69 


\section{List of Abbreviations and Symbols}

The following abbreviations and acronyms are defined as they apply to solar cells, though in many cases they might be equally well applied to other types of device. For instance, $\mathrm{I}_{\mathrm{sc}}$ is defined as the short-circuit current produced by a solar cell, but that term applies equally well to as galvanic cells and other devices.

Term

3PPA

C10PA

C12PA

C16PA

C1PA

C6PA

C8PA

CB

CoBpy

$\mathrm{CV}$

DSSC

\section{Abbreviation}

3-Phosphonopropanoic acid

Decylphosphonic acid

Dodecylphosphonic acid

Hexadecylphosphonic acid

Methylphosphonic acid

Hexylphosphonic acid

Octylphosphonic acid

Conduction band

A redox electrolyte based on $\mathrm{Co}^{2+} / \mathrm{Co}^{3+}$ redox couple, as $\mathrm{Co}(\mathrm{bpy})_{3}\left(\mathrm{PF}_{6}\right)_{2} / \mathrm{Co}(\mathrm{bpy})_{3}\left(\mathrm{PF}_{6}\right)_{2}$

Cyclic voltammetry

Dye-sensitized solar cell 
FF

HOMO

HTM

I3I

$I_{\mathrm{sc}}$

iV

$\mathrm{J}_{\mathrm{sc}}$

JV

LSV

LUMO

MO

MP

MPP

PC

PhAA

PhPA

$\mathrm{R}_{\mathrm{p}}$

$\mathrm{R}_{\mathrm{s}}$
Fill factor; the ratio of power produced by a solar cell to the product of its $\mathrm{J}_{\mathrm{sc}}$ and $\mathrm{V}_{\mathrm{oc}}$

Highest occupied molecular orbital

Hole-transport medium

A redox electrolyte based on the iodide-triiodide redox couple

Short-circuit current of a solar cell; the photocurrent produced by a DSSC under short-circuit conditions

Current-voltage, as in current-voltage test of a DSSC

Short-circuit current of a solar cell, normalized to a unit area

Current-voltage, normalized for area

Linear sweep voltammetry

Lowest unoccupied molecular orbital

Molecular orbital

Maximum power

Maximum power point

Personal computer

Phenylarsonic acid

Phenylphosphonic acid

Parallel resistance or shunt resistance

Series resistance 
tC4PA

VB

$\mathrm{V}_{\mathrm{oc}}$

WF
Tert-butylphosphonic acid

Valence band

Open-circuit voltage of a solar cell

Work function 


\section{CHAPTER 1 INTRODUCTION}

\subsection{The need for energy}

The population of the world is growing rapidly. It doubled from approximately three billion in 1960 to approximately six billion in 2000. It passed the seven billion mark in late 2011 or early 2012, and is still increasing over 1\% annually. Projections for future population growth vary over a wide range depending on fertility and other factors, but the 2015 revision of the United Nations Department of Economic and Social Affairs report

titled World Population Prospects ${ }^{1}$ projects that world population will reach 8.5 billion in 2030, 9.7 billion in 2050, and 11.2 billion in 2100 . The worldwide standard of living is also improving, and energy is required for most of the things that comprise this improvement. These are compounding factors that result in a rapidly increasing demand for energy. A major effort is underway to find sources of energy to meet this demand, and sunlight - ubiquitous and free - is one obvious and attractive source. Two other obvious sources are fossil fuels and nuclear power. Neither of these is either free or ubiquitous.

\subsection{Fossil fuels}

The burning of fossil fuels (principally from coal - nearly pure carbon - and petroleum principally a mixture of hydrocarbons) has provided for most of mankind's energy needs 
since the beginning of the industrial revolution. It results in the production of carbon dioxide $\left(\mathrm{CO}_{2}\right)$, which is released into the atmosphere. Carbon dioxide is removed from the atmosphere principally by two mechanisms - consumption by plants, which convert it into vegetable matter, and by being dissolved in the oceans. The latter has been shown to increase the acidity of the oceans. This disrupts the ratio of carbonate ion and bicarbonate ion (shifting the equilibrium toward higher bicarbonate and lower carbonate ion concentrations), which interferes with the formation of calcium carbonate shells, among other effects on marine lifeforms. In short, ocean acidification is considered to be undesirable, potentially resulting in the extinction of many ocean species. This effect alone should be sufficient motivation to seek alternatives to fossil fuels. But there is also the matter of climate change. 


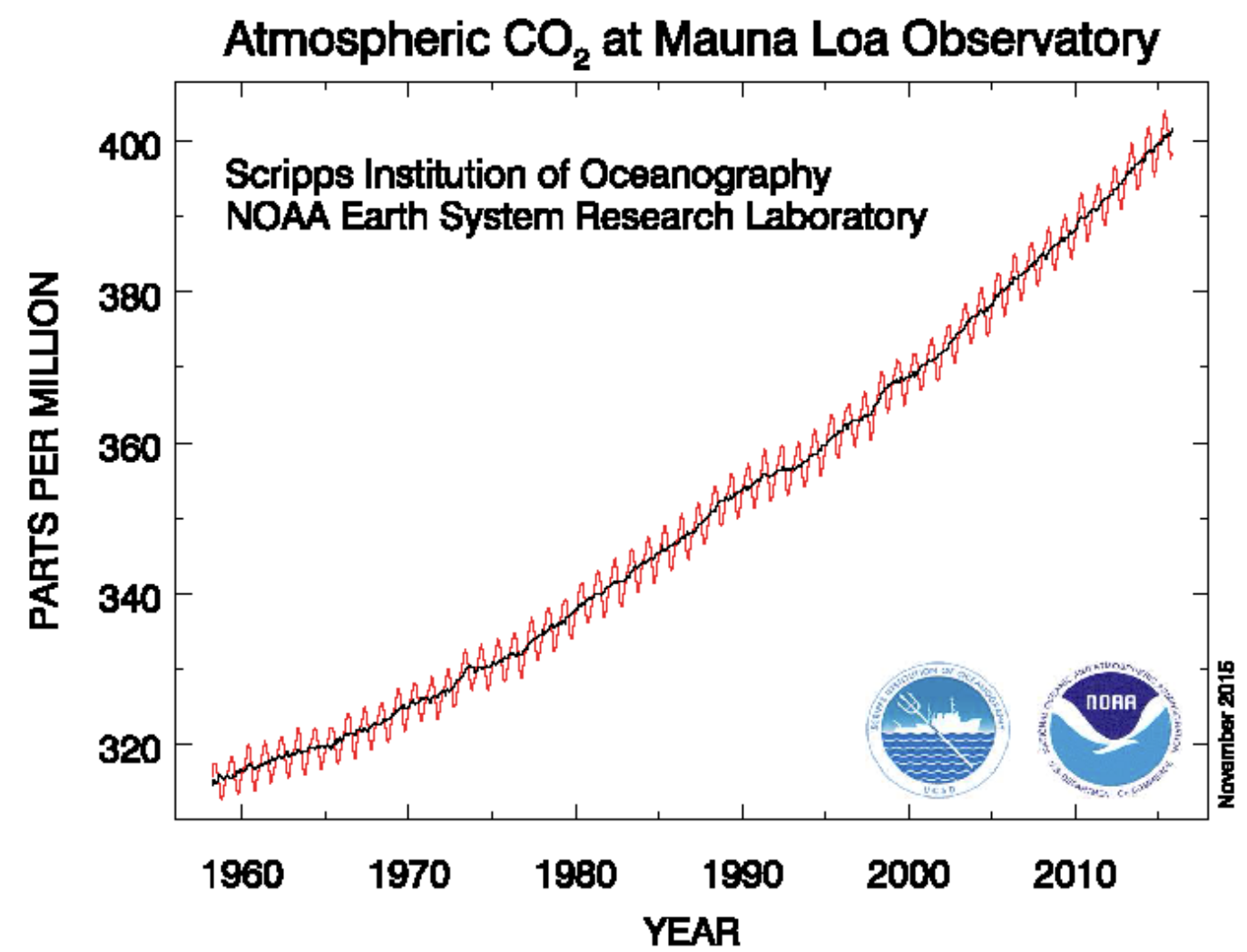

Figure 1.1 Atmospheric $\mathrm{CO}_{2}$ levels as measured by the National Oceanic and Atmospheric Administration at Mauna Loa Observatory Source: http://www.esrl.noaa.gov/gmd/ccgg/trends

The combined consumption of $\mathrm{CO}_{2}$ by plant life and by the oceans does not keep up with the rate at which it is being added to the atmosphere. As a result, the concentration of atmospheric $\mathrm{CO}_{2}$ has increased remarkably since the beginning of the industrial revolution (about $280 \mathrm{ppm}$ at that time), and most remarkably in the past half century. As recently as 1960, it was measured at $315 \mathrm{ppm}$, and has passed $400 \mathrm{ppm}$ as reported by the National Oceanic and Atmospheric Administration. ${ }^{2}$ Carbon dioxide is known to absorb 
infrared radiation radiated from the Earth (both day and night), which would otherwise escape and carry away heat. By that mechanism it traps heat in the Earth's atmosphere (the greenhouse effect), resulting in a gradual warming of the Earth's temperature. The average temperature of the Earth does indeed appear to be gradually increasing, resulting in many effects around the world collectively referred to as Climate Change or Global Warming. Many of these effects, such as a rise in the level of the oceans, are predicted to result in profound problems: flooding of coastal cities and large areas of low-lying land, for example. Climatological models differ in the details of their predictions; the rate of change is uncertain, and the specific regions that will become hotter or drier or wetter cannot be predicted with certainty, but the overall trend predicted by all models is similar. The overall effect of global warming will, for the most part at least, not be good. For all these reasons it is reasonable to conclude that continued reliance on fossil fuels for our energy needs is highly undesirable. It is worth noting that there are enormous known reserves of fossil fuels, enough to supply the energy needs of humankind for hundreds of years. The environmental effects resulting from the combustion of these enormous reserves are incalculable. To avoid this trajectory it will be necessary to develop alternative sources of energy, the sooner the better. 


\subsection{Other energy options}

Energy options begin with conservation, which has already been shown to be of great value in reducing the need for additional energy sources. Still, it is certain that demand for energy will continue to increase, so all potential sources must be evaluated and used as appropriate.

\subsection{Nuclear energy}

Nuclear power is potentially a source of energy, but it poses its own set of difficulties. These will not be elaborated here, other than to cite disposal of nuclear waste as being a particularly stubborn problem. There is active debate within the environmental community as to whether the benefits of nuclear energy outweigh the risks.

\subsection{Geothermal energy}

Geothermal energy, which taps into the heat in the interior of the Earth, would on the face of it appear to be free and ubiquitous. Unfortunately, in most areas it would be necessary to drill much deeper into the Earth than is practical or even possible with current technology to reach a level at which sufficiently high temperatures are found. Only in geologically active areas (e.g., volcanic regions) are large amounts of heat available at 
accessible depths. Large-scale use of geothermal energy in such areas is itself controversial, as it is often believed to adversely affect local hot springs and geysers.

\subsection{Nuclear fusion}

Research on nuclear fusion continues to make advances, but reliable containment of a fusion reaction remains elusive. It has been quipped that nuclear fusion is thirty years away, and it always will be. Until it actually arrives it cannot be part of the energy plan.

\subsection{What's left? Solar energy}

If we are not to rely on fossil fuels or nuclear energy or any of the other options discussed above, then we are left with solar energy in one form or another as our only real choice. Energy from wind, biomass, and hydroelectric (all being indirectly derived from the sun) can make significant contributions, but the direct utilization of solar energy has the appeal of simplicity and the potential to be the lowest cost option of all. Sunlight can be used directly to heat water for domestic use, as well as for passive solar heating of residences. It can also be used to directly generate electricity by means of a photovoltaic (PV) device. There are a number of types of PV devices, some of which have been commercialized and which are already in use at significant levels (principally siliconbased devices). Other types of PV devices are still in the research stage. The dye- 
sensitized solar cell (DSSC or DSC) is one such device. Research on this type of device is the subject of this dissertation.

\subsection{Energy from the sun}

The sun delivers more energy to the Earth's surface in one hour than humanity uses in a

year. ${ }^{3}$ If even a fraction of that energy could be captured, it would more than satisfy all foreseeable needs for energy.

Under clear midday skies the sun typically delivers about one kilowatt of power per square meter $\left(1 \mathrm{~kW} / \mathrm{m}^{2}\right)$, or about 5,400 horsepower per acre, or $3.5 \mathrm{MW}$ per square mile at the Earth's surface. In the Portland, Oregon area, at a latitude of $45^{\circ} 31^{\prime} \mathrm{N}$, and with an often-cloudy maritime climate, over the course of a year a typical commercially available solar panel operating at $18 \%$ efficiency delivers energy equivalent to approximately three hours per day of full sunlight. Thus, a 200 watt solar panel (consisting of multiple connected solar cells, with a total area a little over a square meter) produces approximately 220 kilowatt hours of energy per year. 


\subsection{Silicon solar cells}

Solar cells are coming into increased usage worldwide by power companies, businesses, and homeowners. Most of the devices currently being installed are made from highpurity silicon. The requirement for ultra-high purity material currently makes these devices expensive, as measured both in terms of dollars and in terms of large amounts of energy required for the purification and subsequent production processes (multiple hightemperature melts). Efforts are underway to improve these costs by using smaller quantities of silicon (thinner devices). To this date, however, no totally acceptable solution has been found (for silicon solar cells) so there is an active search for alternative materials that can be used to make PV devices at lower cost.

\subsection{Dye-sensitized solar cells}

Dye-sensitized solar cells (DSSCs) are one example of an alternative PV device, and they show great promise as sources of sunlight-derived energy. They are constructed from low-cost materials and have comfortably cleared the $10 \%$ efficiency hurdle. This figure is a generally accepted threshold value for PV devices to be commercially viable. A large part of the cost of a PV system is due to the installation work involved, plus an AC inverter and other electrical materials, as well as permits. Since these costs are more or less fixed, there is a lot of potential long-term value to be gained by installing PV devices of the highest efficiency that can be justified based on up-front cost. 
In their current state DSSCs have significant problems that need to be solved before they can be practical large-scale commercial devices. These problems will be discussed in a later chapter delving into the principles of DSSC operation. The research reported here is directed at helping to address these problems, at both a fundamental level (improving our understanding of DSSCs) and a practical level as well (finding viable solutions).

Furthermore, some aspects of DSSC research may be directly or indirectly transferrable to other types of photovoltaic devices, such as perovskite solar cells.

Problems with DSSCs notwithstanding, it must be noted that at least two companies (Gcell.com and Solaronix.com) currently offer products based on DSSCs.

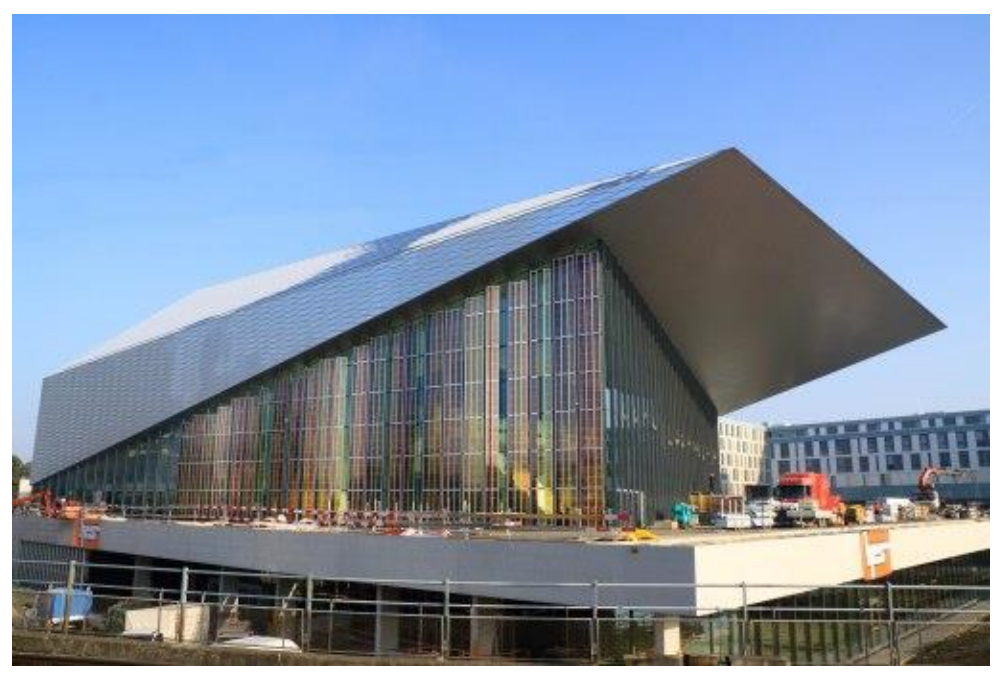

Figure 1.2 Solaronix' multicolored transparent photovoltaic façade at the SwissTech Convention Center, EPFL, Switzerland

Source: http://www.solaronix.com/documents/solaronix_solar_cells 


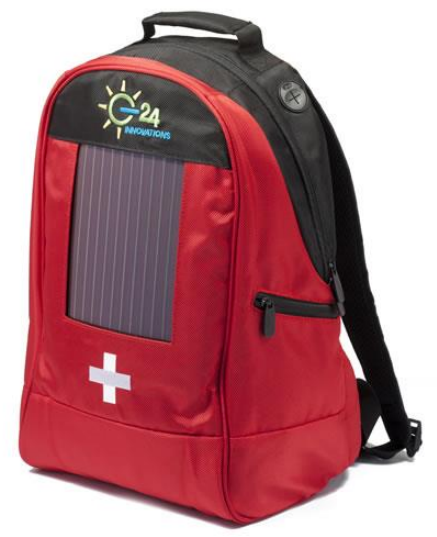

Figure 1.3 A commercially available DSSC-powered backpack, from Gcell.com Source: http://gcell.com/product/gratzel-solar-backpack

\subsection{The atmosphere}

The atmosphere of the Earth consists mostly of gases, but also includes dust, clouds, and other particulates that play important roles in its properties. One important effect of the atmosphere is that it substantially attenuates the amount of solar radiation reaching the surface of the Earth. 


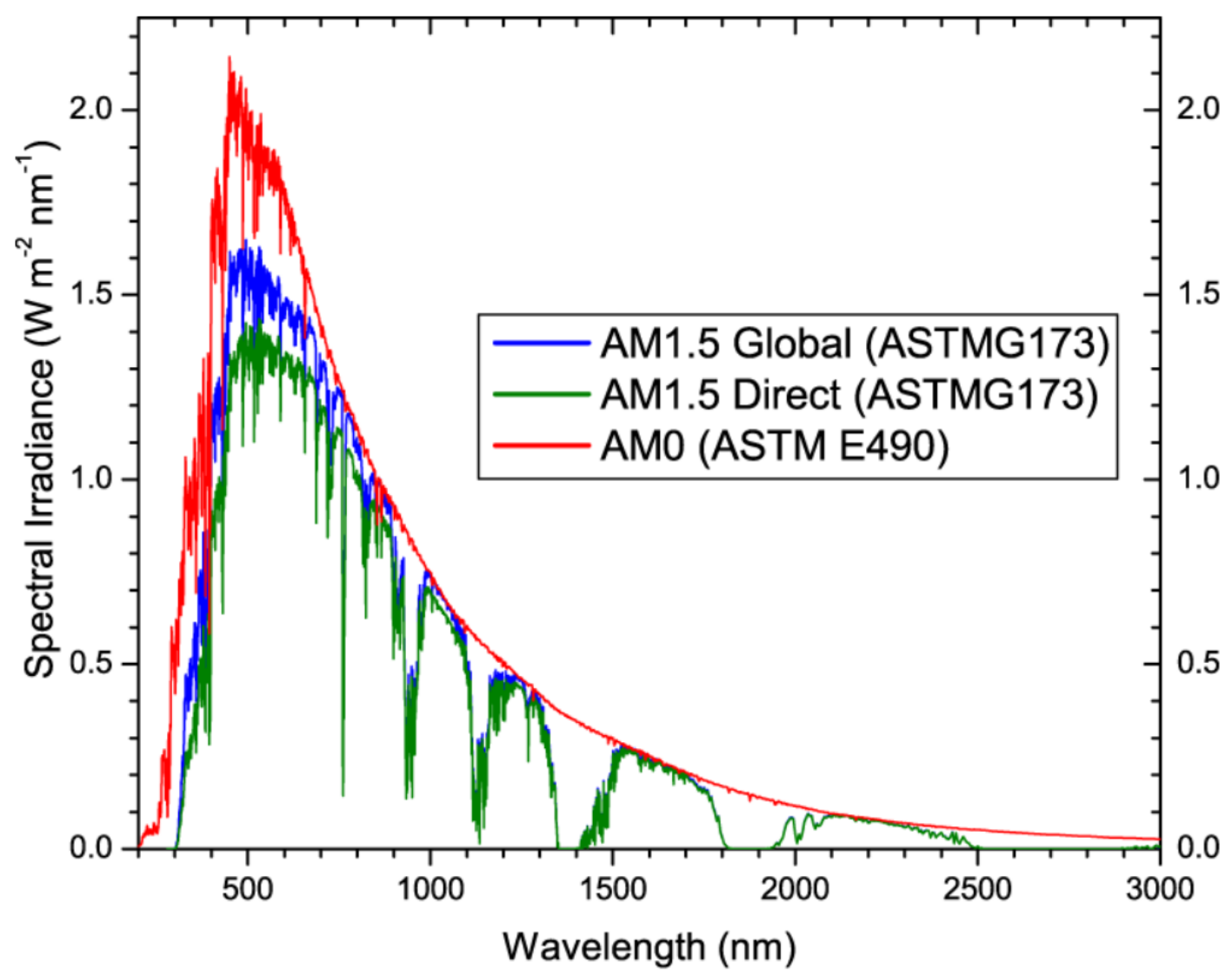

Figure 1.4 The AM1.5 solar spectrum. The red curve is the solar spectrum before it enters the atmosphere. Absorptions by various components of the atmosphere attenuate the light reaching the surface of the Earth. These are most pronounced in the IR region. Source: http://www.pveducation.org/pvcdrom/appendices/standard-solar-spectra, derived from data provided by NREL

The spectrum used in DSSC research is the AM1.5 Global (ASTMG173) standard. On the web page referenced in the caption of Figure 1.4 the difference between the Global and the Direct spectra are described thus: 
Two standards are defined for terrestrial use. The AM1.5 Global spectrum is designed for flat plate modules and has an integrated power of 1000 $\mathrm{W} / \mathrm{m}^{2}\left(100 \mathrm{~mW} / \mathrm{cm}^{2}\right)$. The AM1.5 Direct (+circumsolar) spectrum is defined for solar concentrator work. It includes the the direct beam from the sun plus the circumsolar component in a disk 2.5 degrees around the sun. The direct plus circumsolar spectrum has an integrated power density of $900 \mathrm{~W} / \mathrm{m}^{2}$. The SMARTS (Simple Model of the Atmospheric Radiative Transfer of Sunshine) program is used to generate the standard spectra and can also be used to generate other spectra as required.

The atmosphere of the Earth consists principally of gases such as nitrogen (78\%) and oxygen $(21 \%)$. It also contains approximately $1 \%$ argon and traces of the other noble gases: helium, neon, krypton, xenon, and radon. The remaining constituents include carbon dioxide and water vapor. Additionally, a number of anthropogenic gases are present, many of which are greenhouse gases. These gases are typically reported in terms of parts per million, or ppm. These include a variety of halogenated hydrocarbons used as refrigerants, as well as methane. Some methane is released as part of natural processes such as anaerobic decomposition of organic matter, but a great deal is released as a result of production of fossil fuels. Methane has a powerful greenhouse gas effect. It slowly oxidizes in the atmosphere to produce $\mathrm{CO}_{2}$; it has a half-life of about seven years. 


\subsection{Solar energy}

Solar energy is the energy arriving from the sun in the form of electromagnetic radiation. This includes visible light (about $380-750 \mathrm{~nm}$ ), but also includes infrared light, radio waves, ultraviolet light, and x-rays. Most of the higher energy radiation never makes it to the surface of the Earth - the atmosphere absorbs it. Ultraviolet light at wavelengths shorter than $200 \mathrm{~nm}$ (the vacuum UV region) is absorbed by oxygen, and most of the remaining UV light ( $\lambda=200$ to $300 \mathrm{~nm}$ ) is absorbed by ozone. Particulate matter in the atmosphere also absorbs or scatters light, deflecting it away before it can reach the surface of the Earth.

The power flux at the surface of the Earth varies, depending on a number of factors, including the position of the sun in the sky. This of course varies with latitude, time of year, and time of day. When the sun is directly overhead, sunlight has the shortest possible path in which to be attenuated.

In order that measurements of photovoltaic devices have a practical correspondence to real conditions under which they might be used, the American Society for Testing and Materials (ASTM) defines standard solar irradiation as an AM 1.5 spectrum, often referred to as "one sun". It is defined as the light reaching the surface of the Earth after passing at an angle through 1.5 atmospheric masses. The corresponding power flux is $1000 \mathrm{~W} / \mathrm{m}^{2}$, or $100 \mathrm{~mW} / \mathrm{cm}^{2}$. It is assumed to have a spectral distribution similar to that 
of the sun, which is essentially $5500 \mathrm{~K}$ blackbody radiation, with some gaps due to absorptions by several components in the atmosphere.

\subsection{Efficiency}

A solar cell is an energy conversion device, converting incident photons to electrical energy. The overall efficiency of a solar cell is the fraction of incident solar energy that is converted to deliverable electrical energy. As a practical example, experimental devices typically have a light-absorbing area ("active area") on the order of $1 \mathrm{~cm}^{2}$. They are most often tested at illumination levels of approximately one standard sun, or 100 $\mathrm{mW} / \mathrm{cm}^{2}$. Depending on the type of device being tested, a typical experimental device might deliver $10-15 \mathrm{~mW}$ of output power, which would be reported as $10-15 \%$ efficiency.

From a practical point of view efficiency would be measured in terms of how much a system would cost - including installation and maintenance over the life of the system, all prorated to an annual cost - versus how many dollars' worth of electricity it would deliver each year. To a homeowner or to a power plant manager considering whether to install a system, the question is the same: Will the system save (make) money for me, and if so, over what time period? 
Initial installation costs include solar panels, inverters, hardware, labor, and permits, of which the solar panel costs are only a fraction. In order to be economically justifiable, a solar panel must have reasonably high conversion efficiency and a reasonable life. A device which fails by either of these measures could not justify the other installation costs. Research on DSSCs seeks to improve both of these metrics. 


\section{CHAPTER 2 EXPERIMENTAL}

\subsection{Chemicals and materials}

Fluorine-doped tin oxide glass (Tec 7, $2.2 \mathrm{~mm}$ FTO glass) was obtained as 12 inch by 12 inch squares from the Hartford Glass Company in Hartford City, IN. Pilkington Glass Company provided FTO glass (Tec 15, $2.2 \mathrm{~mm}$ and Tec 8, $3.2 \mathrm{~mm}$ ) used in some early experiments. All FTO glass was cut, washed, and otherwise processed as described in later sections. Aeroxide $\mathrm{P}-25 \mathrm{TiO}_{2}$ was generously provided by the Evonik Degussa Corporation.

Tyzor AA-105 and Tyzor LA were obtained courtesy of E.I. DuPont de Nemours and Company. Tyzor AA-105 is a DuPont trade name for $\mathrm{Ti}(\mathrm{AcAc})_{2}(\mathrm{OEt})(\mathrm{O}-\mathrm{iPr})$. Tyzor LA is an ammonium salt of a lactic acid titanate chelate.

Tetra-n-butyl ammonium iodide was from TCI. 4-t-butyl pyridine was Aldrich 99\%. Iodine was resublimed, from Merck. Deoxycholic acid was Aldrich 99+\%. Chloroplatinic acid hexahydrate was from E. M. Science. Nitrosonium tetrafluoborate (97\%) was from Acros Organics. 3-methoxypropionitrile was Alfa Aesar 99\%. Valeronitrile was Aldrich 99.5\%. 2,2'-bipyridine was from Aldrich. Cobalt (II) chloride hexahydrate was Mallincrodt AR grade. 5,10,15,20-Tetrakis(4-carboxyphenyl)porphine (TCPP) was obtained from TCI. N-719 dye was from Aldrich. Triton X-100 was 
obtained from Aldrich. Acetylacetone was Sigma-Aldrich Reagent Plus grade. Absolute ethanol was from Pharmco-Aaper. Acetonitrile was Sigma-Aldrich Chromasolv Plus grade. Propylene carbonate was from Aldrich; it was distilled under vacuum, using the center $40 \%$ fraction. n-Hexylphosphonic acid, min. 97\%, n-octylphosphonic acid, min. 97\%, n-dodecylphosphonic acid, min. 97\%, and n-hexadecylphosphonic acid, min. 97\%, were obtained from Strem Chemicals. Ammonium hexafluorophosphate was Acros Organics 99.5\% extra pure. Methanol was Aldrich biotech grade.

Methylphosphonic acid, 98\%, phenylarsonic acid, 97\%, and n-decylphosphonic acid, 98\%, were obtained from Alfa Aesar. Phenylphosphonic acid, 98\%, tert-butylphosphonic acid, 98\%, and 3-phosphonopropanoic acid were obtained from Acros Organics. Deoxycholic acid was Aldrich, 99+\%. Materials were used as received from the manufacturer unless otherwise specified.

\subsection{Instruments and software}

Two furnaces were used for preparation of electrodes. A Thermolyne 47900 furnace was used to prepare platinized counterelectrodes, and a Fisher Scientific Isotemp furnace model 650-14 was used exclusively for sintering $\mathrm{TiO}_{2}$ electrodes. In order to avoid any possibility of cross-contamination, materials containing platinum or other metals were prohibited from the Fisher furnace. 
A Gamry Reference 600 Potentiostat/Galvanostat was used to perform current-voltage (iV) experiments. Data were collected using Gamry Framework software, version 5.60, running on a PC in a Windows 7 Home Premium environment. Gamry Echem Analyst software, version 5.60, was used for inspection of the data and in some cases to generate graphics. In most cases, data were transferred to IGOR Pro software, version 6.3.7.2. Custom-written IGOR Pro software was used to normalize the iV curves, generate graphics, and to calculate cell efficiencies and other metrics. Microsoft Excel 2010 was also used in some cases to process data and to prepare graphics.

Some iV experiments were performed using a Keithley 236 Source Measure Unit. The light source for these experiments was a $50 \mathrm{~W}$ quartz-halogen lamp.

Illumination levels were determined using an IL 1700 Research Radiometer manufactured by International Light Technologies in Peabody, MA. A silicon detector was employed for calibration measurements. UV-Vis spectra were run on a Shimadzu UV-3600 UV-Vis-NIR spectrophotometer controlled by Shimadzu UVProbe software, version 2.33. Spectral response work was done using a monochromator made by Photon Technology International Inc.

An LED lamp (color balance $5000 \mathrm{~K}$ ) was used as the light source for testing cells. The lamp was powered by a custom-built DC power supply to eliminate $240 \mathrm{~Hz}$ ripple. A 
$150 \mathrm{~W}$ Xenon arc lamp (temporarily borrowed from a SPEX Fluorolog fluorimeter) was used as a source of UV radiation for testing cells that did not use a sensitizing dye.

\subsection{Construction of dye-sensitized solar cells}

The term "sandwich cell" aptly describes the basic construction of a dye-sensitized solar

cell. Such a cell is comprised of a front photoelectrode and a back counterelectrode, held together with the faces of the electrodes either touching or nearly so. The photoelectrode has a thin film of $\mathrm{TiO}_{2}$ nanoparticles, coated with a sensitizing dye. The counterelectrode is lightly platinized. The space between the electrodes is filled with an electrolyte.

\subsection{Preparation of electrodes}

Photoelectrodes and counterelectrodes are both constructed from Tec-7 glass. This glass is manufactured with one face coated with fluorine-doped tin oxide (FTO). Fluorine doped tin oxide is optically transparent and is an electrical conductor. It is received as squares, 12 inches $(30.5 \mathrm{~cm})$ on a side. These squares are cut into six rectangular plates, each 6 inches $x 4$ inches $(15.25 \mathrm{~cm} \mathrm{x} 10.16 \mathrm{~cm})$. The plates are washed using Sparkleen 1 glass cleaner ( $10 \mathrm{~g}$ in $1800 \mathrm{~mL}$ of deionized water) in an ultrasonic bath for one hour. They are rinsed with copious quantities of deionized water and allowed to air dry. Up to 
this point, the preparation of a plate is the same for counterelectrodes and photoelectrodes. Each plate ultimately yields 30 usable electrodes, plus four unusable electrodes from the ends of the plate.

The preparation of both photoelectrodes and (platinized) counterelectrodes (described in following sections) requires heating the electrodes to $500^{\circ} \mathrm{C}$. In order to avoid any possibility that photoelectrodes might be contaminated by platinum, the heating cycles are carried out in separate furnaces. One furnace is used for operations in which metals (e.g., Pt) are used and the other is reserved for metal-free procedures (photoelectrodes).

\subsection{Counterelectrodes}

Counterelectrodes are treated on the FTO face with an ethanolic solution of chloroplatinic acid, after which they are heated to $500^{\circ} \mathrm{C}$ to decompose the acid and leave a lightly platinized surface. Afterward the plate is scored and snapped into individual counterelectrodes according to the guidelines in Figure 2.1. 


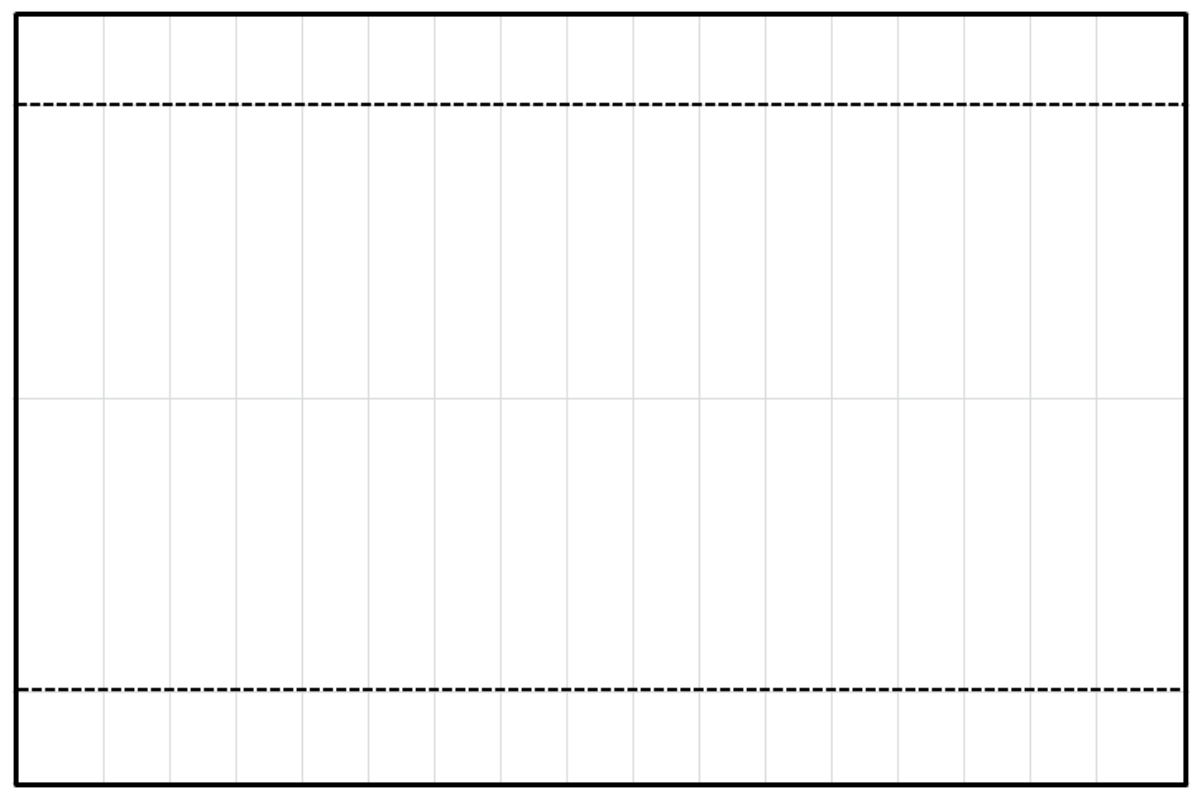

Figure 2.1 Scoring and masking diagram for a plate of electrodes

A typical plate is divided into multiple electrodes as shown in Figure 2.1. For counterelectrodes, the conductive face of the glass is lightly platinized. For photoelectrodes, the area inside the dashed lines is coated with a $\mathrm{TiO}_{2}$ dense underlayer, followed by a mesoporous layer of $\mathrm{P}-25 \mathrm{TiO}_{2}$ nanoparticles. Fine lines represent slide boundaries; the plate is scored and snapped along these lines. Note that there are sixteen vertical score lines, plus one horizontal line along the center axis of the plate. 


\subsection{Photoelectrodes}

A plate is masked using a strip of $3 / 4$ " Scotch ${ }^{\circledR}$ tape along each long edge, such that the central area of each plate is left exposed (approximately $15.25 \mathrm{~cm} \mathrm{X} 6.1 \mathrm{~cm}$.) A thin dense underlayer of $\mathrm{TiO}_{2}$ is applied using a solution of Tyzor AA-105 $(50 \mathrm{mM}$ in absolute ethanol) to the plate. The plate is moved about to spread the solution, and excess is drained off. The still-wet plate is placed inside a level, sealed plastic box so that the remaining solution will spread uniformly and dry slowly. After the plate is dry, the mask is removed and it is pyrolyzed in air by slowly ramping up the temperature $\left(50^{\circ}\right.$ $\mathrm{C}$ per 30 minutes) until it reaches $500^{\circ} \mathrm{C}$. It is held at that temperature for one hour, and then allowed to slowly cool to room temperature.

A solution of $8.3 \mathrm{~g}$ of acetylacetone and $1.5 \mathrm{~g}$ of Triton X-100 in $65 \mathrm{~mL}$ of absolute ethanol is prepared in advance. This solution is used to prepare a suspension of $\mathrm{P}-25$ $\mathrm{TiO}_{2}(1.0 \mathrm{~g} \mathrm{P}-25 \mathrm{in} 3.0 \mathrm{~mL}$ of the solution, sonicated for one hour).

The cool plates are again masked, then prewet with the same solution used to prepare the $\mathrm{TiO}_{2}$ suspension. Excess prewet solution is drained, and $1.0 \mathrm{~mL}$ of the suspension is distributed over the plate. The plate is tipped to and fro in an irregular motion to distribute the $\mathrm{TiO}_{2}$ uniformly, with excess solution being drained during the tipping operation. The plate is placed in a level, sealed plastic box so that the suspension will flow to a uniform thickness before it slowly dries. 
After the plate is dry, the mask is removed and the plate is sintered in air using the same gradual thermal profile as described for the underlayer. The temperature is slowly ramped up to $500^{\circ} \mathrm{C}$, held for an hour, and allowed to slowly cool to room temperature.

The cool plate is scored into individual electrodes using a wheel-type glass cutting tool. Scoring is done on the non-conductive face of the glass (opposite the face on which the $\mathrm{TiO}_{2}$ has been applied). Before scoring, a strip of thick tape (typically blue painter's tape) is applied on the uncoated region along each long edge of the slide, on the face with the $\mathrm{TiO}_{2}$. When the plate is placed $\mathrm{TiO}_{2}$-side down on a flat surface to be scored, the tape supports the $\mathrm{TiO}_{2}$ off the surface and prevents it from being damaged. The plate is placed on top of a guide sheet similar to Figure 2.1, and a straightedge is used to guide a glass cutter along the score lines. 


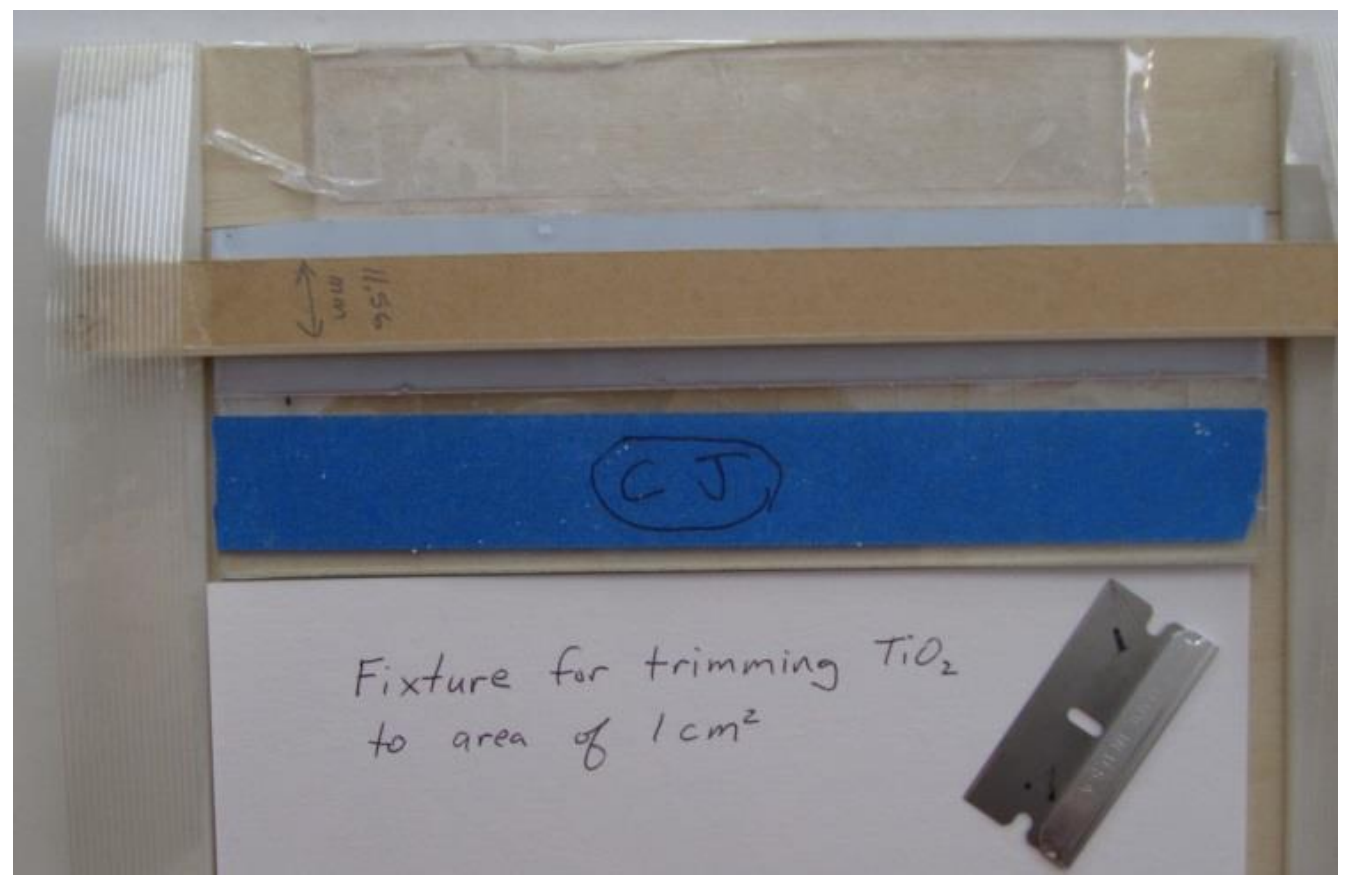

Figure 2.2 Fixture used to trim $\mathrm{TiO}_{2}$ from half-plates

After the plate has been scored, it is snapped along the horizontal score line to separate the plate into two half-plates ( 2 inches by 6 inches), each consisting of fifteen usable electrodes, plus an unusable slide on each end. Before being snapped into individual electrodes, the $\mathrm{TiO}_{2}$ area is trimmed (using a razor blade) to an area of $1.0 \mathrm{~cm}^{2}$ on each slide. This is accomplished by placing the half-plate into a special fixture. Figure 2.2 shows a half-plate of electrodes (Plate $\mathrm{CJ}$ ) in position in the fixture. The $\mathrm{TiO}_{2}$ visible in the photograph will be scraped away, leaving a $1.0 \mathrm{~cm}^{2}$ rectangle of $\mathrm{TiO}_{2}$ film in the area protected below the protective strip of plastic. The plastic appears brown because of a layer of protective adhesive paper provided by the manufacturer. The fixture consists of a rectangular base with stops affixed to it that precisely position the plate being trimmed. Above the base, a rectangular strip of acrylic polymer is supported on top of plastic plates 
a little thicker than the half-plate of electrodes. The strip is of a width $(11.56 \mathrm{~mm})$, such that when $\mathrm{TiO}_{2}$ outside the area protected by the strip is scraped away, the remaining $\mathrm{TiO}_{2}$ area on the slide will be $1.0 \mathrm{~cm}^{2}$. Each individual slide is $8.65 \mathrm{~mm}$ in width. The remaining rectangle of $\mathrm{TiO}_{2}$ is not on the end of the slide; it is spaced $5 \mathrm{~mm}$ from the end to allow for a seal when it is assembled into a cell.

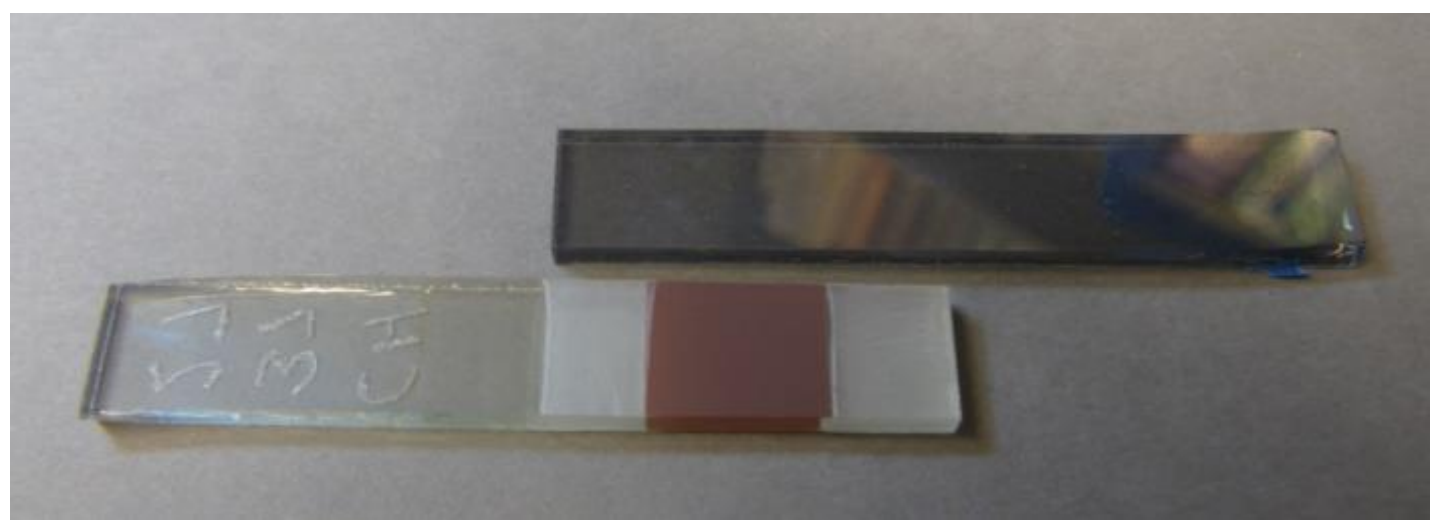

Figure 2.3 A typical electrode, with Parafilm ${ }^{\circledR}$ strips and a counterelectrode

Overall slide dimensions are $50 \mathrm{~mm}$ long by $8.65 \mathrm{~mm}$ wide. The $\mathrm{TiO}_{2}$ area has been trimmed to a nominal length of $11.6 \mathrm{~mm}$, giving the $\mathrm{TiO}_{2}$ a nominal area of $1.0 \mathrm{~cm}^{2}$. The slide has a wrap of Parafilm $®$ on either side of the $\mathrm{TiO}_{2}$, the first step in assembling the cell.

After the electrodes have been trimmed to uniform area, they are snapped into individual electrodes and sintered once more, using the same gradual temperature profile. After 
holding at $500^{\circ} \mathrm{C}$ for one hour, the electrodes are slowly cooled to $120^{\circ} \mathrm{C}$. They are held at that temperature in the furnace until they are treated with a solution, either of a dye or some other substance.

\subsection{Treatment with TCPP dye}

Each slide is placed, while still at $120^{\circ} \mathrm{C}$, into a $5 \mathrm{~mL}$ polypropylene snap-cap sample vial which has previously been charged with $2.5 \mathrm{~mL}$ of TCPP solution $(100 \mu \mathrm{M}$ in absolute ethanol). The vials are capped and stored in the dark overnight to allow the $\mathrm{TiO}_{2}$ to be uniformly dyed throughout the thickness of the layer.

\subsection{Other treatments}

Electrodes in many cases are treated with phosphonic acids or other coadsorbates either before, after, or during the treatment with TCPP. In all cases, the treatment is similar to that described for treatment with dye; the same types of vials are used, and the volume of solution is in all cases $2.5 \mathrm{~mL}$. 


\section{Coadsorbate Acid}

Methylphosphonic acid

Tert-butylphosphonic acid

1-Hexylphosphonic acid

1-Octylphosphonic acid

1-Decylphosphonic acid

1-Dodecylphosphonic acid

1-Hexadecylphosphonic acid

3-Phosphonopropanoic acid

Phenylphosphonic acid

Phenylarsonic acid

\section{Abbreviation}

C1PA

tC4PA

C6PA

C8PA

C10PA

C12PA

C16PA

3PPA

PhPA

PhAA

Table 2.1 Acids used as coadsorbates

Table 2.1 is a list of the phosphonic (and arsonic) acids used as coadsorbates in this work. Specific concentrations of coadsorbates and solvents used are reported in descriptions of individual experiments. 


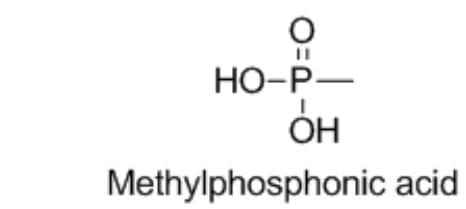<smiles>CC(C)(C)P(=O)(O)O</smiles>

$t$-Butylphosphonic acid (tC4PA)<smiles>CCCCCCP(=O)(O)O</smiles>

1-Hexylphosphonic acid (C6PA)

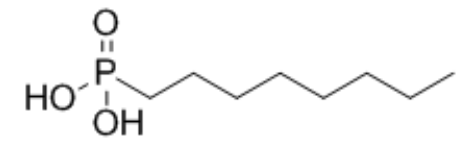

1-Octylphosphonic acid (C8PA)<smiles>CCCCCCCCCCP(=O)(O)O</smiles>

1-Decylphosphonic acid (C10PA)<smiles>CCCCCCCCCCCCP(=O)(O)O</smiles>

1-Dodecylphosphonic acid (C12PA)

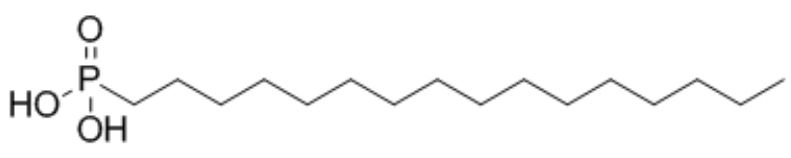

1-Hexadecylphosphonic acid (C16PA)

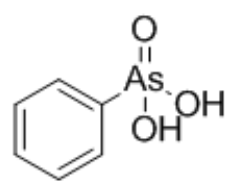

Phenylarsonic acid<smiles>O=P(O)(O)c1ccccc1</smiles>

Phenylphosphonic acid<smiles>O=C(O)CCP(=O)(O)O</smiles>

3-Phosphonopropanoic acid (3PPA)

Figure 2.4 Structures of phosphonic and arsonic acids employed as coadsorbates 


\subsection{Building cells}

One at a time, electrodes are withdrawn from their final treatment solution and rinsed briefly, first with absolute ethanol, then with acetonitrile. Each slide is dried under a stream of nitrogen and wrapped with two narrow strips of Parafilm ${ }^{\circledR}$, one on each side of the $\mathrm{TiO}_{2}$ area. Each wrap is begun on the non-conductive side, continued across the front face, and continued to the back again, where it overlaps itself. Note that on the front face of the slide, there is only one thickness of Parafilm®. A platinized counterelectrode is pressed firmly onto the slide. The Parafilm® strips stick to the counterelectrode sufficiently to temporarily hold the cell together. The cell is wrapped with two more strips of Parafilm ${ }^{\circledR}$ which serve to hold the two electrodes together. A capillary tube is used to transfer electrolyte to the cell, which wicks in the fluid by capillary action. The end of the counterelectrode is wrapped with a strip of aluminum foil to protect it during the next step. The working-electrode end of the cell is held with a pair of locking forceps and given a quick dip in molten paraffin wax at $70^{\circ} \mathrm{C}$. It is not entirely immersed; it is dipped such that about $2 \mathrm{~cm}$ of the working electrode is left as bare FTO. The aluminum foil covering part of the counterelectrode serves the same purpose: after a razor blade is used to cut it away, a bare FTO surface is exposed, providing for clean electrical connections during testing.

The paraffin-coated cell is immediately cooled with a stream of compressed air. The paraffin serves to seal the open gaps at the edge of the cell, in order to prevent exposure 
to air and to prevent evaporation of the solvent in the electrolyte. After the foil is cut away, the cell is immediately subjected to its first iV test.

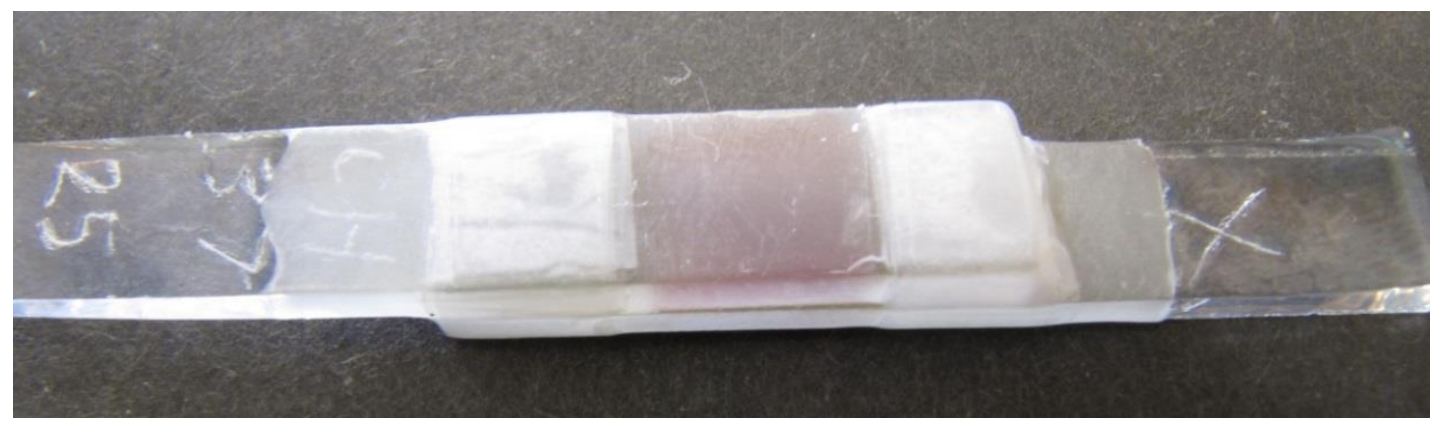

Figure 2.5 A typical cell, fully assembled and ready to be tested. The photoelectrode is on top, with its identifier $\mathrm{CH}-3725$ scribed into the back of the slide. The ends of the electrodes are not coated with paraffin to enable clean electrical connections.

\subsection{Light sources}

Most iV tests were done using an LED lamp (5000 K color balance, 1000 lumens) mounted in a fixture that positions it at a distance such that the cell to be tested is illuminated at 1.0 sun. In a few cases a $50 \mathrm{~W}$ quartz-halogen lamp with a UV filter was used as the light source. 


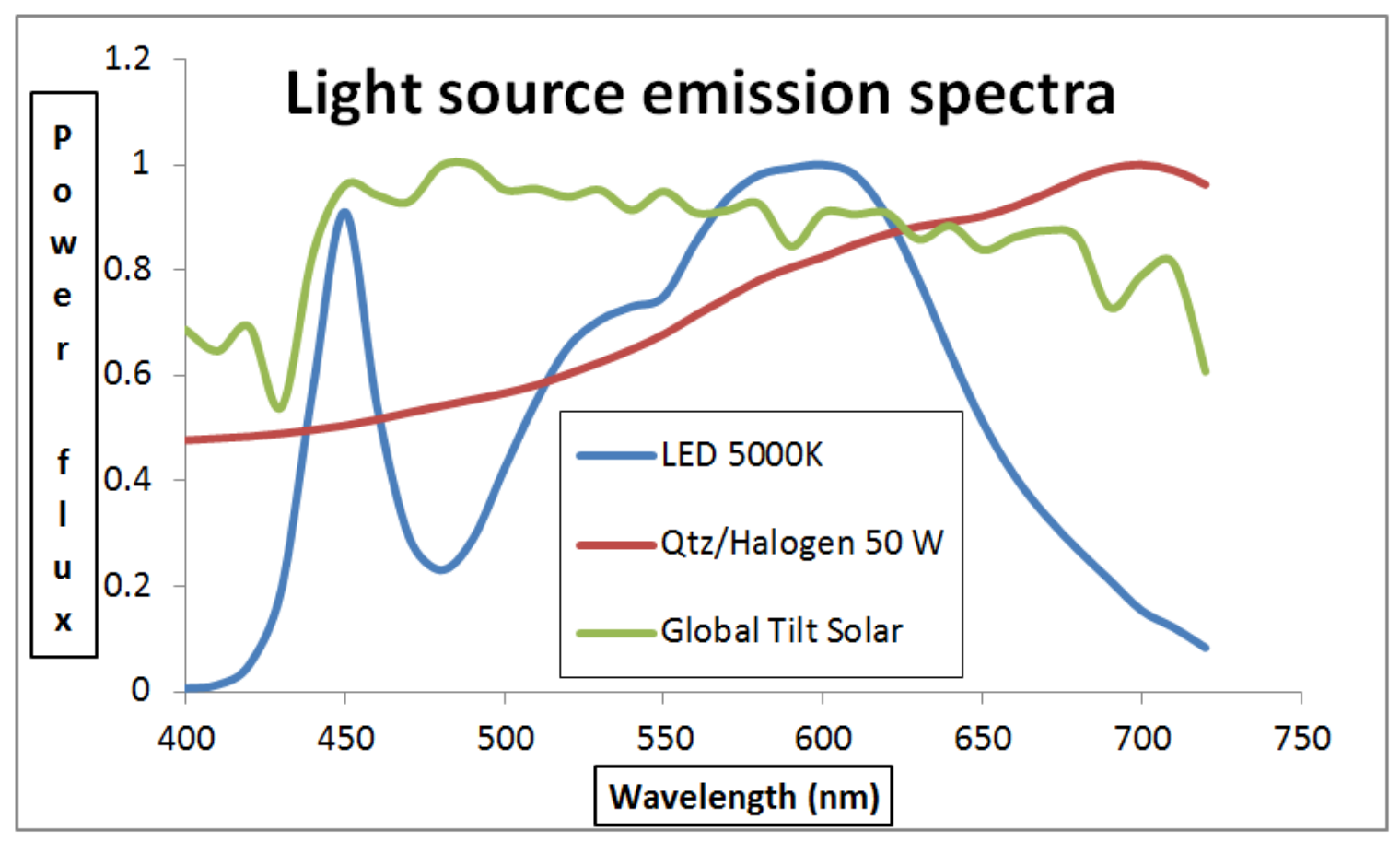

Figure 2.6 Global tilt solar spectra with emission spectra of a white (5000 K) LED and a $50 \mathrm{~W}$ quartz-halogen lamp. Each spectrum was normalized to the wavelength of maximum power flux. Power flux units are arbitrary. Source of the solar spectrum: http://www.pveducation.org/pvcdrom/appendices/standard-solar-spectra, derived from data provided by NREL

In Figure 2.6 the curve labelled "Global tilt solar" is the same as the "AM1.5 Direct" (ASTMG173) in Figure 1.4. This is the spectrum intended for use with flat plate modules. The spectra for the LED and the quartz-halogen lamp were acquired by passing the light through a monochromator at intervals of $10 \mathrm{~nm}$ and measuring the emergent light with a IL 1700 Research Radiometer. 


\subsection{Testing DSSCs}

Immediately after each cell was built, it was subjected to a dark iV experiment (linear sweep voltammetry or sometimes cyclic voltammetry), followed immediately by an illuminated iV experiment using a Gamry potentiostat with an LED light source. It was then removed from the test fixture and placed into an amber bottle to protect it from light. After a set of cells had been tested, the amber bottle containing them all was placed into a dark drawer for storage until the next set of iV tests, performed one or more hours later.

Some tests were done at reduced light levels, typically $0.5,0.25,0.125$, and 0.0625 suns. The level of illumination was controlled by varying the distance between the lamp and the cell being tested. A series of spacers were prepared to enable rapid and precise positioning of the lamp. The light intensity was measured with an IL 1700 Research Radiometer.

During testing, the cell under test was held in precise position in a custom fixture. After being mounted and connected to the potentiostat, a lid was placed over the assembly so as to provide complete darkness during dark trials. An aperture in the lid was opened during illuminated trials. The interior of the test box is painted flat black to eliminate stray reflections. When not being tested, cells were kept in dark or near-dark conditions. 


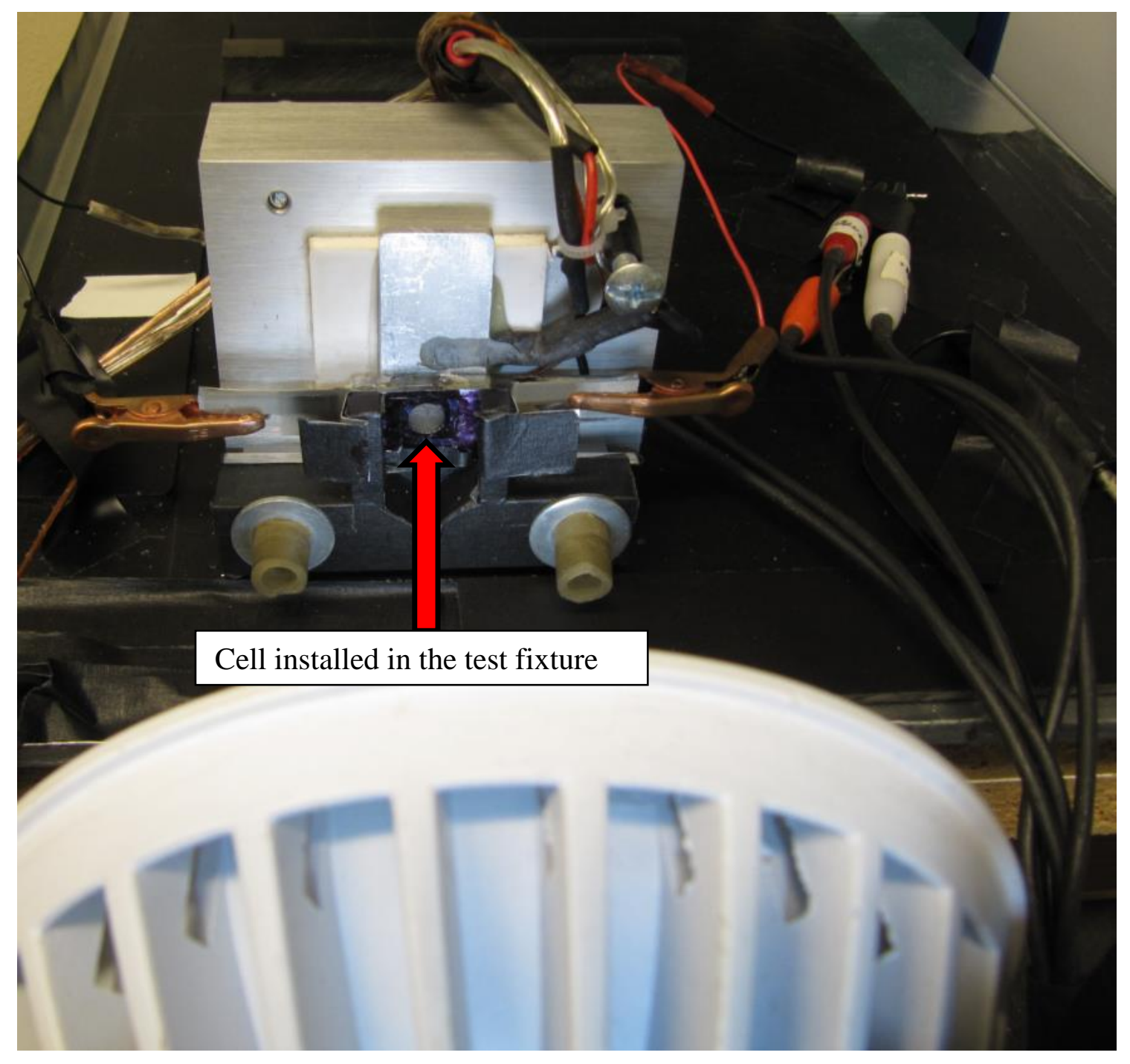

Figure 2.7 A cell in the iV test station, with the cover removed for clarity. In the foreground the back of the LED light source is seen, directed at a cell mounted on the test stage and connected with alligator clips. The cell is masked by an aluminum strip with a hole 0.25 inch in diameter 


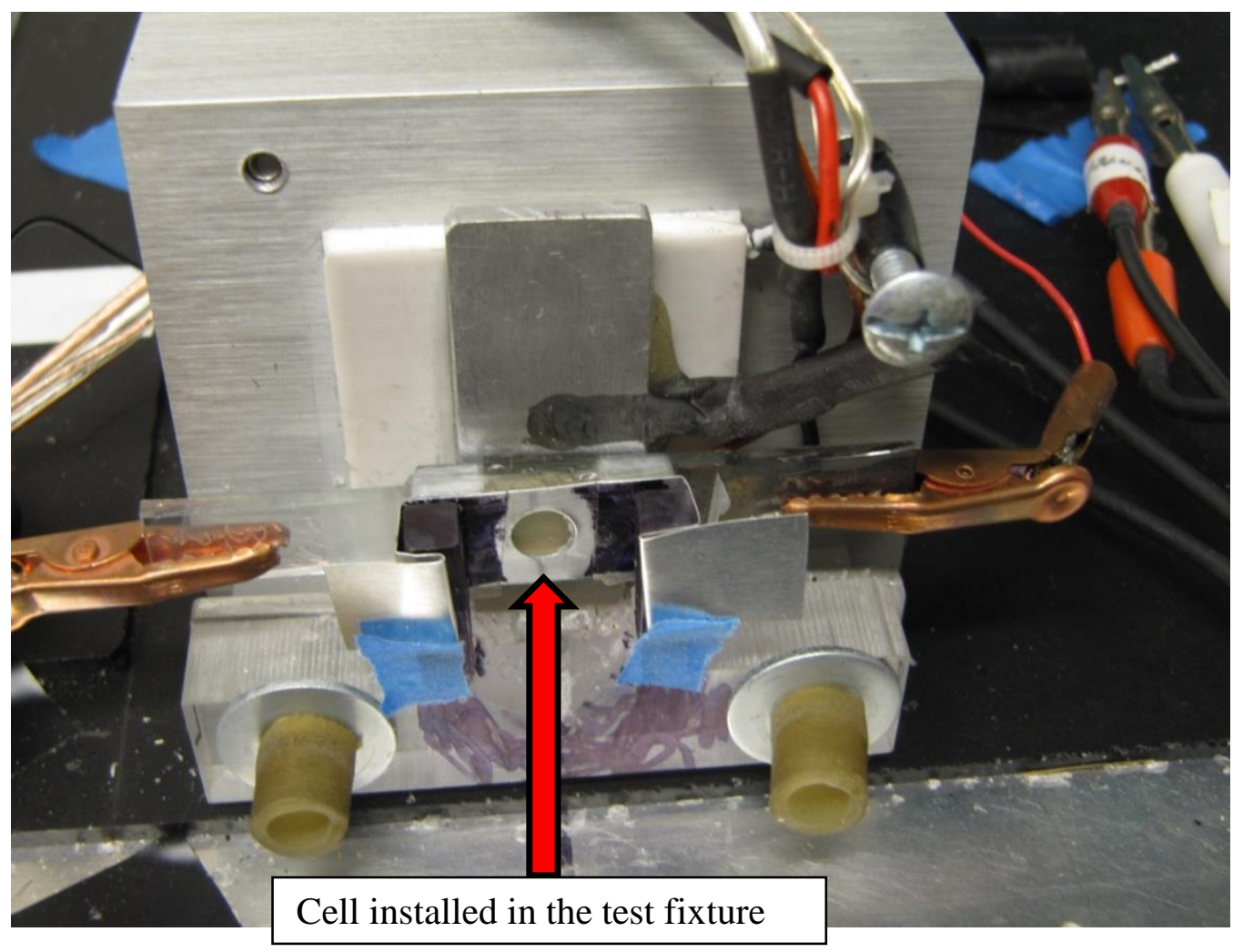

Figure 2.8 Close-up of the test stage with cell to be tested mounted in position 


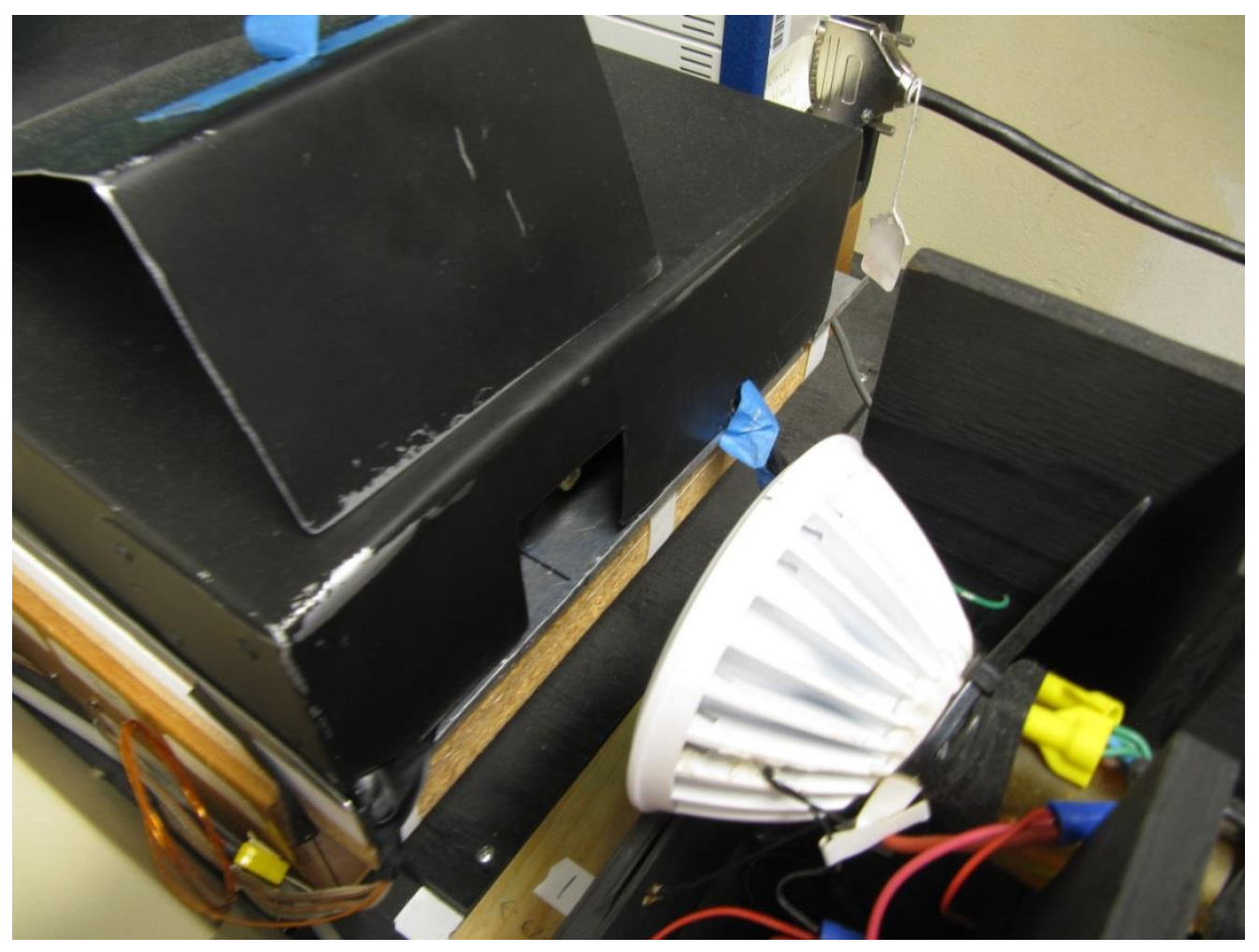

Figure 2.9 Test station with the lid in place. During dark trials the black L-shaped piece resting on top is lowered to cover the light port. The Gamry potentiostat can be seen in the background

After each cell was built, it was immediately tested, then re-tested at intervals, typically hourly or semi-hourly for six hours, then at intervals of 24,48 , and 72 hours. In addition, some cells were tested at much greater ages.

Each test consisted of two iV trials; a dark trial first, followed immediately by a test at 1.0 sun illumination. An iV trial was effected on the potentiostat by running a linear sweep voltammetry (LSV) experiment. Scans were run from 0.05 to $-0.99 \mathrm{~V}$ at 200 
$\mathrm{mV} / \mathrm{s}$. Before the scan was started, the cell was preconditioned (under illumination) for five seconds at a potential of $0 \mathrm{~V}$. This held the cell at short circuit conditions, which stabilized the cell before data collection was started.

The true active area of each cell (nominally $1.0 \mathrm{~cm}^{2}$ ) was determined by analyzing photographs of the cells before assembly, using ImageJ software version $1.48 \mathrm{v}$. Multiple measurements of each cell area were collected and averaged. The uncertainty of the final averaged area was estimated to be $+/-3 \%$.

Some tests were done using a mask, comprised of a piece of lightweight aluminum sheet metal through which a hole with an area of $0.32 \mathrm{~cm}^{2}$ (as determined by ImageJ) had been cut. This enabled direct comparison of the performances of multiple cells, without the complication of the additive uncertainties in the areas of the individual cells.

\subsection{Preparation of I3I-1 electrolyte}

The electrolyte used for most experiments was based on the iodide-triiodide redox couple. The electrolyte designated I3I-1 contained only tetra-n-butylammonium iodide $(0.5 \mathrm{M})$ and iodine $(0.05 \mathrm{M})$ in propylene carbonate. 


\subsection{Synthesis of Co tris-bipyridyl hexafluorophosphate}

The cobalt complex $\operatorname{Co}(\mathrm{bpy})_{3}\left(\mathrm{PF}_{6}\right)_{2}$ was prepared according to literature procedures ${ }^{4}$ for use in the preparation of CoBpy electrolytes.

\subsection{Preparation of CoBpy electrolytes}

\section{CoBpy-1}

The electrolyte designated CoBpy-1 was prepared by making a solution of $\mathrm{Co}(\mathrm{bpy})_{3}\left(\mathrm{PF}_{6}\right)_{2}(0.22 \mathrm{M}), \mathrm{LiClO}_{4}(0.1 \mathrm{M})$, and $t$-butylpyridine $(0.2 \mathrm{M})$ in propylene carbonate. To this was added sufficient $\mathrm{NOBF}_{4}(0.25 \mathrm{M}$ in acetonitrile) to oxidize $10 \%$ of the $\mathrm{Co}(\mathrm{bpy})_{3}\left(\mathrm{PF}_{6}\right)_{2}$ to $\mathrm{Co}(\mathrm{bpy})_{3}\left(\mathrm{PF}_{6}\right)_{3}$. This electrolyte formulation is a slight modification of a literature preparation. ${ }^{5}$ It contains only the two components of the redox couple, without any additional additives.

\section{CoBpy-3}

The electrolyte designated CoBpy-3 was prepared identically to CoBpy-1, but was modified by the addition of $t$-butylpyridine $(0.2 \mathrm{M})$. 


\section{CHAPTER 3 DYE-SENSITIZED SOLAR CELLS}

\subsection{History of dye-sensitized solar cells}

Photoelectrochemical cells have been of interest as potentially large-scale harvesters of sunlight for many years, but as recently as 1984 the situation still looked bleak; efficiencies and stabilities of experimental cells were low. ${ }^{6}$ In 1991, Michael Grätzel and Brian O'Regan published a seminal paper in Nature in which DSSCs with efficiencies of nearly $9 \%$ under AM 1.5 conditions were reported, due to a combination of several innovations in materials and processing they introduced. ${ }^{7}$ In recognition of this step-function improvement, this class of cell is often referred to as "Grätzel cells", or generically as dye-sensitized solar cells (DSSCs or DSCs). The breakthrough cell used a ruthenium tris-bipyridyl dye with an electrolyte based on the iodide-triiodide redox couple. Efficiencies over $10 \%$ were attained soon after, but then for a number of years additional improvements occurred incrementally. Finally in 2010, a DSSC attained $11 \%$ efficiency, ${ }^{8}$ still making use of essentially the same materials and structures that enabled the 1991 breakthrough.

In 2011 Yella et al. reported a cell with $12.3 \%$ efficiency at AM1.5. This cell utilized a porphyrin dye with a cobalt (II/III) redox electrolyte. This electrolyte makes higher open circuit voltages possible, but tends to suffer from leakage of photocurrent. Although porphyrins had been investigated as sensitizers for DSSCs for many years, this was the 
first time they exceeded the performance of the ruthenium-based dyes. The dye employed had been engineered specifically to reduce the loss of photocurrent that would otherwise have occurred. In 2012, Han, et al. reported 11.4\% efficiency using a ruthenium tris-bpy dye with iodide-triiodide electrolyte. To achieve this result, they utilized a novel donor-pi-acceptor coadsorbate. ${ }^{9}$ Currently the record is $13 \%$ efficiency at AM 1.5 conditions using a porphyrin dye with cobalt (II/III) redox electrolyte. ${ }^{10}$. The record using a porphyrin dye with I3I electrolyte is $11.5 \% .{ }^{11}$

\subsection{Basis for the operation of a dye-sensitized solar cell}

A dye-sensitized solar cell (DSSC) is very simple in its basic construction and operation. The essential function of a DSSC is to absorb light and convert it into electricity. A semiconductor such as titanium dioxide $\left(\mathrm{TiO}_{2}\right)$ is deposited onto an electrical conductor and coated with a monolayer of a sensitizing dye. The dye captures incoming photons and injects electrons into the semiconductor. The rest of the cell is an electrochemical system (to be described in later sections) that enables the cell to provide a sustained current. 


\subsection{Conductors and insulators}

An electrical conductor is a material through which an electrical current can pass with little resistance. An electrical insulator is just the opposite - a material through which an electrical current does not easily pass. Generalizing broadly, metals are typically good conductors, and most nonmetals are typically insulators. The basis for these different behaviors lies in the nature and occupancy of the chemical bonds present in each type of material. In essence, the Pauli exclusion principle is responsible; a material in which all the available bonding orbitals are fully occupied (an insulator) cannot pass an electrical current because there is simply no place for any additional electrons to go. In a metal there are many partially-filled orbitals (states) at nearly identical energy levels in what is referred to as the conduction band. Electrons can freely move from one state to another, providing electron mobility and hence electrical conductivity. A brief treatment of band theory in section 3.5 expands on the concepts underlying electrical conductivity.

\subsection{Semiconductors}

As the name suggests, a semiconductor has intermediate electrical conductivity, which is a reflection of the fact that its bonding is intermediate between that of a conductor and an insulator; i.e., a semiconductor has a comparatively small density of partially-occupied orbitals (charge carriers) to provide electrical conductivity. A typical semiconductor might have a charge carrier density of approximately $10^{17} / \mathrm{cm}^{3}$ compared with 
approximately $10^{22} / \mathrm{cm}^{3}$ for copper, an excellent electrical conductor. The structural details responsible for this marginal behavior turn out to impart some very useful characteristics to many semiconductors. Solid state electronics (transistors, etc.) represent many important applications for these materials. But these same characteristics are also responsible for the utility of semiconductors in photovoltaic devices, of both the solid state (p/n junction) and electrochemical varieties.

\subsection{Orbitals and states}

Semiconductors are large covalently bound structures. A sample of single-crystal silicon, for example, consists of a large array of tetrahedrally bonded silicon atoms. Other than defect sites and inevitable traces of impurities, a crystal is essentially one large molecule.

An organic chemist might find it convenient to think of a semiconductor as a large molecule having a large number of occupied (bonding) molecular orbitals (MOs) that are fully occupied by electrons, and a large number of (antibonding or nonbonding) orbitals at a higher energy level that are almost entirely unoccupied. The lower-energy MOs are closely spaced together in their energy content, as are the higher energy MOs. The 
energy difference between these two sets of orbitals is analogous to the HOMO-LUMO energy difference.

The fundamental study of semiconductors is largely the province of solid state physicists, and they do not employ the language of molecular orbitals, etc. Each MO is referred to as a "state". The lower-energy set of states collectively comprises the valence band (VB), and the higher-energy set of states is the conduction band (CB). The energy gap (in which there are no states) between the top of the VB and the bottom of the CB is the bandgap.

In a semiconductor the VB states are all (or nearly all) full, and the CB states are all (or nearly all) empty. Electrons in the VB are not free to travel through the solid, because all of the states of similar energy content are already full. However, an electron in the CB is free to travel, since there are many unoccupied states at very similar energy levels. Thus a sample of a semiconductor will normally act like a good electrical insulator, but if some of the states in the $\mathrm{CB}$ become populated with electrons, it becomes a good conductor due to their mobility. Similarly, an electron vacancy in the valence band is called a hole, and a VB hole can exhibit similarly high mobility. 


\subsection{Energy levels}

The bandgap in a semiconductor is a measure of the difference between the VB and CB, but it turns out that there is more that can be said about these energy levels. They can be referenced not only against each other, but against an absolute energy scale, external to and independent of any particular semiconductor. This standard is the standard hydrogen electrode, or SHE, which is defined to have a potential of 0 volts on the electrochemical scale. Experimentally a more convenient reference electrode such as the standard calomel electrode (SCE) at a potential of $+0.2444 \mathrm{~V}$ vs SHE is generally used. Thus, an electron occupying one of the states in a semiconductor, or a particular orbital in an organic molecule, exists at a certain energy level, expressed as a potential with reference to a convenient reference electrode.

\subsection{Chromophores}

A chromophore is a structure within a molecule that has bonding and antibonding orbitals separated by an energy difference (HOMO-LUMO transition) matching the energy content of light in or near to the visible range (extending into the UV and near infrared regions). Thus if a molecule contains a chromophore that absorbs photons in the red range, red light is absorbed but green and blue are not, so the compound would appear blue-green. Due to conformational differences and vibrational levels, absorptions by chromophores are often broad, reflecting a large variation in the HOMO-LUMO gap depending on these variables. A chromophore that has a high probability of capturing a 
passing photon of the correct energy will have a strong absorption, or high extinction

coefficient. A molecule may possess more than one chromophore, which may or may not have overlapping absorbances. A molecule with strong absorbances over most or all of the visible range will appear black or nearly so. Photons at the red end of the visible spectrum have energy in the range of $1.6 \mathrm{eV}$; at the blue end, around $3.1 \mathrm{eV}$.

\subsection{Light absorption by a semiconductor}

Just as an organic molecule can absorb a photon of appropriate energy content by boosting an electron from the HOMO to the LUMO, a semiconductor can use the energy from a photon to excite an electron from the VB to the $\mathrm{CB}$. The minimum amount of energy to do this corresponds to the bandgap of the semiconductor. When a semiconductor captures a photon and excites an electron into the $\mathrm{CB}$, it converts the energy of the photon into an electronic form, which under the right conditions can be used to generate an electrical potential, i.e., a voltage.

The minimum energy required to boost an electron from the VB to the $\mathrm{CB}$ depends only on the bandgap; the absolute energy levels with respect to SHE have no bearing. Anatase $\mathrm{TiO}_{2}$ (the type most often used in DSSCs) has a bandgap of $3.2 \mathrm{eV}$, which corresponds to a photon in the near ultraviolet. Sunlight at the surface of the Earth contains only a small proportion of photons with this much energy, so on the face of it it would appear that $\mathrm{TiO}_{2}$ would not be very useful for converting sunlight into electricity; nearly all the light 
would be wasted. But there is a way around this problem called sensitization - the surface of the $\mathrm{TiO}_{2}$ can be coated with a dye that absorbs light over a wide range of wavelengths, corresponding to a large fraction of the solar spectrum.

\subsection{Dyes}

A dye in general is a molecule that is intended to bind to some substrate (such as fabric) and impart a color. Thus it must possess one or more chromophores. It must also possess some means, e.g., a chemical functional group that enables it to bind tightly to the intended substrate. A pigment, by way of contrast, does not bind to a substrate, but rather is admixed in a finely divided form with the material whose color is to be modified.

Several classes of dye have received extensive attention for use in DSSCs, but the workhorse for most of the record-setting devices has been ruthenium tris(bipyridyl) dyes, (such as N719), bound to the surface of the $\mathrm{TiO}_{2}$ by carboxylic acid functions. ${ }^{12-15}$ These dyes work very well, but for a number of reasons including cost and toxicity, they are not assumed to be the ultimate solution.

Porphyrin dyes have also been studied since the earliest days (1991) of modern DSSCs, ${ }^{16}$ despite the fact that until recently their efficiencies fell far short of the ruthenium dyes. 
The record (11\%) cell in 2010 employed an improved porphyrin dye (a Donor-pi-linkerAcceptor porphyrin dye designated YD2) with an iodide-triiodide (I3I) electrolyte. ${ }^{8}$

The subsequent record DSSC $(12.3 \%)^{17}$ made use of a different redox couple, based on $\left[\right.$ tris(bpy) $\left.\mathrm{Co}^{3+} / \mathrm{Co}^{2+}\right]$ complexes (CoBpy), in conjunction with a modified version of YD2 designated YD2-o-C8. The improvement is attributed in large part to this electrolyte, but it also required the modifications to YD2 in order to allow the electrolyte to work properly. Otherwise, the back reaction occurs at an unacceptable rate in this device. The current record efficiency is $13 \%$, produced by a cell using a porphyrin dye with CoBpy redox system. ${ }^{10}$

\subsection{Dyes on semiconductors}

Suppose a semiconductor surface is coated with a red dye. Now suppose a photon is absorbed by the dye molecule, promoting an electron from the HOMO to the LUMO. What happens next? It depends on the dye and the semiconductor, in particular the energy levels of the CB of the semiconductor and the LUMO of the dye. When a photon is absorbed by the dye, an electron is promoted from the HOMO to the LUMO of the dye. This is an excited state, so the electron won't stay there very long; it will find some path to lose the extra energy acquired from the photon. It can simply fall back to the HOMO and emit a photon (fluorescence). Or - just maybe - it can move into the CB of the semiconductor to which the dye is bound. 
The "maybe" depends on whether the LUMO of the dye is at higher or lower energy than the $\mathrm{CB}$ of the dye. If (and only if) the energy level of the LUMO is higher than that of the $\mathrm{CB}$ and other circumstances are favorable, the electron can fall (be injected) into the $\mathrm{CB}$ of the semiconductor. The injection of an electron from a dye molecule into a semiconductor is a crucial step for the operation of a DSSC. The net effect is that a photon which would not have had sufficient energy to promote an electron directly from the VB into the $\mathrm{CB}$ of the semiconductor (and which therefore would not have been absorbed) nevertheless is absorbed (by the dye) and results in an electron being injected into the $\mathrm{CB}$ (from the excited dye molecule, not from the $\mathrm{VB}$ of the semiconductor). If the electron is not removed from the $\mathrm{CB}$ of the $\mathrm{TiO}_{2}$ it will revert to the $\mathrm{HOMO}$ of the dye. This would be an example of a back reaction. Any reaction that removes an electron from the $\mathrm{CB}$ of the semiconductor before it has been made to do useful work is a type of back reaction.

A fully implemented DSSC is constructed such that after an electron has been injected into the $\mathrm{CB}$ it can move into an external wire. It travels through the wire, passes through a useful load resistance such as a light bulb, and returns to the cell (the counterelectrode). From the counterelectrode the electron is provided a path back to the oxidized dye molecule, by means of a suitable medium capable of transporting electrical charge. 


\subsection{Holes and hole-transport media}

After being excited by a photon and injecting an electron into $\mathrm{TiO}_{2}$, a dye molecule is left in an oxidized state. There is a single electron remaining in the HOMO, and the vacancy can be considered to be a hole. The hole can be filled by a reducing agent in the electrolyte (the desired event), but this creates a new hole in the reducing medium. In a liquid electrolyte, the hole (the oxidized half of the redox couple) migrates to the counterelectrode by diffusion. In a solid-state medium, atoms are locked in place but the hole nevertheless diffuses to the counterelectrode by purely electronic mechanisms. Thus it is reasonable to think of the redox medium as transporting holes from place to place; it is often referred to as a hole transport medium, or HTM. This terminology becomes especially applicable when considering the use of an organic solid-state medium as a replacement for liquid redox systems, since most such media have holes, not electrons, as their principal charge carriers.

\subsection{Liquid hole-transport media}

The role of a redox electrolyte in a DSSC is to complete the last leg of the electrical circuit consisting (so far) of a photoelectrode with dye-sensitized $\mathrm{TiO}_{2}$ and an external circuit containing a useful load resistance. Electrons which have exited the DSSC and passed through the load must return to the cell to maintain charge balance (or, to satisfy Kirchoff's first law). Each dye molecule that gave up an electron after being excited by a 
photon has been oxidized and must ultimately be reduced so that it does not fall apart (the bonding orbital is only half occupied) and so that it can be ready to absorb another photon and repeat the cycle. Specifically, an electron must be restored to the bonding HOMO in the dye from which it came. This reduction is accomplished by the reduced half of a redox couple in the electrolyte. Note that the HOMO has a particular energy level and the reducing species must be at a somewhat higher energy level for the reduction to occur. However, it is desirable that the reducing species should be only a little higher in energy than the HOMO of the dye, because the difference represents wasted energy, as indicated by a reduction in cell voltage from what might otherwise have been obtained. Thus it is necessary to use a redox couple that is energetically tuned to the dye in the cell.

A suitable redox electrolyte must satisfy several criteria. As noted above, its redox potential must be a suitable match for the dye in use in order to maximize open-circuit voltage $\left(\mathrm{V}_{\mathrm{oc}}\right)$.

In liquid electrolyte systems charge is carried by ions shuttling back and forth between the two electrodes, diffusing through the solvent. The redox species must be sufficiently mobile for ion diffusion to occur at a rate sufficient to keep up with the needs of the cell while it is under full illumination. This precludes the use of viscous solvents and/or bulky ions which would limit the diffusion rate and thereby limit the amount of current produced by the cell. 


\subsection{Strengths and weaknesses of I3I electrolytes}

The iodide-triiodide redox couple performs remarkably well in DSSCs. The redox potential of this couple is reasonably well matched with that of the HOMO of many dyes used in DSSCs and solubility is good in suitable solvents. Ion mobility is sufficient so as not to limit $\mathrm{I}_{\mathrm{sc}}$, and most remarkable of all is the fact that the oxidized species $\left(\mathrm{I}_{3}{ }^{-}\right)$is far more readily reduced at the counterelectrode than at the photoanode, though the latter reaction occurs to an undesirable extent.

Liquid electrolytes come with some baggage, including most obviously the inherent threat of leakage. (However, in a private discussion, Brian O'Regan argued that leakage is not an issue; in his opinion adequate sealing is readily achievable.) Other problems include freezing, and the corrosive nature of the free iodine present in the I3I electrolyte which will attack aluminum or even silver used as a conductive matrix needed for cells of practical size. Perhaps the most serious indictment of the I3I redox couple is that it limits the voltage that can be delivered by a DSSC, thereby lowering its efficiency. The efficiency of DSSCs needs to be improved. The internal quantum yield is near unity, but the voltage produced is less than could be expected. Some fraction of this reduced voltage can be attributed to internal series resistance in the cells, but it is at least partially due to the I3I redox couple used in the current liquid electrolyte.

The energy level of I3I is about $0.9 \mathrm{eV}$ higher than the level of the oxidized dye HOMO which it reduces. The excess energy (a considerable fraction of the absorbed energy) is 
wasted as heat. Thus, significant improvements in voltage (and efficiency) are very likely attainable if a suitable replacement for the I3I redox couple can be found. As will be seen, most or all potential replacements will almost certainly introduce a new set of problems, in the form of what amounts to a short-circuit across the cell.

\subsection{Solid-state HTMs}

There is a broad consensus that the liquid-based electrolyte should be replaced by a solidstate material (a hole-transport material, or HTM) to eliminate the issues associated with liquid electrolytes in general and iodide-based electrolytes in particular, as discussed in the previous section.

\subsection{Principles of DSSC operation}

Figure 3.1 is an energy level diagram corresponding to the principal components of a DSSC, with both the favorable and unfavorable reactions that occur within the cell identified. The parenthesized numbers in red represent the sequence of events within an operational DSSC, beginning with the absorption of a photon (1) and ending with the 
return of electrons to the back electrode of the cell (8). Favorable events are depicted in black, and unfavorable events (two representative modes of back-reaction) are in red.

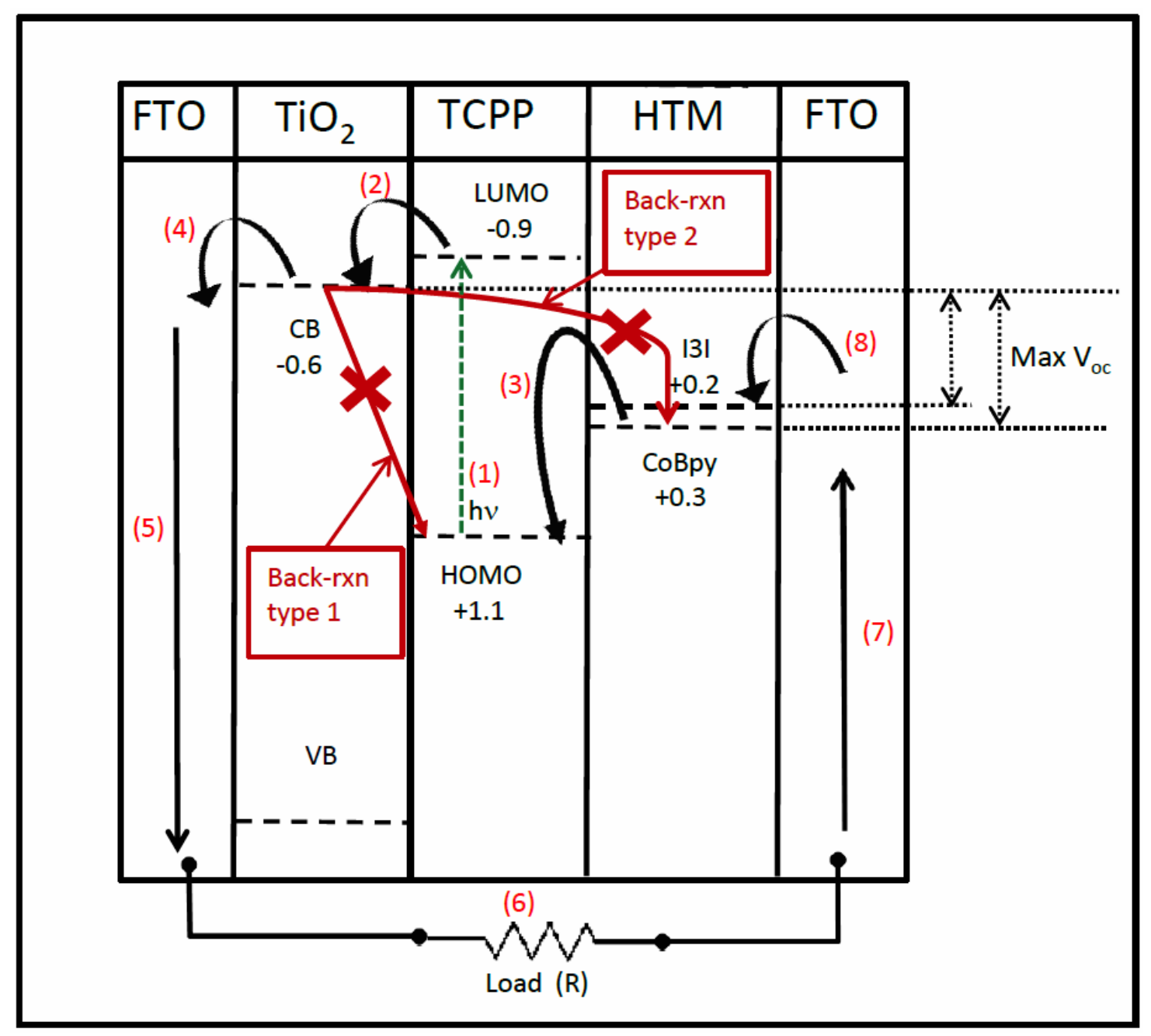

Figure 3.1 Energy level diagram of the components and processes in a DSSC.

Energy levels are reported vs. SCE

(1) A photon enters the cell and is captured by a dye molecule, and an electron in the dye molecule is promoted into an excited energy level. (2) The excited electron is injected into the conduction band of the $\mathrm{TiO}_{2}$ nanoparticle to which it is bound. (3) The missing 
electron in the dye is replenished by an iodide ion. (4) The injected electron is conducted through the $\mathrm{TiO}_{2}$ nanoparticle layer into the conductive FTO. (5) The electron passes into a wire and (6) through a load doing useful work. (7) The electron leaves the load and continues through the wire back to the DSSC. (8) At the back electrode, two electrons are provided to an $\mathrm{I}_{3}{ }^{-}$ion, regenerating three iodides. The maximum $\mathrm{V}_{\mathrm{oc}}$ achievable by the cell is limited by the difference between the lower edge of the conduction band of $\mathrm{TiO}_{2}$ and the solution potential of the redox electrolyte. CoBpy electrolytes have a potential somewhat positive of those based on I3I, permitting a larger $\mathrm{V}_{\mathrm{oc}}$.

It is possible for an electron that has been injected into $\mathrm{TiO}_{2}$ to reduce an oxidized dye molecule (back-reaction type 1), but it is not generally a significant problem and is not the back-reaction of principal interest in the research reported upon here.

The type 2 back reaction (reduction of oxidized electrolyte such as triiodide ion by electrons from the $\mathrm{CB}$ of the $\mathrm{TiO}_{2}$ ) is the reaction of interest. The use of coadsorbates is expected to slow the rate at which this reaction occurs by physically blocking access to the surface of the $\mathrm{TiO}_{2}$, thus preventing triiodide ion from reaching the surface and being reduced to three iodide ions.

$$
\mathrm{I}_{3}^{-}+2 \mathrm{e}^{-} \rightarrow 3 \mathrm{I}^{-}
$$

Equation 3.1 Reduction of triiodide to iodide 
Figure 3.1 includes Co (II/III) tris-bipyridyl complexes (CoBpy) as an alternative redox couple. It would potentially offer the advantage of improved $\mathrm{V}_{\text {oc }}$, but is more subject to type 2 back reactions than the iodide-triiodide couple. ${ }^{18-22}$

Figure 3.2 is a cartoon that illustrates the basic structure and operation of the same DSSC based on titania $\left(\mathrm{TiO}_{2}\right)$ nanoparticles; it does not illustrate the unfavorable reactions. The device as shown in Figure 3.2 is just as it was introduced by O'Regan and Grätzel in $1991 ;^{7}$ changes since then have consisted of improvements of dyes and other details of the system, but no major changes have been introduced until recently. 


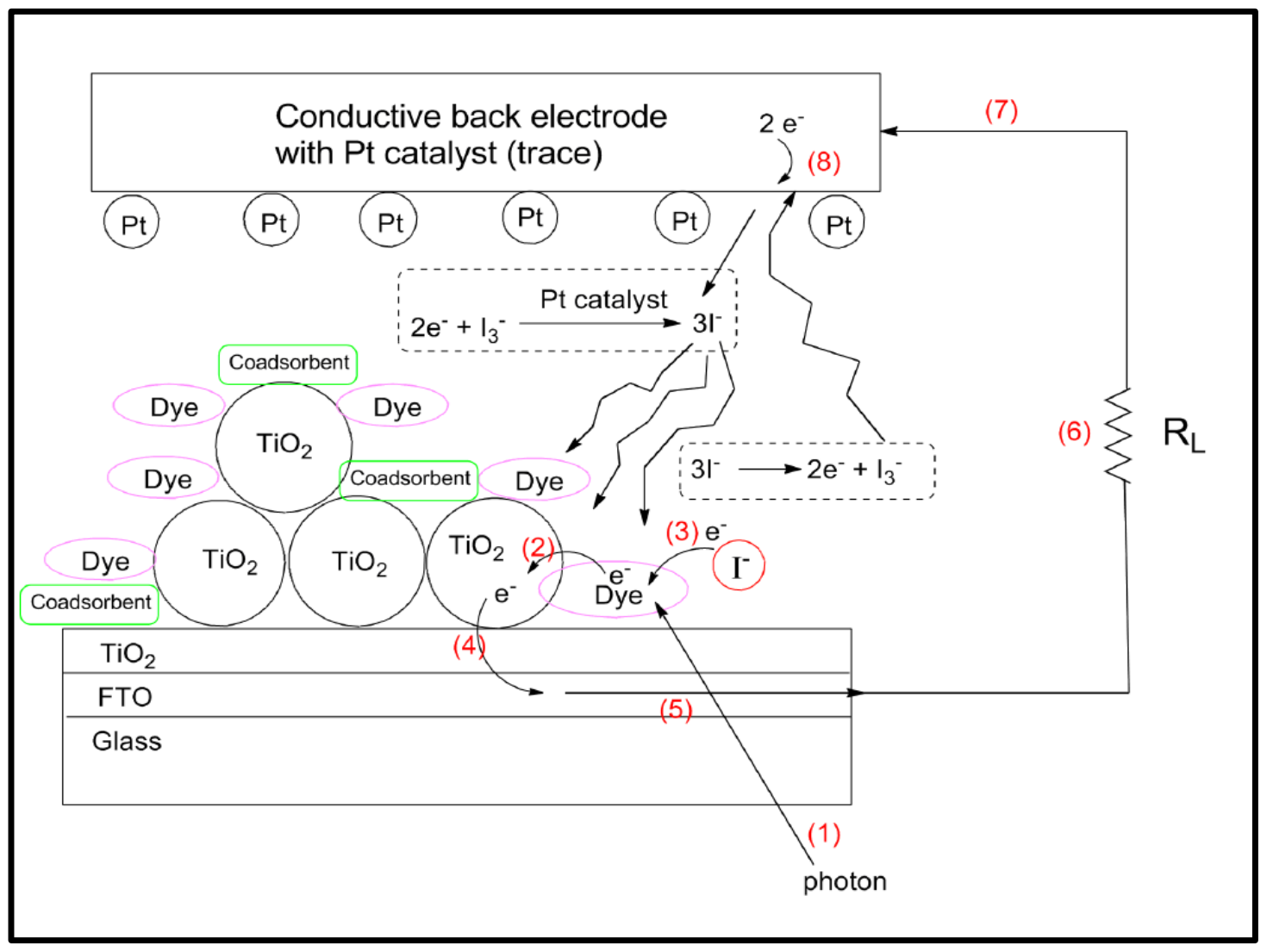

Figure 3.2 Basic structure and processes of a DSSC. The parenthesized numbers in red correspond to the same steps depicted in Figure 3.1

Construction of a DSSC begins with a piece of glass, which has been coated on one face with an electrically conductive, transparent material such as FTO (fluorine-doped tin oxide). A thin dense underlayer of $\mathrm{TiO}_{2}$ is deposited onto the FTO, followed by a layer of $\mathrm{TiO}_{2}$ nanoparticles (typically 10 to $20 \mathrm{~nm}$ in diameter, about $10 \mu \mathrm{m}$ total thickness). The particle layer, being constructed of nanoparticles, has a large surface area approximately $1000 \mathrm{~cm}^{2}$ per $\mathrm{cm}^{2}$. Since $\mathrm{TiO}_{2}$ is white, it is necessary to coat the $\mathrm{TiO}_{2}$ with a monolayer of highly light-absorbent dye. Because of the high surface area, a monolayer of dye is typically sufficient to allow strong light absorption. 
The weak point of the standard DSSC is the redox electrolyte solution, which effectively serves as a relay for electrons as they shuttle between the back electrode and the dye molecules on the working electrode. The electrolyte is in an organic solvent, relies upon diffusion to carry the redox species, is subject to such hazards as leaking and freezing, and the iodine component can be corrosive to metal contacts. This is a crucial weakness for scaled-up devices, which will require a matrix of metal conductors (aluminum would be ideal if it were stable in the chemical environment of the cell) to keep resistive loads low.

Note that the counterelectrode has a trace of platinum on its surface. This is crucial to the efficient operation of a cell which employs the I3I electrolyte. The reduction of $\mathrm{I}_{3}{ }^{-}$at the surface of FTO is slow due to a complex multi-step mechanism. ${ }^{23,24}$ In the absence of a catalytic surface this would be a bottleneck preventing any reasonable current to be produced by the device.

For the same mechanistic reason, the rate of the type 2 back reaction at the photoanode (in which the $\mathrm{I}_{3}{ }^{-}$ion may be reduced by electrons at the surface of the $\mathrm{TiO}_{2}$ or at exposed FTO) is also slow; in this case, it is a good thing, since the back reaction represents the loss of electrons which would otherwise be part of the current flow produced by the cell. However, the rate of loss is still sufficient to reduce the efficiency of a DSSC with an unprotected photoanode. To some extent the effect depends on the nature of the dye used 
in the cell. Efforts have been made to modify the surface so as to minimize the losses due to the back reaction. ${ }^{25-29}$ All that being said, it is still the case that a simple DSSC with no protective surface treatments works tolerably well, a result which has elicited the remark that it "seems surprising that the DSSC works at all." 30 If the exposed surface of the $\mathrm{TiO}_{2}$ could be insulated from the electrolyte system, the back-reaction problem would be solved. Exactly this approach has been successfully employed, but improvements are still needed.

The slow kinetics for reduction of $\mathrm{I}_{3}^{-}$at the surface of $\mathrm{TiO}_{2}$ is a (lucky) special case, attributed to a complex multistep mechanism. ${ }^{23,24}$ Other potentially useful redox couples such as CoBpy are not so graced. In order for such electrolytes to be useful, the type 2 back reaction must be controlled.

\subsection{Hole transport materials}

The purpose of the redox electrolyte system is to transport electrons from the counter electrode to the dye molecules that were oxidized after absorbing a photon. The I3I system and CoBpy system both conduct charge by means of ion diffusion through a solvent. Any viable solid-state replacement must accomplish the same purpose, but the mechanism of conductivity will depend on the specific material. Most electrically conductive solid-state organic materials use holes as the majority carrier. As a result, hypothetical discussions of solid-state conductors for use in DSSCs usually refer to them as hole transport materials (HTMs). For the sake of simplicity, in this document the 
terms HTM, redox electrolyte, and redox mediator are used interchangeably, notwithstanding the fact that the liquid and solid materials are fundamentally different in their mode of operation. Liquid systems contain oxidized and reduced species; by analogy, a hole in a solid HTM can be thought of as a locally oxidized region in the HTM. For a solid HTM, the "back reaction" would be transfer of an electron from the anode to a hole in the HTM. The issues to be considered herein are primarily concerned with the interfaces between the HTM and the other surfaces in the DSSC.

\subsection{Evaluation of DSSCs}

In the final analysis, the most important criterion for evaluating a DSSC is its efficiency, which is the fraction of incident light energy falling on it that is successfully converted to usable electrical power. It has been calculated that the maximum theoretical efficiency for a single-junction PV device is $~ 32 \%{ }^{31}$ Currently some silicon-based PV devices demonstrate efficiencies around $25.6 \% .^{32}$ A rule of thumb is that to be practical an efficiency of at least $10 \%$ is required, so DSSCs have the potential to be serious competitors if remaining practical problems can be solved.

In the study of experimental PV devices, it is useful to measure a number of cell parameters in addition to efficiency. The values demonstrated for these parameters provide valuable insights into the actual processes occurring inside the cell, enabling 
enlightened attempts to make improvements, and to evaluate which attempts are successful (or not) and to understand why.

Three commonly used criteria are open-circuit voltage $\left(\mathrm{V}_{\mathrm{oc}}\right)$, fill factor $(\mathrm{FF})$, and shortcircuit current $\left(\mathrm{I}_{\mathrm{sc}}\right)$. The short-circuit current depends in part on the photoactive area of the device, and is often normalized to a unit area and referred to as $\mathrm{J}_{\mathrm{sc}}$. These measurements are typically reported when the cell is at full illumination ("one sun", or AM 1.5). Measurements are sometimes made at other (higher or lower) levels of illumination in order to gain additional insights into the cell processes. For example, if the light intensity were to be doubled it would reasonably be expected that $\mathrm{J}_{\mathrm{sc}}$ would approximately double as well. A failure to do so would be diagnostic of some sort of problem with the cell. For example, if the redox electrolyte were of insufficient concentration it might be unable to shuttle electrons quickly enough to keep up with the (potential) photocurrent.

The $\mathrm{V}_{\mathrm{oc}}$ is the voltage the cell can deliver at open circuit, i.e., when no current is actually flowing from the cell. This is a measure of the electrochemical potential across the cell when it is under full illumination.

The $\mathrm{J}_{\mathrm{sc}}$ is a measure of how much current the cell can deliver when it is short-circuited (externally). This is a measure of several factors, including how efficiently light is 
absorbed by the cell, how efficiently electrons are injected from the dye into the $\mathrm{TiO}_{2}$, and how well back reactions are controlled.

The fill factor will be discussed more fully in the following paragraphs, but briefly stated it is a measure of how well a cell is able to deliver both good current (as near to $\mathrm{J}_{\mathrm{sc}}$ as possible) and good voltage (as near to $\mathrm{V}_{\mathrm{oc}}$ as possible).

Of these three metrics, $\mathbf{J}_{\mathrm{sc}}$ can be considered the most important. Efforts to improve DSSCs emphasize improving or at least not harming $\mathbf{J}_{\mathrm{sc}}$ while attempting to improve other aspects of the cell. Roughly speaking, a high-performance DSSC might produce in the neighborhood of $20 \mathrm{~mA} / \mathrm{cm}^{2}$ of photocurrent. To achieve that figure at one sun illumination a cell would be required to absorb nearly every photon in the visible range and convert it to photocurrent. This in turn would require a dye with a high absorbance across the visible spectrum (black), and with quantum efficiency approaching $100 \%$. In addition there must be no losses due to back reactions or other non-productive decay paths. Each of these requirements poses challenges, with the result that generally $\mathbf{J}_{\mathrm{sc}}$ is the most closely watched metric for DSSC performance. Improvements in $\mathrm{J}_{\mathrm{sc}}$ have tremendous leverage in influencing the overall performance of a DSSC.

The open circuit voltage is also important, but tends to not be terribly vulnerable to modifications in a DSSC. The $\mathrm{V}_{\text {oc }}$ of a cell is largely controlled by the dye and redox couple used in the cell as shown in Figure 3.1. 
The fill factor is to a large extent a measure of losses within the cell due to such factors as high serial resistance or low shunt resistance. As such, it is an valuable indicator of overall cell quality, and is also one of the three numerical factors used to calculate efficiency. Fill factor by definition must fall in a range between 0 and 1 , with a typical fill factor for an efficient cell being in the range of 0.7. A current-voltage curve for a resistor (no photoactive component, purely linear resistance) would be a straight line and would have a fill factor of 0 since it passes through the origin. A perfect fill factor (1.00) is not possible, since it would reflect operating a cell at full open circuit potential $\mathrm{V}_{\text {oc }}$ and at the same time at short-circuit current $\mathrm{J}_{\mathrm{sc}}$, but a minimum $\mathrm{FF}$ of around 0.6 is required for a cell to be considered viable. ${ }^{33}$ The DSSC that currently holds the record for efficiency $(13 \%)$ has a FF of $0.78, \mathrm{~J}_{\mathrm{sc}}$ of $18.1 \mathrm{~mA} / \mathrm{cm}^{2}$, and $\mathrm{V}_{\mathrm{oc}}$ of $910 \mathrm{mV} .^{10}$

A standard technique for evaluating a DSSC is a current-voltage (iV) curve, or if normalized for the area of the device under test, a JV curve. This is a plot of current delivered by a DSSC as the voltage across it is varied. Such a curve can be (rather laboriously) generated with no more equipment than a voltmeter, an ammeter, and a variable resistor. The voltmeter alone can measure the $\mathrm{V}_{\mathrm{oc}}$, the ammeter used to measure the $\mathrm{I}_{\mathrm{sc}}$. With the variable resistor connected across the cell, the voltmeter also across the cell, and the ammeter in series with the resistor, as the resistance is varied from infinite (open circuit) to 0 ohms (short circuit) a series of voltage/current data pairs can be collected at successively smaller resistances. It is not necessary to measure the value of 
the resistor at each point; by providing a successively larger load (smaller resistance) the voltage measured will decrease and the current will increase. A plot of the data points would comprise an iV curve for the cell. The absolute value of the resistance at each point could be calculated by simple application of Ohm's law, $R=|\mathrm{V} / \mathrm{I}|$. There is one point at which this would be of interest; the maximum power point, or MaxPP, which is the point at which the product of the current and the voltage is at a maximum. The resistance at that point would be the resistance of the ideal load for the cell under test, to force it to operate at its peak efficiency. Maximum power point is discussed later in this section.

This is not a practical method, but it serves to illustrate the nature of an iV curve. In practice $\mathrm{iV}$ curves are obtained by use of a potentiostat or a source-measure unit. Voltage (over a programmed range) is applied to the cell while it is illuminated (a light curve) or not (a dark curve), and the current passing through the device is plotted as a function of the applied voltage. The polarity of the applied potential is opposed to the potential being generated by the device being tested, so when the two potentials are of equal magnitude, they sum to zero. At that point, no current can flow, so it is the equivalent of an open circuit, and the applied potential at that point is the $\mathrm{V}_{\mathrm{oc}}$ of the cell. Similarly, at the point where the applied potential is zero, it is the equivalent of a short circuit across the cell, and the current measured is the $\mathrm{I}_{\mathrm{sc}}$ of the cell. It is customary to scan a voltage range extending past $0 \mathrm{~V}$ (positive or negative of 0 , depending on the sign convention being used) and also past the anticipated $\mathrm{V}_{\mathrm{oc}}$ for the cell. These extensions could not be 
accomplished using the primitive voltmeter/ammeter/resistor setup; nor could dark curves be generated.

The power produced at each point along the curve is the product of the voltage and current at that point. At one unique point along the curve this product will be at a maximum value; this is the maximum power (MP) that can be delivered by this particular device under the same conditions of illumination and temperature. The product of the $\mathrm{V}_{\mathrm{oc}}$ and the $\mathrm{I}_{\mathrm{sc}}$ represents an ideal maximum, but unattainable, power level. Any source of electrical power has built in resistances and other inefficiencies which consume some of its power. The ratio of the attainable power at MP to the idealized product of $\mathrm{V}_{\mathrm{oc}} * \mathrm{I}_{\mathrm{sc}}$ is defined as the fill factor. The efficiency of the device depends greatly on this factor.

$\%$ Efficiency $=100 * \mathrm{P}_{\text {out }} / \mathrm{P}_{\text {in }}=100 *\left(\mathrm{FF} * \mathrm{~V}_{\mathrm{oc}} * \mathrm{I}_{\mathrm{sc}}\right) / \mathrm{P}_{\mathrm{in}}$

\section{Equation 3.2 Efficiency of a DSSC}

The power output (in watts) at any point along the JV curve is the product of the voltage and amperage at that point. There is one particular point on the curve at which this product reaches a maximum value, abbreviated MaxPP in Figure 3.3. The maximum power point corresponds to the point of maximum efficiency and which also corresponds to a load resistor having a resistance defined by:

$$
\mathrm{R}_{\text {load }}=\mathrm{V}_{\text {maxpp }} / \mathrm{J}_{\operatorname{maxpp}}
$$


Equation 3.3 Load resistance at the maximum power point

If light intensity varies, the voltage and current at the max power point change (hence the optimum load resistance changes as well). Inverters for solar panels (operating under changing natural light) continuously adjust the load they apply in order to keep the connected panels operating at their maximum power point.

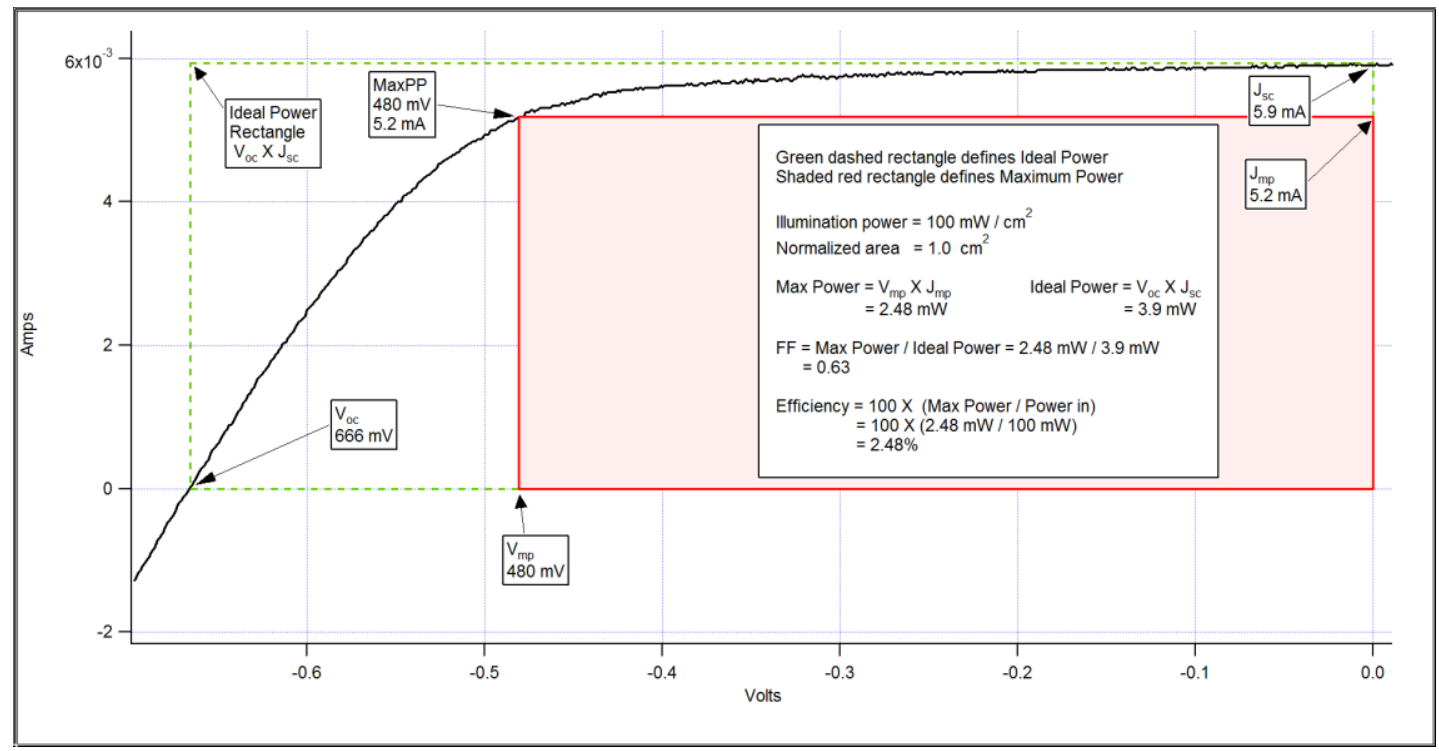

Figure 3.3 JV curve from a typical DSSC

Figure 3.3 illustrates the key features of a JV curve. The cell was made with TCPP sensitizing dye and I3I-1 electrolyte. It was tested at 1.0 sun irradiation with a LED light source rated at $5000 \mathrm{~K}$ color balance. Total cell area was approximately $1.0 \mathrm{~cm}^{2}$; a mask 
exposing $0.32 \mathrm{~cm}^{2}$ was employed and the current was normalized to $1.0 \mathrm{~cm}^{2}$. The total area within the green dashed rectangle corresponds to the ideal amount of power that would be produced by the cell if it were possible to achieve the maximum voltage $\left(\mathrm{V}_{\mathrm{oc}}\right)$ and the maximum current $\left(\mathrm{J}_{\mathrm{sc}}\right)$ simultaneously. This is not possible because it would require that the cell be operated at both short-circuit and open-circuit conditions simultaneously. The area within the red rectangle corresponds to the amount of power that would actually be delivered by the cell, if an optimum load resistance were employed. The ratio of these areas, Actual Power/Ideal Power, is the fill factor.

Along the (nearly) horizontal leg of the iV curve, deviation from true horizontal reflects primarily "leakage" within the cell; this is due principally to the back reaction. Electrons are captured from the anode in the course of reducing the oxidized component of the redox couple. If a solid state p-type HTM were being employed instead of a liquid electrolyte, the lost electrons would be filling holes in the medium. 


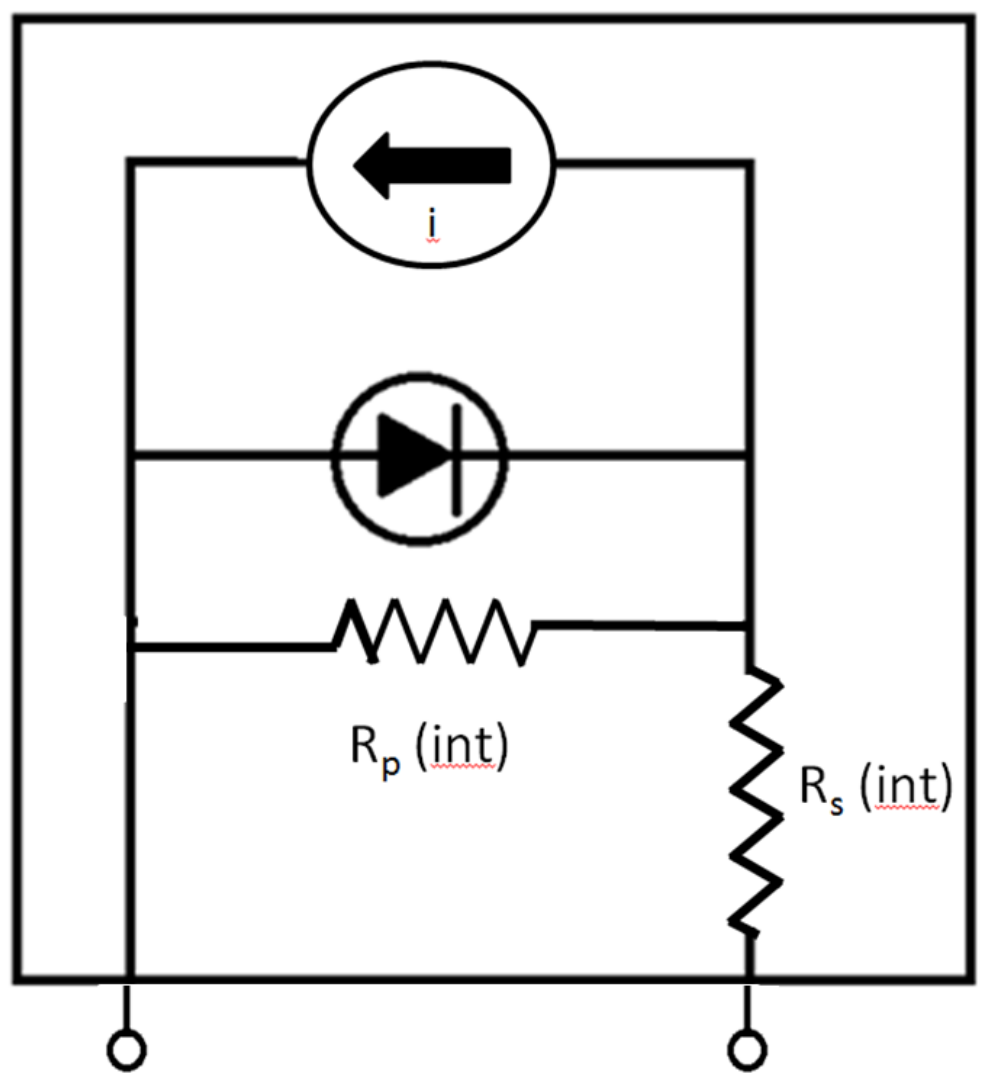

Figure 3.4 Equivalent circuit representation of a DSSC

Figure 3.4 is an equivalent circuit representation of a solar cell. The photocurrent source is represented as an arrow within a circle. The formal (positive) current flows in the direction of the arrow. A diode in parallel with the photocurrent serves to represent the voltage limit of the cell; any voltage above the forward bias voltage of the diode would be short-circuited. The unavoidable internal leakage current is represented by a shunt resistor connecting the two electrodes of the cell, in parallel with the current source, represented as $R_{p}$. Along the (nearly) vertical leg of the $i V$ curve, deviation from the vertical represents impediments to current flow and is the electrical equivalent of a series resistor in the circuit. Hence it is represented as $R_{s}$. 
The efficiency of a DSSC is improved by making $\mathrm{R}_{\mathrm{p}}$ as large as possible (iV curve flat on top; minimum internal current leakage) and $\mathrm{R}_{\mathrm{s}}$ as small as possible (iV curve as steep as possible on the semi-vertical leg; minimum voltage drop and power loss due to internal resistance).

Experimentally it is not possible to (significantly) decrease the series resistance or to increase the parallel resistance of a particular cell at all, although series resistance can be reduced slightly by using silver paint to make electrical contact with the electrodes.

\subsection{Experimental simulation of increased $R_{s}$ and decreased $R_{p}$}

It is possible to simulate the effects of decreasing the parallel resistance $\mathrm{R}_{\mathrm{p}}$ of a DSSC by adding a resistor in parallel with (across) the cell being tested. This mimics the effect of increasing the internal leakage of photocurrent, such as occurs as the result of a backreaction in which oxidized electrolyte is reduced at the photoanode (decreasing the photocurrent).

Similarly the effects of increasing the serial resistance $\mathrm{R}_{\mathrm{s}}$ can be simulated by adding external resistance in series with the cell. A schematic of a DSSC with external series and parallel resistors is shown in Figure 3.5. 


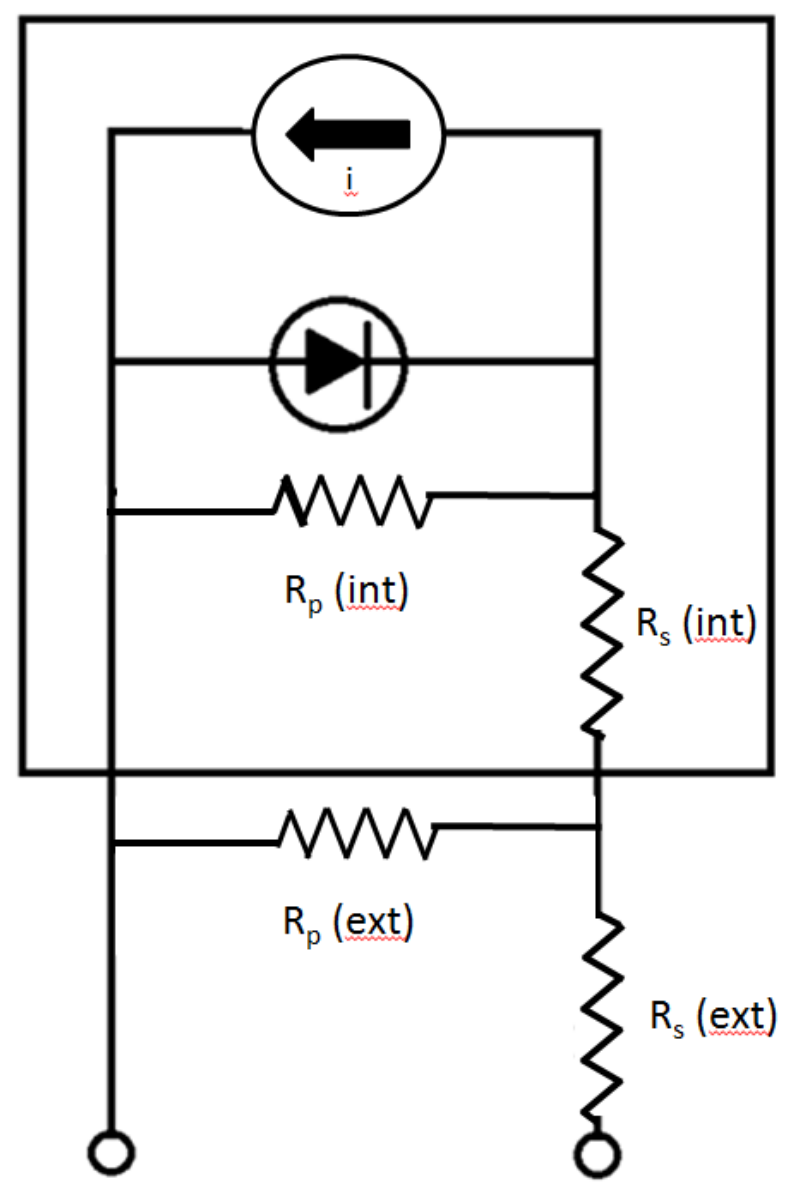

Figure 3.5 Equivalent circuit of a DSSC showing internal and external resistances

The inner box represents the DSSC. The outer box includes external resistances added to simulate the effects that would result if the series resistance was increased or the parallel resistance decreased. Experimental results are depicted in Figure 3.6 (decreased $\mathrm{R}_{\mathrm{p}}$ ) and in Figure 3.7 (increased $\mathrm{R}_{\mathrm{s}}$ ).

The effective $R_{s}$ in the circuit is the sum of $R_{s}(i n t)$ and $R_{s}(e x t)$, and the effective $R_{p}$ is approximated as the effective resistance of parallel resistors, with $\mathrm{R}_{\mathrm{p}}(\mathrm{int})$ being the series sum of $\mathrm{R}_{\mathrm{p}}$ (int) plus $\mathrm{R}_{\mathrm{s}}$ (int). By testing a DSSC with and without external series and 
parallel resistors, a series of $\mathrm{iV}$ curves was generated showing the effects of these added resistances.

$$
\begin{aligned}
& \mathrm{R}_{\mathrm{s}}(\text { eff })=\mathrm{R}_{\mathrm{s}}(\text { int })+\mathrm{R}_{\mathrm{s}}(\mathrm{ext}) \\
& \left.\mathrm{R}_{\mathrm{p}}(\mathrm{eff})=\left[\left(\mathrm{R}_{\mathrm{p}}(\mathrm{int})+\mathrm{R}_{\mathrm{s}}(\text { int })\right) * \mathrm{R}_{\mathrm{p}}(\mathrm{ext})\right] /\left[\mathrm{R}_{\mathrm{p}}(\text { int })+\mathrm{R}_{\mathrm{s}}(\mathrm{int})\right)+\mathrm{R}_{\mathrm{p}}(\mathrm{ext})\right]
\end{aligned}
$$

Equation 3.4 Approximate effective $\mathrm{R}_{\mathrm{s}}$ and $\mathrm{R}_{\mathrm{p}}$ for the circuit in Figure 3.5.

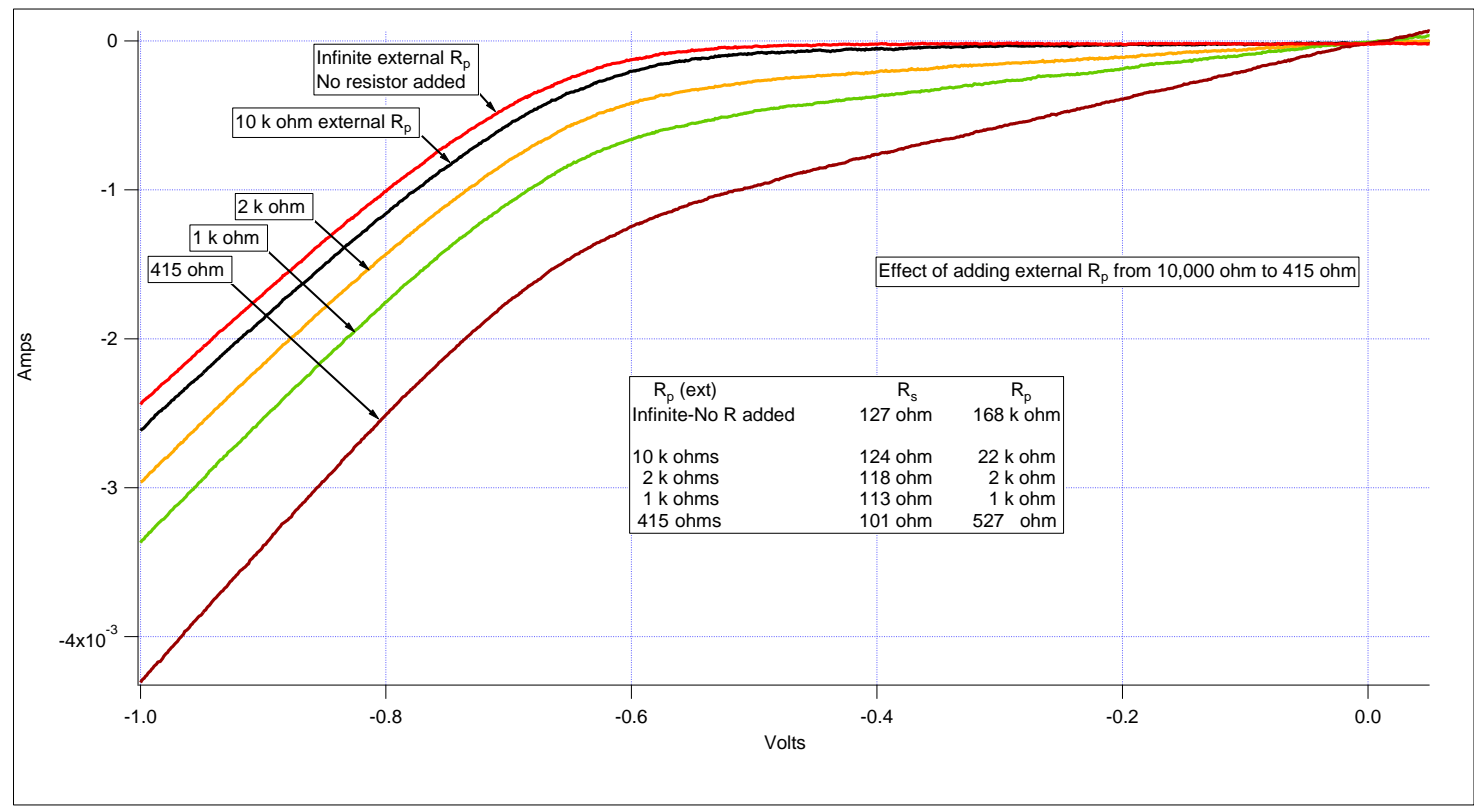

Figure 3.6 Effect of artificially decreasing the shunt resistance of a DSSC by adding external resistance in parallel to the cell under test

In Figure 3.6 and Figure 3.7 the same DSSC was used. All of the iV curves were generated in the dark, hence there is not any photocurrent. For this cell, in the absence of 
any external series or parallel resistances, $R_{s}($ int) was approximately 127 ohms and $\mathrm{R}_{\mathrm{p}}$ (int) was approximately $168 \mathrm{~K}$ ohms.

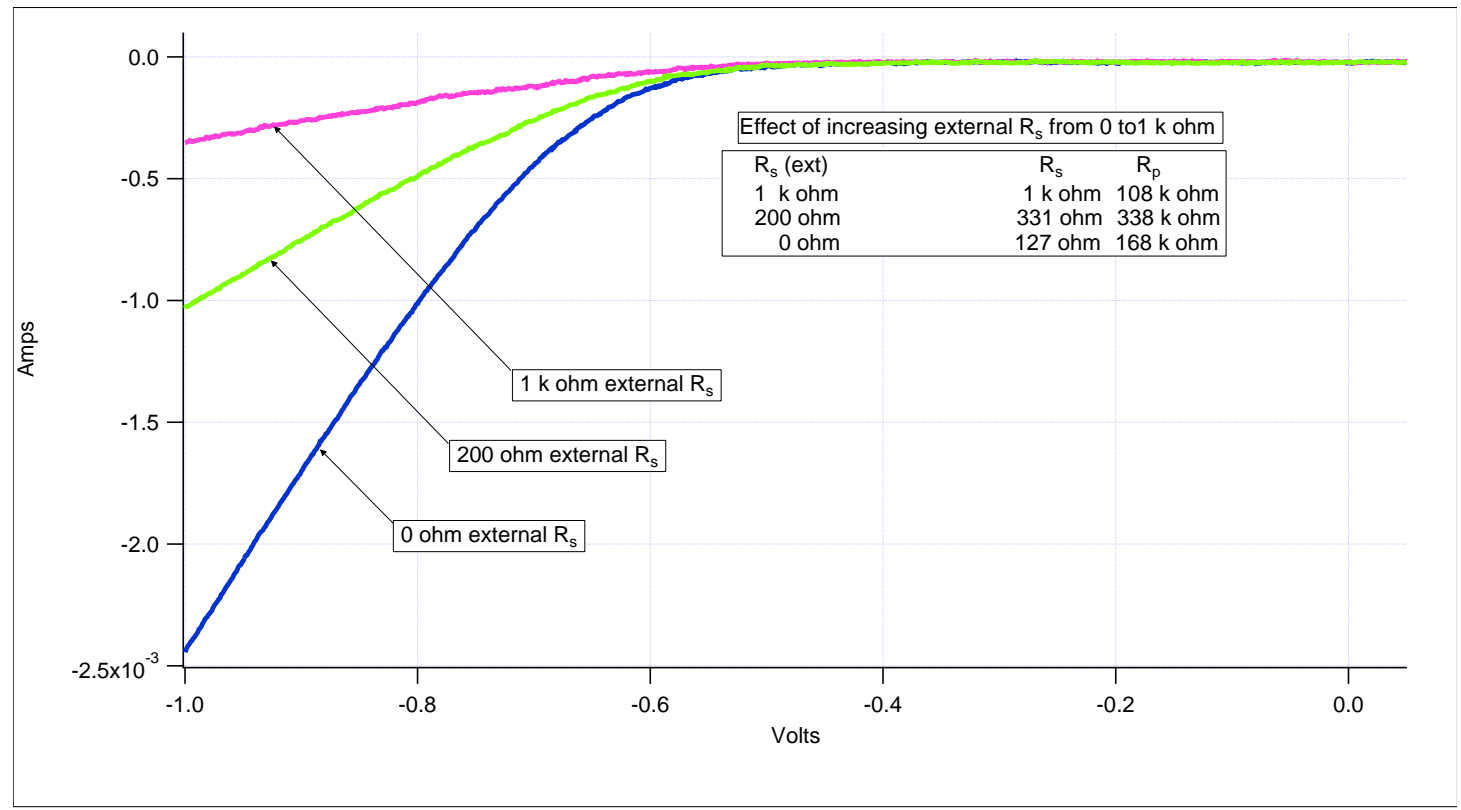

Figure 3.7 Effect of adding external $\mathrm{R}_{\mathrm{s}}$ to a DSSC

Figure 3.6 demonstrates effects similar to those that would be caused by decreasing the internal shunt resistance of a DSSC, as is caused by the back reaction. Figure 3.7 demonstrates effects similar to those that would be caused by increasing the internal series resistance of a DSSC.

\subsection{Preventing the type 2 back reaction}

There are several strategies for preventing access to the anode by redox species. Surface treatments (blocking agents) are one approach. ${ }^{25}$ Another more recent strategy is to 
modify the dye molecule itself with bulky substituents that obstruct diffusion to the surface by the oxidized half of the redox couple. ${ }^{17}$ Finally, some work has been done in which the redox couple itself has been deliberately made bulky (by the addition of substituents) to impede its access to the surface. ${ }^{5,18,20,21}$ The approach of making the redox components bulky does reduce the back reaction, but it also impedes diffusion of the oxidized redox component to the cathode, so it limits the short-circuit current to unacceptably low values. Thin conformal inorganic coatings (such as alumina, ${ }^{22,34}$ silicon dioxide, ${ }^{35}$ and zirconium oxide ${ }^{36}$ ) on the surface of the $\mathrm{TiO}_{2}$ have also been employed.

Alternatively, if the dye molecule is provided with bulky or long-chain substituents, they might prevent the migration of oxidized redox species to the surface. Such an approach has recently been investigated and shown to be feasible. ${ }^{4,17}$ Efforts to date have involved synthesizing dyes with long alkyl or alkoxy substituents; the dyes are then dissolved in a suitable solvent and adsorbed onto the $\mathrm{TiO}_{2}$ in the usual manner. One potential drawback to this approach is the need for a more complex synthesis of the dye.

\subsection{Coadsorbates}

If a substance other than a dye is adsorbed onto the surface of a semiconductor, it is referred to as a coadsorbate or coadsorbent. Coadsorbates occupy part of the semiconductor surface that is not covered by dye molecules, and thereby block access to 
the surface by the oxidized half of the redox couple. In this role they are referred to as blocking agents.

Substances may be applied before, simultaneously with, or after the deposition of the dye. For the sake of clarity, the word coadsorbate will be employed as the generic term encompassing all three treatment sequences. Substances used to treat an electrode before treatment with dye will be referred to as pre-adsorbates. Substances applied simultaneously with the dye (in the same solution) will be designated sim-adsorbates, and those applied to an electrode after the dye has been applied will be referred to as post-adsorbates.

Regardless of the application sequence employed there is a competition for surface binding sites, with decreased dye loading as a consequence. ${ }^{25}$ Part of the challenge is to find conditions that result in sufficient dye adsorption so as to provide efficient absorption of light, while still allowing the remaining surface to be well covered with the coadsorbate. Organic blocking agents bound to the surface have been investigated for some time. ${ }^{25-29,37}$ Deoxycholic acid and chenodeoxycholic acid are routinely employed as coadsorbates, ${ }^{25}$ though their exact mode of action is still unclear. ${ }^{27}$

A coadsorbate must bind well to the surface of the $\mathrm{TiO}_{2}$. Carboxylic acids bind well, but phosphonic acids bind even more tightly. ${ }^{38-41}$ A number of compounds with carboxylate binding groups have been investigated. ${ }^{9,25,27-29,42}$ Wang investigated the use of decylphosphonic acid (as a sim-adsorbate) with a ruthenium-based dye, Z-907. ${ }^{40}$ It was 
found to improve $\mathrm{J}_{\mathrm{sc}}$ and efficiency in newly-made cells. There was not a significant effect on $\mathrm{V}_{\mathrm{oc}}$ at the outset but there was significant stabilization of $\mathrm{V}_{\mathrm{oc}}$ as cells were aged up to 1000 hours at $80^{\circ} \mathrm{C}$. It is worth noting that the improvement in $\mathrm{J}_{\mathrm{sc}}$ was realized despite the fact that dye loading was reduced by 30 to $40 \%$.

Coadsorbates affect the behavior of a DSSC by several mechanisms. First, they serve as blocking agents as previously discussed. They have also been shown to protect the surface from water in the system, ${ }^{43}$ which is known to participate in the photodegradation of $\mathrm{TiO}_{2} .{ }^{6}$ They also assist in preventing dye stacking.

Coadsorbates generally modify the work function of the surface to which they are adsorbed as a result of the dipole created at the surface by the adsorbate. ${ }^{42,44,45}$ By so doing they in effect tune the potential of the $\mathrm{TiO}_{2}$ surface in a controllable manner, which can be utilized to improve the efficiency of electron injection from the excited dye.

Rivest et al. determined that a series of phosphonic acids including substituted phenylphosphonic acids and one alkyl phosphonic acid increase the work function of anatase $\mathrm{TiO}_{2}$ over a range of about $1 \mathrm{eV} .^{43}$

The research reported here deals principally with the use of a variety of phosphonic acids as coadsorbates with TCPP as the sensitizing dye. 


\subsection{Summary}

It seems likely that, as part of the process of improving the efficiency of DSSCs, the current I3I system will be replaced by another HTM (either solid or liquid), and this will necessitate finding a means to prevent the HTM from making electrical contact with the anode, i.e., getting close enough such that electrons can be transferred from the photoanode to the oxidized HTM component at a significant rate. The use of blocking agents (coadsorbates) is likely to be a method of general utility for this purpose. The coadsorbate must bind tightly to the surface so that subsequent exposure to solvents (including the solvent in a liquid redox electrolyte) do not remove or disturb it. Phosphonates bind more tightly than carboxylates, ${ }^{39}$ which makes them promising candidates as coadsorbates. There has been very little in the literature regarding the use of phosphonate-anchored coadsorbates, though some phosphonate-anchored dyes have been investigated and found to be of somewhat lower efficiency than similar dyes with carboxylate anchors. ${ }^{46}$ Nevertheless phosphonate-anchored dyes continue to be investigated. $^{39,47-50}$

There is considerable literature on the use of phosphonates to treat the surface of titanium

dental implants and other medical components to make them more biocompatible. ${ }^{51-53}$ In this work, a bifunctional phosphonic acid is employed, with the other functional group serving as a site for the subsequent attachment of biologically familiar moieties to 
promote acceptance by the body. One of the principal reasons that phosphonates are of interest in this application is their tight binding to $\mathrm{TiO}_{2}$ surfaces. 


\section{CHAPTER 4 DEVELOPMENT OF METHODS}

\subsection{Philosophy of experimental practices}

Simplicity and consistency of practice were the guiding principles underlying experimental design wherever possible. For example, the electrolyte designated as I3I-1 consists only of tetra-n-butylammonium iodide and elemental iodine in propylene carbonate solvent. Except as otherwise noted, additives such as $t$-butylpyridine were not utilized, so that the effects of the phosphonic acid coadsorbates being tested do not have to be disentangled from the effects of other additives.

\subsection{Goals}

The two primary goals of this work were to gain an improved understanding of the operation of DSSCs, and to use this new understanding to improve their performance. The criteria for improved performance include efficiency, life, and cost. It was (correctly) anticipated that this would require the construction and testing of a large number of DSSCs, and that methods that afford a high degree of reproducibility would be essential. This in effect created a third goal, the development of reproducible methods for the rapid preparation and testing of DSSCs. The satisfactory execution of the first two goals required the accomplishment of the third. In practice experimental work was undertaken on all three fronts simultaneously. 


\subsection{Methods to assemble and seal a DSSC}

One important aspect of DSSC construction proved to be particularly challenging: Sealing the DSSC, though seemingly trivial, is in fact a sticky wicket. A number of materials and methods were tested before an acceptable solution was discovered. Sealing of the cell is necessary to prevent the loss of solvent from the electrolyte, as well as to prevent exposure of the cell to oxygen and moisture.

For quick-and-dirty tests, demonstrations, and outreach experiments the procedure often employed is to simply use a pair of office-type binder clips to press the photoanode and counterelectrode into tight contact. This method is unsatisfactory for a number of reasons. First, pressing the photoactive layer on the anode into direct physical contact with the platinized counterelectrode would seem to invite loss of photocurrent through a direct physical short-circuit. Second, the pressure applied by the clips might be expected to crush and physically damage the $\mathrm{TiO}_{2}$ film on the anode. Third, it is impossible to seal cells held together in this manner. The clips tend to block part of the active area of the cell, making measurements of the active area suspect at best, and the assembly is difficult to accurately position (distance and angle) with respect to the light source during testing. Finally, the method sometimes results in a glass slide becoming projectile, as a binder clip slips off the edge of the slide and launches it into the laboratory.

A standard literature technique for sealing cells involves the use of Surlyn ${ }^{\circledR}$ polymer film, typically either $25 \mu \mathrm{m}$ or $50 \mu \mathrm{m}$ thick. The $\mathrm{TiO}_{2}$ area on the anode is trimmed 
(typically to $0.25 \mathrm{~cm}^{2}$ ) in such a way that the area remaining is surrounded by bare glass. A gasket of Surlyn ${ }^{\circledR}$ is placed around the area, and the counterelectrode is put in place on top of the gasket. The assembly is heated gently while being pressed together, and the Surlyn ${ }^{\circledR}$ forms a seal. Before assembly a small hole is drilled in the counterelectrode, to be used for filling with electrolyte. The cell is filled with electrolyte by placing a drop onto the hole in the counterelectrode, then placing the assembly into a vacuum chamber. When the air is withdrawn, the small cavity in the cell releases its air. Upon restoring the chamber to atmospheric pressure, the cavity in the cell is filled with electrolyte. The excess is wiped off, and the hole is sealed using a small piece of Surlyn® and a microscope cover slip, pressed together and heated to effect the seal. This method produces very good results and is standard in the literature, but it is time consuming and the preparation and manipulation of tiny Surlyn ${ }^{\circledR}$ gaskets, nearly invisible and prone to jumping around due to static electricity, makes the method difficult to implement. It was decided to seek a simpler method to maximize throughput and minimize fatigue.

On occasion an experiment was done using the binder clip method, or variations thereof in order to make progress until better methods could be found. In addition, several types of test fixture were devised to hold the slides in close proximity without using a spring clamp. These methods did not address the need to space the two electrodes apart.

A variation on the Surlyn ${ }^{\circledR}$ method was developed, using a square of Surlyn ${ }^{\circledR}$ with a hole 0.25 inch in diameter punched in it. After punching the hole, the gasket was split 
into two halves. The $\mathrm{TiO}_{2}$ area was a disc 0.25 inch in diameter, applied as a paste through a mask. The two gasket pieces were positioned around the disc, leaving a small gap on each side of the cell between the two Surlyn ${ }^{\circledR}$ pieces. Electrolyte was added through one of the gaps, while displaced air escaped through the gap on the other side. After being filled the small gap on each side of the cell was sealed with epoxy or hot glue. The filling operation was unreliable (often the electrolyte raced around the outer perimeter of the $\mathrm{TiO}_{2}$ disc, trapping air in the center) so this method did not produce satisfactory results. Variations of this method were tested, also using hot glue or one of several types of epoxy to seal the cell, but it was ultimately concluded that these methods tend to poison the cell with substance extracted into the electrolyte.

Ultimately a satisfactory method of assembly and sealing was developed. A thin strip of Parafilm ${ }^{\circledR}$ on each side of the $\mathrm{TiO}_{2}$ area serves to space the two electrodes apart and also provides a seal on those sides. After the counterelectrode is pressed into place, Parafilm® strips are wrapped around the cell so as to hold the two electrodes together. After the cell is filled with electrolyte (by capillary action) the cell is dipped into molten paraffin to provide the final seal. The method is described in greater detail in the Experimental section.

The paraffin coating the front of the cell is thin and transparent, but nonetheless modulates light intensity delivered to the photoanode. This effect was measured, and was consistently found to be a $4 \%$ reduction in intensity. This value was determined by 
comparing the photocurrent produced by a cell with the paraffin in place with that of the same cell with the paraffin scraped off to reveal a clean glass surface. The cell was redipped in paraffin and the photocurrent was measured again, to eliminate effects due to hysteresis or aging, and was found to be nearly identical to the original photocurrent. This experiment was repeated on several occasions to verify that consistent results would be obtained.

\subsection{Electrolytes}

Most work was done using an electrolyte (I3I-1) based on the iodide-triiodide redox couple, which is the workhorse system for most DSSC research. Electrolytes based on this redox couple are designated I3I-n, where $\mathrm{n}$ is an integer used to indicate the precise formulation; in some cases certain additives were included in the electrolyte. Some experiments were also performed using a cobalt (II)/(III) redox system; these were designated CoBpy-n, analogous to the system used for the I3I electrolytes.

The iodide-triiodide (I3I) redox couple is often employed in DSSCs. Iodide ion (typically in the range of $0.5 \mathrm{M})$ and elemental iodine $(0.05 \mathrm{M})$ are combined in solution. Several solvents are commonly employed. Most often a mixture of acetonitrile (BP $82^{\circ} \mathrm{C}$ ) and valeronitrile (BP $139-141^{\circ} \mathrm{C}$ ) are used, but a 80/20 V/V mixture of propylene carbonate $\left(\mathrm{BP} 242^{\circ} \mathrm{C}\right)(20 \%)$ and ethylene carbonate $\left(\mathrm{BP} 261^{\circ} \mathrm{C}\right)(80 \%)$ is sometimes used. $^{25}$ This was the practice in the Wamser lab at the beginning of this research. This 
was later modified to utilize pure propylene carbonate, as the ethylene carbonate did not appear to offer any significant advantage. Propylene carbonate was chosen over the nitrile mixture due to its lower volatility; even without sealing, evaporation of the solvent was slow, in contrast with the more volatile nitriles.

Since the effects of surface-active agents were under study, substances commonly used as performance-enhancing additives in DSSC electrolytes were not used in the I3I-1 and CoBpy-1 formulations. For example, 4-t-butylpyridine (TBP) is often included at about 0.5 M concentration. For similar reasons, tetra-n-butylammonium iodide was chosen over the commonly used lithium iodide as the source of iodide ion, since lithium ion has been shown to move the lower edge of the $\mathrm{TiO}_{2}$ conduction band to more negative values. $^{54}$

Propylene carbonate was used as the solvent for the cobalt electrolyte. The basic CoBpy electrolyte (CoBpy-1), like the basic I3I-1 electrolyte, contains only the redox couple without any additives. Some tests were also done with electrolytes using TBP, lithium perchlorate, or both, for a total of four variations on this electrolyte.

\subsection{Methods used to apply a thin dense $\mathrm{TiO}_{2}$ underlayer}

Several methods for applying the thin dense $\mathrm{TiO}_{2}$ underlayer were investigated. Initial work was done using a $1 \%$ solution of titanium tetraisopropoxide in isopropanol. An 
aqueous system using ammonium hexafluorotitanate and boric acid was also used, as well as Tyzor LA, also an aqueous system. Deposition from the aqueous system was controlled by temperature and concentration, as well as $\mathrm{pH}$ in the case of the Tyzor LA system. Ultimately a method was developed (as described in the Experimental section) using Tyzor AA-105. By varying the concentration of Tyzor AA-105 in the solution used for application it was possible to control the thickness of the dense underlayer. Pyrolysis of Tyzor precursors have been shown to generate $\mathrm{TiO}_{2}$ primarily in its anatase crystalline form. ${ }^{55}$

\subsection{Methods used to apply a mesoporous film of $\mathrm{P}-25 \mathrm{TiO}_{2}$}

A method commonly used to apply the mesoporous $\mathrm{TiO}_{2}$ layer, referred to as doctor blading, was used in the initial experiments. In this method, strips of Scotch tape are applied to the sheet of glass to be made into slides, and a suspension of $\mathrm{TiO}_{2}$ nanoparticles in water containing surfactants is applied to the glass and spread using a glass stir rod. The glass rod is supported off the glass surface by the tape strips, which serve to control the thickness of the liquid layer, giving indirect control over the thickness of the final dry layer of $\mathrm{TiO}_{2}$. If different dry-layer thicknesses are desired, a double layer of tape can be used, and/or the proportion of $\mathrm{TiO}_{2}$ in the suspension can be adjusted upward or downward. These tactics have their limits; in particular, it is difficult to obtain a layer thicker than 10 or 12 microns without severe cracking occurring as the film dries. 
For this and other reasons alternative methods were developed for application of the $\mathrm{TiO}_{2}$ layer.

The first of these alternate methods was dip-coating. A formulation for a $\mathrm{TiO}_{2}$ suspension was developed that made it possible to maintain better control of the $\mathrm{TiO}_{2}$ thickness. The suspension was mostly ethanol and contained a relatively small amount of $\mathrm{TiO}_{2}$, with the result that a single dip would result in only a very thin layer of $\mathrm{TiO}_{2}$ being deposited. Each successive dip, followed by a few seconds of air-drying, would add to the thickness in a controllable way. However, it was still found that after the layer built to a certain thickness, still apparently in excellent condition, the next dip would result in catastrophic cracking and peeling; some critical threshold had been reached, and it appeared to be similar to the limit obtainable by means of the doctor blade method.

Silk screening of a $\mathrm{TiO}_{2}$ paste is a method employed in some labs, and so was briefly investigated. It was found that the technique was very difficult to control using a simple silk screen and manual application methods. The labs where this method is used generally have sophisticated professional silk screening machinery, at substantial cost.

A novel method for the application of the $\mathrm{TiO}_{2}$ layer was developed. It is described in the Experimental section. Briefly, it involves masking a plate of FTO glass with tape, applying a suspension of $\mathrm{TiO}_{2}$, and spreading the suspension uniformly by tipping the plate back and forth; it is then placed on a level surface and allowed to dry. The 
thickness of the $\mathrm{TiO}_{2}$ layer can be controlled by adjusting the proportion of $\mathrm{TiO}_{2}$ in the suspension. However, it is still found that attempts to apply a thick layer often result in a high degree of cracking.

\subsection{Adsorption of TCPP}

The sensitizing dye TCPP is insoluble in water and acetonitrile, but it is readily soluble in absolute ethanol and tetrahydrofuran. For most experimental work, a solution of TCPP in absolute ethanol $(100 \mu \mathrm{M})$ was employed. Typically each electrode (with a $\mathrm{TiO}_{2}$ area of $1.0 \mathrm{~cm}^{2}$ ) was treated with $2.5 \mathrm{~mL}$ of this solution, in the dark overnight. The adsorption of TCPP onto $\mathrm{TiO}_{2}$ is somewhat slow so the long soak time is employed to ensure that adsorption is complete. When adsorption is complete, about 80 nmoles of TCPP are adsorbed, about one third of the dye in the $2.5 \mathrm{~mL}$ aliquot used to treat the electrode. By way of contrast, some dyes such as blackberry dye (often used in outreach classes with young students) can fully dye an electrode in just a few minutes.

\subsection{Desorption of TCPP}

For cells sensitized with TCPP it was found that the short-circuit current $\left(\mathrm{I}_{\mathrm{sc}}\right)$ and efficiency can be significantly improved by treating the dyed slide with absolute ethanol for two hours immediately after withdrawing it from the dye solution. A small amount 
$(\sim 10 \%)$ of TCPP is desorbed from the electrode during this treatment. The appearance of the electrode does not change noticeably but the desorption solution is slightly fluorescent. The use of a two-hour desorption cycle was incorporated into the standard process for making electrodes.

As noted, desorption of TCPP from the electrode into pure ethanol is slow and results in improved cell performance. However, if a TCPP-dyed electrode is treated with a solution of a phosphonic acid coadsorbate, the TCPP often is observed to desorb quickly and to a greater extent than is desirable. The extent of this desorption is affected by the particular phosphonic acid employed, its concentration, and the duration of the treatment.

\section{Orthogonal solvents}

One approach to minimize desorption of TCPP by post-adsorbates is the use of orthogonal solvents; i.e., applying the post-adsorbate in a solvent in which TCPP is not soluble. Water and acetonitrile are such solvents, and were employed in some experiments. 


\subsection{Treatment of TCPP slides with MeCN}

In some cases acetonitrile was used as the solvent for post-adsorbates. Control cells were prepared employing a treatment with acetonitrile of the same duration (two hours) and it was discovered that some benefit in $\mathrm{J}_{\mathrm{sc}}$ and efficiency was produced by this treatment. No detectable quantity of TCPP is desorbed. This treatment was also incorporated as part of the standard procedure for preparing electrodes.

\subsection{Light source for testing}

For DSSC testing quartz-halogen lamps were used in some early work, but they provide a spectrum consisting of $3200 \mathrm{~K}$ blackbody radiation, considerably red-shifted from the $5500 \mathrm{~K}$ blackbody radiation of the solar spectrum. When high-intensity LED lamps became available, they were incorporated into the test system. These lamps do not induce much heating in the subject under illumination. Therefore, neither an individual cell under test, nor the stage on which the cell is mounted increase significantly in temperature during a single test or rapid series of tests. This is true even if an experiment such as chronoamperometry is run, which may entail continuous illumination for several minutes.

A LED flood lamp with a nominal $5000 \mathrm{~K}$ color value was employed for most testing. It was found that the intensity of the light was not steady; it oscillated at $240 \mathrm{~Hz}$ due to the 
electronic power supply built into the base of the lamp. The magnitude of the oscillation was sufficient to cause significant uncertainty in the $\mathrm{J}_{\mathrm{sc}}$ delivered by a cell under test. A series of iV tests were run at a high scan rate so that the iV curve would display the waveform of the light as a smooth curve. The peak-to-peak variation in brightness was around $10 \%$, as measured by the ripple in the resulting iV curves. Thus the $\mathrm{I}_{\mathrm{sc}}$ measured could vary by $+/-5 \%$, based on pure luck of the draw, making it difficult to detect small differences between cells at a high confidence level.

To correct this problem, the base of the lamp was opened to gain access to the internal electronics. The voltage being delivered to the LED element was found to be direct current with a $240 \mathrm{~Hz}$ ripple. An external RC filter circuit was added to smooth the ripple to a peak-to-peak variation of less than $1 \%$.

\subsection{Light levels}

Testing DSSCs at a range of light intensities is informative and potentially diagnostic. In actual use, solar cells experience a wide range of illumination levels. It is a convenient truth that many types of solar cells operate at higher efficiency under low lighting conditions than under a full sun, so under low light the cell in effect partially compensates for the low light level. In a DSSC, comparing the responses (especially $\mathrm{I}_{\mathrm{sc}}$ and efficiency) under varying light levels can provide insights into the internal operation 
of the cell. If $\mathrm{I}_{\mathrm{sc}}$ were linear with respect to light intensity, then doubling the brightness should be expected to double the photocurrent. But if brightness is doubled again, and again, and again - at what point if any should we expect the photocurrent to fail to keep up? Sooner or later, an upper limit of current output would have to be reached when the capacity of some resource in the cell is exceeded. In a DSSC, one source of current limit results from the fact that current is carried by ionic species diffusing through the electrolyte.

Experimentally, testing at reduced light intensities was accomplished by using an appropriate spacer to control the distance of the light source from the cell under test. The required distances were determined by measuring light intensity as the distance was adjusted; when the desired intensity was attained the distance between the base of the lamp housing and the base of the test stage was measured and a spacer block was cut accordingly. A series of reduced light level experiments could be performed rapidly by substituting in the appropriate block for each test.

\subsection{Using a mask for iV tests}

It is necessary to have an accurate measurement of the area exposed to light when testing a DSSC so that normalized photocurrent and efficiency can be accurately calculated. The full area of the photoactive area can be measured, as for example by using a computer program such as ImageJ to analyze a photograph of the slide. The precision of this 
method was estimated to be $+/-3 \%$ uncertainty due to such issues as slightly irregular edges. In some cases this method was used.

An alternative approach is to use a mask of known area for all tests. This enables a more reliable comparison of different cells, since it is certain that the area exposed to light is the same in all cases. In addition, the area exposed by the mask can be determined with greater precision than is possible for measurement of $\mathrm{TiO}_{2}$ areas. The mask used was prepared by punching a circular hole nominally 0.25 inch $(6.35 \mathrm{~mm})$ in diameter in a strip of aluminum Dymo® tape. This non-adhesive tape is 0.5 inches $(12.7 \mathrm{~mm})$ wide and approximately $100 \mu \mathrm{M}$ thick. (By comparison, standard aluminum foil is about $16 \mu \mathrm{M}$ thick.) The gauge of the metal is sufficient that it is mechanically stable. Photographs reveal that edges of the hole are quite smooth. ImageJ was used to measure the area of the hole, and the result $\left(0.32 \mathrm{~cm}^{2}\right)$ was in excellent agreement with the area calculated $\left(0.317 \mathrm{~cm}^{2}\right)$ based on the nominal diameter of the hole. Precision was estimated to be less than $1 \%$ uncertainty.

\subsection{Parameters for iV tests}

Current-voltage (iV) curves were the principal method used for evaluation of DSSCs. They were generated using a Gamry potentiostat running linear sweep voltammetry (LSV) experiments. The effect of different values for test parameters such as scan rate and scan direction were investigated before settling on a standard set to use. 


\section{Forward or reverse scan direction?}

The question of which direction to run LSV scans (iV tests) was investigated. Scans were run in both forward and reverse directions and the results compared. An experiment in the forward direction begins at a small positive voltage $(0.05 \mathrm{~V})$ so that the scan crosses the vertical axis (where $\mathrm{I}_{\mathrm{sc}}$ is measured) and continues to a voltage more negative than the $\mathrm{V}_{\mathrm{oc}}$ of the cell to be tested. An experiment in the negative direction begins at a voltage more negative than the $\mathrm{V}_{\mathrm{oc}}$ of the cell to be tested and continues in a positive direction until the vertical axis is crossed. For these experiments the forward scans ended at $-0.99 \mathrm{~V}$ and the reverse scans started at $-0.99 \mathrm{~V}$.

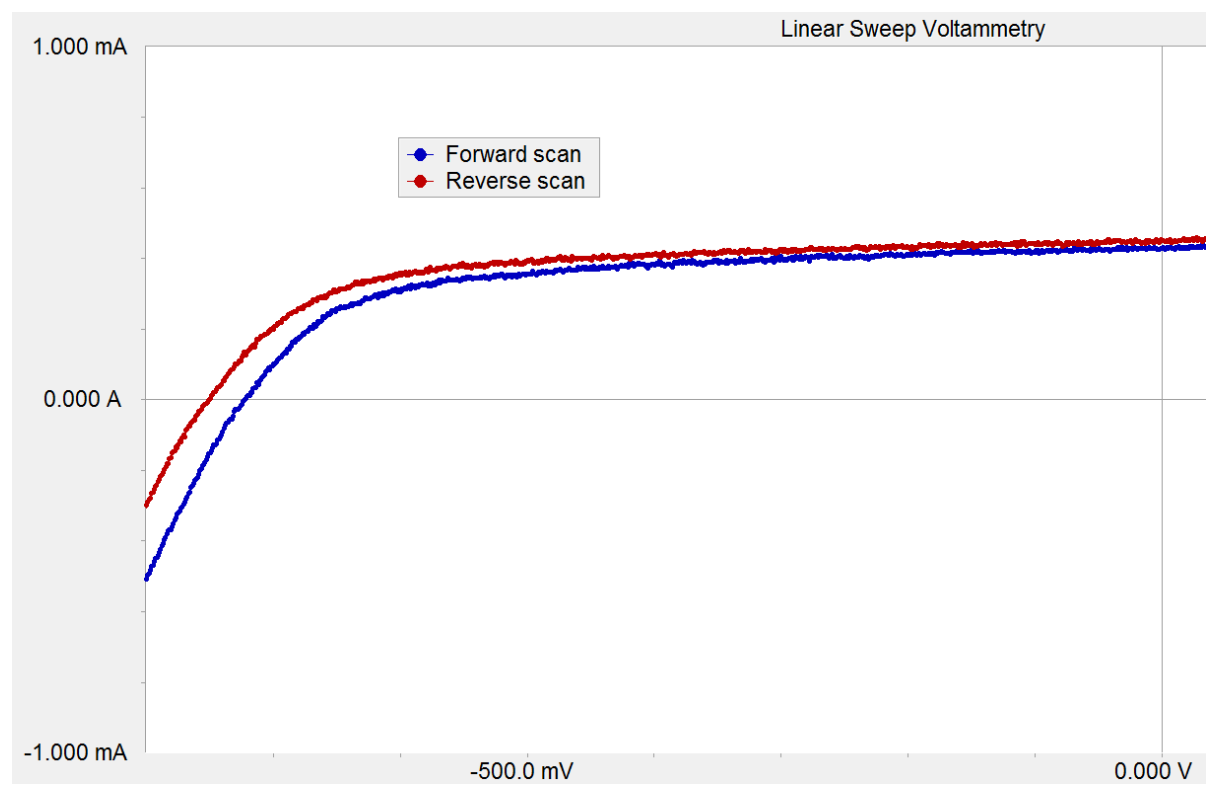

Figure 4.1 LSV scans, forward $(+0.05 \mathrm{~V}$ to $-0.8 \mathrm{~V})$ and reverse $(-0.8 \mathrm{~V}$ to $+0.05 \mathrm{~V})$. The full scans extend to $-0.99 \mathrm{~V}$ but have been cropped at $-0.8 \mathrm{~V}$ for clarity 
From the scans in Figure 4.1 it can be seen that scanning in the reverse direction will result in higher $\mathrm{V}_{\mathrm{oc}}$ and $\mathrm{J}_{\mathrm{sc}}$ values. The reverse scan started at $-0.99 \mathrm{~V}$, and it seems likely that energy was stored in the cell (electrochemically and/or as capacitance) by the application of excess negative potential. Forward scans were adopted as the standard procedure in order to avoid any possibility of obtaining biased results.

\section{Choice of scan rate}

The selection of a standard scan rate to use was investigated. For reasons of time economy it was desirable to use a reasonably fast scan rate, but it was not known if different scan rates would have a significant effect on the results obtained. Scan rates from $5 \mathrm{mV} / \mathrm{s}$ to $2560 \mathrm{mV} / \mathrm{sec}$ were tested, and the results are shown in Figure 4.2. Results were not greatly affected by the scan rate, except that very high rates resulted in noisy data. A scan rate of $200 \mathrm{mV} / \mathrm{s}$ was adopted; it was fast enough to permit rapid testing without resulting in noisy data. 


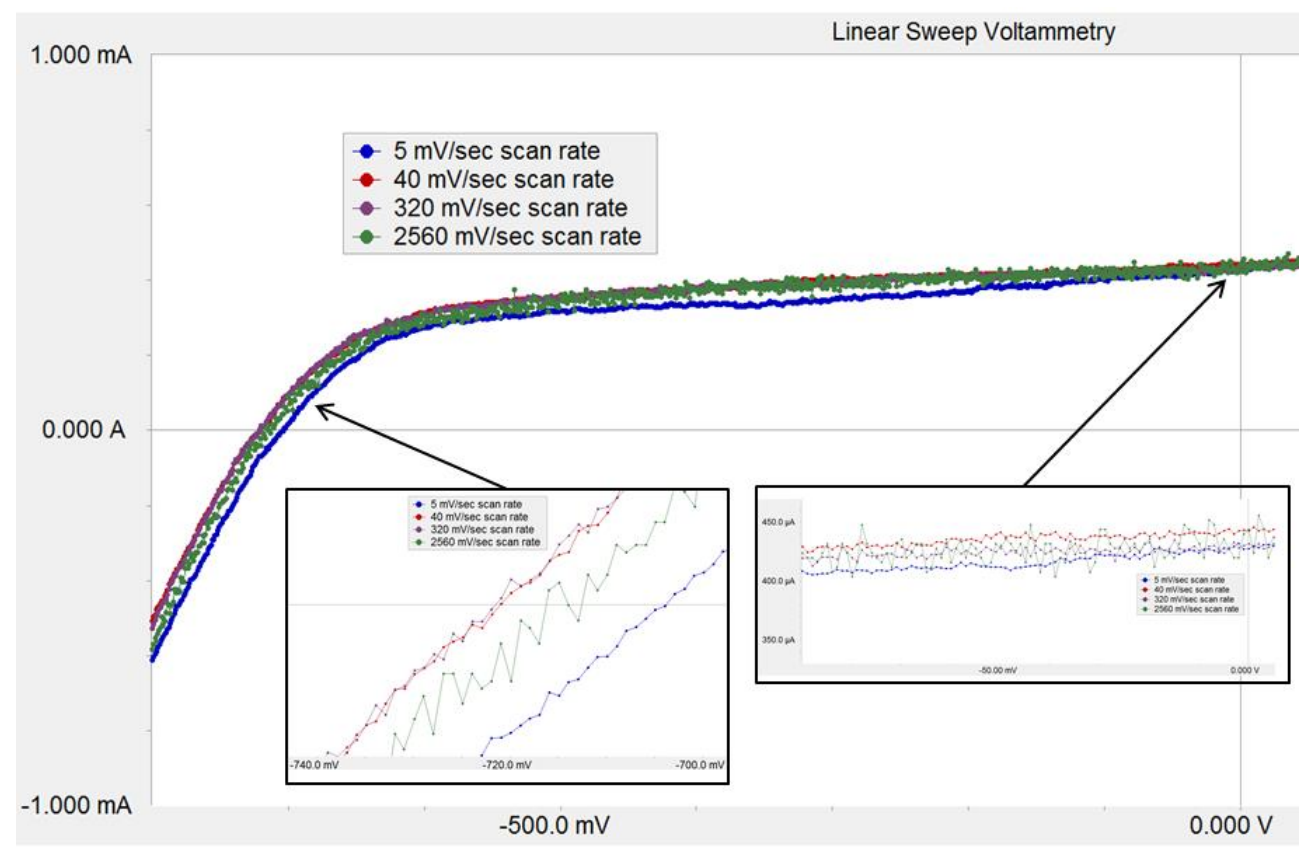

Figure 4.2 LSV scans (forward) at scan rates from $5 \mathrm{mV} / \mathrm{sec}$ to $2560 \mathrm{mV} / \mathrm{sec}$. The full scans extend to $-0.99 \mathrm{~V}$ but have been cropped at $-0.8 \mathrm{~V}$ for clarity

The cell used for the scans in Figure 4.1 and Figure 4.2 was 5 weeks old. It was prepared using C8PA as a sim-adsorbate at a concentration of $80 \mu \mathrm{M}$.

The procedure used for each light trial began by turning on the LED light source and allowing it to stabilize for a few seconds, with the shutter on the test station still closed so that the cell was in the dark. The shutter was opened and the cell exposed to light for about a second before the iV experiment on the potentiostat was initiated. The LSV experiment began by holding the cell at short-circuit for 5 seconds to allow the cell to stabilize before beginning the scan. 


\section{CHAPTER 5 RESULTS AND DISCUSSION}

\subsection{Reproducibility without coadsorbates}

Slides from three plates $(\mathrm{CB}, \mathrm{CE}$, and $\mathrm{CF})$ were randomly selected and built into DSSCs. They were tested immediately after being constructed. Results are summarized in Table 5.1. Plate $\mathrm{CB}$ was prepared slightly differently than plates $\mathrm{CE}$ and $\mathrm{CF}$, in that the electrodes from this plate were not given the standard two hour treatment with acetonitrile. 


$\begin{array}{ccccccc}\text { Cell } & \begin{array}{c}\text { Area } \\ \left(\mathbf{( c m}^{2}\right)\end{array} & \begin{array}{c}\mathbf{V}_{\text {oc }} \\ (\mathbf{m V})\end{array} & \begin{array}{c}\mathbf{J}_{\mathbf{s c}} \\ \left(\mathbf{m A} / \mathbf{c m}^{2}\right)\end{array} & \mathbf{F F} & \begin{array}{c}\text { Efficiency } \\ \%\end{array} & \text { Notes } \\ \text { CB_3538 } & 0.93 & 548 & 6.0 & 0.33 & 1.11 & \text { No MeCN treatment } \\ \text { CB_3545 } & 0.91 & 567 & 5.2 & 0.31 & 0.92 & \text { No MeCN treatment } \\ \text { CB_3554 } & 0.97 & 569 & 5.6 & 0.35 & 1.12 & \text { No MeCN treatment } \\ \text { CB_3558 } & 0.90 & 554 & 6.1 & 0.29 & 0.98 & \text { No MeCN treatment } \\ \text { CB_3534 } & 0.96 & 574 & 6.1 & 0.31 & 1.09 & \text { No MeCN treatment } \\ \text { CB_3548 } & 0.91 & 554 & 6.6 & 0.32 & 1.16 & \text { No MeCN treatment } \\ \text { Mean } & \mathbf{0 . 9 3} & \mathbf{5 6 1} & \mathbf{5 . 9} & \mathbf{0 . 3 2} & \mathbf{1 . 0 6} & \\ \text { SD } & \mathbf{0 . 0 3} & \mathbf{9} & \mathbf{0 . 4} & \mathbf{0 . 0 2} & \mathbf{0 . 0 8} & \\ & & & & & & \\ \text { CE_3628 } & 0.99 & 577 & 5.8 & 0.30 & 1.01 & \\ \text { CE_3642 } & 1.02 & 586 & 7.3 & 0.28 & 1.22 & \\ \text { CE_3622 } & 1.01 & 577 & 6.4 & 0.34 & 1.24 & \\ \text { CE_3627 } & 0.99 & 564 & 7.7 & 0.30 & 1.32 & \\ \text { CE_3637 } & 1.01 & 604 & 6.5 & 0.32 & 1.28 & \\ \text { Mean } & \mathbf{1 . 0 0} & \mathbf{5 8 2} & \mathbf{6 . 8} & \mathbf{0 . 3 1} & \mathbf{1 . 2 1} & \\ \text { SD } & \mathbf{0 . 0 1} & \mathbf{1 3} & \mathbf{0 . 7} & \mathbf{0 . 0 2} & \mathbf{0 . 1 1} & \\ & & & & & & \\ \text { CF_3657 } & 0.98 & 574 & 6.8 & 0.29 & 1.13 & \\ \text { CF_3673 } & 1.00 & 602 & 7.3 & 0.29 & 1.28 & \\ \text { CF_3652 } & 1.04 & 567 & 6.7 & 0.30 & 1.14 & \\ \text { CF_3664 } & 1.06 & 580 & 6.2 & 0.32 & 1.14 & \\ \text { CF_3679 } & 0.99 & 613 & 6.0 & 0.38 & 1.39 & \\ \text { Mean } & \mathbf{1 . 0 1} & \mathbf{5 8 7} & \mathbf{6 . 6} & \mathbf{0 . 3 2} & \mathbf{1 . 2 2} & \\ \text { SD } & \mathbf{0 . 0 3} & \mathbf{1 7} & \mathbf{0 . 5} & \mathbf{0 . 0 3} & \mathbf{0 . 1 0} & \end{array}$

Table 5.1 Results of cell reproducibility test without coadsorbates

Electrodes from three different plates were used to generate cells that were subjected to an iV test immediately after construction. Illumination was provided by an LED lamp at 1 sun irradiation. For each cell the raw open-circuit voltage $\left(\mathrm{V}_{\mathrm{oc}}\right)$ and short-circuit current $\left(\mathrm{I}_{\mathrm{sc}}\right)$ are reported. Area-dependent values including $\mathrm{J}_{\mathrm{sc}}$ and efficiency have been 
normalized. The mean and standard deviation for each metric of each group of slides is reported. Slides from plate CB were not given a wash with acetonitrile.

A table with reproducibility data for cells prepared using sim-adsorbates is presented in section 5.18 on page 131 .

\section{Summary of procedures used for the reproducibility study}

Each glass plate produces 30 slides, each approximately $9 \mathrm{~mm}$ by $50 \mathrm{~mm}$. Each slide is scribed with a unique identifier consisting of a two letter code (the plate ID) followed by a four digit sequence number. A suspension of titanium dioxide (P25) was applied to a portion of each electrode, and later trimmed to a nominal area of $1.00 \mathrm{~cm}^{2}$. Slides were photographed after trimming, and the actual P25 area was determined by examination with ImageJ software. Slides were subsequently sintered and placed (hot) into a solution (2.5 mL per slide) of tetrakis(4-carboxyphenyl)porphine (TCPP, $100 \mu \mathrm{M}$ in absolute $\mathrm{EtOH}$ ), and soaked overnight. Each slide was then transferred into $2.5 \mathrm{~mL}$ of absolute ethanol for two hours to desorb a small amount of the dye, followed by a two hour treatment in acetonitrile $(\mathrm{MeCN})$. After the $\mathrm{MeCN}$ treatment, the slides were dried under nitrogen and assembled into cells and tested immediately. The electrolyte (I3I-1) used the iodide-triiodide redox couple in propylene carbonate solvent. It did not contain any additives such as 4-t-butyl pyridine. Each cell was tested under dark conditions, followed by a test under $100 \mathrm{~mW} / \mathrm{cm}^{2}$ illumination supplied by an LED, color temperature $5000 \mathrm{~K}$. 
Slides from three plates were tested: Six slides from plate $C B$, and five each from plates $\mathrm{CE}$ and $\mathrm{CF}$. Plates $\mathrm{CE}$ and $\mathrm{CF}$ were treated identically, as per procedure outlined above. The six CB slides were treated as per the procedure above except that they were not treated with acetonitrile after the ethanol desorption treatment. These cells did not perform as well as the cells from plates $\mathrm{CE}$ and $\mathrm{CF}$, but their cell-to-cell reproducibility was similar to that exhibited by $\mathrm{CE}$ and $\mathrm{CF}$ cells.

\subsection{Quantity of TCPP adsorbed on a $1.0 \mathrm{~cm}^{2}$ electrode}

Control cells (no phosphonic acid) were monitored during the adsorption and desorption processes by means of UV-Vis spectroscopy to determine the quantity of TCPP typically remaining on an electrode after dye adsorption followed by a partial desorption in ethanol. 


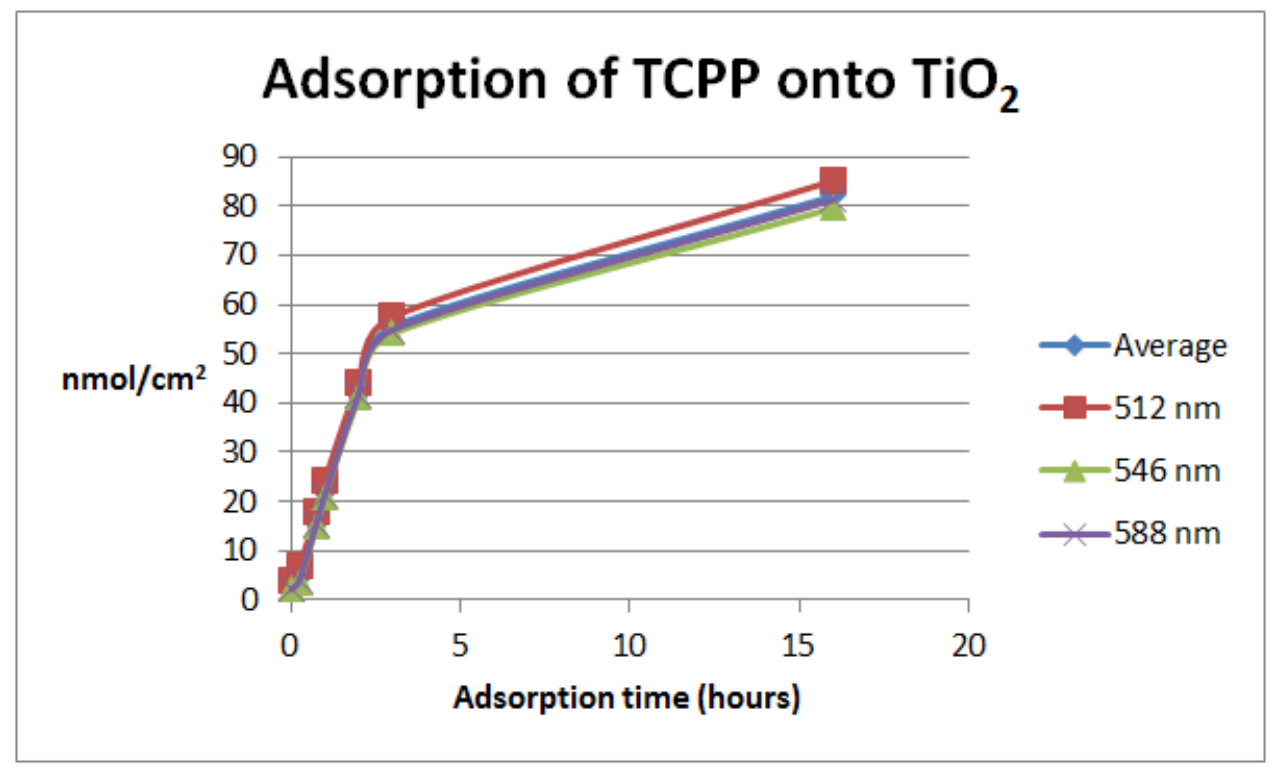

Figure 5.1 Adsorption of TCPP from $100 \mu \mathrm{M}$ solution $(2.5 \mathrm{~mL})$ in absolute ethanol

Electrodes were treated with $100 \mathrm{mM}$ solution of TCPP in absolute ethanol, $2.5 \mathrm{~mL}$ per slide in a cuvette. UV-Vis spectra were taken by placing the electrode along the side of the cuvette so that it did not interfere with the path of the light beam. Spectra were collected at frequent intervals up to three hours, and at 16 hours when treatment with TCPP was complete. As TCPP was adsorbed, the absorbance of the solution gradually decreased. The absorbances of three Q bands (at $512 \mathrm{~nm}, 546 \mathrm{~nm}$, and $588 \mathrm{~nm}$ ) were individually used for the calculations and found to be in good agreement. Adsorption is rapid for the first three hours, but slows as the $\mathrm{TiO}_{2}$ becomes saturated. Results for one typical electrode are plotted along with the average in Figure 5.1. The average density of TCPP adsorption was $82 \mathrm{nmol} / \mathrm{cm}^{2}$. 


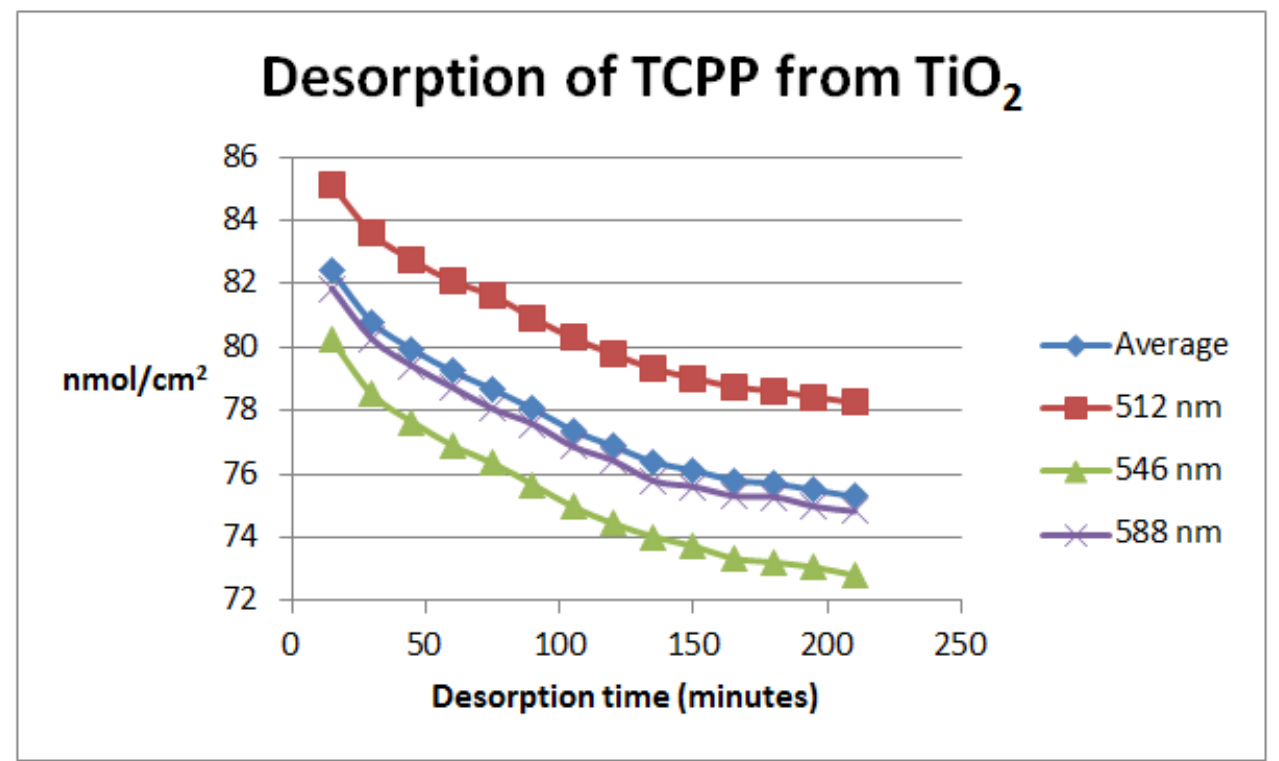

Figure 5.2 Desorption of TCPP from $\mathrm{TiO}_{2}$ into absolute ethanol. The plot depicts the normalized quantity of TCPP remaining on the electrode during the desorption treatment

After the adsorption treatment was complete, the electrode was rinsed and placed into 2.5 $\mathrm{mL}$ of absolute ethanol in a cuvette. UV-Vis spectra were collected at frequent intervals with the electrode sideways as described above. The same Q bands used to calculate adsorption were used to calculate how many nmoles of TCPP had desorbed from the electrode. Figure 5.2 depicts the normalized density of TCPP remaining on the electrode as desorption progressed. 


\subsection{Performance of a DSSC as a function of excitation wavelength}

In a standard iV test of a DSSC, the cell is excited by full-spectrum light at an intensity of one sun. This approach provides information about how a cell might perform under natural daylight. However, additional information can be gleaned by selectively exciting the cell at a narrow range of wavelengths and observing the effects on performance metrics.

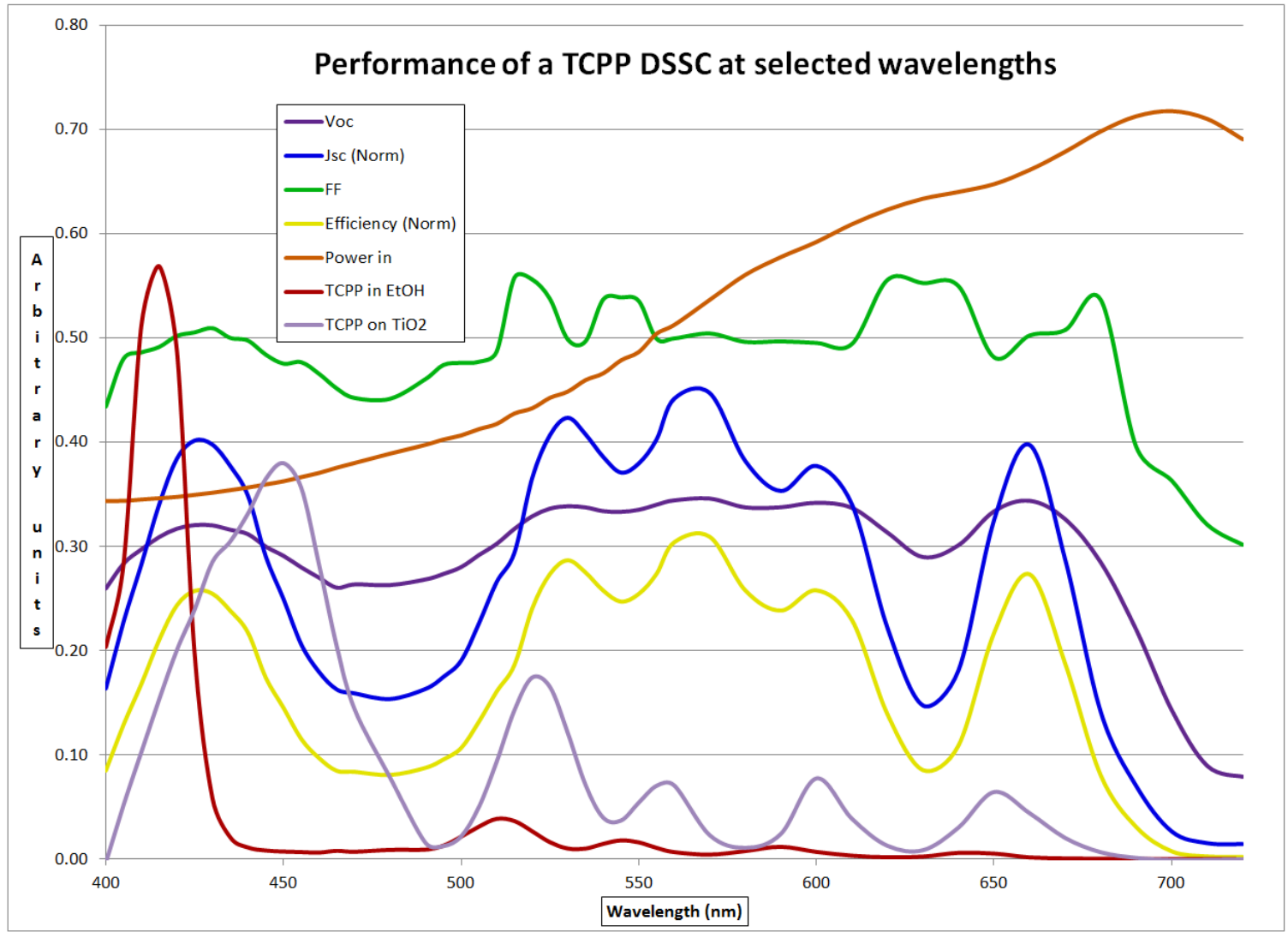

Figure 5.3 Performance of a TCPP DSSC as a function of excitation wavelength 
In Figure 5.3 a DSSC using I31 electrolyte with TCPP as sensitizer was given a series of complete iV tests while being excited at specific wavelengths at intervals of 5 or $10 \mathrm{~nm}$ from 400 to $720 \mathrm{~nm}$. For each of these tests, $\mathrm{V}_{\mathrm{oc}}$ and $\mathrm{I}_{\mathrm{sc}}$ were directly measured, and in addition the radiant power available to the cell was measured using a radiometer. From these data, $\mathrm{J}_{\mathrm{sc}}, \mathrm{FF}$, and efficiency were calculated. The $\mathrm{J}_{\mathrm{sc}}$ and efficiency values were normalized relative to the radiant power available at each wavelength. Figure 5.3 includes plots of radiant power, $\mathrm{V}_{\mathrm{oc}}, \mathrm{J}_{\mathrm{sc}}, \mathrm{FF}$, and efficiency at each tested wavelength. In addition, the absorbance spectrum of TCPP in ethanol and the absorbance spectrum of TCPP adsorbed on $\mathrm{TiO}_{2}$ are plotted. The vertical axis is in arbitrary units for all of the data plotted except FF; each of the other data sets has been scaled for visual clarity in the figure.

Excitation was provided by light from a $50 \mathrm{~W}$ quartz-halogen lamp passed through a monochromator. The iV tests were performed using a Keithley source-measure unit controlled by a LabVIEW program on a PC. The radiant energy at each wavelength was measured using an IL700 radiometer. It varied from approximately $500 \mu \mathrm{W} / \mathrm{cm}^{2}(0.5 \%$ of a sun) at $400 \mathrm{~nm}$ to approximately $1000 \mu \mathrm{W} / \mathrm{cm}^{2}(1 \%$ of a sun) at $720 \mathrm{~nm}$.

Figure 5.3 reveals a number of interesting things. Most importantly, efficiency can be seen to track directly with $\mathrm{J}_{\mathrm{sc}}$. Fill factor and $\mathrm{V}_{\mathrm{oc}}$ remain more or less constant, except in regions where very little light is absorbed (corresponding to dips in $\mathrm{J}_{\mathrm{sc}}$ ). Even in those regions $\mathrm{FF}$ and $\mathrm{V}_{\mathrm{oc}}$ show remarkably low variability. In the absence of an external load 
(open-circuit conditions) electrons are injected into the $\mathrm{TiO}_{2}$ and the potential across the cell increases until an equilibrium is reached at which point the leakage rate due to recombination reactions is equal to the rate of electron injection. The factors limiting $\mathrm{V}_{\mathrm{oc}}$ (lower edge of the $\mathrm{TiO}_{2} \mathrm{CB}$ and the redox potential of the electrolyte) have not changed, so even a small amount of absorbed light is sufficient to maintain the cell at this equilibrium. Fill factor remains fairly constant for related reasons; since $\mathrm{V}_{\mathrm{oc}}$ is fairly constant, the shape of the iV curve remains fairly constant as well, despite the fact that $\mathbf{J}_{\mathrm{sc}}$ is of course directly dependent on how much light is absorbed.

The absorption peaks of TCPP adsorbed on $\mathrm{TiO}_{2}$ are red-shifted from those of TCPP in ethanol. These spectra were taken using dry electrodes. The red shifts are consistent with those reported by Cherian and $\mathrm{Wamser}^{56}$ and are attributed to a polar environment created by the high dipole moment of the $\mathrm{TiO}_{2}$ surface. The relative absorbances of the Soret and Q bands appear to differ significantly, i.e., the Q bands seem disproportionately large compared with the spectra taken in ethanol solution. This is an artifact of light scattering by the mesoporous $\mathrm{TiO}_{2}$ film at wavelengths shorter than about $500 \mathrm{~nm}$; in measuring the absorbance spectra of dry TCPP electrodes it was often noted that the apparent absorbance of the Soret band varied widely and frequently was so ragged as to be unusable, presumably due to small variations in morphology from one electrode to the next. 
The peak in $\mathrm{J}_{\mathrm{sc}}$ corresponding to the Soret band is blue-shifted with respect to the corresponding absorbance of adsorbed TCPP, whereas the $\mathrm{J}_{\mathrm{sc}}$ peaks corresponding to the Q bands are slightly red-shifted from those of (dry) adsorbed TCPP. These effects are attributed to the polarity of the propylene carbonate solvent in the electrolyte. It has been previously reported that increasing solvent polarity causes a blue shift of the Soret band and red shifts of the Q bands. ${ }^{57}$

\subsection{Procedures for application of coadsorbates}

The notion of using a coadsorbate in combination with a sensitizing dye in a DSSC is self-explanatory on the surface. The purpose of the coadsorbate is to make some desired improvement to the DSSC, such as efficiency or life. The question becomes how best to accomplish the application of two substances. The fundamental difficulty is that the dye and the coadsorbate compete for binding sites on the $\mathrm{TiO}_{2}$. In an idealized scenario, the surface of the $\mathrm{TiO}_{2}$ will be optimally loaded with dye, and the coadsorbate will be adsorbed into available spaces between the dye molecules in sufficient quantity to accomplish the purpose for which it is being applied.

There are a variety of ways to apply two different substances to the $\mathrm{TiO}_{2}$. Considering a system that is to have one dye and one coadsorbate, the coadsorbate can be applied before (pre-adsorbate), during (sim-adsorbate), or after (post-adsorbate) the $\mathrm{TiO}_{2}$ is treated with the dye. 
For the pre- and post- cases, the slide is treated with a solution of one substance and then with a solution of the other substance, either coadsorbate followed by dye, or dye followed by coadsorbate.

\section{Pre-adsorption procedure}

Pre-adsorption procedures were straightforward; cells were treated with a solution of the coadsorbate for a period of hours, typically overnight. After treatment slides were rinsed to remove excess solution and dried before being transferred to a dye solution. Solvents used for pre-adsorbates included absolute ethanol, water, and acetonitrile.

Concentrations were in the range from $8 \mu \mathrm{M}$ to $1.0 \mathrm{mM}$. Specific treatments are reported with discussions of individual experiments.

\section{Sim-adsorption procedure}

The most obvious procedure for the sim-adsorption case is to treat the slide with a solution containing both substances from the outset, but modified protocols are possible. For example, the slide can be treated with a solution of dye for some period of time, at which point the coadsorbate is added. This gives the dye a head start, first crack at binding sites on the $\mathrm{TiO}_{2}$. Due to the fact that the solution still contains a significant 
concentration of dye, the equilibrium controlling desorption is shifted toward retaining the dye.

\section{Post-adsorption procedure}

In the post-adsorption protocol electrodes were treated first with the sensitizing dye, followed by treatment with a solution containing the post-adsorbate. This sequence gives the dye first opportunity at preferred binding sites, but allows the coadsorbate an opportunity to displace the dye without competition by dye in the solution.

If a dye treated with TCPP is soaked in absolute ethanol, some TCPP is desorbed as discussed in section 4.8 (in which some desorption is shown to improve $\mathrm{I}_{\mathrm{sc}}$ ). Up to a point this appears to be beneficial (probably by reducing dye-stacking), but clearly there must come a point at which too much TCPP is desorbed. In the absence of a species competing for adsorption sites, the desorption process is slow and controllable. A TCPP molecule might momentarily desorb from the surface and then readsorb, possibly at a better binding site. But if for example a phosphonic acid is present in the ethanol when a TCPP molecule leaves the surface of the $\mathrm{TiO}_{2}$, it will likely take the spot vacated by the dye. Since phosphonic acids bind more tightly than carboxylic acids, and since the solution contains a much higher concentration of phosphonic acid than of dye, it is inevitable that the surface will become increasingly occupied by phosphonic acid molecules and correspondingly devoid of dye. 


\section{The use of orthogonal solvents for post-adsorption}

The rationale for the use of orthogonal solvents was discussed earlier. In practice it was not found to be an effective procedure. To take the example of a phosphonic acid postadsorbate treatment in acetonitrile, it was found that although no TCPP went into solution (being insoluble in acetonitrile), it was nevertheless displaced from the surface of the $\mathrm{TiO}_{2}$. This became evident when electrodes so treated were rinsed with absolute ethanol. Significant amounts of TCPP were rinsed away, the exact amount depending on which phosphonic acid was used, its concentration, and the duration of the treatment.

\subsection{Effects of sintered phosphonate treatments}

Discussion thus far has focused on methods of applying coadsorbates before, during, or after adsorption of sensitizing dye. Another variant of surface treatment was also tested, in which $\mathrm{TiO}_{2}$ electrodes (previously sintered) were treated with phosphonic acids (as well as phosphoric acid) and calcined to burn away all organic material. The intent was to leave a phosphate residue bound to the surface of the $\mathrm{TiO}_{2}$. The effects of such a residue on subsequent DSSC performance (after application of a sensitizing dye in the normal manner) were then determined.

Electrodes were prepared by applying and sintering $\mathrm{TiO}_{2}$ in the normal manner, followed by treatment with solutions of phosphoric acid, decylphosphonic acid, and 
phenylphosphonic acid. Phosphoric acid was applied as a $1.0 \mathrm{mM}$ aqueous solution. The phosphonic acids were applied as both aqueous and ethanolic solutions, $1.0 \mathrm{mM}$ in all cases. Control electrodes were prepared by soaking in either ethanol or water for the same period as the test electrodes.

The electrodes were soaked in their respective solutions for one week, after which they were rinsed briefly with absolute ethanol and dried under a stream of dry filtered air. The electrodes were sintered at $500^{\circ} \mathrm{C}$ for one hour followed by treatment with TCPP (100 $\mu \mathrm{M}$ in absolute ethanol) overnight. Each electrode was then rinsed and transferred to a vial containing three $\mathrm{mL}$ of absolute ethanol and allowed to desorb for two hours. None of the electrodes lost significant amounts of TCPP during this treatment. Each electrode was dried under dry air and stored in a desiccator until being built into finished DSSCs and tested.

An interesting difference was noted between the electrodes treated with phenylphosphonic acid as contrasted with those treated with decylphosphonic acid. The electrodes treated with phenylphosphonic acid adsorbed TCPP to a normal extent, but the electrodes treated with decylphosphonic acid adsorbed only small amounts of TCPP. These differences were independent of whether the phosphonic acid was applied from an aqueous or ethanolic solution. Electrodes treated with phosphoric acid adsorbed TCPP to a normal degree of dye loading. Presumably phenylphosphonic acid and phosphoric acid were volatilized before they could decompose, leaving no residue and having no effect on 
TCPP adsorption. The decylphosphonic acid was apparently decomposed before it could volatilize, leaving a residue that almost totally prevented subsequent adsorption of TCPP.

The electrodes that had only adsorbed trace amounts of TCPP were not built into cells and tested, but the $\mathrm{iV}$ tests of the remaining electrodes did not yield any significant differences from the control cells. This approach (pre-sinter treatment of $\mathrm{TiO}_{2}$ with phosphonic acids) was not pursued any farther.

\subsection{Electrodes prepared with pre-adsorbed phosphonic acids with and without subsequent treatment with TCPP}

Electrodes were prepared to observe the effects of phosphonic acid pre-adsorbates on electrodes with and without the use of TCPP as a sensitizing dye. The electrodes were all treated with phosphonic acids as pre-adsorbates (except for the control cells). One set was subsequently treated with TCPP dye in the usual manner and the other set was not. The two sets of electrodes were from the same plate, in order to avoid any plate-to-plate variability. Each set consisted of a control electrode (no coadsorbate) and a series of electrodes treated with various pre-adsorbates. There are four general cases to be considered, but since 10 pre-adsorbates (plus control) were compared there are 22 cases in all as shown in Table 5.2. 


\begin{tabular}{|c|c|c|l|c|c|c|}
\hline Case & CoA & Dye & & Case & CoA & Dye \\
\hline 1-A & None & None & & 1-B & None & TCPP \\
\hline 2-A & C1PA & None & & 2-B & C1PA & TCPP \\
\hline 3-A & tC4PA & None & & 3-B & tC4PA & TCPP \\
\hline 4-A & C6PA & None & & 4-B & C6PA & TCPP \\
\hline 5-A & C8PA & None & & $5-B$ & C8PA & TCPP \\
\hline 6-A & C10PA & None & & $6-B$ & C10PA & TCPP \\
\hline 7-A & C12PA & None & & 7-B & C12PA & TCPP \\
\hline 8-A & C16PA & None & & 8-B & C16PA & TCPP \\
\hline 9-A & 3PPA & None & & 9-B & 3PPA & TCPP \\
\hline 10-A & PhenPA & None & & 10-B & PhenPA & TCPP \\
\hline 11-A & PhenAA & None & & $11-B$ & PhenAA & TCPP \\
\hline
\end{tabular}

Table 5.2 Specific cases of electrodes with and without dye and/or coadsorbate

Electrodes were treated overnight with an adsorbate ( $200 \mu \mathrm{M}$ in abs. ethanol), followed by overnight treatment with TCPP $(2.5 \mathrm{~mL}$ of $100 \mu \mathrm{M}$ in abs. EtOH). The effect on dye loading was determined, as well as the standard DSSC performance metrics.

\subsection{Effect of pre-adsorbates on efficiency of TCPP-sensitized cells}

As shown in Table 5.3 and Figure 5.4 all of the pre-adsorbates resulted in a loss of efficiency. Most of the cells treated with pre-adsorbates had their peak efficiency when first created, at 0 hours. The only exceptions were phenylphosphonic acid and phenylarsonic acid, both of which had peak efficiency at 3 to 5 hours, similar to the control. 
Age

$\begin{array}{llllllll}\text { (Hours) } & 0 & 3 & 5 & 22 & 48 & 72 & 336\end{array}$

Eff. Eff. Eff. Eff. Eff. Eff. Eff.

Pre-

$\begin{array}{llllllll}\text { adsorbate } & (\%) & (\%) & (\%) & (\%) & (\%) & (\%) & (\%)\end{array}$

$\begin{array}{llllllll}\text { CTRL } & 2.15 & 2.37 & 2.51 & 2.13 & 1.77 & 1.51 & 0.45\end{array}$

$\begin{array}{llllllll}\text { C1PA } & 1.02 & 0.76 & 0.59 & 0.43 & 0.20 & 0.08 & 0.01\end{array}$

$\begin{array}{llllllll}\text { tC4PA } & 1.02 & 0.75 & 0.66 & 0.31 & 0.14 & 0.09 & 0.03\end{array}$

$\begin{array}{llllllll}\text { C6PA } & 1.34 & 1.24 & 1.16 & 0.60 & 0.13 & 0.03 & 0.02\end{array}$

$\begin{array}{llllllll}\text { C8PA } & 1.26 & 1.03 & 0.90 & 0.70 & 0.69 & 0.34 & 0.07\end{array}$

$\begin{array}{llllllll}\text { C10PA } & 1.37 & 1.07 & 1.01 & 0.86 & 0.77 & 0.71 & 0.19\end{array}$

$\begin{array}{llllllll}\text { C12PA } & 0.97 & 0.70 & 0.63 & 0.46 & 0.38 & 0.23 & 0.07\end{array}$

$\begin{array}{llllllll}\text { C16PA } & 0.44 & 0.28 & 0.26 & 0.20 & 0.08 & 0.03 & 0.04\end{array}$

$\begin{array}{llllllll}\text { 3PPA } & 0.61 & 0.47 & 0.45 & 0.14 & 0.02 & 0.01 & 0.00\end{array}$

$\begin{array}{llllllll}\text { PhenPA } & 1.05 & 1.35 & 1.37 & 0.50 & 0.15 & 0.05 & 0.00\end{array}$

$\begin{array}{llllllll}\text { PhenAA } & 1.67 & 1.96 & 1.83 & 1.05 & 0.65 & 0.49 & 0.06\end{array}$

Table 5.3 Efficiency of cells treated with pre-adsorbates, from 0 to 336 hours

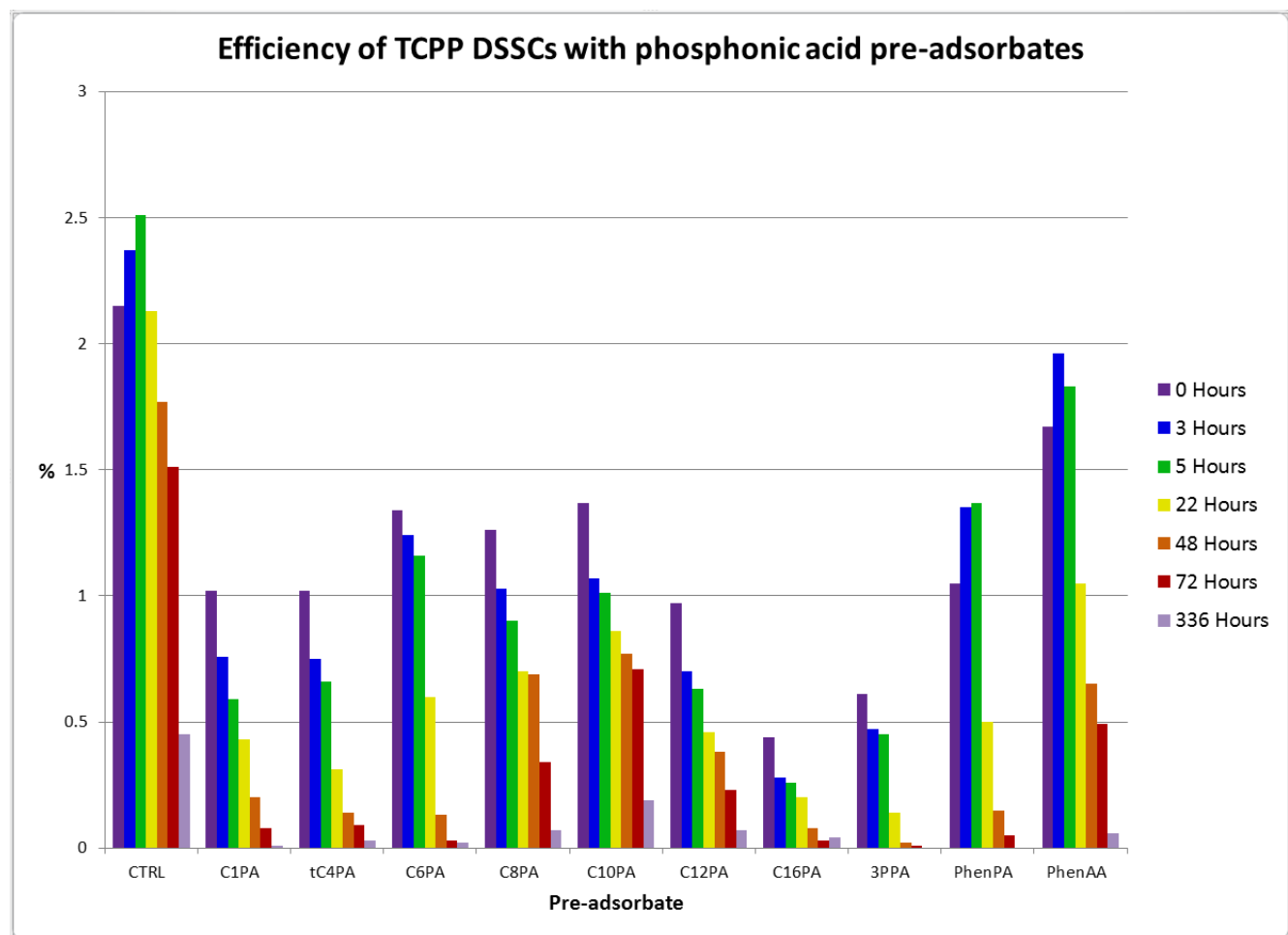

Figure 5.4 Effect of pre-adsorbates on efficiency of TCPP DSSCs 


\subsection{Effect of pre-adsorbates on $V_{\text {oc }}$ of TCPP-sensitized cells}

The open-circuit voltage of cells was not greatly affected by the use of pre-adsorbates.

All cells, with and without pre-adsorbates, show a significant improvement in $\mathrm{V}_{\mathrm{oc}}$ up to the age of about 48 hours, with some attaining their maximum $V_{o c}$ at 22 hours. Only one cell, treated with 3PPA, showed significantly different behavior. It reached its peak $\mathrm{V}_{\mathrm{oc}}$ $(589 \mathrm{mV})$ at 5 hours, and declined rapidly thereafter, to a low of $200 \mathrm{mV}$ after 336 hours (14 days). All of the other cells retained significant $\mathrm{V}_{\text {oc }}$ even at that age. 


\begin{tabular}{|c|c|c|c|c|c|c|c|}
\hline Coadsorbate & $\begin{array}{c}\mathrm{V}_{\mathrm{oc}}(0) \\
\mathrm{mV}\end{array}$ & $\begin{array}{c}\mathrm{V}_{\mathrm{oc}}(3) \\
\mathrm{mV}\end{array}$ & $\begin{array}{c}\mathrm{V}_{\mathrm{oc}}(5) \\
\mathrm{mV}\end{array}$ & $\begin{array}{c}\mathrm{V}_{\mathrm{oc}}(22) \\
\mathrm{mV}\end{array}$ & $\begin{array}{c}\mathrm{V}_{\mathrm{oc}}(48) \\
\mathrm{mV}\end{array}$ & $\begin{array}{c}\mathrm{V}_{\mathrm{oc}}(72) \\
\mathrm{mV}\end{array}$ & $\begin{array}{c}\mathrm{V}_{\mathrm{oc}}(336) \\
\mathrm{mV}\end{array}$ \\
\hline CTRL & 559 & 611 & 637 & 676 & 693 & 696 & 634 \\
\hline C1PA & 550 & 604 & 623 & 639 & 627 & 603 & 477 \\
\hline tC4PA & 581 & 620 & 636 & 647 & 627 & 612 & 576 \\
\hline C6PA & 578 & 624 & 649 & 658 & 631 & 605 & 564 \\
\hline C8PA & 601 & 648 & 668 & 684 & 693 & 672 & 621 \\
\hline C10PA & 607 & 650 & 671 & 687 & 691 & 689 & 646 \\
\hline C12PA & 595 & 640 & 658 & 671 & 671 & 654 & 616 \\
\hline C16PA & 592 & 629 & 643 & 657 & 648 & 624 & 619 \\
\hline 3PPA & 506 & 567 & 589 & 567 & 534 & 487 & 200 \\
\hline PhenPA & 493 & 573 & 609 & 635 & 619 & 604 & 540 \\
\hline PhenAA & 554 & 614 & 637 & 663 & 666 & 662 & 570 \\
\hline
\end{tabular}

Table $5.4 \mathrm{~V}_{\mathrm{oc}}$ of cells treated with pre-adsorbates from 0 hours to 336 hours

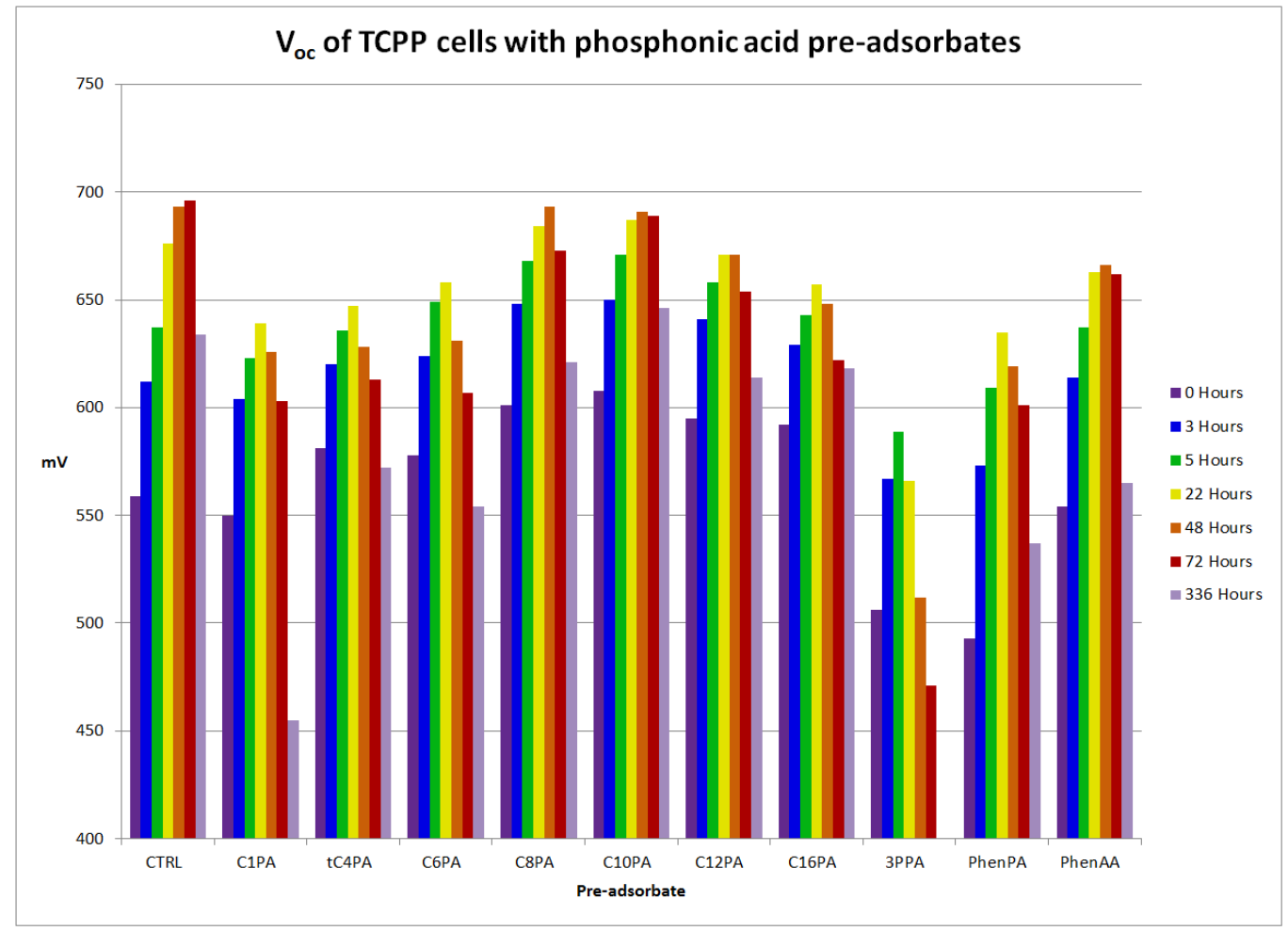

Figure 5.5 $\mathrm{V}_{\mathrm{oc}}$ of TCPP cells with phosphonic acid pre-adsorbates 
For the alkyl phosphonic acids, a trend is apparent with increasing $\mathrm{V}_{\mathrm{oc}}$ from C1PA to C8PA. The results for C10PA are very similar to those of C8PA, and as the series continues through C12PA and C16PA there is a gradual decline in $\mathrm{V}_{\mathrm{oc}}$. Overall these effects are relatively small and do not have a large effect on efficiency.

\subsection{Effect of pre-adsorbates on fill factor of TCPP-sensitized cells}

Fill factor is an important contributor to cell efficiency. In Table 5.5 and Figure 5.6 it can be seen that several of the cells prepared using pre-adsorbates demonstrated fill factors significantly improved over that of the control. In fact at 0 and 3 hours every one of the cells prepared with a pre-adsorbate had a fill factor better than that of the control. With only a few exceptions the pre-adsorbed cells continued to equal or exceed the fill factor of the control at ages up to 48 hours, after which the cells treated with pre-adsorbates began in general to decline. The best fill factor $(0.74)$ was produced by the use of C12PA, contrasted with 0.68 obtained by the control at its peak at 48 hours. 


$\begin{array}{lccccccc}\begin{array}{l}\text { Age (Hours) } \\ \text { Pre- }\end{array} & \mathbf{0} & \mathbf{3} & \mathbf{5} & \mathbf{2 2} & \mathbf{4 8} & \mathbf{7 2} & \mathbf{3 3 6} \\ \begin{array}{l}\text { adsorbate } \\ \text { CTRL }\end{array} & \mathbf{F F} & \mathbf{F F} & \mathbf{F F} & \mathbf{F F} & \mathbf{F F} & \mathbf{F F} & \mathbf{F F} \\ \text { C1PA } & 0.60 & 0.60 & 0.63 & 0.66 & 0.68 & 0.66 & 0.55 \\ \text { tC4PA } & 0.64 & 0.66 & 0.63 & 0.64 & 0.55 & 0.44 & 0.27 \\ \text { C6PA } & 0.68 & 0.69 & 0.70 & 0.63 & 0.64 & 0.55 & 0.31 \\ \text { C8PA } & 0.65 & 0.69 & 0.68 & 0.70 & 0.58 & 0.34 & 0.36 \\ \text { C10PA } & 0.67 & 0.68 & 0.68 & 0.67 & 0.67 & 0.63 & 0.34 \\ \text { C12PA } & 0.66 & 0.71 & 0.72 & 0.72 & 0.71 & 0.71 & 0.58 \\ \text { C16PA } & 0.70 & 0.73 & 0.73 & 0.74 & 0.74 & 0.73 & 0.43 \\ \text { 3PPA } & 0.72 & 0.73 & 0.71 & 0.72 & 0.46 & 0.41 & 0.42 \\ \text { PhenPA } & 0.69 & 0.72 & 0.72 & 0.67 & 0.41 & 0.30 & 0.00 \\ \text { PhenAA } & 0.63 & 0.62 & 0.64 & 0.66 & 0.69 & 0.47 & 0.00 \\ & 0.65 & 0.66 & 0.67 & 0.69 & 0.72 & 0.69 & 0.44\end{array}$

Table 5.5 Effect of pre-adsorbates on fill factor from 0 to 336 hours

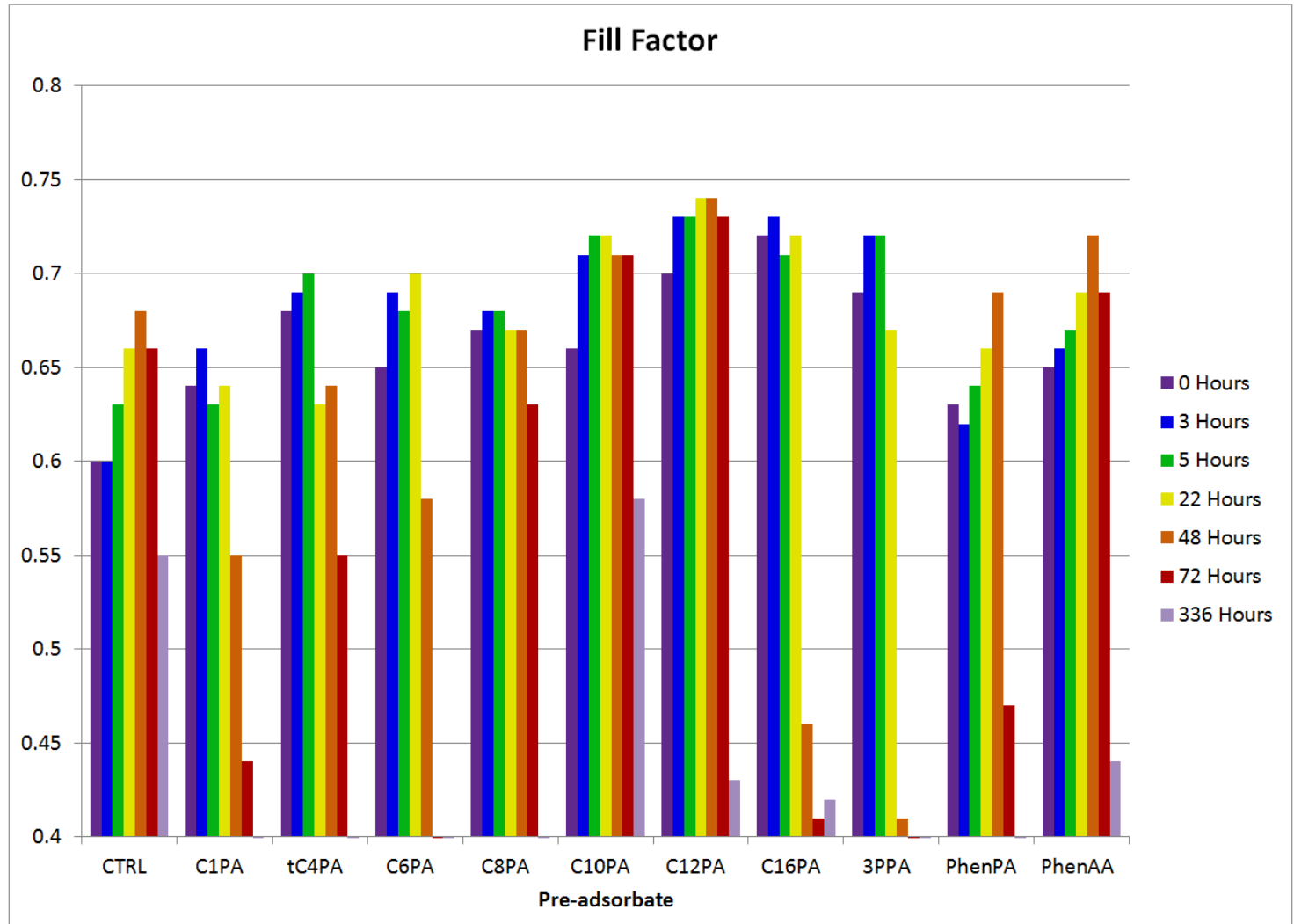

Figure 5.6 Effect of pre-adsorbates on fill factor 


\subsection{Effect of pre-adsorbates on $\mathrm{J}_{\mathrm{sc}}$ of TCPP-sensitized cells}

The short-circuit current of a cell is the most sensitive factor in determining overall cell efficiency. Other factors such as $\mathrm{V}_{\mathrm{oc}}$ are important, but $\mathrm{V}_{\mathrm{oc}}$ tends to not vary greatly in response to variations in cell preparation. A high value for short-circuit current, on the other hand, is an elusive target. Changes in cell preparation, in particular changes involving the use of coadsorbates, often have large effects on $\mathrm{J}_{\mathrm{sc}}$. Cells using preadsorbed phosphonic acids consistently produced $\mathrm{J}_{\mathrm{sc}}$ values below those of control cells. These results are presented in Table 5.6 and are shown graphically in Figure 5.7. However, it was also found that cells pre-adsorbed with PAs produce more photocurrent per molecule of adsorbed TCPP, as will be seen later in this section. 


$\begin{array}{lccccccc}\text { Age (Hours) } & \mathbf{0} & \mathbf{3} & \mathbf{5} & \mathbf{2 2} & \mathbf{4 8} & \mathbf{7 2} & \mathbf{3 3 6} \\ & \mathbf{J}_{\mathbf{s c}} & \mathbf{J}_{\mathbf{s c}} & \mathbf{J}_{\mathbf{s c}} & \mathbf{J}_{\mathbf{s c}} & \mathbf{J}_{\mathbf{s c}} & \mathbf{J}_{\mathbf{s c}} & \mathbf{J}_{\mathbf{s c}} \\ \text { Pre-adsorbate } & \mathbf{m A} & \mathbf{m A} & \mathbf{m A} & \mathbf{m A} & \mathbf{m A} & \mathbf{m A} & \mathbf{m A} \\ \text { CTRL } & 6.4 & 6.5 & 6.3 & 4.8 & 3.8 & 3.3 & 1.3 \\ \text { C1PA } & 2.9 & 1.9 & 1.5 & 1.1 & 0.6 & 0.3 & 0.1 \\ \text { tC4PA } & 2.6 & 1.7 & 1.5 & 0.8 & 0.4 & 0.3 & 0.2 \\ \text { C6PA } & 3.6 & 2.9 & 2.6 & 1.3 & 0.4 & 0.2 & 0.1 \\ \text { C8PA } & 3.1 & 2.3 & 2.0 & 1.5 & 1.5 & 0.8 & 0.3 \\ \text { C10PA } & 3.4 & 2.3 & 2.1 & 1.7 & 1.6 & 1.5 & 0.5 \\ \text { C12PA } & 2.3 & 1.5 & 1.3 & 0.9 & 0.8 & 0.5 & 0.3 \\ \text { C16PA } & 1.1 & 0.6 & 0.6 & 0.4 & 0.3 & 0.1 & 0.2 \\ \text { 3PPA } & 1.8 & 1.2 & 1.1 & 0.4 & 0.1 & 0.1 & 0.0 \\ \text { PhenPA } & 3.4 & 3.8 & 3.5 & 1.2 & 0.4 & 0.2 & 0.1 \\ \text { PhenAA } & 4.6 & 4.9 & 4.3 & 2.3 & 1.4 & 1.1 & 0.3\end{array}$

Table $5.6 \mathrm{~J}_{\mathrm{sc}}$ values of TCPP cells treated with pre-adsorbates

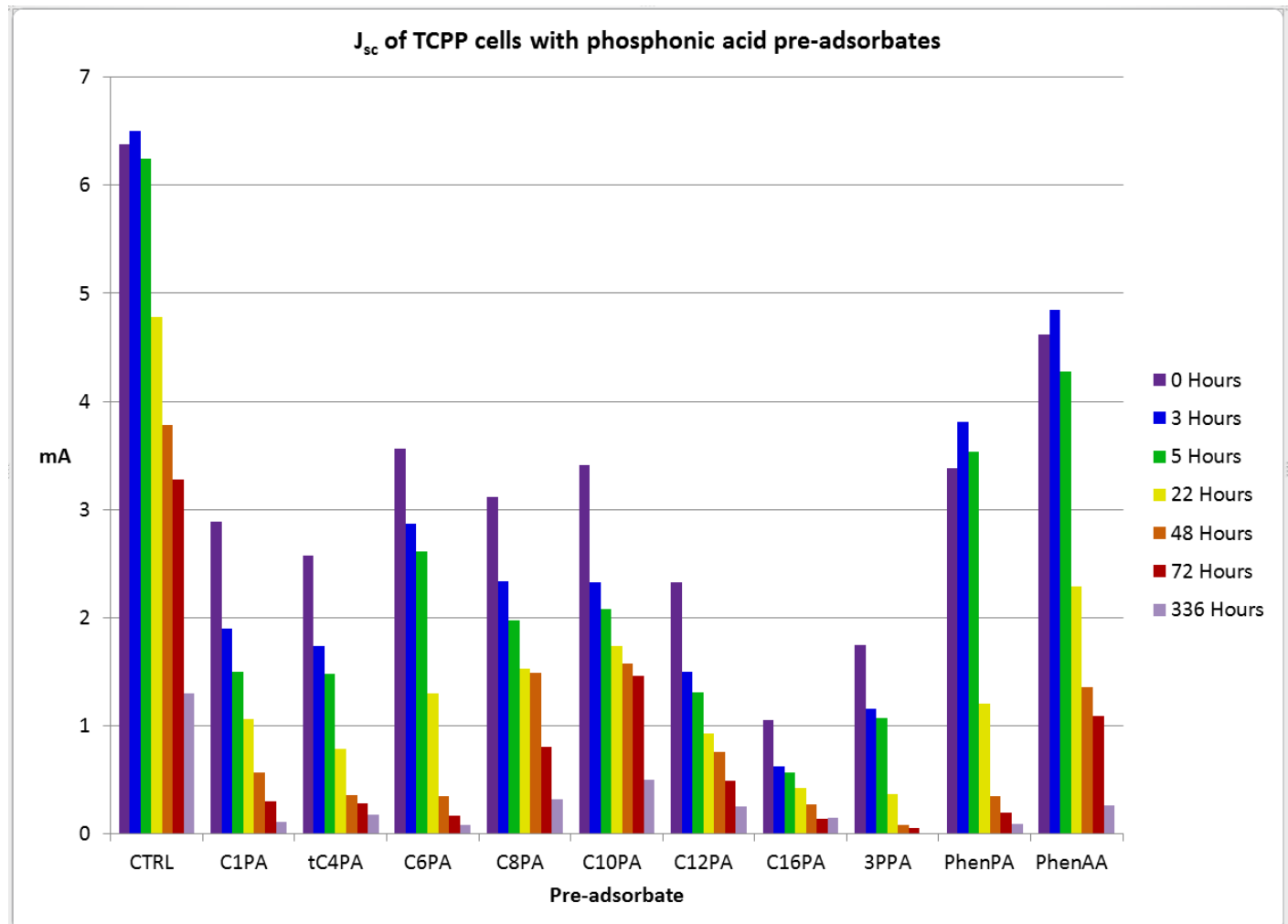

Figure 5.7 Effect of pre-adsorbates on the $\mathrm{J}_{\mathrm{sc}}$ of cells sensitized with TCPP dye 
Cells treated with alkyl phosphonic acid pre-adsorbates, as well as 3PPA, produced their highest $\mathrm{J}_{\mathrm{sc}}$ values when they were tested immediately after being built. Thereafter the short-circuit currents obtained from these cells began to decrease fairly rapidly, with the result that after 5 hours each was able to produce only half or two thirds of its original $\mathrm{J}_{\mathrm{sc}}$. The control, along with cells treated with phenylphosphonic acid and phenylarsonic acid (the aryl pnictogen acids), demonstrated its highest $\mathrm{J}_{\mathrm{sc}}$ at the age of 3 hours, declining only moderately by 5 hours. Phenylarsonic acid, in particular, showed aging behavior closely parallel to that of the control.

\subsection{Dye loading of cells treated with pre-adsorbates}

Cells treated with pre-adsorbates uniformly showed reduced dye loading due to part of the surface being occupied by pre-adsorbate molecules. However, the amount of dye adsorbed varied considerably depending on which pre-adsorbate was employed. The quantity of TCPP adsorbed by each electrode was determined by measuring the UV-Vis absorption of the TCPP solution from each slide after dye adsorption was complete. Since each electrode was treated with a specific volume $(2.5 \mathrm{~mL})$ of dye solution, it was possible to calculate the amount of dye adsorbed by each electrode from the change in absorbance of the solution before and after treating the electrode. Absorbances in the Qbands of TCPP (at $644 \mathrm{~nm}, 588 \mathrm{~nm}, 546 \mathrm{~nm}$, and $512 \mathrm{~nm}$ ) were averaged to calculate the concentration of TCPP remaining in solution after each slide had been treated and compared with absorbances of unused dye solution. Calibrations with solutions of TCPP 
over a range of concentrations demonstrated that absorbances of the $\mathrm{Q}$ bands obeyed the Beer-Lambert law closely and could be used as a reliable gauge of concentration in the range of interest.

Dye loading values (normalized to the control electrode) are shown in Table 5.7, along with values for the ratio of $\mathrm{J}_{\mathrm{sc}}$ (test cell): $\mathrm{J}_{\mathrm{sc}}$ (control cell) at ages ranging from 0 to 48 hours. Figure 5.8 depicts the dye loading for cells prepared with each of the preadsorbates, normalized to the control. It can be seen that the two aryl acids (phenylphosphonic acid and phenylarsonic acid) resulted in far higher TCPP adsorption (by a factor of 2 to 3 ) than the alkyl phosphonic acids.

It would be expected that reduced dye loading would result in reduced photocurrent, and that was found to be the case. However, there was only a rough correlation between dye loading and short-circuit current. The cells treated with pre-adsorbates produced significantly larger values of $\mathrm{J}_{\mathrm{sc}}$ than would be expected based on their comparative dye loadings, which is to say that for the treated cells each nanomole of adsorbed TCPP produced more photocurrent than that produced in untreated (control) cells. These results (normalized to the control) are depicted graphically in Figure 5.9. 


\begin{tabular}{|c|c|c|c|c|c|c|c|}
\hline $\begin{array}{c}\text { Dye } \\
\text { loading } \\
\text { and } J_{s c} \\
\text { Ratios }\end{array}$ & $\begin{array}{c}\text { Dye } \\
\text { load- } \\
\text { ing } \\
\text { (nmol) }\end{array}$ & $\begin{array}{c}\text { Dye } \\
\text { loading } \\
\text { ratio } \\
\text { (Cell/ } \\
\text { CTRL) }\end{array}$ & $\begin{array}{l}\mathrm{J}_{\mathrm{sc}} \\
(0 \mathrm{~h}) \\
\text { ratio } \\
\text { (Cell// } \\
\text { CTRL) }\end{array}$ & $\begin{array}{l}J_{\text {sc }} \\
(3 h) \\
\text { ratio } \\
\text { (Cell/ } \\
\text { CTRL) }\end{array}$ & $\begin{array}{c}J_{s c} \\
(5 h) \\
\text { ratio } \\
\text { (Cell/ } \\
\text { CTRL) }\end{array}$ & $\begin{array}{l}\mathrm{J}_{\mathrm{sc}} \\
(22 \mathrm{~h}) \\
\text { ratio } \\
\text { (Cell/ } \\
\text { CTRL) }\end{array}$ & $\begin{array}{c}J_{s c} \\
(48 h) \\
\text { ratio } \\
\text { (Cell/ } \\
\text { CTRL) }\end{array}$ \\
\hline CTRL & 129 & 1 & 1 & 1 & 1 & 1 & 1 \\
\hline C1F & 3 & 0.24 & 0.45 & 0.29 & 0.24 & 0.22 & 0.15 \\
\hline tC4PA & 38 & 0.29 & 0.40 & 0.27 & 0.24 & 0.16 & 0.10 \\
\hline C6PA & 30 & 0.23 & 0.56 & 0.44 & 0.42 & 0.27 & 0.09 \\
\hline $\mathrm{C} 8 \mathrm{P}$ & 28 & 0.22 & 0.49 & 0.36 & 0.32 & 0.32 & 0.39 \\
\hline C10PA & 28 & 0.21 & 0.53 & 0.36 & 0.33 & 0.36 & 0.41 \\
\hline C12PA & 21 & 0.16 & 0.36 & 0.23 & 0.21 & 0.19 & 0.20 \\
\hline C16P & 18 & 0.14 & 0.16 & 0.09 & 0.09 & 0.09 & 0.07 \\
\hline & 22 & 0.17 & 0.27 & 0.18 & 0.17 & 0.08 & 0.02 \\
\hline hen & 77 & 0.58 & 0.53 & 0.59 & 0.56 & 0.25 & 0.09 \\
\hline nen & 64 & 0.49 & 0.72 & 0.75 & 0.68 & 0.48 & 0.36 \\
\hline
\end{tabular}

Table 5.7 Dye loading and $\mathrm{J}_{\mathrm{sc}}$ ratios of cells pre-treated with coadsorbates normalized to the untreated control cell, from 0 to $48 \mathrm{~h}$

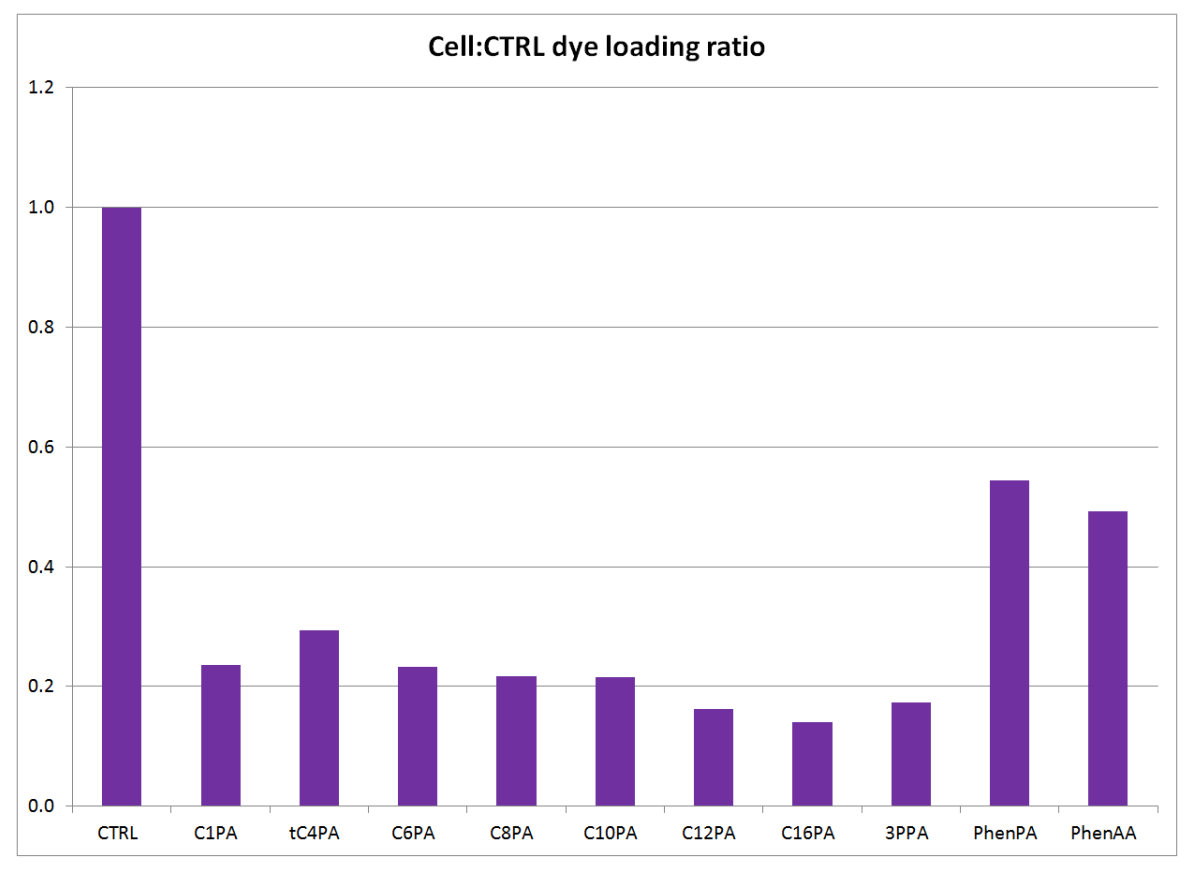

Figure 5.8 Dye loading ratio of cells treated with pre-adsorbates normalized to the control cell 
In Figure 5.8 it can be seen that the two aryl pnictogen acids permitted heavier dye loading - roughly two or three times as much - as the series of alkyl phosphonic acids and 3PPA. Tert-butylphosphonic acid resulted in the greatest adsorption of the alkyl series (0.29), with a steady reduction in adsorption for longer chains, down to 0.14 for C16PA. 3-Phosphonopropanoic acid had an TCPP adsorption of 0.17 , comparable to C12PA (0.16).

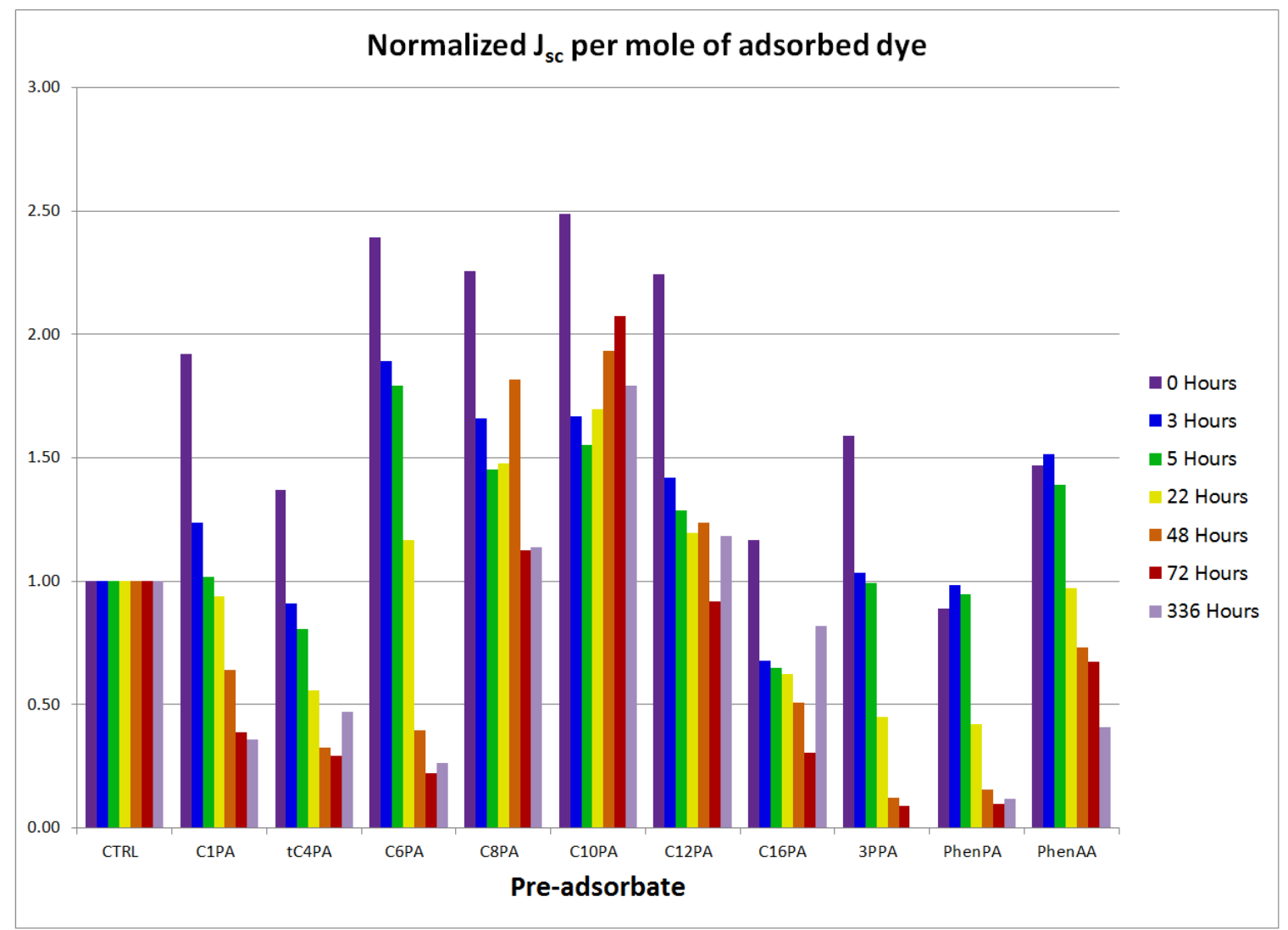

Figure 5.9 Ratio of the $\mathrm{J}_{\mathrm{sc}}$ of cells treated with pre-adsorbates, as photocurrent per mole of adsorbed TCPP, normalized to the control cell at ages from 0 to 336 hours 
In Figure 5.9 values for the photocurrent per nanomole of dye are shown normalized to the control at ages from 0 hours to 336 hours (two weeks). Cells treated with several of the linear alkyl phosphonic acids (from C6PA - C12PA) produced photocurrent:dye ratios substantially better than that of the controls; up to nearly 2.5 times as much in the case of C10PA. Moreover this improved photocurrent performance was sustained for up to two weeks in the case of C10PA. With the exception of phenylphosphonic acid all of the pre-adsorbates produced substantially more photocurrent per mole of adsorbed dye than the control for the initial test and in some cases for several hours longer.

In Table 5.8 and Figure 5.10 the $\mathrm{J}_{\mathrm{sc}}$ data are shown as photocurrent per nanomole of TCPP. The alkyl PAs uniformly show an initial spike by this metric, and immediately begin a decline. This behavior is different than that exhibited by the aryl PAs and by the control, which all showed a small increase at 3 hours and only a small decline after 5 hours. Referring again to Figure 5.9 in which these data were normalized to the control shows that the cells treated with pre-adsorbates tended to age faster than the control. However, cells treated with the C8PA, C10PA, and C12PA declined more slowly than did the others. 
Age

(Hours)

$$
\begin{array}{lllllll}
0 & 3 & 5 & 22 & 48 & 72 & 336
\end{array}
$$

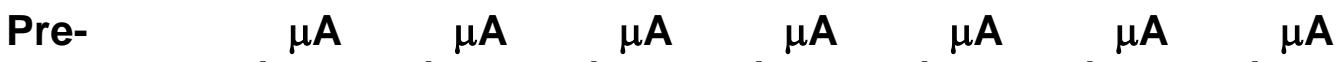
adsorbate / $\mathrm{nmol} / \mathrm{nmol} / \mathrm{nmol} / \mathrm{nmol} / \mathrm{nmol} / \mathrm{nmol} / \mathrm{nmol}$

$\begin{array}{lccccccc}\text { CTRL } & 49 & 50 & 48 & 37 & 29 & 25 & 10 \\ \text { C1PA } & 95 & 62 & 49 & 35 & 19 & 10 & 4 \\ \text { tC4PA } & 68 & 46 & 39 & 20 & 9 & 7 & 5 \\ \text { C6PA } & 118 & 95 & 86 & 43 & 12 & 6 & 3 \\ \text { C8PA } & 111 & 83 & 70 & 55 & 53 & 29 & 11 \\ \text { C10PA } & 123 & 84 & 75 & 63 & 56 & 53 & 18 \\ \text { C12PA } & 111 & 71 & 62 & 44 & 36 & 23 & 12 \\ \text { C16PA } & 58 & 34 & 31 & 23 & 15 & 8 & 8 \\ \text { 3PPA } & 78 & 52 & 48 & 17 & 4 & 2 & 0 \\ \text { PhenPA } & 44 & 49 & 46 & 16 & 5 & 2 & 1 \\ \text { PhenAA } & 72 & 76 & 67 & 36 & 21 & 17 & 4\end{array}$

Table 5.8 $\mathrm{J}_{\mathrm{sc}}$ per nanomole of adsorbed TCPP $(\mu \mathrm{A} / \mathrm{nmol})$. These data are presented graphically in Figure 5.10

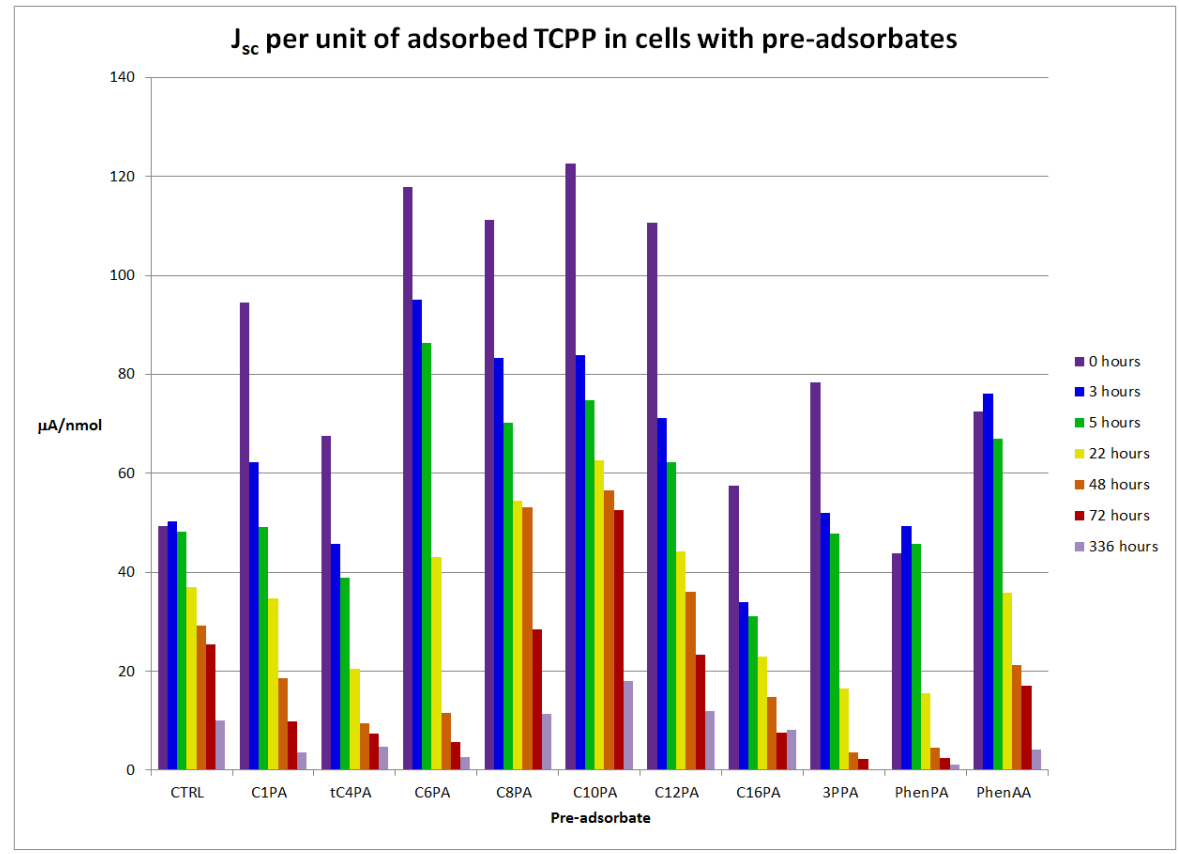

Figure 5.10 Effect of pre-adsorbates on the amount of photocurrent produced per nanomole of adsorbed TCPP in units of $\mu \mathrm{A} / \mathrm{nmol}$ 


\subsection{Electrodes with pre-adsorbates and without TCPP}

In order to study the effects of adsorbates on $\mathrm{TiO}_{2}$ without a sensitizing dye, electrodes were treated overnight with solutions ( $200 \mu \mathrm{M}$ in absolute ethanol, $2.5 \mathrm{~mL}$ per slide) of phosphonic acids, as well as phenylarsonic acid. Each electrode was rinsed with absolute ethanol and acetonitrile before being dried under nitrogen and immediately built into a cell and tested. In the absence of a sensitizing dye a $\mathrm{TiO}_{2}$ - based solar cell can only operate by direct excitation of an electron from the valence band to the conduction band of $\mathrm{TiO}_{2}$. The bandgap of $\mathrm{TiO}_{2}$ is $3.2 \mathrm{eV}$, corresponding to a wavelength of $388 \mathrm{~nm}$, in the near UV region. A white LED lamp was not a suitable light source; since there are essentially no UV photons in its spectrum no photocurrent was detected. Similarly a 500 W quartz halogen lamp (with the UV filter removed) resulted in only a miniscule photocurrent (a few nanoamps). A xenon arc lamp at a total irradiance of 2 suns provided normalized photocurrents up to nearly $1 \mathrm{~mA} / \mathrm{cm}^{2}$. Based on the response range of the radiometer sensor ( $\sim 250 \mathrm{~nm}$ to $1100 \mathrm{~nm})$ and the emission spectrum of the highpressure xenon lamp used as the light source for these experiments, it is estimated that approximately $10 \%$ (or $0.2 \mathrm{sun}, 20 \mathrm{~mW} / \mathrm{cm}^{2}$ ) of the irradiation was in the $\mathrm{UV}$ range. Efficiency calculations are based on this estimate. There is considerable uncertainty in this estimate, but the comparative trends are of much greater interest than the absolute values in this case, since non-sensitized $\mathrm{TiO}_{2}$ solar cells are not the subject of this study. Cells were tested at intervals up to 312 hours (13 days). 


\subsection{Efficiency of cells treated with pre-adsorbates but without TCPP}

Efficiency of the cells treated with pre-adsorbates is presented in Table 5.9 and Figure 5.11. Longer alkyl tails correlate with decreasing efficiency. Cells treated with 3PPA produce efficiencies comparable to those of C16PA. Cells prepared with phenylarsonic acid produce significantly better efficiencies than those with phenylphosphonic acid.

Although efficiency decreases somewhat with age for all the cells, the declines are slow and, even after 13 days, not as severe as the efficiency losses seen for cells treated with TCPP dye after treatment with pre-adsorbates. Since the only obvious difference between these two sets of cells is the presence or absence of TCPP, the changes in efficiency with age would seem to be attributable to some failure related to the TCPP. 


$\begin{array}{lcccccc}\begin{array}{l}\text { Age } \\ \text { (Hours) }\end{array} & \mathbf{0} & \mathbf{2} & \mathbf{4} & \mathbf{2 4} & \mathbf{4 8} & \mathbf{3 1 2} \\ \text { Efficiency } & \% & \% & \% & \% & \% & \% \\ \text { CTRL } & 1.10 & 0.95 & 0.90 & 0.85 & -- & 0.85 \\ \text { C1PA } & 1.00 & 0.95 & 0.95 & 0.95 & 0.90 & 0.90 \\ \text { tC4PA } & 0.70 & 0.80 & 0.80 & 0.70 & 0.80 & 0.80 \\ \text { C6PA } & 0.75 & 0.75 & 0.75 & 0.70 & 0.65 & 0.70 \\ \text { C8PA } & 0.70 & 0.75 & 0.75 & 0.70 & 0.70 & 0.65 \\ \text { C10PA } & 0.70 & 0.70 & 0.75 & 0.65 & 0.60 & 0.55 \\ \text { C12PA } & 0.60 & 0.60 & 0.60 & 0.55 & 0.50 & 0.60 \\ \text { C16PA } & 0.60 & 0.55 & 0.55 & 0.55 & 0.55 & 0.45 \\ \text { 3PPA } & 0.60 & 0.55 & 0.60 & 0.55 & 0.45 & 0.30 \\ \text { PhenPA } & 0.65 & 0.65 & 0.60 & 0.55 & 0.55 & 0.50 \\ \text { PhenAA } & 0.85 & 0.80 & 0.85 & 0.75 & 0.80 & 0.70\end{array}$

Table 5.9 Estimated efficiencies of cells with pre-adsorbates but without TCPP

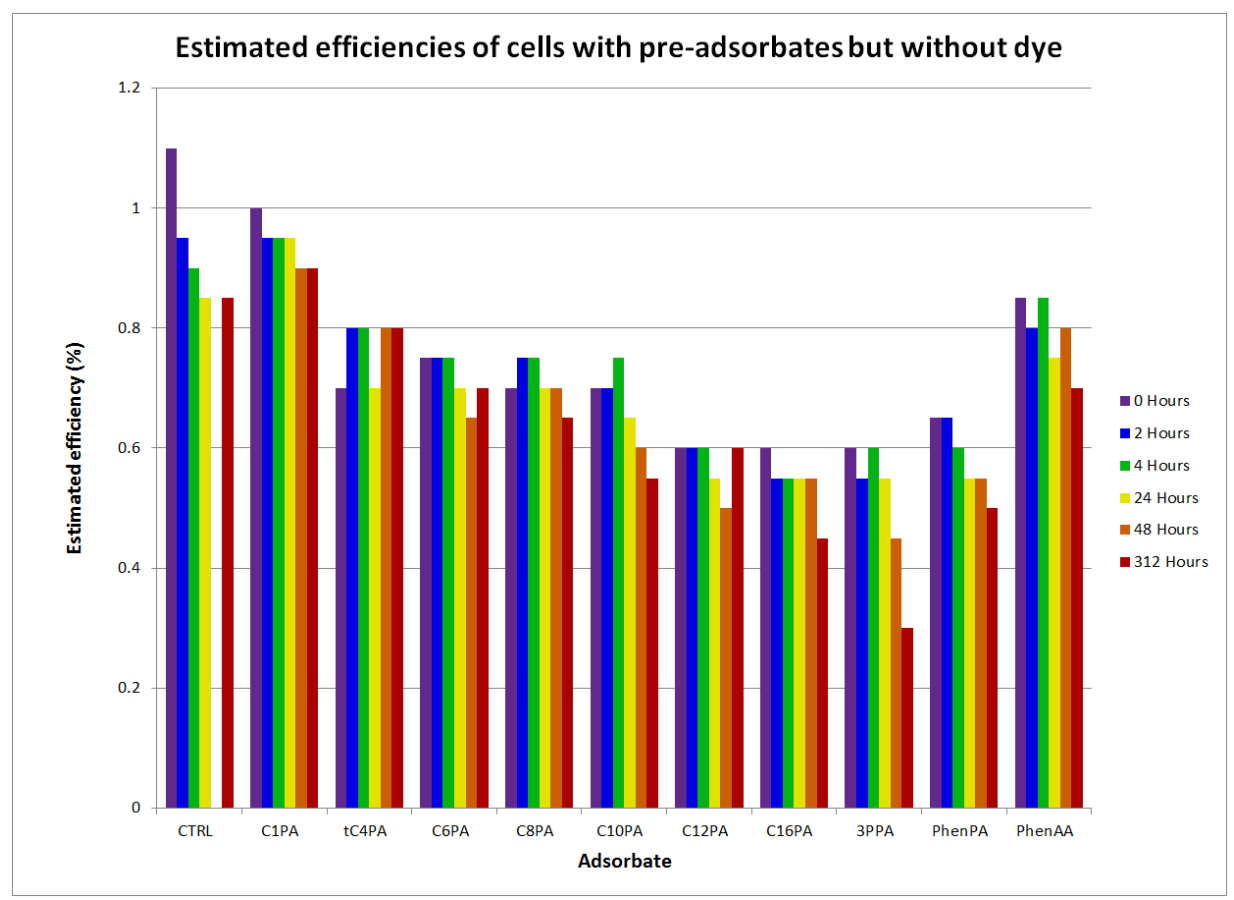

Figure 5.11 Estimated efficiencies of cells treated with pre-adsorbates but without sensitizing TCPP. Irradiation (UV portion of Xe lamp spectrum) was estimated to be 0.2 sun, or about $10 \%$ of the total irradiation 


\section{$5.14 \mathrm{~V}_{\text {oc }}$ of cells treated with pre-adsorbates but without TCPP}

The open-circuit voltage data for these cells are presented in Table 5.10 and Figure 5.12. The $\mathrm{V}_{\mathrm{oc}}$ of the control was lower than that of the treated cells, and decayed with time. For most of the cells with pre-adsorbates, $\mathrm{V}_{\mathrm{oc}}$ basically held steady even after 312 hours. There is not an obvious trend in $\mathrm{V}_{\mathrm{oc}}$ related to the structures of the pre-adsorbates, but the range of $\mathrm{V}_{\mathrm{oc}}$ values (generally in the range of $400-500 \mathrm{mV}$ ) is considerably below that of the analogous cells with TCPP, which were generally in the range $600-700 \mathrm{mV}$. 


$\begin{array}{lcccccc}\begin{array}{l}\text { Age } \\ \text { (Hours) }\end{array} & \mathbf{0} & \mathbf{2} & \mathbf{4} & \mathbf{2 4} & \mathbf{4 8} & \mathbf{3 1 2} \\ \mathbf{V}_{\text {oc }} & \mathbf{m V} & \mathbf{m V} & \mathbf{m V} & \mathbf{m V} & \mathbf{m V} & \mathbf{m V} \\ \text { CTRL } & 482 & 412 & 401 & 365 & -- & 357 \\ \text { C1PA } & 486 & 460 & 452 & 444 & 444 & 431 \\ \text { tC4PA } & 463 & 467 & 463 & 472 & 486 & 491 \\ \text { C6PA } & 440 & 457 & 470 & 491 & 492 & 503 \\ \text { C8PA } & 429 & 459 & 469 & 495 & 502 & 491 \\ \text { C10PA } & 432 & 449 & 451 & 449 & 453 & 437 \\ \text { C12PA } & 424 & 442 & 442 & 438 & 439 & 438 \\ \text { C16PA } & 432 & 449 & 444 & 458 & 455 & 432 \\ \text { 3PPA } & 407 & 433 & 449 & 481 & 495 & 448 \\ \text { PhenPA } & 390 & 420 & 425 & 436 & 451 & 455 \\ \text { PhenAA } & 468 & 460 & 444 & 439 & 445 & 436\end{array}$

Table 5.10 $\mathrm{V}_{\mathrm{oc}}$ of cells with pre-adsorbates but without TCPP

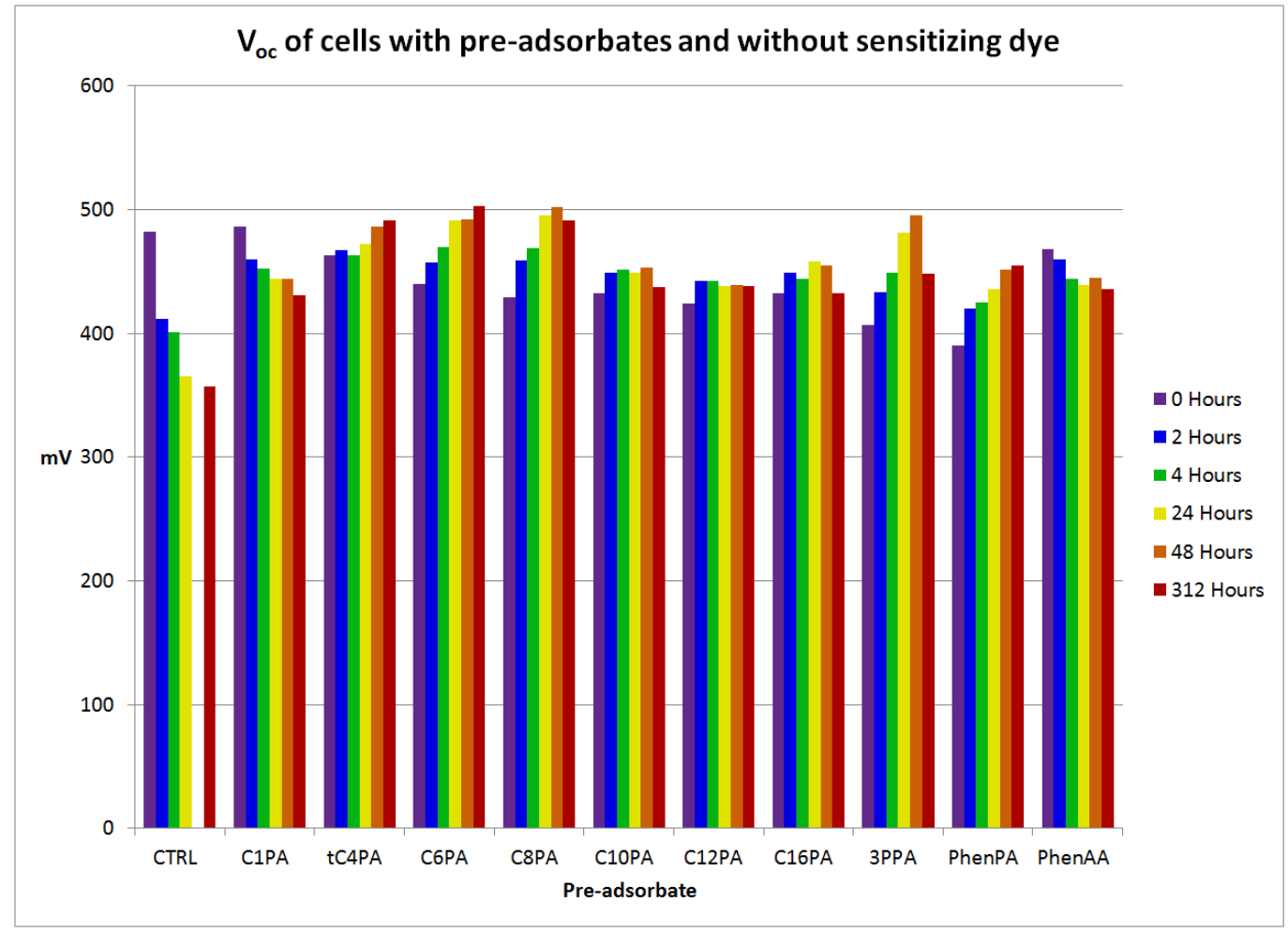

Figure $5.12 \mathrm{~V}_{\text {oc }}$ of cells with pre-adsorbates but without TCPP 


\subsection{Fill factor of cells with pre-adsorbates but without TCPP}

The fill factors for cells with pre-adsorbates and without TCPP are presented in Table

5.11 and Figure 5.13.

$\begin{array}{lcccccc}\begin{array}{l}\text { Age (Hours) } \\ \text { FF }\end{array} & \mathbf{0} & \mathbf{2} & \mathbf{4} & \mathbf{2 4} & \mathbf{4 8} & \mathbf{3 1 2} \\ \text { CTRL } & 0.52 & 0.53 & 0.53 & 0.53 & --- & 0.54 \\ \text { C1PA } & 0.55 & 0.54 & 0.54 & 0.56 & 0.53 & 0.55 \\ \text { tC4PA } & 0.49 & 0.49 & 0.50 & 0.45 & 0.49 & 0.50 \\ \text { C6PA } & 0.55 & 0.53 & 0.51 & 0.49 & 0.47 & 0.47 \\ \text { C8PA } & 0.50 & 0.53 & 0.48 & 0.47 & 0.48 & 0.43 \\ \text { C10PA } & 0.51 & 0.48 & 0.52 & 0.48 & 0.45 & 0.46 \\ \text { C12PA } & 0.46 & 0.48 & 0.44 & 0.46 & 0.42 & 0.46 \\ \text { C16PA } & 0.46 & 0.42 & 0.43 & 0.45 & 0.48 & 0.42 \\ \text { 3PPA } & 0.51 & 0.49 & 0.48 & 0.44 & 0.44 & 0.40 \\ \text { PhenPA } & 0.51 & 0.48 & 0.47 & 0.45 & 0.42 & 0.41 \\ \text { PhenAA } & 0.57 & 0.52 & 0.53 & 0.51 & 0.53 & 0.52\end{array}$

Table 5.11 Fill factor of cells with pre-adsorbates but without TCPP

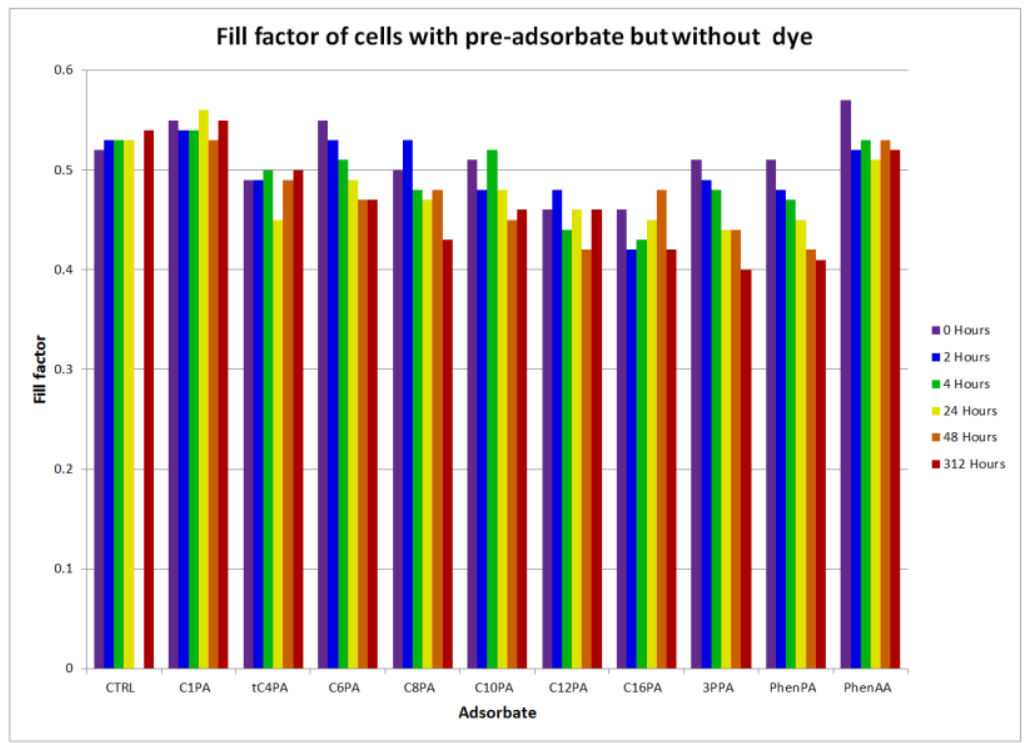

Figure 5.13 Fill factor of cells with pre-adsorbates but without TCPP 
The best results by this metric were produced by the use of C1PA and PhenAA, being consistently better than 0.5 at all tests up to 13 days. PhenPA and 3PPA show a small but steady decay in FF. The linear alkyl PAs show a small but steady trend, declining slowly from average values of about 0.54 for C1PA to about 0.44 for C16PA. As with efficiency and $\mathrm{V}_{\mathrm{oc}}$, the most striking thing about $\mathrm{FF}$ is the relative constancy over time, i.e. the stability of the cells.

\section{$5.16 \mathrm{~J}_{\mathrm{sc}}$ of cells with pre-adsorbate but without TCPP}

The short-circuit currents for cells with adsorbates but without TCPP are presented in Table 5.12 and Figure 5.14. 


$\begin{array}{lcccccc}\begin{array}{l}\text { Age } \\ \text { (Hours) }\end{array} & \mathbf{0} & \mathbf{2} & \mathbf{4} & \mathbf{2 4} & \mathbf{4 8} & \mathbf{3 1 2} \\ \mathbf{J}_{\text {sc }} & \mathbf{m A} & \mathbf{m A} & \mathbf{m A} & \mathbf{m A} & \mathbf{m A} & \mathbf{m A} \\ \text { CTRL } & 0.86 & 0.85 & 0.84 & 0.86 & -- & 0.89 \\ \text { C1PA } & 0.75 & 0.77 & 0.80 & 0.76 & 0.77 & 0.76 \\ \text { tC4PA } & 0.63 & 0.68 & 0.68 & 0.68 & 0.69 & 0.67 \\ \text { C6PA } & 0.61 & 0.61 & 0.62 & 0.59 & 0.58 & 0.60 \\ \text { C8PA } & 0.65 & 0.60 & 0.68 & 0.62 & 0.59 & 0.61 \\ \text { C10PA } & 0.63 & 0.63 & 0.63 & 0.62 & 0.59 & 0.57 \\ \text { C12PA } & 0.63 & 0.59 & 0.61 & 0.56 & 0.56 & 0.58 \\ \text { C16PA } & 0.61 & 0.59 & 0.60 & 0.55 & 0.49 & 0.52 \\ \text { 3PPA } & 0.57 & 0.53 & 0.54 & 0.53 & 0.42 & 0.36 \\ \text { PhenPA } & 0.66 & 0.63 & 0.62 & 0.58 & 0.58 & 0.54 \\ \text { PhenAA } & 0.64 & 0.66 & 0.71 & 0.67 & 0.67 & 0.62\end{array}$

Table 5.12 $\mathrm{J}_{\mathrm{sc}}$ of cells with pre-adsorbates but without TCPP

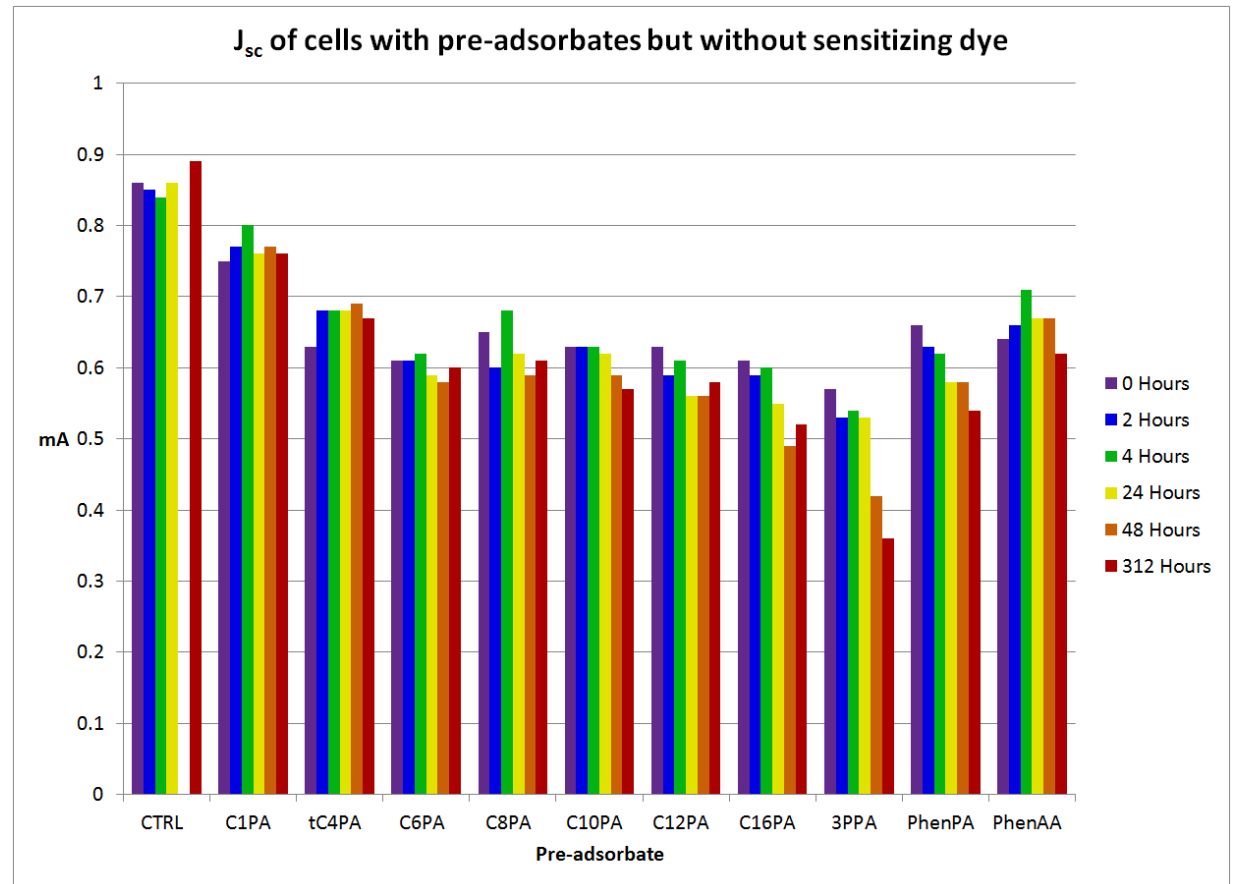

Figure 5.14 $\mathrm{J}_{\mathrm{sc}}$ of cells with pre-adsorbates but without TCPP 
The comparative $\mathrm{J}_{\mathrm{sc}}$ values for these cells serve as the principal explanation for the differences in efficiency of the cells. The control produced the highest $\mathrm{J}_{\mathrm{sc}}$, averaging about $0.86 \mathrm{~mA} / \mathrm{cm}^{2}$. Of the cells treated with coadsorbates, methylphosphonic acid provided the highest $\mathrm{J}_{\mathrm{sc}}$ (averaging about $0.77 \mathrm{~mA} / \mathrm{cm}^{2}$ ). The other linear alkyl PAs all produced fairly similar results. Phenylarsonic acid produced somewhat more photocurrent than the linear alkyl PAs, being about on par with tC4PA. Phenylphosphonic acid initially produced a $\mathrm{J}_{\mathrm{sc}}$ of $0.66 \mathrm{~mA} / \mathrm{cm}^{2}$, and slowly decayed to $0.54 \mathrm{~mA} / \mathrm{cm}^{2}$. The lowest performer was 3PPA, which consistently produced the lowest photocurrent and also showed the greatest amount of degradation as it aged. But once again, the most significant result was the relative stability of $\mathrm{J}_{\mathrm{sc}}$ as the cells aged. This is in sharp contrast to the behavior of the analogous cells with TCPP, which showed a sharp decline in $\mathbf{J}_{\mathrm{sc}}$ after a few hours.

\subsection{Summary of overall effects of pre-adsorbates without TCPP}

It is noteworthy that the cells which did not make use of TCPP demonstrated much greater stability by all metrics than did identical cells with TCPP as a sensitizing dye. This suggests (not surprisingly) that some sort of degradation related to the dye is responsible for most of the overall performance degradation of these cells. Other possible factors, such as degradation of the $\mathrm{TiO}_{2}$ itself, or of the electrolyte, would appear to be exonerated. Moreover, it seems clear that the PAs are not slowly desorbed into the 
electrolyte. If they were being desorbed, then the performance metrics of the affected cells would show a steady drift toward those of the control cell, and this is not observed for any of the adsorbates tested. This finding can be extrapolated to cells with these coadsorbates and with the use of sensitizing dyes; there is no reason that the presence of a dye should affect the equilibrium between the adsorbed PAs and the solvent electrolyte solvent.

\subsection{Phosphonic acids as sim-adsorbates at $8 \mu \mathrm{M}$ concentration}

\section{Reproducibility}

In order to determine the reproducibility of electrodes prepared using sim-adsorbates, three sets of cells (designated $\mathrm{CG}_{-} 1, \mathrm{CG}_{-} 2$, and $\mathrm{CG}_{-}$3) were prepared from plate $\mathrm{CG}$, using four alkyl phosphonic acids (C8PA, C10PA, C12PA, and C16PA) as simadsorbates. Electrodes were treated overnight in the dark in an absolute ethanol solution (2.5 mL per slide) containing TCPP $(100 \mu \mathrm{M})$ and a sim-adsorbate $(8 \mu \mathrm{M})$. Each set included a control electrode treated with TCPP but without a sim-adsorbate. Cells were tested immediately after being prepared, and again at 1,2, 3, and 4 hours of age.

Results for the four principal metrics are presented in Table 5.13 for cells prepared using sim-adsorbates and tested at $0.1 \mathrm{~h}$, along with standard deviations. In sections 5.19 to 5.23, the averaged data are presented graphically in Figure 5.15 (efficiency), Figure 5.16 
$\left(\mathrm{V}_{\mathrm{oc}}\right)$, Figure $5.17(\mathrm{FF})$, and Figure $5.18\left(\mathrm{~J}_{\mathrm{sc}}\right)$, with the same data presented in tabular form immediately prior to each figure.

$\begin{array}{lccccc}\text { Batch } & \begin{array}{c}\text { Sim- } \\ \text { ads }\end{array} & \begin{array}{c}\text { Eff } \\ (\%)\end{array} & \begin{array}{c}\mathbf{V}_{\text {oc }} \\ (\mathbf{m V})\end{array} & \mathbf{F F} & \begin{array}{c}\mathbf{J}_{\mathbf{s c}} \\ (\mathbf{m A})\end{array} \\ \text { CG_1 } & \text { CTRL } & 1.4 & 685 & 0.43 & 4.9 \\ \text { CG_2 } & \text { CTRL } & 1.6 & 631 & 0.43 & 5.8 \\ \text { CG_3 } & \text { CTRL } & 1.4 & 617 & 0.40 & 5.7 \\ \text { Mean } & \text { CTRL } & 1.5 & 644 & 0.42 & 5.4 \\ \text { SD } & \text { CTRL } & 0.1 & 36 & 0.02 & 0.5 \\ & & & & & \\ \text { CG_1 } & \text { C8PA } & 1.7 & 668 & 0.44 & 5.7 \\ \text { CG_2 } & \text { C8PA } & 1.5 & 641 & 0.41 & 5.7 \\ \text { CG_3 } & \text { C8PA } & 1.4 & 645 & 0.45 & 4.8 \\ \text { Mean } & \text { C8PA } & 1.5 & 651 & 0.43 & 5.4 \\ \text { SD } & \text { C8PA } & 0.1 & 15 & 0.02 & 0.5 \\ & & & & & \\ \text { CG_1 } & \text { C10PA } & 1.5 & 670 & 0.38 & 6.1 \\ \text { CG_2 } & \text { C10PA } & 1.5 & 657 & 0.42 & 5.4 \\ \text { CG_3 } & \text { C10PA } & 1.5 & 648 & 0.43 & 5.3 \\ \text { Mean } & \text { C10PA } & 1.5 & 658 & 0.41 & 5.6 \\ \text { SD } & \text { C10PA } & 0.0 & 11 & 0.03 & 0.4 \\ & & & & & \\ \text { CG_1 } & \text { C12PA } & 1.6 & 688 & 0.44 & 5.3 \\ \text { CG_2 } & \text { C12PA } & 1.6 & 663 & 0.45 & 5.5 \\ \text { CG_3 } & \text { C12PA } & 1.3 & 662 & 0.41 & 4.7 \\ \text { Mean } & \text { C12PA } & 1.5 & 671 & 0.43 & 5.2 \\ \text { SD } & \text { C12PA } & 0.2 & 15 & 0.02 & 0.4 \\ & & & & & \\ \text { CG_1 } & \text { C16PA } & 1.6 & 661 & 0.41 & 5.7 \\ \text { CG_2 } & \text { C16PA } & 1.6 & 655 & 0.42 & 5.9 \\ \text { CG_3 } & \text { C16PA } & 1.6 & 633 & 0.41 & 6.0 \\ \text { Mean } & \text { C16PA } & 1.6 & 650 & 0.41 & 5.9 \\ \text { SD } & \text { C16PA } & 0.0 & 15 & 0.01 & 0.1\end{array}$

Table 5.13 Performance metrics at $0.1 \mathrm{~h}$ of cells treated with $8 \mu \mathrm{M}$ sim-adsorbates 
5.19 Efficiencies of cells with sim-adsorbates at $8 \mu \mathrm{M}$ concentration

Avg. Efficiency (\%)

Age

0.1 Hours

CTRL C8PA C10PA C12PA C16PA

1 Hours

$\begin{array}{lllll}1.47 & 1.50 & 1.48 & 1.50 & 1.58\end{array}$

2 Hours

1.54

1.50

1.50

$1.39 \quad 1.54$

3 Hours

1.50

1.50

1.48

1.33

1.52

4 Hours

$1.45 \quad 1.50$

1.42

1.19

1.47

1.46

1.40

1.37

1.11

1.39

Table 5.14 Average efficiency of cells with $8 \mu \mathrm{M}$ sim-adsorbates

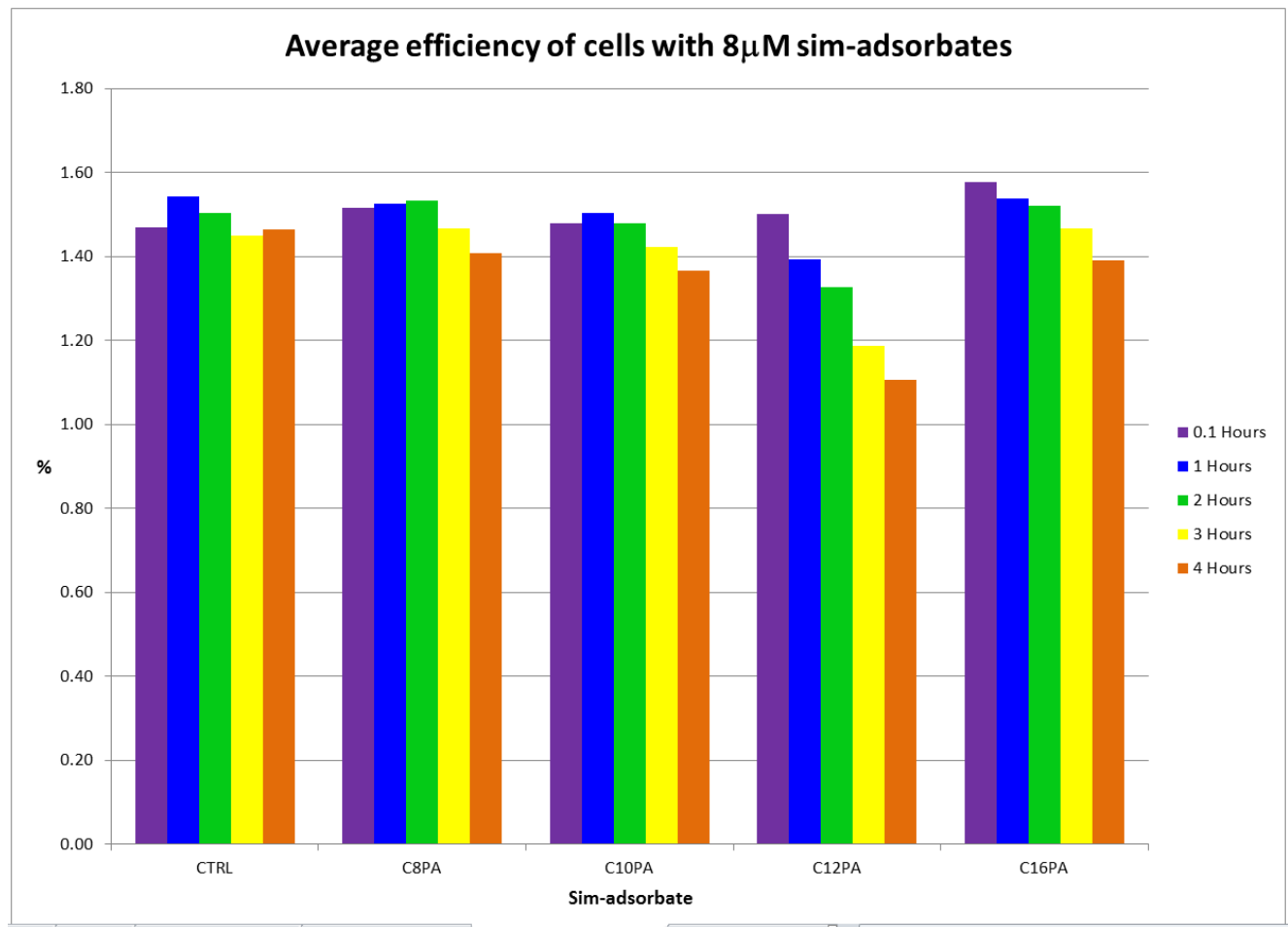

Figure 5.15 Average efficiency of cells treated with $8 \mu \mathrm{M}$ sim-adsorbates 
The average efficiencies of cells treated with a variety of PAs as sim-adsorbates were similar for all cells including the controls, with the exception of C12PA which showed a steady decline over four hours, from a high of $1.50 \%$ to $1.11 \%$. C16PA, which started with its efficiency somewhat higher than the control, also showed a steady decline in efficiency over this period, falling from an initial efficiency of $1.58 \%$ to $1.39 \%$, ending up lower than the control at the final time period.

\section{$5.20 \mathrm{~V}_{\text {oc }}$ of cells with sim-adsorbates at $8 \mu \mathrm{M}$ concentration}

The open-circuit voltages produced by cells with sim-adsorbates are presented in Table 5.15 and Figure 5.16. 
Avg. $V_{\text {oc }}(\mathrm{mV})$

Age

0.1 Hours

1 Hours

2 Hours

3 Hours

4 Hours

$\begin{array}{ccccc}\text { CTRL } & \text { C8PA } & \text { C10PA } & \text { C12PA } & \text { C16PA } \\ 644 & 651 & 658 & 671 & 650 \\ 681 & 693 & 695 & 702 & 684 \\ 697 & 711 & 710 & 720 & 702 \\ 709 & 722 & 721 & 731 & 715 \\ 718 & 731 & 730 & 740 & 724\end{array}$

Table 5.15 Average $\mathrm{V}_{\mathrm{oc}}$ of cells treated with $8 \mu \mathrm{M}$ sim-adsorbates

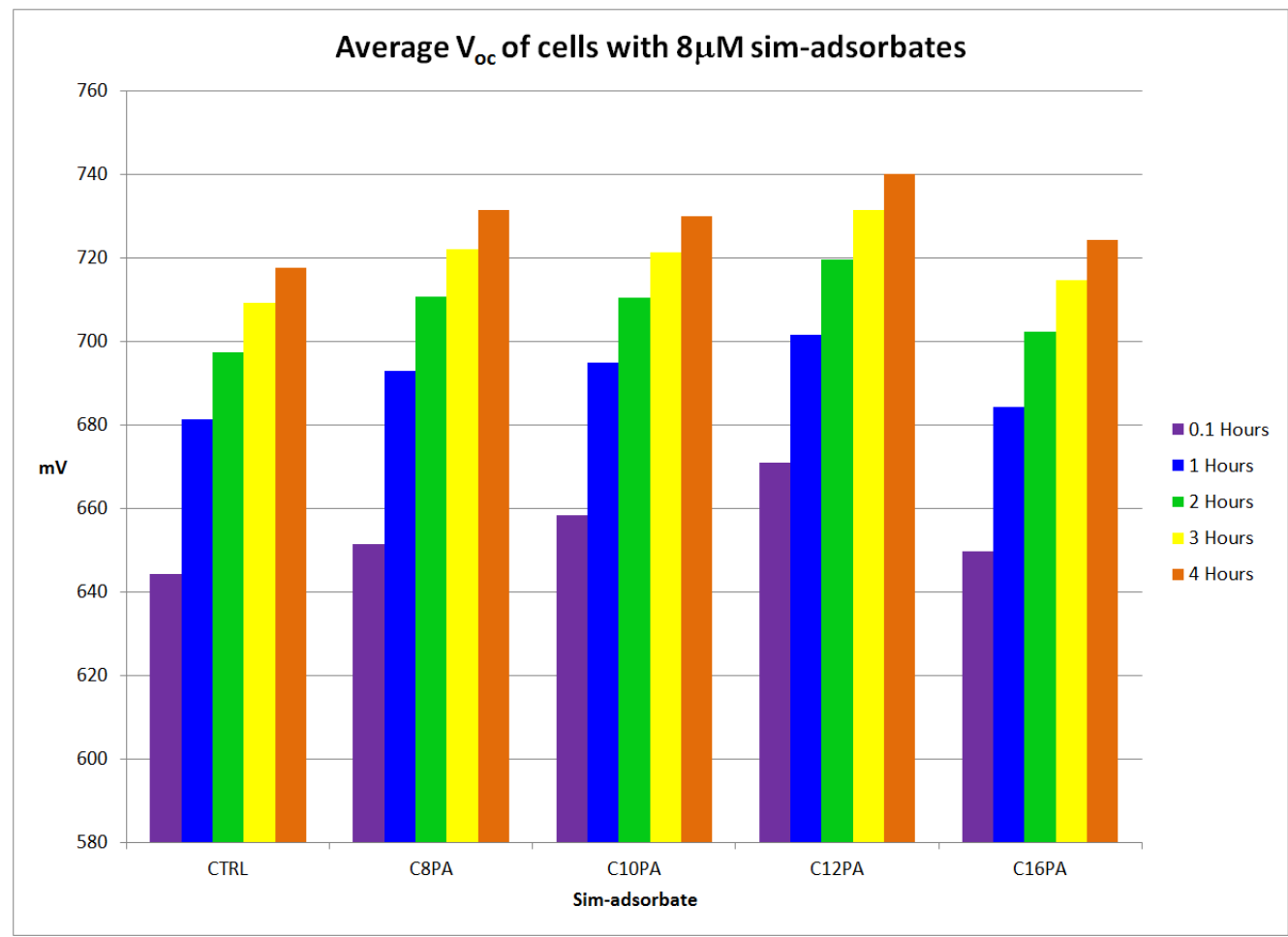

Figure 5.16 Average $\mathrm{V}_{\mathrm{oc}}$ of cells treated with $8 \mu \mathrm{M}$ sim-adsorbates

All cells, including controls, showed a steady increase in $\mathrm{V}_{\mathrm{oc}}$ over the first four hours.

For C8PA, C10PA, and C12PA, there is a small trend toward higher $\mathrm{V}_{\mathrm{oc}}$ for longer alkyl 
chains. The trend is broken by C16PA, but even in this case the test cells produced higher $\mathrm{V}_{\text {oc }}$ than the control cells.

\subsection{Fill factors of cells with sim-adsorbates at $8 \mu \mathrm{M}$ concentration}

The average fill factors produced by cells with sim-adsorbates are presented in

Table 5.16 and Figure 5.17. 
Avg. FF

Age

0.1 Hours

CTRL C8PA C10PA C12PA C16PA

1 Hours

2 Hours

0.42

0.4

0.41

0.43

0.41

0.46

0.5

0.45

0.48

0.46

0.48

0.5

0.49

0.52

0.49

0.49

0.5

0.51

0.54

0.51

4 Hours

0.52

0.5

0.54

0.56

0.53

Table 5.16 Average fill factor of cells treated with $8 \mu \mathrm{M}$ sim-adsorbates

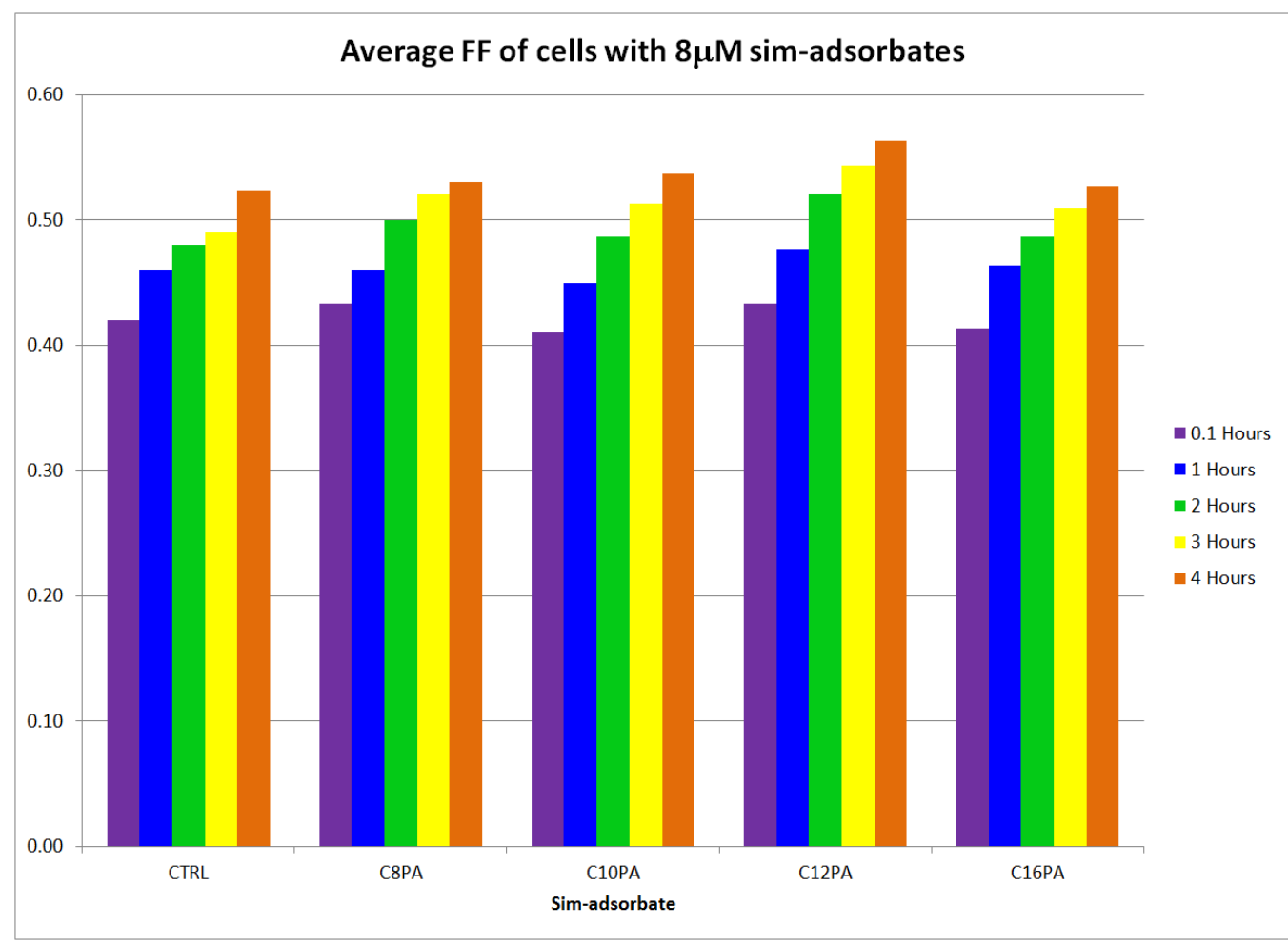

Figure 5.17 Average fill factor of cells treated with $8 \mu \mathrm{M}$ sim-adsorbates

The trends in fill factors closely parallel the results seen for $\mathrm{V}_{\mathrm{oc}}$ values; for all sets of cells, FF improves over the first four hours. However, the fill factors for each type of cell (including the controls) are so similar that there is no detectable trend. 


\section{$5.22 \mathrm{~J}_{s c}$ values of cells with sim-adsorbates at $8 \mu \mathrm{M}$ concentration}

The average short-circuit currents produced by cells with sim-adsorbates are presented in Table 5.17 and Figure 5.18.

$\begin{array}{lccccc}\text { Avg. } \mathbf{J}_{\text {sc }}(\mathbf{m A}) & & & & & \\ \text { Age } & \text { CTRL } & \text { C8PA } & \text { C10PA } & \text { C12PA } & \text { C16PA } \\ \text { 0.1 Hours } & 5.4 & 5.4 & 5.6 & 5.2 & 5.9 \\ \text { 1 Hours } & 5.0 & 4.8 & 4.8 & 4.2 & 4.9 \\ \text { 2 Hours } & 4.6 & 4.3 & 4.3 & 3.6 & 4.5 \\ \text { 3 Hours } & 4.3 & 3.9 & 3.9 & 3.0 & 4.0 \\ \text { 4 Hours } & 4.0 & 3.6 & 3.5 & 2.7 & 3.6\end{array}$

Table 5.17 Average $\mathrm{J}_{\mathrm{sc}}$ of cells treated with $8 \mu \mathrm{M}$ sim-adsorbates

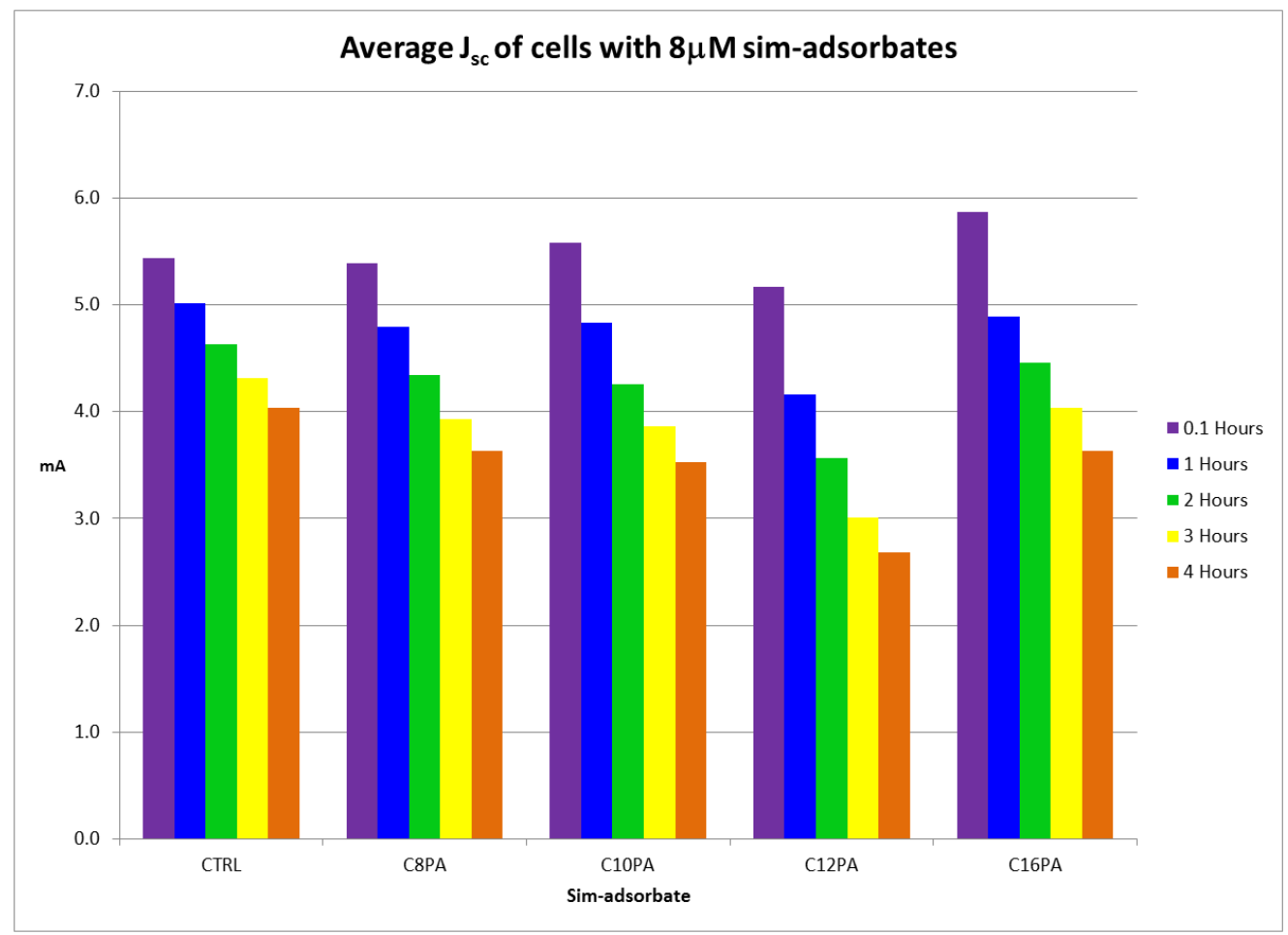

Figure 5.18 Average $\mathrm{J}_{\mathrm{sc}}$ of cells treated with $8 \mu \mathrm{M}$ sim-adsorbates 
The control cells produced an average $\mathrm{J}_{\mathrm{sc}}$ of $5.4 \mathrm{~mA} / \mathrm{cm}^{2}$ at time 0 , which had declined to $4.0 \mathrm{~mA} / \mathrm{cm}^{2}$ after 4 hours. The average short-circuit current produced by the cells treated with sim-adsorbates shows little effect in $\mathrm{J}_{\mathrm{sc}}$ that can be attributed to the sim-adsorbates. At the initial test, the highest average $\mathrm{J}_{\mathrm{sc}}\left(5.9 \mathrm{~mA} / \mathrm{cm}^{2}\right)$ was obtained from the C16PA cells, but the difference between it and the other sets of cells was not significant. The cells treated with sim-adsorbates showed slightly faster reduction in $\mathbf{J}_{\mathrm{sc}}$ than the set of control cells. The cell using C12PA showed a faster decline in $\mathrm{J}_{\mathrm{sc}}$ than the other groups of cells.

\subsection{Summary of effects of sim-adsorbates at $8 \mu \mathrm{M}$ concentration}

Cells prepared with sim-adsorbates at a concentration of $8 \mu \mathrm{M}$ do not show large effects as measured by any of the standard cell metrics. On average, cells prepared with C8PA, C10PA, C12PA and C16PA as sim-adsorbates perform in a manner very similar to control cells when tested hourly up to four hours. In all cases, overall efficiency declines slowly over this period. Short-circuit current undergoes the largest decline, but this is largely offset by significant increases in $\mathrm{V}_{\mathrm{oc}}$ and $\mathrm{FF}$. In the case of $\mathrm{C} 12 \mathrm{PA}$, the decline in $\mathbf{J}_{\mathrm{sc}}$ was larger than for the other sets of cells, with the result that the overall efficiency of this set of cells declined more significantly than that of the other sets. 


\subsection{Determination of optimal sim-adsorbate concentration}

Results obtained from the work using sim-adsorbates at a concentration of $8 \mu \mathrm{M}$ did not result in significant effects. It was known from prior work that sim-adsorbates can produce significant effects in cell performance, so the effects of sim-adsorbates at a range of concentrations ranging from $2.0 \mu \mathrm{M}$ to $160 \mu \mathrm{M}$ were used to prepare a set of cells with TCPP as the sensitizer. Decylphosphonic acid (C10PA) was used for this set of cells. Each concentration was tested on one cell.

The quantity of TCPP adsorbed by each cell was determined by means of UV-Vis spectra of the soaking solutions after cell treatment was complete. The electrodes were treated for $24 \mathrm{~h}$ in their dye solutions, followed by treatment in absolute ethanol $(1.5 \mathrm{~h})$ and acetonitrile $(1 \mathrm{~h})$. After drying under a stream of dry nitrogen, each electrode was assembled into a cell using I3I-1 electrolyte, and tested at one sun illumination with a white LED lamp. 


\begin{tabular}{|c|c|c|c|c|c|c|c|}
\hline $\begin{array}{l}\text { [C10PA] } \\
\mu \mathrm{M}\end{array}$ & $\begin{array}{c}\text { TCPP } \\
\text { loading } \\
\text { after sim- } \\
\text { adsorption } \\
\left(\mathrm{nmol} / \mathrm{cm}^{2}\right)\end{array}$ & $\begin{array}{c}\text { TCPP } \\
\text { loading } \\
\text { after EtOH } \\
\text { desorption } \\
\left(\mathrm{nmol} / \mathrm{cm}^{2}\right)\end{array}$ & $\begin{array}{l}\text { Eff } \\
(\%)\end{array}$ & $\begin{array}{l}\mathrm{V}_{\mathrm{oc}} \\
(\mathrm{mV})\end{array}$ & FF & $\begin{array}{c}\mathbf{J}_{\mathrm{sc}} \\
\left(\mathrm{mA} / \mathbf{c m}^{2}\right)\end{array}$ & $\begin{array}{c}J_{s c} \\
(\mu A \\
/ n m o l)\end{array}$ \\
\hline 0 & 83 & 75 & 1.11 & 576 & 0.32 & 6.1 & 81 \\
\hline 2 & 78 & 71 & 0.93 & 569 & 0.29 & 5.6 & 79 \\
\hline 8 & 83 & 77 & 0.94 & 555 & 0.27 & 6.3 & 82 \\
\hline 20 & 65 & 56 & 1.11 & 584 & 0.27 & 7.1 & 125 \\
\hline 40 & 39 & 32 & 1.27 & 628 & 0.28 & 7.3 & 231 \\
\hline 80 & 33 & 28 & 1.19 & 607 & 0.33 & 6.1 & 218 \\
\hline 160 & 24 & 18 & 1.04 & 591 & 0.46 & 3.8 & 211 \\
\hline
\end{tabular}

Table 5.18 Performance metrics at $0.1 \mathrm{~h}$ of cells treated with varying concentrations of decylphosphonic acid as a sim-adsorbate

The electrodes treated with concentrations of decylphosphonic acid above $20 \mu \mathrm{M}$ retained noticeably - by visual inspection - lower amounts of TCPP due to displacement by the acid. The cell treated with $40 \mu \mathrm{M} \mathrm{C10PA}$ resulted in a $\mathrm{J}_{\mathrm{sc}}$ of $7.3 \mathrm{~mA} / \mathrm{cm}^{2}$, substantially higher than the $\mathrm{J}_{\mathrm{sc}}$ of the control cell $\left(6.1 \mathrm{~mA} / \mathrm{cm}^{2}\right)$. The same cell produced the highest $\mathrm{V}_{\text {oc }}(628 \mathrm{mV})$. Its efficiency was limited to $1.27 \%$ by a low fill factor of 0.28 . The control cell had a better fill factor $(0.32)$ but with $\mathrm{V}_{\mathrm{oc}}$ and $\mathrm{J}_{\mathrm{sc}}$ being lower than that of the cell with $40 \mu \mathrm{M} \mathrm{C10PA}$, its efficiency was only $1.11 \%$.

In Table 5.18 the amount of photocurrent produced per unit of adsorbed dye is reported in units of $\mu \mathrm{A} / \mathrm{nmol}$. An interesting trend can be seen; cells treated at concentrations up to 8 $\mu \mathrm{M}$ (including the untreated control) show no effect on dye loading. Beginning at concentrations of $20 \mu \mathrm{M}$, a sharp increase in photocurrent production occurs, reaching a 
peak at $40 \mu \mathrm{M}$ and declining only slightly at higher concentrations up to $160 \mu \mathrm{M}$. A similar, but much less pronounced effect was seen when C10PA was applied as a preadsorbate treatment. Dye-loading in the pre-adsorbate case was $28 \mathrm{nmol} / \mathrm{cm}^{2}$, the same as the dye-loading that resulted when $80 \mu \mathrm{M}$ C10PA was applied as a sim-adsorbate. The different treatments resulted in substantially different amounts of photocurrent produced per unit of adsorbed TCPP; $123 \mu \mathrm{A} / \mathrm{nmol}$ in the pre-adsorption case, versus 218 $\mu \mathrm{A} / \mathrm{nmol}$ when $\mathrm{C} 10 \mathrm{PA}$ was applied as a sim-adsorbate at $80 \mu \mathrm{M}$ concentration, a ratio of 4:7 for photocurrent per unit of TCPP. The $\mathrm{V}_{\mathrm{oc}}$ values for these two cells were identical at $607 \mathrm{mV}$.

Remarkably, the cell treated with $160 \mu \mathrm{M}$ C10PA, although having a very light dye load, produced a $\mathrm{J}_{\mathrm{sc}}$ of $3.8 \mathrm{~mA} / \mathrm{cm}^{2}$. With a fill factor of 0.46 , its efficiency was surprisingly good at $1.04 \%$. Based on these results, additional studies were performed using sim-adsorbates at $40 \mu \mathrm{M}$ concentration.

\subsection{Phosphonic acids as sim-adsorbates at $40 \mu \mathrm{M}$ concentration}

Electrodes were prepared using a variety of phosphonic acids at a concentration of $40 \mu \mathrm{M}$ as sim-adsorbates with TCPP. The results of current-voltage tests at 1 sun performed at $0.1 \mathrm{~h}$ (immediately after being assembled) and at $2 \mathrm{~h}$ are shown in Table 5.19 and graphically in Figure 5.19 (efficiency), Figure $5.20\left(\mathrm{~V}_{\mathrm{oc}}\right)$, Figure $5.21(\mathrm{FF})$, and Figure $5.22\left(\mathrm{~J}_{\mathrm{sc}}\right)$. These data represent one cell prepared with each of the sim-adsorbates. 


\begin{tabular}{|c|c|c|c|c|c|c|c|c|c|c|}
\hline PA & $\begin{array}{c}\text { Age } \\
\text { (h) }\end{array}$ & $\begin{array}{l}\text { Eff } \\
(\%)\end{array}$ & $\begin{array}{c}J_{s c} \\
(m A)\end{array}$ & $\begin{array}{c}V_{o c} \\
(m V)\end{array}$ & FF & $\begin{array}{c}\text { Age } \\
\text { (h) }\end{array}$ & $\begin{array}{l}\text { Eff } \\
(\%)\end{array}$ & $\begin{array}{c}\mathrm{J}_{\mathrm{sc}} \\
(\mathrm{mA})\end{array}$ & $\begin{array}{c}V_{o c} \\
(m V)\end{array}$ & FF \\
\hline CTRL & 0.1 & 1.15 & 6.6 & 579 & 0.30 & 2 & 1.30 & 5.4 & 654 & 0.37 \\
\hline C1PA & 0.1 & 1.22 & 6.6 & 557 & 0.33 & 2 & 1.41 & 5.2 & 648 & 0.42 \\
\hline tC4PA & 0.1 & 1.37 & 6.9 & 574 & 0.35 & 2 & 1.47 & 5.1 & 638 & 0.45 \\
\hline C6PA & 0.1 & 1.29 & 8.0 & 606 & 0.27 & 2 & 1.62 & 6.4 & 665 & 0.38 \\
\hline C8PA & 0.1 & 1.41 & 8.4 & 588 & 0.29 & 2 & 1.66 & 6.7 & 661 & 0.38 \\
\hline C10PA & 0.1 & 1.27 & 7.3 & 628 & 0.28 & 2 & 1.53 & 5.7 & 688 & 0.39 \\
\hline C12PA & 0.1 & 1.44 & 8.0 & 616 & 0.29 & 2 & 1.55 & 5.4 & 678 & 0.43 \\
\hline C16PA & 0.1 & 1.46 & 8.7 & 618 & 0.27 & 2 & 1.77 & 6.6 & 672 & 0.40 \\
\hline 3PPA & 0.1 & 1.08 & 5.5 & 517 & 0.38 & 2 & 1.39 & 5.3 & 607 & 0.44 \\
\hline PhPA & 0.1 & 1.32 & 6.9 & 565 & 0.34 & 2 & 1.48 & 5.7 & 635 & 0.41 \\
\hline
\end{tabular}

Table 5.19 Performance metrics at $0.1 \mathrm{~h}$ and $2.0 \mathrm{~h}$ of cells treated with $40 \mu \mathrm{M}$ phosphonic acid sim-adsorbates

\section{Eff. of cells with PA sim-adsorbates}

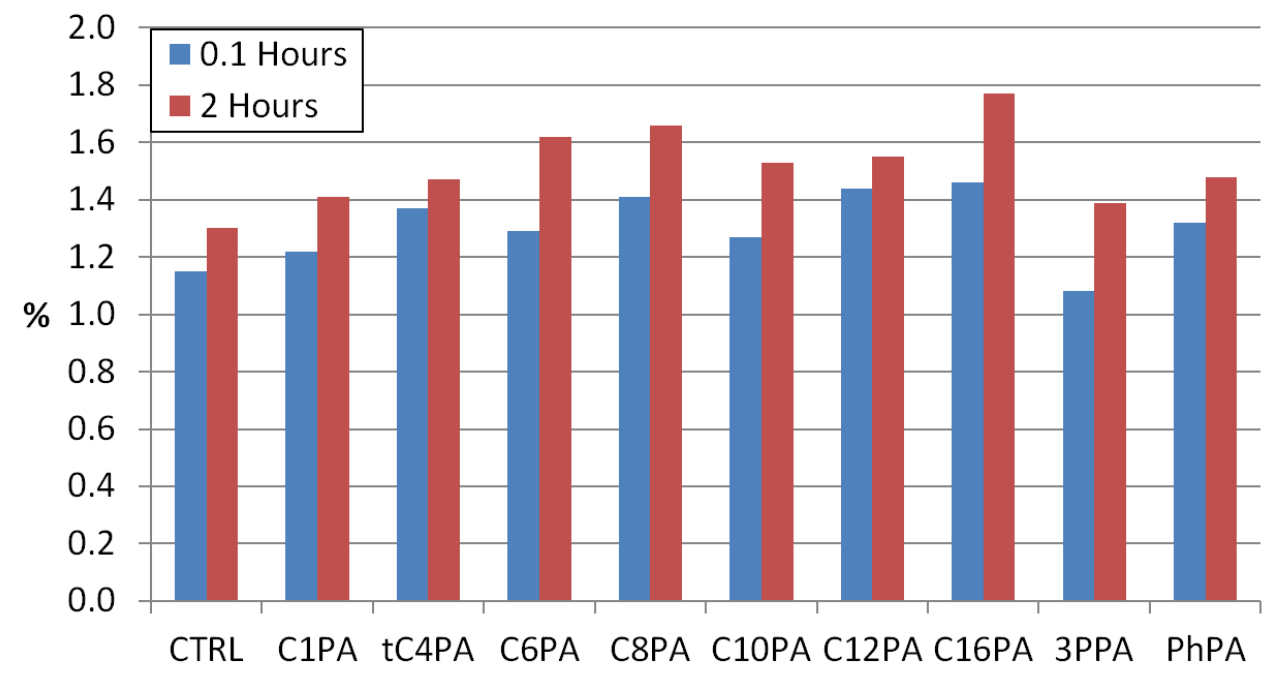

Figure 5.19 Efficiencies of TCPP cells prepared with $40 \mu \mathrm{M}$ PA sim-adsorbates. 
For all of the cells, efficiency improved after 2 hours. With the exception of 3PPA, all of the sim-adsorbates resulted in higher efficiency than the control when tested at $0 \mathrm{~h}$ and again at $2 \mathrm{~h}$

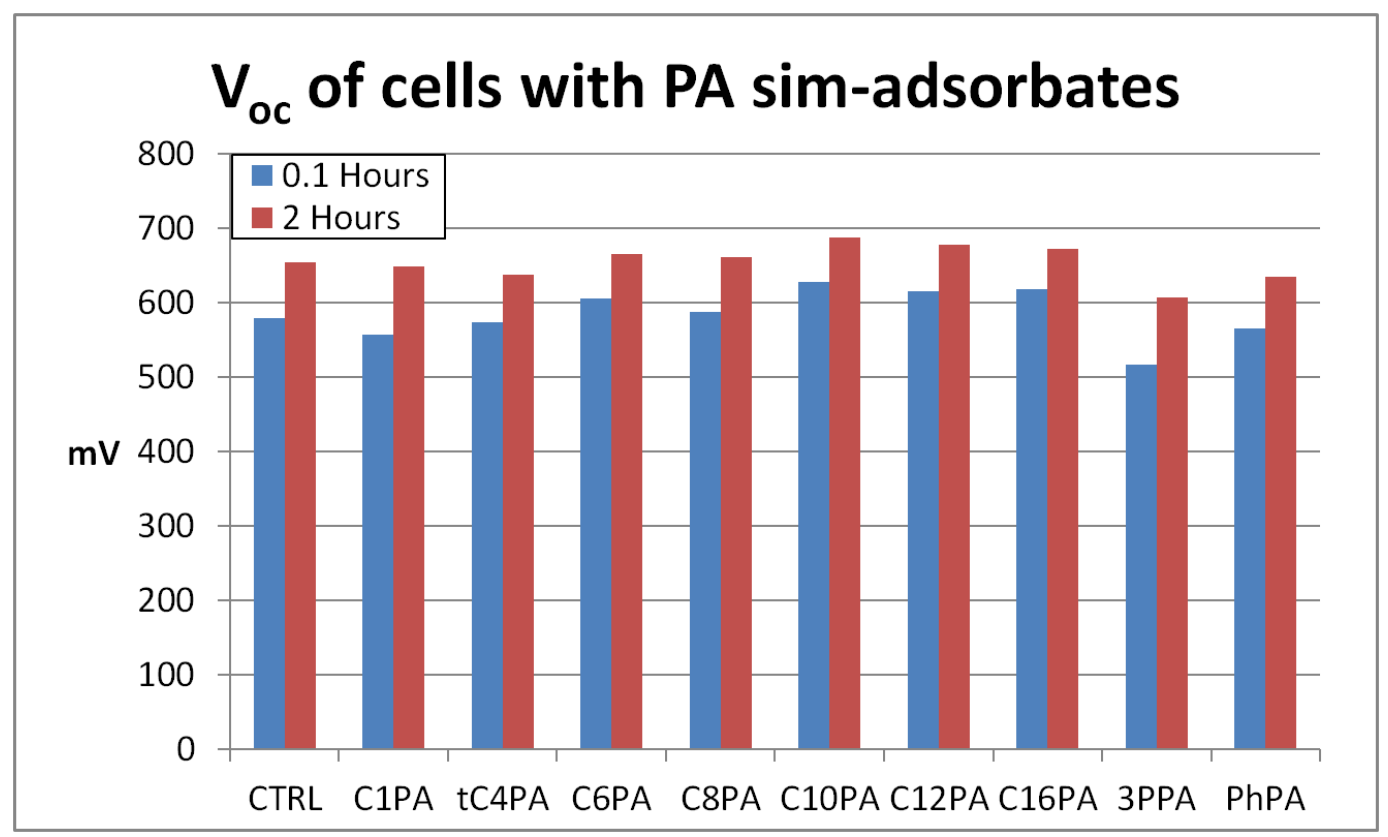

Figure 5.20 $\mathrm{V}_{\mathrm{oc}}$ values of TCPP cells prepared with $40 \mu \mathrm{M}$ PA sim-adsorbates

For all cells, $\mathrm{V}_{\text {oc }}$ increased from $0 \mathrm{~h}$ to $2 \mathrm{~h}$. All of the cells except those prepared using 3PPA and PhPA as sim-adsorbates had essentially the same $\mathrm{V}_{\mathrm{oc}}$ at $0 \mathrm{~h}$ and again at $2 \mathrm{~h}$. Cells prepared with 3PPA and PhPA produced $\mathrm{V}_{\mathrm{oc}}$ values slightly lower than the other cells. 


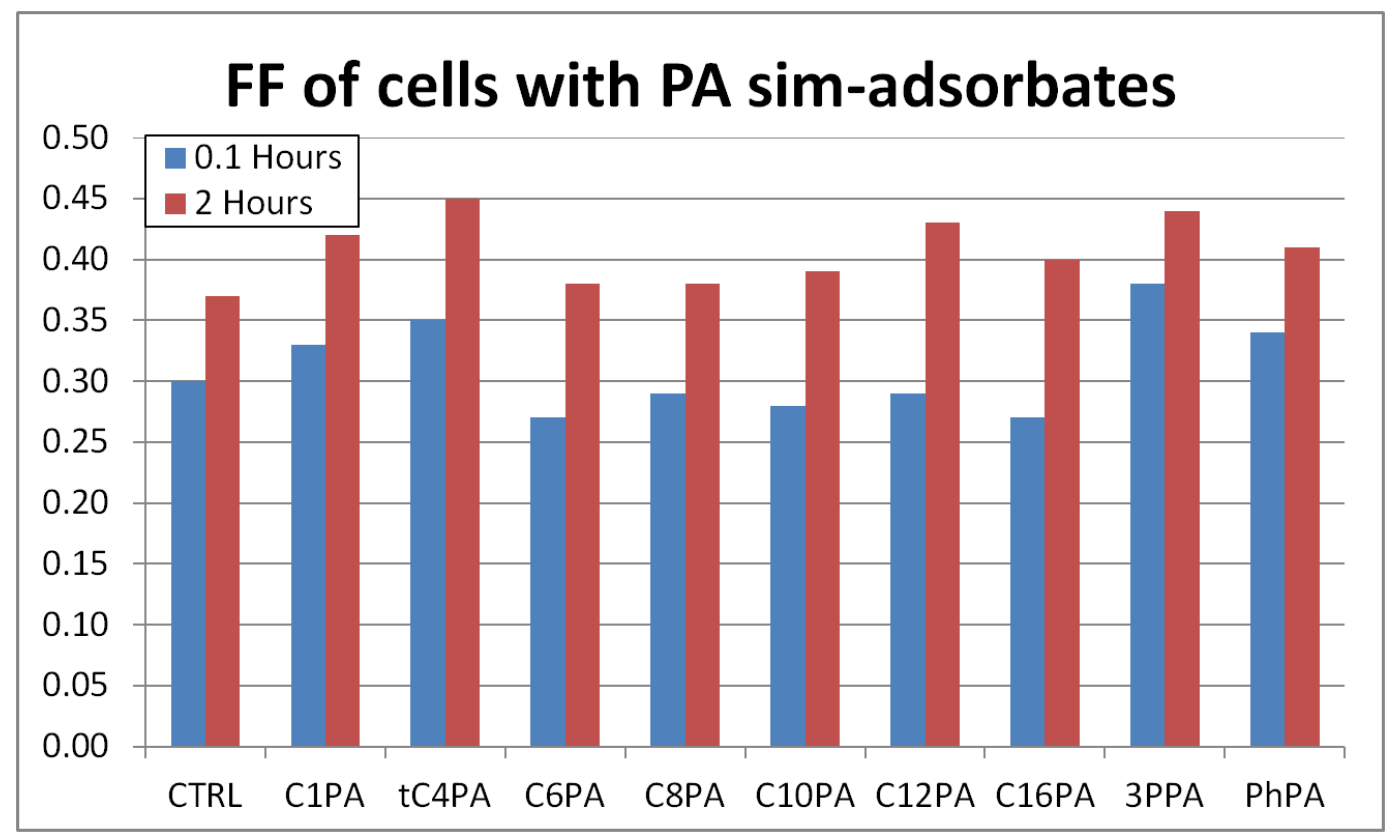

Figure 5.21 Fill factors of TCPP cells prepared with $40 \mu \mathrm{M}$ PA sim-adsorbates

Fill factor improved over the first two hours for all of the cells, and there is not any correlation with the structures of the sim-adsorbates. All cells had a FF in the range 0.27 -0.38 in their test at $0 \mathrm{~h}$, and had increased to the range $0.37-0.44$ at the age of 2 hours.

C1PA and tC4PA had slightly better FF than the control, but C6PA - C16PA all had lower FF than the control initially, but at the 2 hour test they had slightly exceeded that of the control. 3PPA had significantly better FF than the control in both tests. 


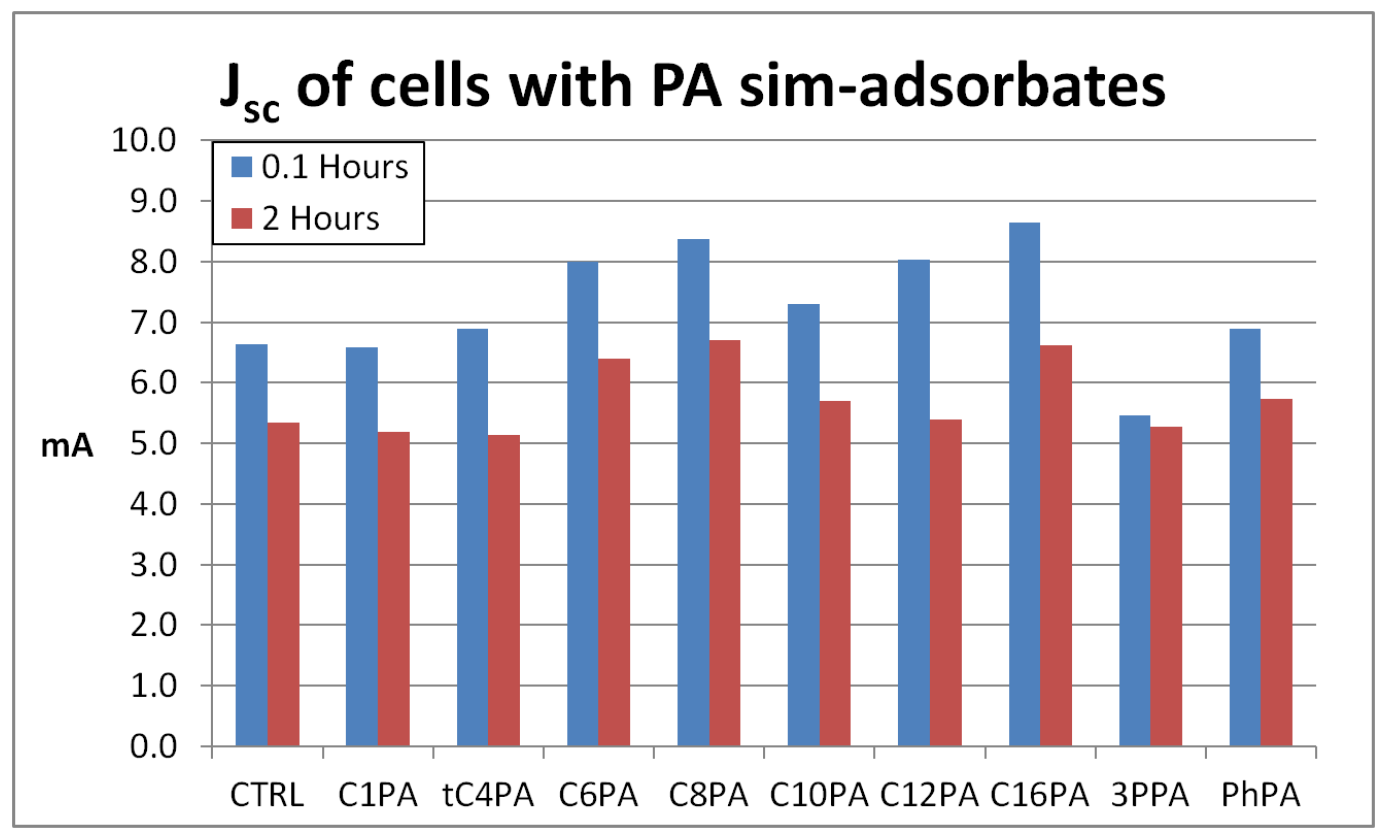

Figure $5.22 \mathrm{~J}_{\mathrm{sc}}$ values of TCPP cells prepared with $40 \mu \mathrm{M}$ PA sim-adsorbates

The cell treated with $\mathrm{C} 16 \mathrm{PA}$ showed the highest initial $\mathrm{J}_{\mathrm{sc}}, 8.7 \mathrm{~mA} / \mathrm{cm}^{2}$. This is a noteworthy $\mathbf{J}_{\mathrm{sc}}$ to be obtained from a TCPP cell. It is substantially higher than the $\mathrm{J}_{\mathrm{sc}}$ produced by the control, $6.6 \mathrm{~mA}$. After 2 hours photocurrent had decreased in all cells.

\subsection{Summary of effects of sim-adsorbates at $40 \mu \mathrm{M}$ concentration}

C16PA had the highest efficiency at the initial test and again at 2 hours. The efficiency of all these cells was limited by their small fill factors, even at the age of 2 hours. The high values for $\mathrm{J}_{\mathrm{sc}}$ and $\mathrm{V}_{\mathrm{oc}}$ of the treated cells resulted in all of these cells producing higher efficiencies than the controls, at 0.1 hour and again at 2 hours. 
Four of the treated cells produced $\mathrm{J}_{\mathrm{sc}}$ values at $8.0 \mathrm{~mA} / \mathrm{cm}^{2}$ or higher. These results are noteworthy, and suggest that the sim-adsorbates were responsible for this affect. The control cell, at $6.6 \mathrm{~mA}$, was at the high end of the photocurrents typically produced by an untreated TCPP cell.

\subsection{Phosphonic acids as post-adsorbates}

\section{Choice of solvent for post-adsorbates}

After preliminary trials using absolute ethanol and water as solvents for phosphonic acid post-adsorbates, acetonitrile was selected as the preferred solvent. Both aqueous and ethanolic treatments were found to be unsatisfactory. Aqueous treatments tended to produce cells with very poor performance, and unpredictable variability. This is probably due to the difficulty of totally drying the cell after such treatment. Ethanolic solutions of PAs generally resulted in large amounts of TCPP being desorbed, with consequent poor performance. It was found that solutions of PAs in acetonitrile produced more controllable and consistent results. Even so, the use of post-adsorbates was found to be an unsatisfactory protocol and it was not used extensively. Nevertheless, certain interesting results were obtained and are reported here. The results reported for cells prepared using post-adsorbates are based on data from one cell in each case. 


\section{Electrode preparation and testing}

Electrodes sensitized with TCPP dye were given post-adsorbate treatments with solutions of C10PA $(2 \mathrm{mM})$ in acetonitrile for times ranging from 1 hour to 24 hours. The cells were tested at illumination level of 0.65 sun provided by a LED lamp with color temperature $5000 \mathrm{~K}$. Control electrodes were not treated with C10PA, and are shown as having a treatment time of 0 hours.

\section{Types of electrolytes employed}

The cells were tested using three different electrolytes; I3I-1, CoBpy-1, and CoBpy-3. All electrolytes used propylene carbonate as the solvent. The electrolytes I3I-1 and CoBpy-1 each contain only the active redox couple, but CoBpy-3 also contained $t$-butylpyridine $(0.2 \mathrm{M})$. Similar results were obtained from cells using the two CoBpy electrolytes, but cells using I3I-1 electrolyte responded differently to the post-adsorbate treatment. 


\subsection{Results for cells using I3I-1 electrolyte}

Performance data for cells built using I3I-1 electrolyte are shown in Table 5.20 and are presented graphically in Figure 5.23 (efficiency), Figure 5.24 $\left(\mathrm{V}_{\mathrm{oc}}\right)$, Figure $5.25(\mathrm{FF})$, and Figure $5.26\left(\mathrm{~J}_{\mathrm{sc}}\right)$.

$\begin{array}{rcccc}\begin{array}{c}\text { Treatment } \\ \text { time } \\ \text { (hours) }\end{array} & \begin{array}{c}\mathbf{V}_{\text {oc }} \\ (\mathbf{m V})\end{array} & \begin{array}{c}\mathrm{J}_{\text {sc }} \\ (\mathbf{m A})\end{array} & \text { FF } & \begin{array}{c}\text { Effic- } \\ \text { iency } \\ (\%)\end{array} \\ & & & & \\ 0 & 602 & 1.18 & 0.58 & 0.63 \\ 1 & 557 & 1.94 & 0.53 & 0.88 \\ 2 & 541 & 1.46 & 0.55 & 0.67 \\ 4 & 519 & 1.59 & 0.54 & 0.68 \\ 8 & 522 & 1.19 & 0.57 & 0.55 \\ 24 & 512 & 0.76 & 0.58 & 0.34\end{array}$

Table 5.20 Performance data for cells treated with C10PA (2 mM) in MeCN for cells using I3I-1 electrolyte 


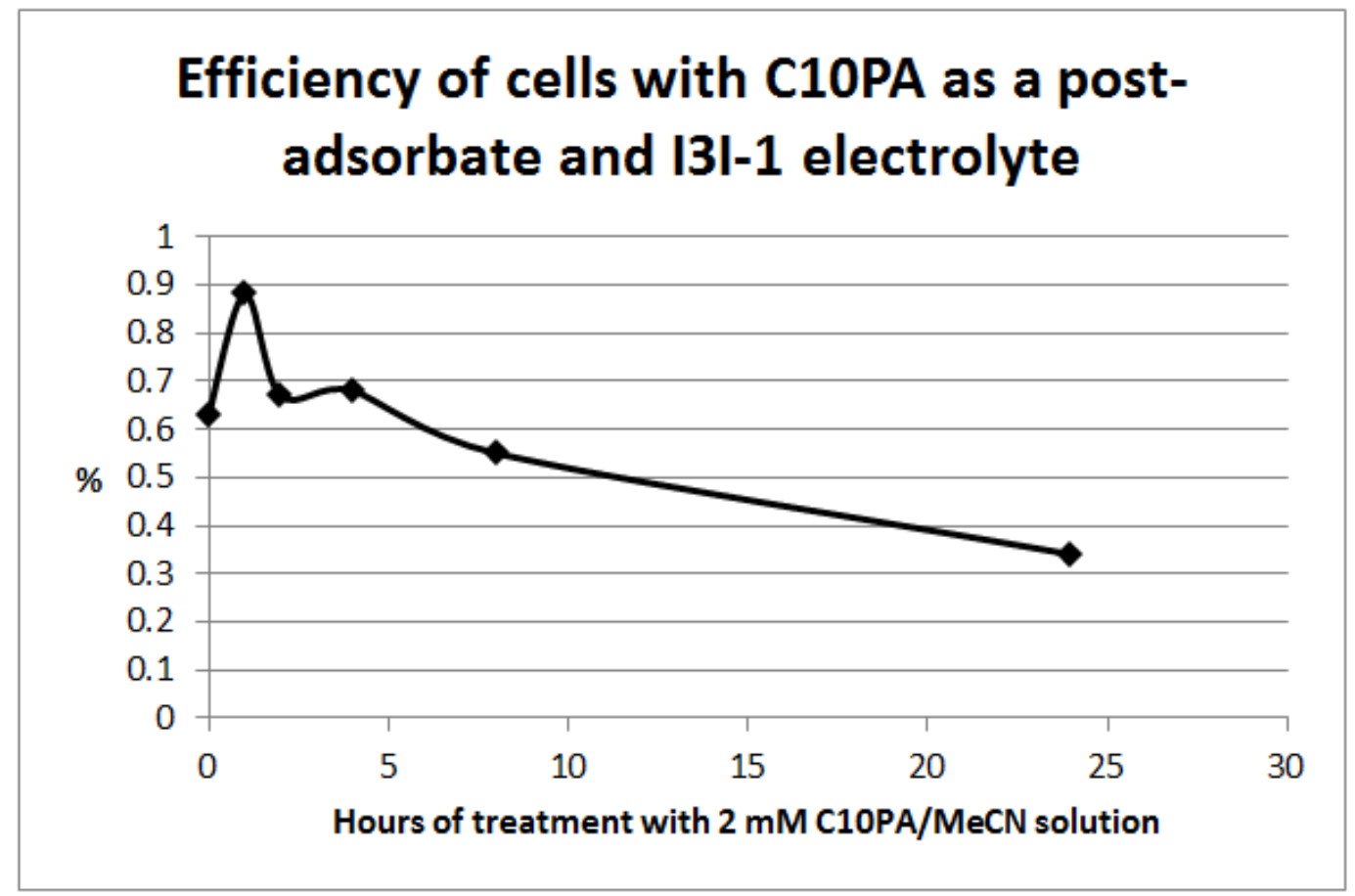

Figure 5.23 Efficiency of cells prepared using C10PA as a post-adsorbate and I3I-1 as electrolyte

For cells using I3I-1 electrolyte efficiency is negatively affected by prolonged postadsorbate treatment with $2 \mathrm{mM} \mathrm{C10PA}$ in MeCN. Treatment for 1 hour resulted in the highest efficiency, $0.88 \%$. Additional hours of treatment resulted in a steady decline, until at 24 hours of treatment the resulting efficiency was only $0.34 \%$. The control produced an efficiency of $0.63 \%$, which was principally due to a low value for $\mathrm{J}_{\mathrm{sc}}$. 


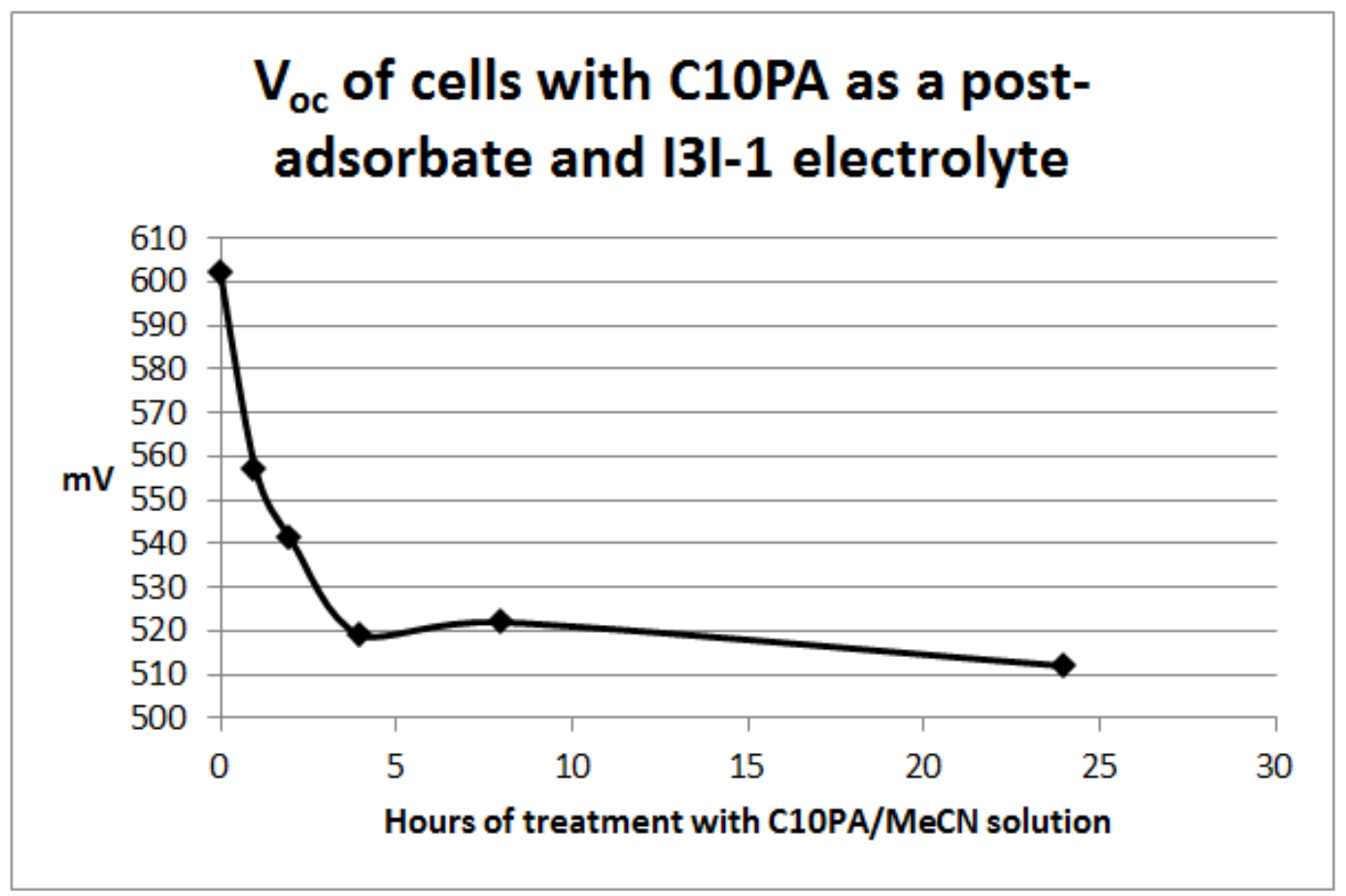

Figure 5.24 $\mathrm{V}_{\mathrm{oc}}$ values of cells prepared using C10PA as a post-adsorbate and I3I-1 as electrolyte

The $\mathrm{V}_{\mathrm{oc}}$ values of these cells follow a clear trend. The control produced a $\mathrm{V}_{\mathrm{oc}}$ of $602 \mathrm{mV}$, falling to $557 \mathrm{mV}$ after 1 hour of treatment. Each additional hour of treatment up to 4 hours resulted in a further decline in $\mathrm{V}_{\mathrm{oc}}$, by which time it had fallen to $519 \mathrm{mV}$.

Additional hours of treatment up to 24 hours resulted in no significant change in $\mathrm{V}_{\mathrm{oc}}$. 


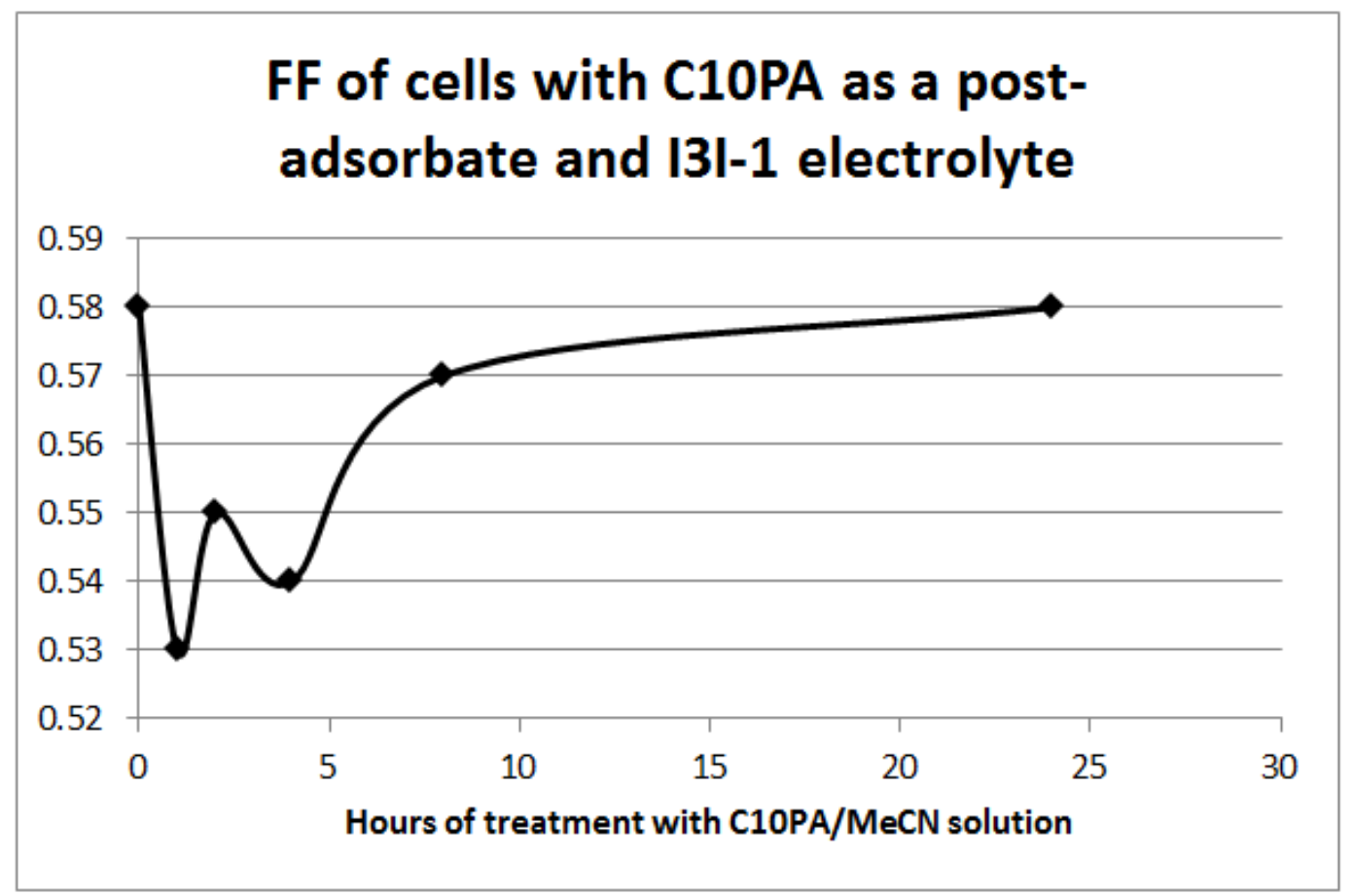

Figure 5.25 Fill factor of cells prepared using C10PA as a post-adsorbate and I3I-1 as electrolyte

The control cell had a fill factor of 0.58. Cells treated with C10PA show a trend to improve FF from the lowest value of 0.53 (1 hour treatment) to a higher value of 0.58 (24 hours treatment). The FF for the cell treated for 4 hours appears to be anomalously low. 


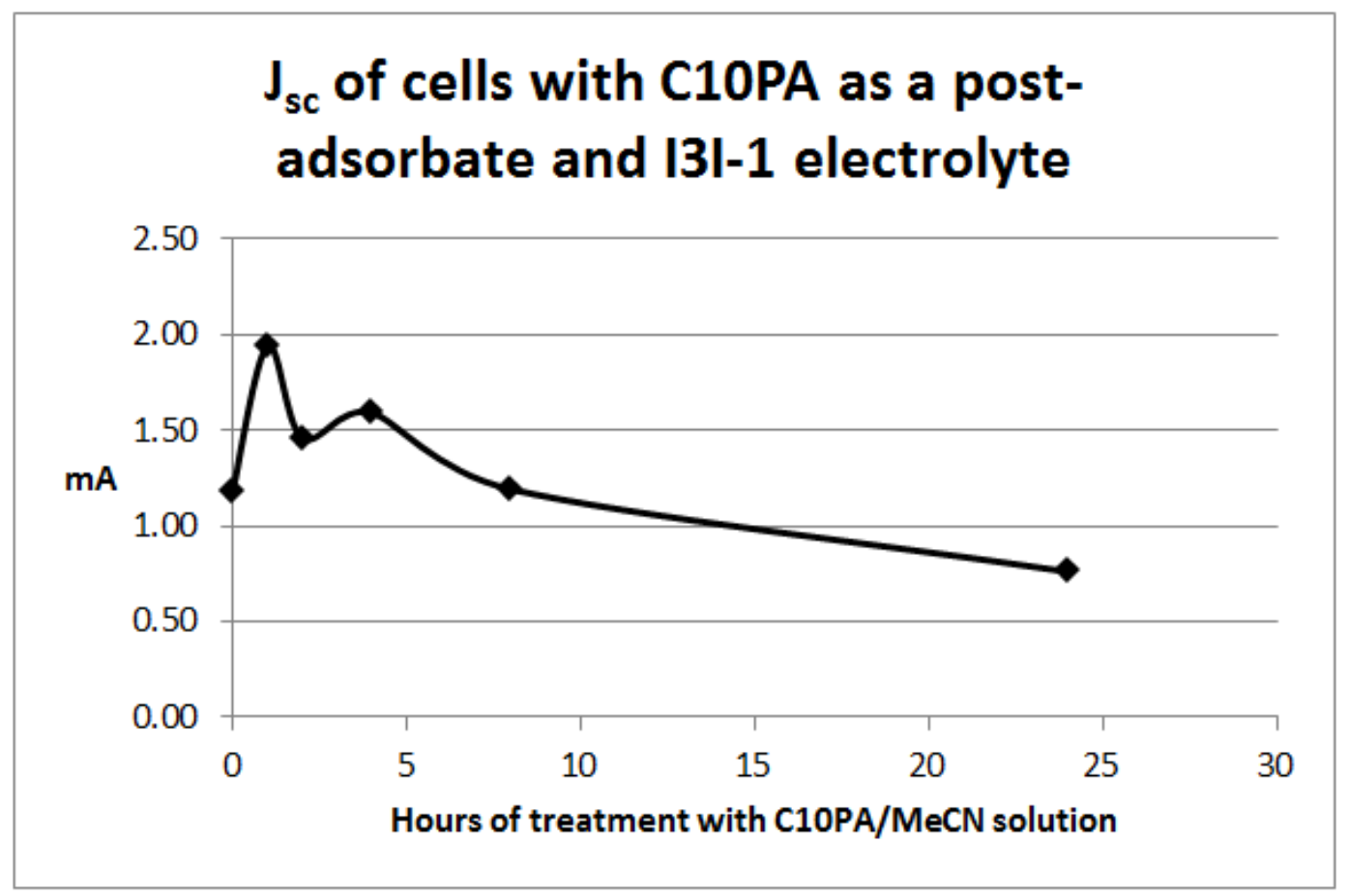

Figure 5.26 $\mathrm{J}_{\mathrm{sc}}$ values of cells prepared using C10PA as a post-adsorbate and I3I-1 as electrolyte

Treatment of cells with C10PA as a post-adsorbate causes a decline in $\mathrm{J}_{\mathrm{sc}}$. Treatment for 1 hour produced a $\mathrm{J}_{\mathrm{sc}}$ of $1.94 \mathrm{~mA} / \mathrm{cm}^{2}$. Treatment for 2 hours resulted in $\mathrm{J}_{\mathrm{sc}}$ falling to $1.46 \mathrm{~mA} / \mathrm{cm}^{2}$, and from there it continued to fall to a low of $0.76 \mathrm{~mA} / \mathrm{cm}^{2}$, with the partial exception of a small anomalous increase after 4 hours of treatment. 


\subsection{Summary of effects produced by post-adsorption treatment of TCPP cells using I3I-1 electrolyte}

For cells using I3I-1 electrolyte the only performance metric that is improved by posttreatment with C10PA in $\mathrm{MeCN}(2 \mathrm{mM})$ is FF. $\mathrm{V}_{\mathrm{oc}}$ is seen to decline smoothly and significantly from a high of $600 \mathrm{mV}$ for an untreated cell to about $520 \mathrm{mV}$ after 4 hours of treatment, at which point it holds steady at longer treatment times. $\mathrm{J}_{\mathrm{sc}}$ declines from a high of nearly $2 \mathrm{~mA} / \mathrm{cm}^{2}$ to about $1.2 \mathrm{~mA} / \mathrm{cm}^{2}$ after 8 hours of treatment, and continues to fall to about $0.75 \mathrm{~mA} / \mathrm{cm}^{2}$ after 24 hours of treatment.

The main point of interest is the effect on $\mathrm{V}_{\mathrm{oc}}$ because cells prepared identically but which used CoBpy electrolytes show a very different response.

\subsection{Results for cells using CoBpy-1 electrolyte}

Performance data for cells built using CoBpy-1 electrolyte are in Table 5.21 and are presented graphically in Figure 5.27 (efficiency), Figure 5.28 $\left(\mathrm{V}_{\text {oc }}\right)$, Figure 5.29 (FF), and Figure $5.30\left(\mathrm{~J}_{\mathrm{sc}}\right)$. 


$\begin{array}{rrrrl}\begin{array}{c}\text { Treatment } \\ \text { time } \\ \text { (hours) }\end{array} & \begin{array}{c}\mathbf{V}_{\mathbf{o c}} \\ (\mathbf{m V})\end{array} & \begin{array}{c}\mathbf{J}_{\mathbf{s c}} \\ (\mathbf{m A})\end{array} & \begin{array}{c}\text { FF } \\ 0\end{array} & \begin{array}{c}\text { Effic- } \\ \text { iency } \\ (\%)\end{array} \\ 1 & 195 & 0.26 & 0.29 & 0.02 \\ 1 & 365 & 0.18 & 0.29 & 0.03 \\ 2 & 377 & 0.16 & 0.31 & 0.03 \\ 4 & 432 & 0.12 & 0.35 & 0.03 \\ 8 & 475 & 0.16 & 0.41 & 0.05 \\ 24 & 461 & 0.10 & 0.40 & 0.03\end{array}$

Table 5.21 Performance data for cells treated with C10PA (2 mM) in MeCN for cells using CoBpy-1 electrolyte 


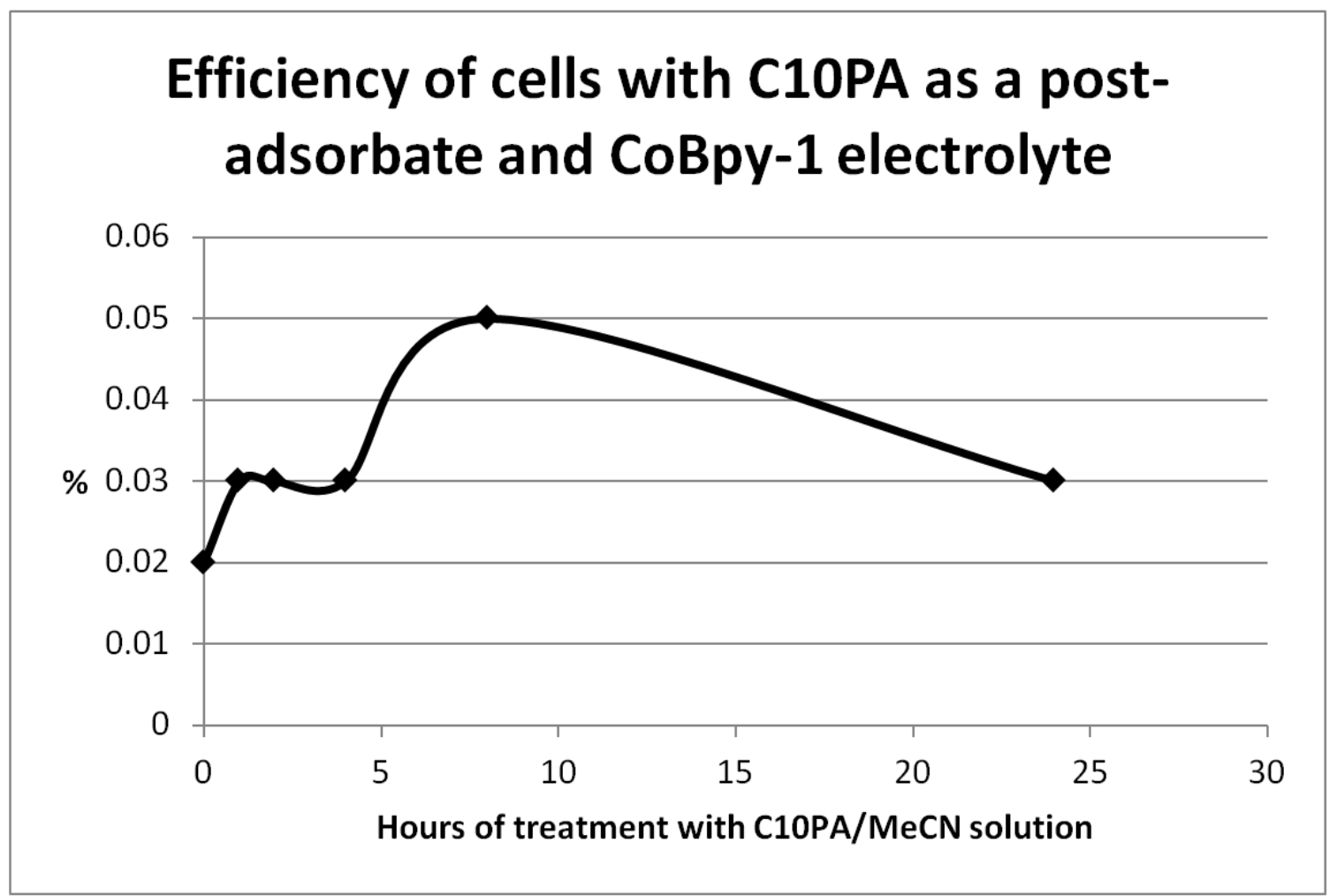

Figure 5.27 Efficiency of cells prepared using C10PA as a post-adsorbate and CoBpy-1 as electrolyte

Treatment with C10PA as a post-adsorbate improves efficiency from a low of $0.02 \%$ (untreated cell) to a high of $0.05 \%$ (8 hour treatment). At 24 hours efficiency fell to $0.03 \%$, due to a decline in $\mathrm{J}_{\mathrm{sc}}$. 


\section{$\mathrm{V}_{\text {oc }}$ of cells with C10PA as a post- adsorbate and CoBpy-1 electrolyte}

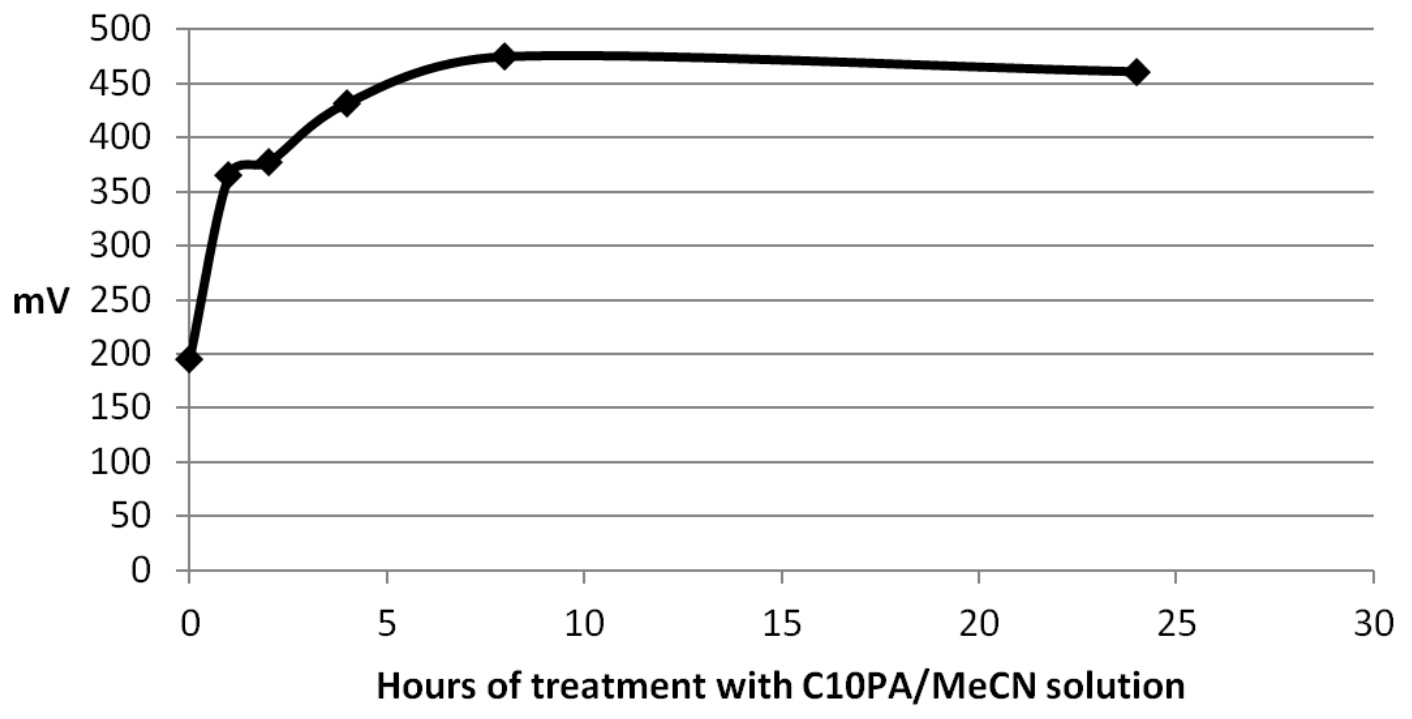

Figure 5.28 $\mathrm{V}_{\mathrm{oc}}$ of cells prepared using C10PA as a post-adsorbate and CoBpy-1 as electrolyte

The $\mathrm{V}_{\mathrm{oc}}$ of TCPP cells using CoBpy-1 electrolyte is dramatically improved by postadsorbate treatment with $2 \mathrm{mM} \mathrm{C10PA}$. The untreated cell had a $\mathrm{V}_{\mathrm{oc}}$ of $195 \mathrm{mV}$. Treatment for 1 hour increased $\mathrm{V}_{\mathrm{oc}}$ to $365 \mathrm{mV}$, with additional treatment up to 8 hours resulting in further increase in $\mathrm{V}_{\text {oc }}$ up to a maximum of $475 \mathrm{mV}$. After 24 hours it fell slightly to $461 \mathrm{mV}$. 


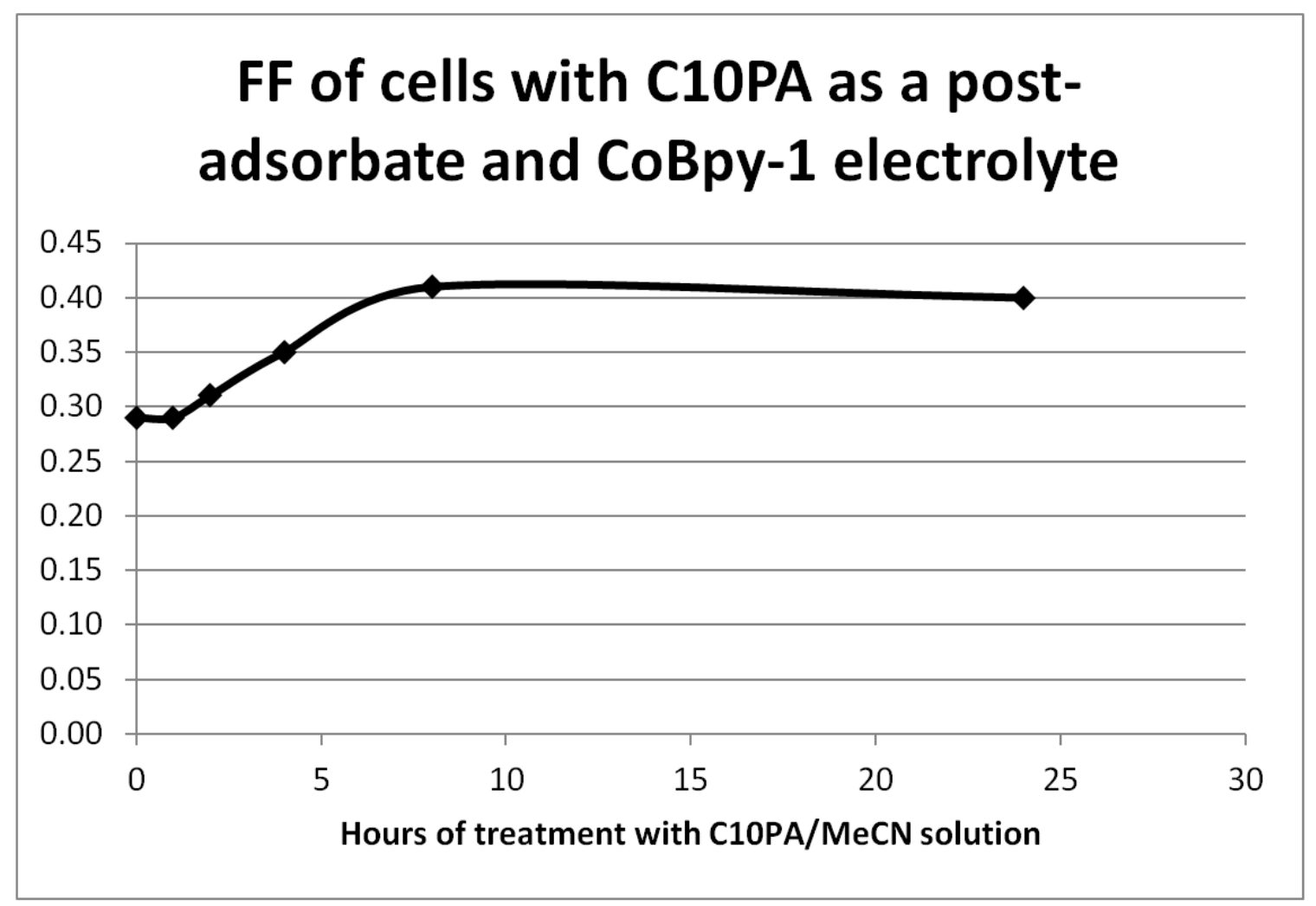

Figure 5.29 Fill factor of cells prepared using C10PA as a post-adsorbate and CoBpy-1 as electrolyte

The fill factor is improved by treatment with C10PA as a post-adsorbate, from 0.29 for an untreated cell to 0.41 after 8 hours of treatment. After 24 hours of treatment FF falls slightly to 0.40 . 


\section{$\mathrm{J}_{\mathrm{sc}}$ of cells with C10PA as a post- adsorbate and CoBpy-1 electrolyte}

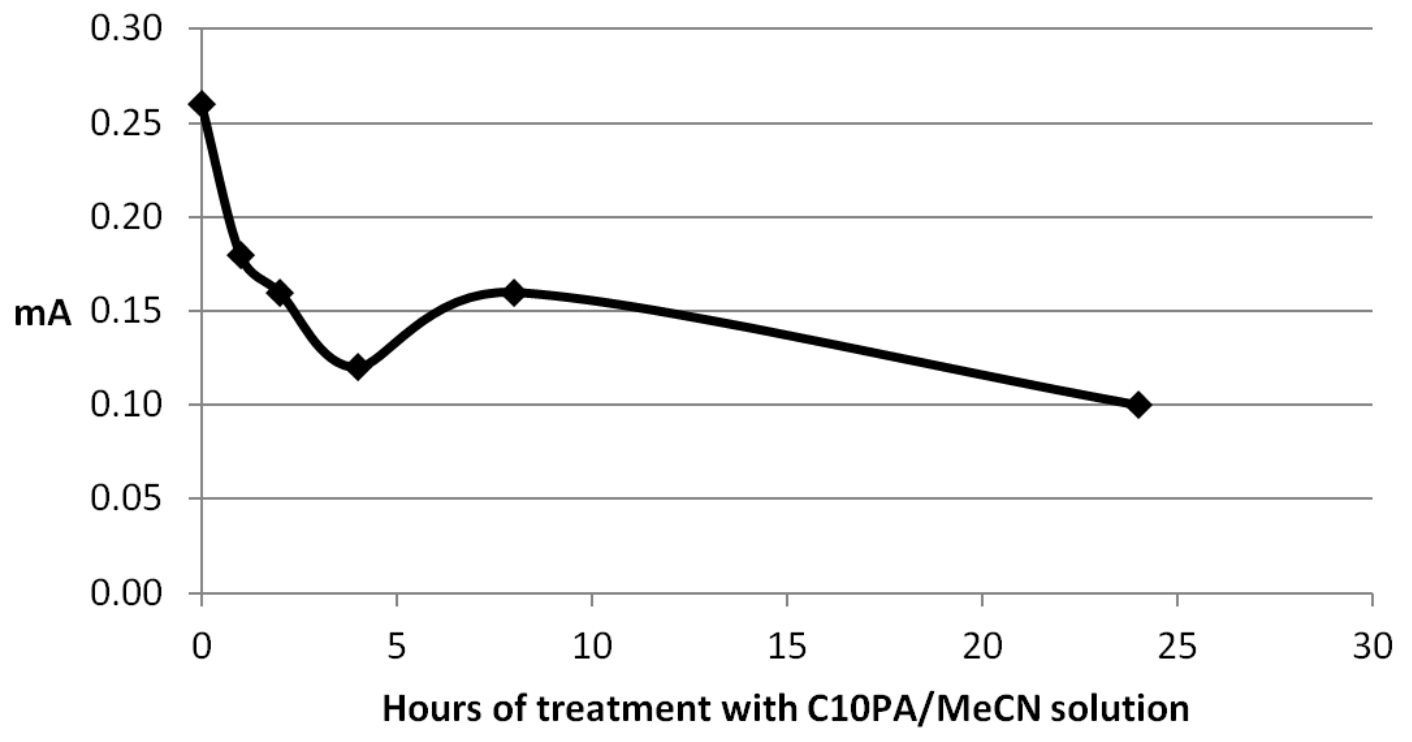

Figure 5.30 $\mathrm{J}_{\mathrm{sc}}$ of cells prepared using C10PA as a post-adsorbate and CoBpy-1 as electrolyte

Treatment with C10PA as a post-adsorbate results in a decrease in the $\mathrm{J}_{\mathrm{sc}}$ values of TCPP cells using CoBpy-1 electrolyte. An untreated cell produced $0.26 \mathrm{~mA} / \mathrm{cm}^{2}$, which fell to $0.18 \mathrm{~mA} / \mathrm{cm}^{2}$ for a cell after 1 hour of treatment, and steadily decreased to $0.12 \mathrm{~mA} / \mathrm{cm}^{2}$ after 4 hours and to $0.10 \mathrm{~mA} / \mathrm{cm}^{2}$ after 24 hours. There is an anomalously high value after 8 hours of treatment, but the overall effect on $\mathrm{J}_{\mathrm{sc}}$ is clear. 


\subsection{Summary of effects produced by post-adsorption treatment of TCPP cells using CoBpy-1 electrolyte}

For cells using CoBpy-1 electrolyte efficiency is seen to be improved by treatment with C10PA ( $2 \mathrm{mM})$ in MeCN, with peak efficiency being by cells given 8 hours of postadsorbate treatment. This improvement is the result of improved $\mathrm{V}_{\text {oc }}$ and FF, despite the negative effect on $\mathrm{J}_{\mathrm{sc}}$. Overall efficiencies are substantially lower than those obtained with I3I-1 electrolyte, primarily due to very low $\mathrm{J}_{\mathrm{sc}}$ values.

\subsection{Results for cells using CoBpy-3 electrolyte}

Performance data for cells built using CoBpy-3 electrolyte are in Table 5.22 and are presented graphically in Figure 5.31 (efficiency), Figure $5.32\left(\mathrm{~V}_{\mathrm{oc}}\right)$, Figure $5.33(\mathrm{FF})$, and Figure $5.34\left(\mathrm{~J}_{\mathrm{sc}}\right)$. 


$\begin{array}{rrrrl}\begin{array}{c}\text { Treatment } \\ \text { time } \\ \text { (hours) }\end{array} & \begin{array}{c}\mathbf{V}_{\text {oc }} \\ (\mathbf{m V})\end{array} & \begin{array}{c}\mathbf{J}_{\text {sc }} \\ (\mathbf{m A})\end{array} & \begin{array}{c}\text { FF } \\ 0\end{array} & \begin{array}{c}\text { Effic- } \\ \text { iency } \\ (\%)\end{array} \\ 1 & 270 & 0.28 & 0.29 & 0.03 \\ 2 & 468 & 0.18 & 0.32 & 0.04 \\ 2 & 484 & 0.15 & 0.36 & 0.04 \\ 4 & 511 & 0.18 & 0.42 & 0.06 \\ 8 & 512 & 0.14 & 0.44 & 0.05 \\ 24 & 520 & 0.13 & 0.51 & 0.05\end{array}$

Table 5.22 Performance data for cells treated with C10PA ( $2 \mathrm{mM})$ in MeCN for cells using CoBpy-3 electrolyte

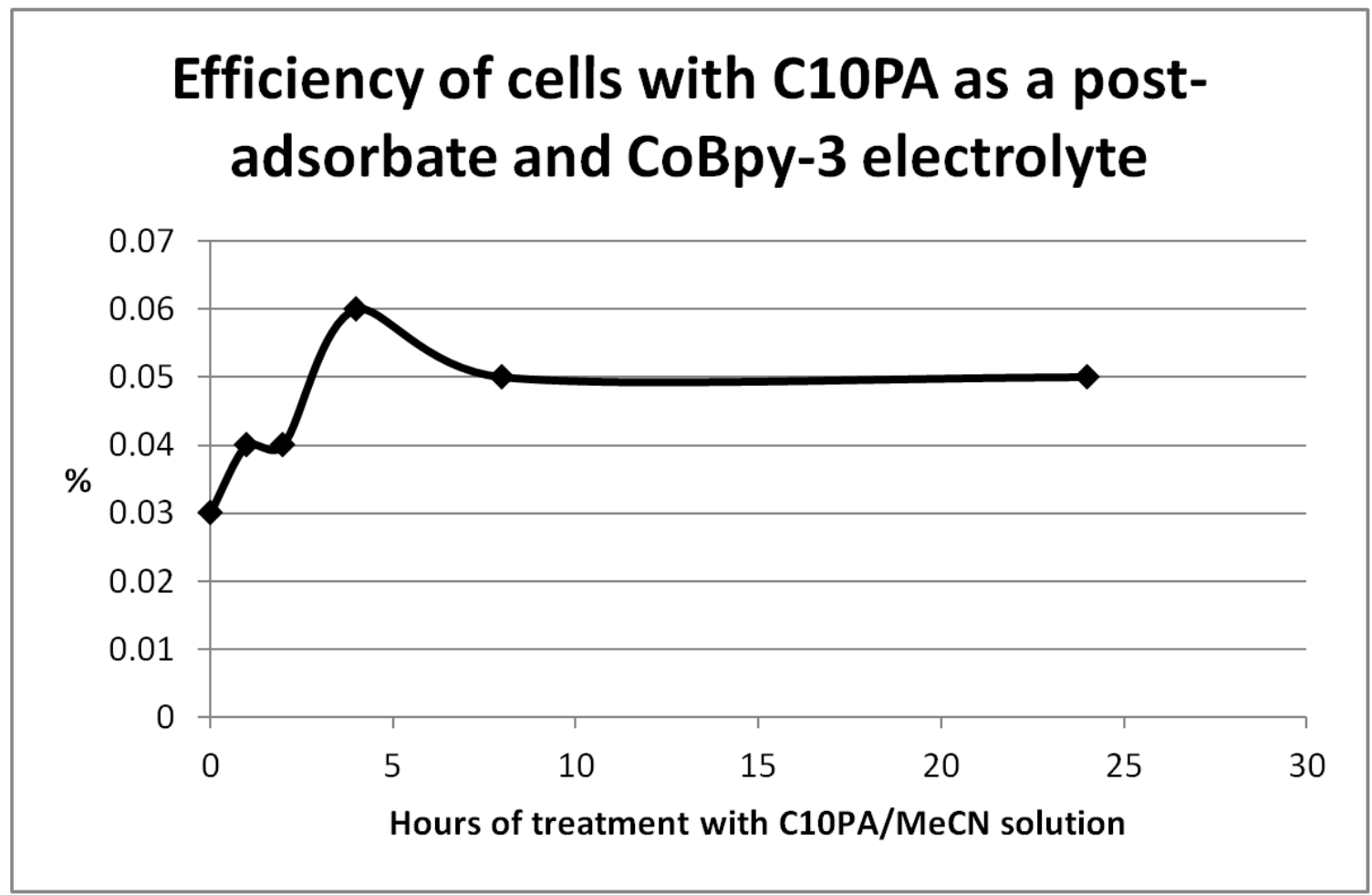

Figure 5.31 Efficiency of cells prepared using C10PA as a post-adsorbate and CoBpy-3 as electrolyte 
Treatment with C10PA as a post-adsorbate improves the efficiency of TCPP cells using CoBpy-3 electrolyte from $0.03 \%$ for an untreated cell to $0.05 \%$ after 8 hours of treatment and holding steady after 24 hours of treatment. An increase to $0.06 \%$ was attained by the cell treated for 4 hours, primarily due to an exceptional $\mathrm{J}_{\mathrm{sc}}$ for that cell.

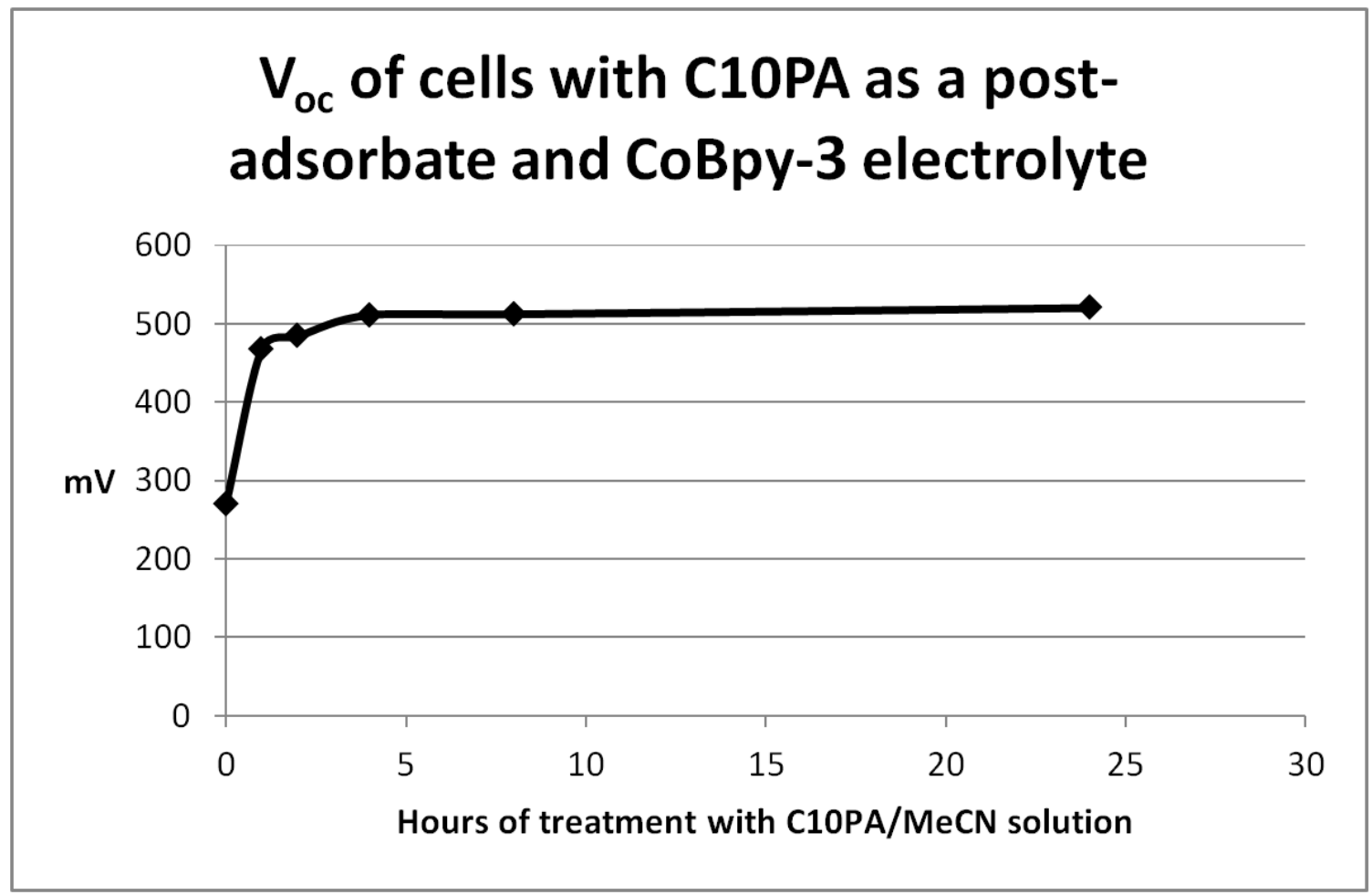

Figure 5.32 $\mathrm{V}_{\mathrm{oc}}$ of cells prepared using C10PA as a post-adsorbate and CoBpy-3 as electrolyte

Treatment with C10PA as a post-adsorbate improves the $\mathrm{V}_{\mathrm{oc}}$ of TCPP cells using CoBpy3 electrolyte from $270 \mathrm{mV}$ for an untreated cell to $468 \mathrm{mV}$ after 1 hour of treatment. 
Additional treatment results in additional increases, with little effect seen after 4 hours of treatment.

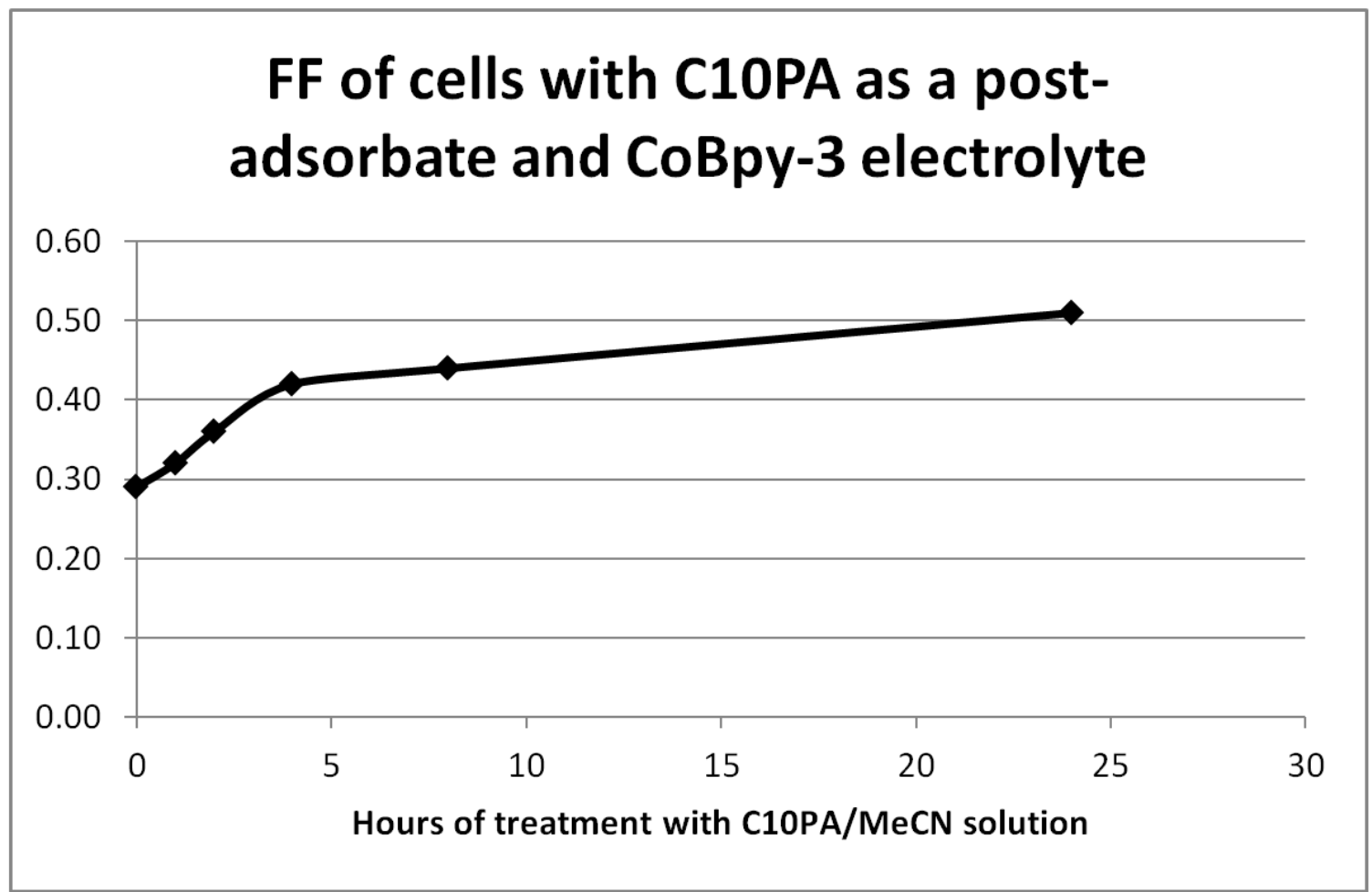

Figure 5.33 Fill factor of cells prepared using C10PA as a post-adsorbate and CoBpy-3 as electrolyte

Treatment with C10PA as a post-adsorbate improves the fill factor of TCPP cells using CoBpy-3 electrolyte. An untreated cell had a fill factor of 0.29 , and this was increased steadily to 0.42 after 4 hours and 0.51 after 24 hours of treatment. 


\section{$\mathrm{J}_{\mathrm{sc}}$ of cells with C10PA as a post- adsorbate and CoBpy-3 electrolyte}

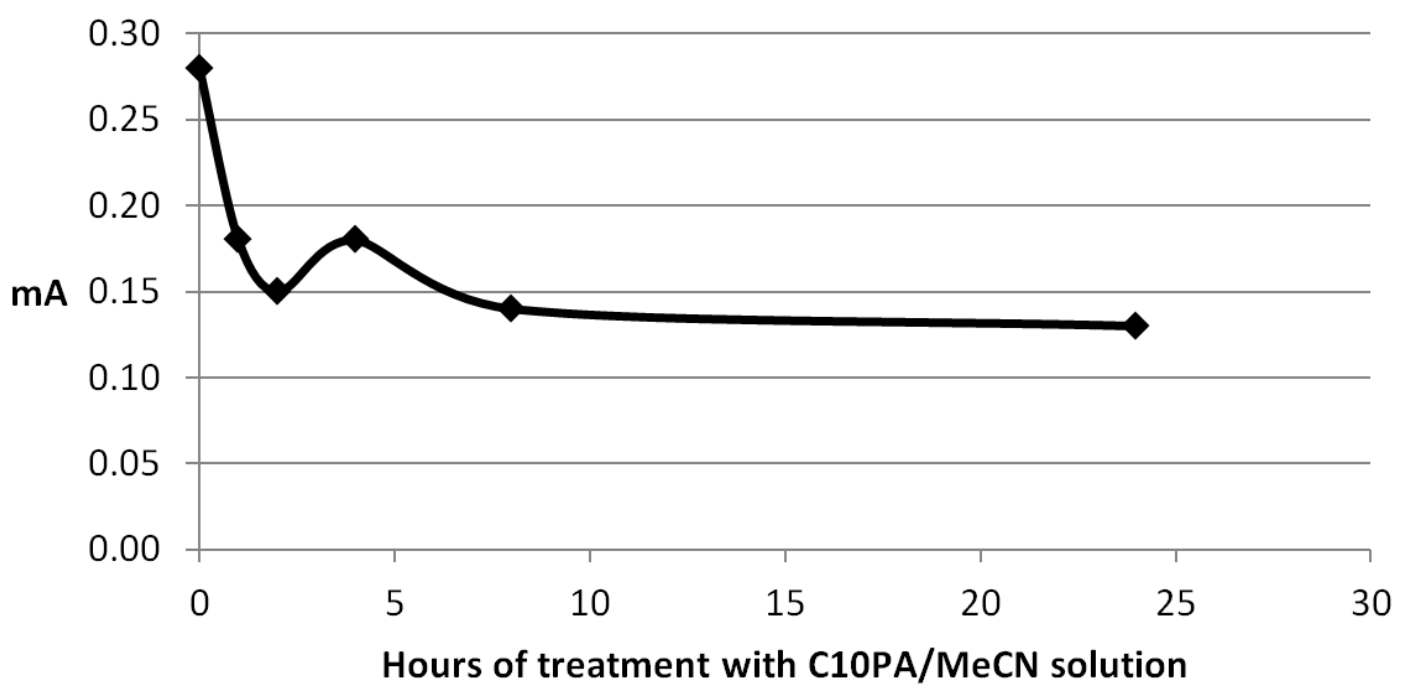

Figure 5.34 $\mathrm{J}_{\mathrm{sc}}$ of cells prepared using C10PA as a post-adsorbate and CoBpy-3 as electrolyte

Treatment with C10PA as a post-adsorbate decreases the $\mathrm{J}_{\mathrm{sc}}$ of TCPP cells using CoBpy3 electrolyte. An untreated cell had a $\mathrm{J}_{\mathrm{sc}}$ of $0.28 \mathrm{~mA} / \mathrm{cm}^{2}$, and 1 hour of treatment caused a reduction to $0.18 \mathrm{~mA} / \mathrm{cm}^{2}$. After 2 hours $\mathrm{J}_{\mathrm{sc}}$ fell to $0.15 \mathrm{~mA} / \mathrm{cm}^{2}$ and then continued to fall slowly to a low of $0.13 \mathrm{~mA} / \mathrm{cm}^{2}$ after 24 hours of treatment. After 4 hours of treatment an anomalous $\mathrm{J}_{\mathrm{sc}}$ of $0.18 \mathrm{~mA} / \mathrm{cm}^{2}$ was produced. 


\subsection{Summary of effects produced by post-adsorption treatment of TCPP cells using CoBpy-3 electrolyte}

For cells prepared with CoBpy-3 electrolyte efficiency is improved by treatment with C10PA. As with CoBpy-1 cells, there is an improvement in $\mathrm{V}_{\text {oc }}$ and $\mathrm{FF}$, as well as a decrease in $\mathrm{J}_{\mathrm{sc}}$. The effects produced by C10PA as a post-adsorbate and CoBpy-3 electrolyte were generally similar to the effects on cells using CoBpy-1 electrolyte. However, the efficiency was better for CoBpy-3 cells, due to the fact that $\mathrm{J}_{\mathrm{sc}}, \mathrm{V}_{\mathrm{oc}}$, and FF were all slightly better for cells using CoBpy-3 electrolyte than for those using CoBpy-1 electrolyte. 


\section{CHAPTER 6 CONCLUSIONS}

The performance (as measured by the metrics of efficiency, fill factor, open-circuit voltage, and short-circuit current) of dye-sensitized solar cells (DSSCs) prepared with TCPP can be modified by the use of phosphonic and arsonic acids as coadsorbates. The effects produced by coadsorbates depend in great measure on the choice of coadsorbate and the method of application. Pre-adsorption, sim-adsorption, and post-adsorption methods produce different results. Choice of solvent, concentration, and length of treatment time also influence the effects obtained. The presumed ideal target structure would be one in which a maximum amount of sensitizing dye is adsorbed to the surface of $\mathrm{TiO}_{2}$, with coadsorbate molecules occupying surface spaces between the dye molecules. That structure would permit maximum light absorption while obstructing recombination reactions on exposed areas on the $\mathrm{TiO}_{2}$ surface.

In practice the use of coadsorbates generally results in reduced dye loading due to competition for binding sites between the dye molecules and the coadsorbate molecules. At first blush this would seem to be entirely undesirable, based on the reasoning that lower dye loading will have the effect of reducing light absorption and therefore photocurrent. In fact that was found to be true in many cases, but it was also found that moderate reduction of dye loading can actually result in improved photocurrent. An electrode treated with TCPP in absolute ethanol ( $2.5 \mathrm{~mL}$ of $100 \mu \mathrm{M}$ TCPP, overnight) will typically adsorb about one third of the TCPP in solution. Treating such an electrode with absolute ethanol for one to two hours results in desorption of a small amount of 
TCPP and a significant improvement in $\mathrm{J}_{\mathrm{sc}}$ and efficiency. The most likely explanation is that the desorbed TCPP molecules were pi-stacked with molecules on the surface, leading to non-productive decay paths for photoexcited states and consequent loss of efficiency.

It remains true that excessive desorption of sensitizing dye must result in an inefficient DSSC, so treatment with coadsorbates required control of the coadsorption process so as to prevent excessive dye desorption. Choice of coadsorbate, solvent, duration of treatment, and protocol (pre-, sim-, or post-) adsorption were all found to be important parameters. The use of orthogonal solvents (e.g., using water, in which TCPP is insoluble, as the solvent for a post-adsorption treatment) was found to be ineffective. Treatment of $\mathrm{TiO}_{2}$ electrodes with phosphorus compounds followed by calcination as a method of surface modification prior to application of TCPP (in lieu of using coadsorbates) was found to be ineffective.

For TCPP cells prepared without coadsorbates $\mathrm{V}_{\text {oc }}$ and FF are generally found to improve significantly for the first few hours after a cell is sealed. $\mathrm{J}_{\mathrm{sc}}$ may either increase or decrease for the first few hours, but thereafter begins a decline. Efficiency is a product of the other three metrics, and thus may either increase or decrease for the first few hours, depending on the relative rates at which the other metrics increase and decrease. $\mathrm{V}_{\mathrm{oc}}$ and FF are usually fairly stable over an extended period of time, but $\mathbf{J}_{\mathrm{sc}}$ typically declines significantly after a few hours and drags efficiency down with it. Efficiency is also higher under low level illumination than at a full sun. 
The coadsorbates tested included a series of alkyl phosphonic acids (methylphosphonic acid, $t$-butylphosphonic acid, hexylphosphonic acid, octylphosphonic acid, decylphosphonic acid, dodecylphosphonic acid, and hexadecylphosphonic acid), as well as phenylphosphonic acid and phenylarsonic acid. 3-Phosphonopropanoic acid was also employed as a coadsorbate.

Often a trend in DSSC metrics (including the extent of dye desorption) can be seen as a function of the length of the alkyl chain. Phenylphosphonic acid and phenylarsonic acid often show similar but not identical effects. 3-Phosphonopropanoic acid generally resulted in cells with lower efficiency than similar cells treated with different coadsorbates. In many cases decylphosphonic acid was among the most beneficial of the coadsorbates, i.e., cells in which it was employed produced the highest (or at least among the highest) efficiency among comparable cells using the other coadsorbates. Taking decylphosphonic acid as a representative example, some general statements can be made regarding results obtained from the various test protocols. Although cells were typically tested multiple times over a period of hours or days, the general statements below are based on results obtained at the first test of each cell, which was consistently done about 5-6 minutes after the cell was filled with electrolyte and sealed.

Cells prepared by treatment with coadsorbates but without any subsequent treatment with TCPP (non-sensitized cells) experienced a reduction of efficiency of about one third 
relative to cells without coadsorbates. $\mathrm{V}_{\mathrm{oc}}$ was reduced by about $10 \%, \mathrm{~J}_{\mathrm{sc}}$ fell by $27 \%$, and FF was largely unaffected. The notable aspect of these cells' behavior was their stability as they aged up to 13 days. All metrics including $\mathbf{J}_{\mathrm{sc}}$ remained little changed over this period, in contrast to TCPP-sensitized cells which experienced major losses in $\mathbf{J}_{\mathrm{sc}}$ and efficiency over the same time period. This demonstrates that the deterioration observed in TCPP cells as they age is due to some failure related to the TCPP. At the same time it demonstrates that phosphonic acid coadsorbates are stable in the cell, neither desorbing nor degrading.

Post-adsorption treatments resulted in the efficiency of TCPP cells using I3I-1 electrolyte to be reduced by nearly half, $\mathrm{V}_{\mathrm{oc}}$ was reduced by about $15 \%$, and $\mathrm{J}_{\mathrm{sc}}$ was reduced by about one third, with FF being unaffected. For cells employing CoBpy electrolytes, very low efficiencies were obtained due mainly to low $\mathrm{J}_{\mathrm{sc}}$ values. However, for cells employing CoBpy electrolytes the use of C10PA as a post-adsorbate caused a dramatic improvement in $\mathrm{V}_{\mathrm{oc}}$ values. For CoBpy-1, $\mathrm{V}_{\mathrm{oc}}$ more than doubled from $195 \mathrm{mV}$ for the control to $461 \mathrm{mV}$. For CoBpy-3, $\mathrm{V}_{\text {oc }}$ increased from $270 \mathrm{mV}$ to $520 \mathrm{mV}$. Treated cells also enjoyed an improvement in FF, and an overall improvement in efficiency despite reduced $\mathrm{J}_{\mathrm{sc}}$ values.

For cells prepared using C10PA as a pre-adsorbate and I3I-1 electrolyte, efficiency was reduced by about one third, caused by a serious decrease in $\mathrm{J}_{\mathrm{sc}}$ of nearly half. $\mathrm{V}_{\mathrm{oc}}$ and FF were each improved by about $10 \%$. 
The most interesting and promising results were obtained from cells using simadsorbates. For cells prepared using low concentrations of C10PA modest improvements were seen in all metrics except FF which was essentially unaffected. At higher concentrations more significant effects were obtained; efficiency was improved by $10 \%$, $\mathrm{V}_{\mathrm{oc}}$ by $8 \%$, and $\mathrm{J}_{\mathrm{sc}}$ improved by $11 \%$, from $6.6 \mathrm{~mA} / \mathrm{cm}^{2}$ to $7.3 \mathrm{~mA} / \mathrm{cm}^{2}$, with $\mathrm{FF}$ declining slightly. Similar treatment with C16PA resulted in an even more remarkable $32 \%$ increase in $\mathrm{J}_{\mathrm{sc}}$ to an unusually high (for a TCPP DSSC) $8.7 \mathrm{~mA} / \mathrm{cm}^{2}$ accompanied by increases in $\mathrm{V}_{\mathrm{oc}}$ and efficiency despite a small decrease in FF.

It is of particular interest to note that the dye loading of the cell using C10PA as a simadsorbate and producing a $\mathbf{J}_{\mathrm{sc}}$ of $7.3 \mathrm{~mA} / \mathrm{cm}^{2}$ was only $39 \%$ that of the untreated cell, or $32 \mathrm{nmol} / \mathrm{cm}^{2}$. A cell pre-adsorbed with C10PA, which had a similar $38 \mathrm{nmol} / \mathrm{cm}^{2}$ dye loading produced a $\mathrm{J}_{\mathrm{sc}}$ of only $3.4 \mathrm{~mA} / \mathrm{cm}^{2}$, with a $\mathrm{V}_{\mathrm{oc}}$ of $607 \mathrm{mV}$. The $\mathrm{V}_{\mathrm{oc}}$ values of the two cells were similar, but the sim-adsorbed cell produced nearly twice as much photocurrent as the pre-adsorbed cell. These results are consistent with the observation that a simple 2 hour desorption in ethanol results in a substantial improvement in $\mathbf{J}_{\mathrm{sc}}$, though this simple treatment results in cells with about twice as much dye as cells treated with C10PA as either a pre- or sim- adsorbate. It suggests that the ethanol desorption does not go far enough to remove excess TCPP. It also suggests that the order in which operations are performed matters; much higher $\mathrm{J}_{\mathrm{sc}}$ values were produced by cells treated with sim-adsorbates than with pre-adsorbates. 
It is reasonable to think that, of the binding sites available on the surface of $\mathrm{TiO}_{2}$, some might be particularly advantageous sites for TCPP to bind, in the sense that those sites would result in particularly effective injection of photoelectrons if occupied by TCPP. A pre-adsorption treatment with a PA might result in many of those optimal sites being unavailable for TCPP to bind, leaving only less efficient sites available, resulting in a reduction of $\mathrm{J}_{\mathrm{sc}}$. A sim-adsorption process would allow TCPP to compete for the favorable sites. Perhaps an even more important factor is that sim-adsorption would facilitate the co-grafting of associated TCPP:PA pairs or larger assemblages, resulting in each TCPP molecule being surrounded in an optimal way by its associated PA molecules. Pre-adsorption of PAs would not permit this sort of coordinated adsorption.

Many of the effects produced by phosphonic acid coadsorbates are small, but when the results obtained from each PA are compared, trends can be observed. For pre-adsorbates, starting with C1PA and considering in order PAs with longer alkyl chains, it is found that higher $\mathrm{V}_{\mathrm{oc}}, \mathrm{J}_{\mathrm{sc}}$, and efficiencies are obtained from longer chains up to C10PA, followed by a decline for C12PA and C16PA. Fill factor reaches its apex with C12PA. A similar examination of the results from cells with sim-adsorbates shows similar trends, except that the improvements in $\mathrm{J}_{\mathrm{sc}}$ and efficiency continue with C12PA and C16PA. Results obtained from 3PPA are not especially favorable by any measure as either a pre- or simadsorbate. Phenylphosphonic acid and especially phenylarsonic acid resulted in higher 
$\mathrm{J}_{\mathrm{sc}}$ and efficiency than any of the other compounds tested as pre-adsorbates, but not as sim-adsorbates.

It is informative to consider the linear alkyl phosphonic acids as a homologous series, distinct from the other coadsorbates tested. Trends in cell performance metrics emerge, and can be interpreted in light of the relative lengths of each PA as compared with the dimensions of TCPP. The conclusions reached from this series can be applied to the analysis of the other coadsorbates tested.

The metrics for the linear alkyl PAs are depicted graphically in Figure 6.1 (simadsorbates) and Figure 6.2 (pre-adsorbates). Each plot is provided with a least-squares line, though in most cases the line shows only a rough trend. The r-squared values for the least squares lines are not as good as would be desired. This is a reflection of the fact that each data point represents a single cell, and despite considerable effort to standardize every aspect of cell preparation and testing, some variability inevitably occurs. The reproducibility tests reported in Table 5.1 and in Table 5.13 provide confidence that uncertainty is within acceptable bounds and that the trends suggested by the least squares lines are valid, despite some uncertainty in the absolute values. 

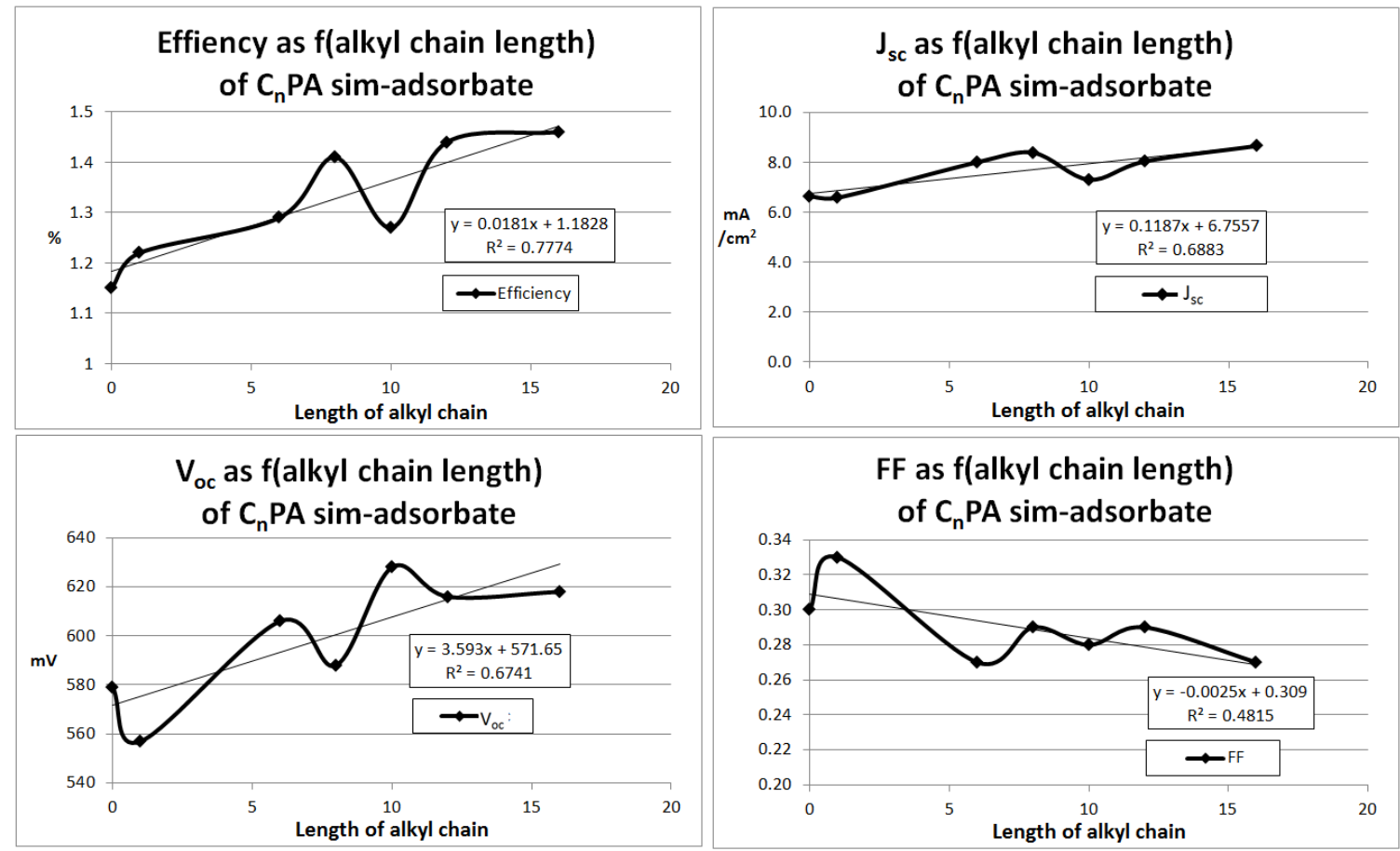

Figure 6.1 Performance metrics of cells prepared using linear alkyl phosphonic acids as sim-adsorbates

Considering first the sim-adsorbates, as the length of the alkyl chain increases from 0 (control) to 16, there is a trend toward higher efficiency, which mirrors the same trend in $\mathrm{J}_{\mathrm{sc}}$ values. Most significant is the fact that in all cases, efficiencies for the treated cells are higher than that of the control. The $\mathrm{V}_{\mathrm{oc}}$ values also show an upward trend, with FF showing a small decline. However, the cells of greatest interest are those in the range of C6PA - C16PA, and within this range FF is essentially flat. C10PA appears to be anomalously low by all metrics, probably due to some small variation in cell preparation.

Fill factor can be considered to be largely a reflection of the leakage current within a DSSC (large value for $\mathrm{R}_{\mathrm{p}}$ results in less current leakage and higher FF). Efficiency is a 
derived quantity, the product of the three primary cell metrics, $\mathrm{J}_{\mathrm{sc}}, \mathrm{V}_{\mathrm{oc}}$, and FF. For cells treated with sim-adsorbates, the cells with the highest efficiencies were prepared with C6PA - C16PA. For these cells, $\mathrm{J}_{\mathrm{sc}}$ shows only a small upward trend, if any, and $\mathrm{V}_{\mathrm{oc}}$ shows a small upward trend. FF is essentially flat, suggesting that these PAs have little effect on current leakage when applied as sim-adsorbates.
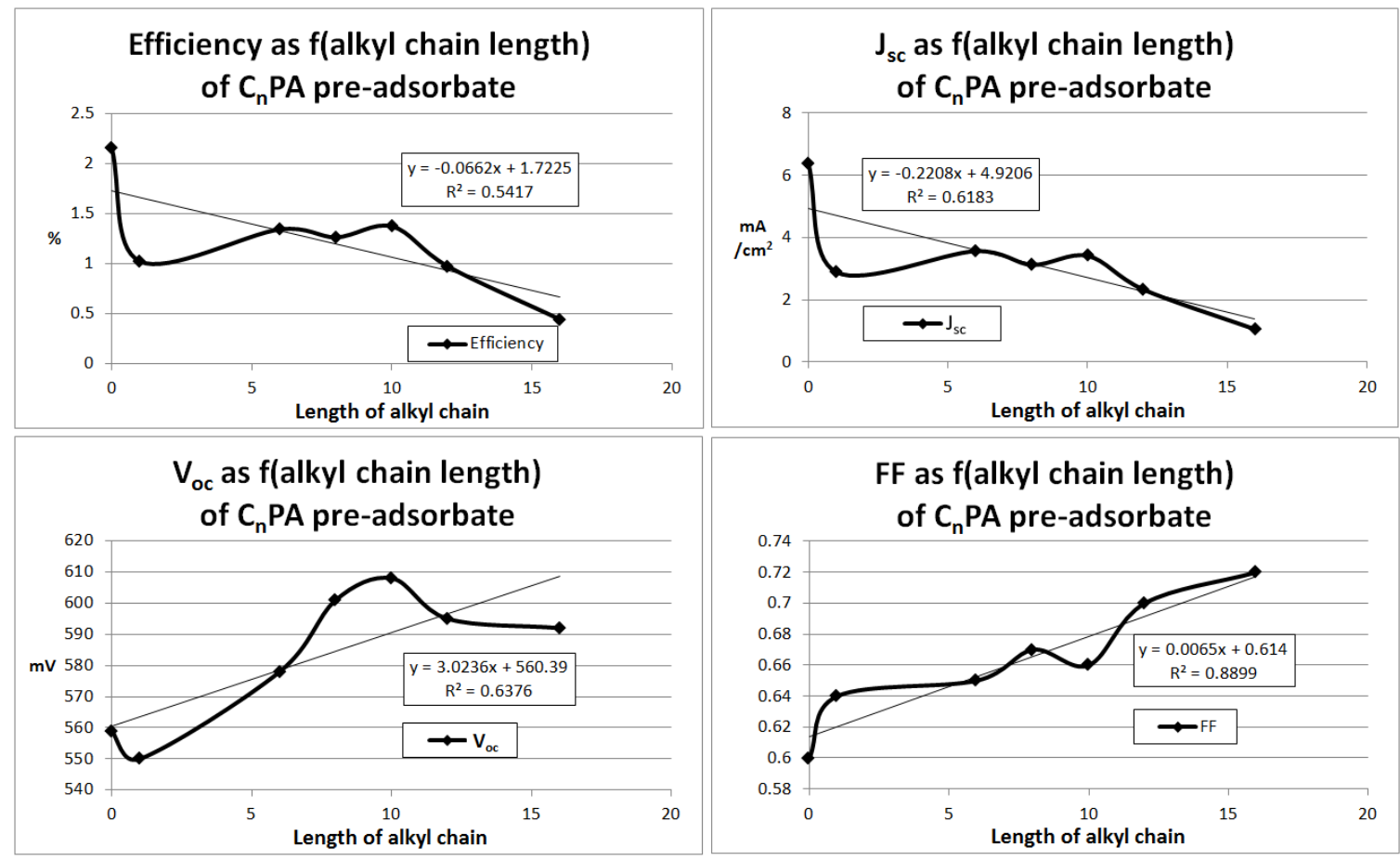

Figure 6.2 Performance metrics of cells prepared using linear alkyl phosphonic acids as pre-adsorbates

Cells prepared using phosphonic acids as pre-adsorbates were not as efficient as the control, but nevertheless performed well enough to be of interest. $\mathrm{J}_{\mathrm{sc}}$ values for the treated cells were essentially flat for the treated cells up to C10PA, and then declined for 
C12PA and C16PA, in all cases being only about one half that of the corresponding cells prepared with sim-adsorbates. $\mathrm{V}_{\text {oc }}$ showed a sharp increase from C1PA - C10PA, and then declined slightly for C12PA and C16PA. FF increased over the series, implying that these PAs result in reduced leakage current when applied as pre-adsorbates, in contrast with the results seen for sim-adsorbates. This effect, combined with effects on the amount of photocurrent produced per TCPP molecule (below), are consistent with a model in which pre-adsorbed PAs lie close to the surface of $\mathrm{TiO}_{2}$, covering the surface between TCPP molecules sufficiently to discourage recombination reactions at the surface. Longer-chain PAs cover the surface more effectively, and would be more subject to entanglement than shorter chains, and very possibly pinned down by TCPP molecules. By contrast, PAs applied as sim-adsorbates would be entrapped between TCPP molecules, roughly orthogonal to the surface. Each PA molecule would have approximately the same footprint, so different chain lengths would not significantly affect the amount of area blocked on the surface, with the result that chain length would not have a significant effect on the ability to impede recombination reactions. Thus, FF would be expected to be about the same for all of the linear alkyl sim-adsorbates, as is observed. The only exception is C1PA, which, due to its compact size, may be able to provide more uniform coverage of the surface than the longer chain alkyl PAs.

The most significant difference between the cells prepared using pre- versus simcoadsorbate treatments is the amount of photocurrent produced per unit of adsorbed TCPP. The control cells for the two tests produced very similar values for $\mathrm{J}_{\mathrm{sc}}(6.4$ 
$\mathrm{mA} / \mathrm{cm}^{2}$ with for the pre-adsorbate test; $6.1 \mathrm{~mA} / \mathrm{cm}^{2}$ with sim-adsorbates), but the treated cells produced significantly different $\mathrm{J}_{\mathrm{sc}}$ values. For pre-adsorbates, Table 5.8 shows that for C6PA - C12PA the photocurrent produced per TCPP was between $111 \mu \mathrm{A} / \mathrm{nmol}$ and $123 \mu \mathrm{A} / \mathrm{nmol}$, and was also fairly high $(95 \mu \mathrm{A} / \mathrm{nmol})$ for C1PA compared with 49 $\mu \mathrm{A} / \mathrm{nmol}$ for the control. A modest increase in the photocurrent:TCPP ratio was seen for 3PPA and PhenAA, as well as tC4PA. C16PA showed little or no increase in this ratio, and PhenPA showed a small (probably insignificant) decrease. These results are for the most part echoed in the dye loading resulting from each of the coadsorbates. For C6PA C10PA, dye loading was $28-30 \mathrm{nmol}$ of $\mathrm{TCPP} / \mathrm{cm}^{2}$.

For the sim-adsorbates, dye loading and the photocurrent:dye ratio were determined for C10PA, for which treatment at a concentration of $40 \mu \mathrm{M}$ resulted in dye loading of 32 $\mathrm{nmol} / \mathrm{cm}^{2}$ and photocurrent of $231 \mu \mathrm{A} / \mathrm{nmol}$. The high $\mathrm{J}_{\mathrm{sc}}$ values produced by cells employing other coadsorbates were probably the result of similarly high photocurrent:dye ratios. In the case of $\mathrm{C} 10 \mathrm{PA}$, the dye loading for pre- and sim- treated cells was comparable, 28 and $32 \mathrm{nmol} / \mathrm{cm}^{2}$, respectively. The dramatically different photocurrent: dye ratios 123 versus $231 \mu \mathrm{A} / \mathrm{nmol}$, respectively, suggest that the two methods of coadsorbate application result in very different assemblages on the $\mathrm{TiO}_{2}$ surface.

Table 5.18 shows that for sim-adsorbate treatments at concentrations of 40,80 , and 160 $\mu \mathrm{M}$ the photocurrent:dye ratio is in the range of $211-231 \mu \mathrm{A} / \mathrm{nmol}$, and a smaller increase (to $125 \mu \mathrm{A} / \mathrm{nmol}$ ) was produced by treatment at $20 \mu \mathrm{M}$. Note that this effect 
continues even as dye loading is reduced to $18 \mathrm{nmol} / \mathrm{cm}^{2}$ by treatment at higher $(160 \mu \mathrm{M})$ concentrations. Increasing concentrations of sim-adsorbates results in decreased dye loading, which means adsorbed TCPP molecules are farther apart. This is consistent with a model in which photocurrent production is enhanced by TCPP molecules being surrounded (and separated from one another) by coadsorbate molecules. This effect might be caused by two factors. The first factor is the physical separation of the TCPP molecules. The second factor would be that the electronic environment of TCPP molecules surrounded by alkyl chains would be different (less polar) than TCPP molecules surrounded by the highly polar solvent (propylene carbonate) in the electrolyte. This is also consistent with the fact that for pre-adsorbed PAs, the effect on $\mathbf{J}_{\mathrm{sc}}$ does not show a dependence on chain length of the PA. If, as proposed, the preadsorbed PAs are to a great extent prone on the surface of the $\mathrm{TiO}_{2}$ rather than extending up from the surface between TCPP molecules, then they are not able to provide the same effects produced by sim-adsorbates.

Figure 6.3 shows that reasonably good separation of TCPP molecules could be effected even by C8PA (and C6PA, not shown) but that longer chains would have a greater ability to keep the molecules well separated and to modify the polarity of the environment around TCPP molecules. The aryl coadsorbates are short enough to nestle below a singly-anchored TCPP molecule, which might be expected to result in heavier dye loading than for taller adsorbates, and they are not tall enough to provide any separation of adjacent TCPP molecules or any modification of the polarity of the environment. 
These coadsorbates do in fact permit much heavier dye loading than any of the alkyl coadsorbates, as predicted by this model, and the photocurrent:dye ratio is much lower than for the C6PA - C12PA alkyl PAs.

As a pre-adsorbate 3PPA results in low dye loading and corresponding reduction of $\mathrm{J}_{\mathrm{sc}}$ and efficiency. Similarly, C16PA as a pre-adsorbate results in even lower dye loading, $\mathrm{J}_{\mathrm{sc}}$, and efficiency than 3PPA. The reasons for this are unclear, but may be due to entanglement by these long chains, resulting in obstruction of a large part of the $\mathrm{TiO}_{2}$ surface, greatly restricting adsorption by TCPP. In sharp contrast, when used as a simadsorbate C16PA resulted in the highest $\mathrm{J}_{\mathrm{sc}}\left(8.7 \mathrm{~mA} / \mathrm{cm}^{2}\right)$ of any coadsorbate, presumably because as a sim-adsorbate it is able to coordinate with TCPP as previously argued. 


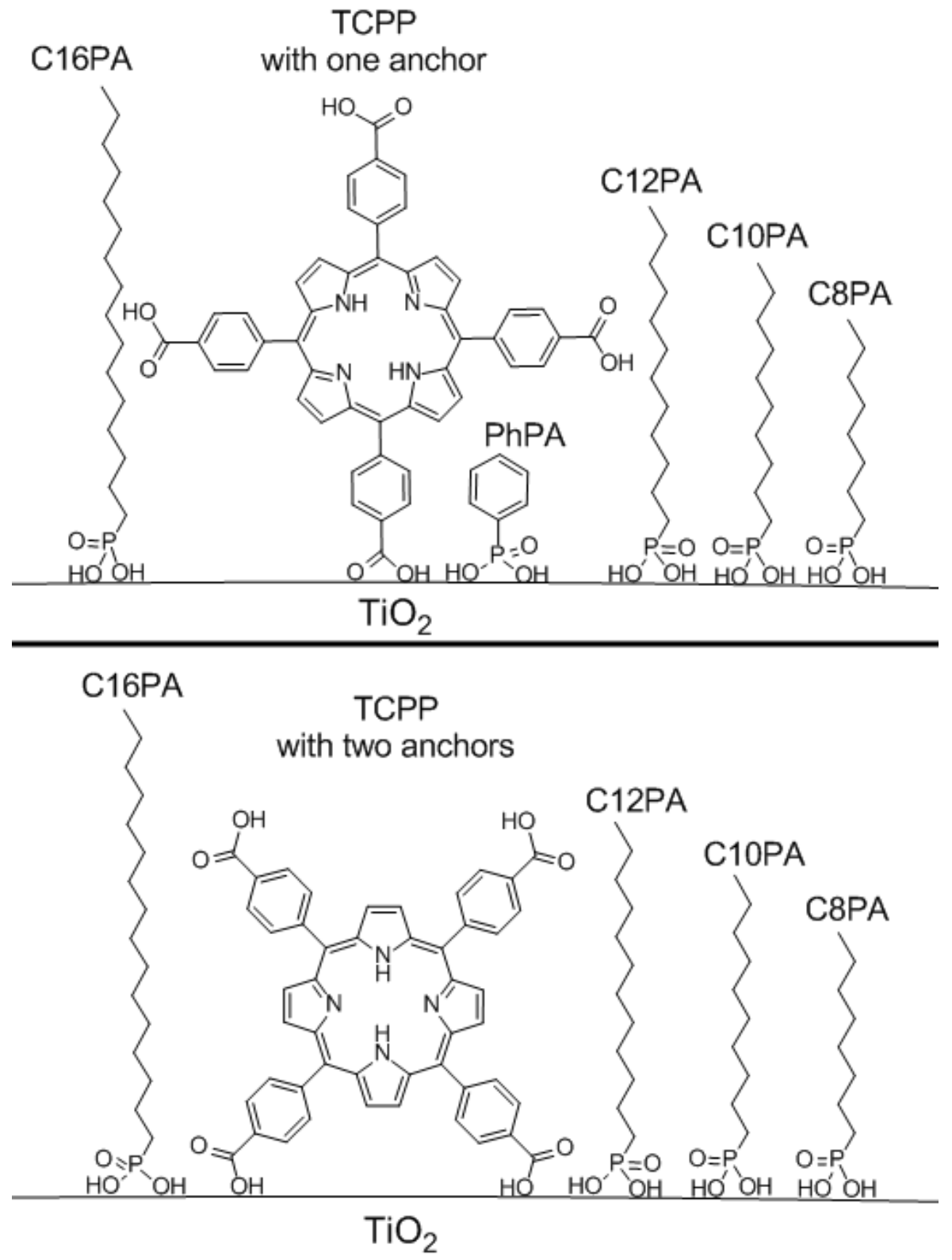

Figure 6.3 Above: Singly anchored $\mathrm{TiO}_{2}$ with several linear alkyl phosphonic acids and phenylphosphonic acid. Below: Doubly anchored $\mathrm{TiO}_{2}$ with the same acids, except phenylphosphonic acid is not depicted. 
In Figure 6.3 the relative heights of TCPP and several of the linear alkyl phosphonic acids are depicted. TCPP is shown in two binding modes: one in which the TCPP is anchored by a single carboxyl group, and the other in which it is anchored by two carboxyl groups. In the singly-anchored mode, only C16PA is as tall as TCPP, and might therefore fully isolate two adjacent TCPP molecules. The slightly shorter C12PA and C10PA are long enough to provide significant shielding, however.

In the doubly-anchored mode, TCPP is only as tall as C12PA, with C10PA and C8PA being tall enough to have significant isolating effect. For reasons of clarity, PhPA is not depicted in the lower drawing with doubly-anchored TCPP, but it can be seen that it would not be able to fit below the TCPP and thus might hinder it from binding in the double-anchor mode, while permitting a single-anchor.

As would be expected, pre-adsorbed PAs result in low dye-loading, and would probably make it especially difficult for TCPP to find a large enough site to bind in the doubleanchor mode. Longer chains would easily entangle with one another on the $\mathrm{TiO}_{2}$ surface, like a bed of seaweed. This model is consistent with the trend toward lower dye loading with longer alkyl chains for pre-adsorbates, and with the observed effects on FF. For sim-adsorbates, on the other hand, TCPP has an opportunity to compete for sites before they have all been claimed. A more favorable configuration of doubly-anchored TCPP molecules well isolated by coadsorbates might well result, and this is consistent with the substantially improved $\mathbf{J}_{\mathrm{sc}}$ exhibited by cells treated with sim-adsorbates as compared 
with those treated with pre-adsorbates. In addition, sim-adsorption greatly increases the likelihood that the alkyl chains of the PAs would extend up between TCPP molecules, rather than lying entangled on the surface.

Many cells exhibited low FF at first test, but it consistently improved with age. The cause of this behavior is not fully understood, but is suspected to have resulted, ironically, from the practice of assembling cells under a nitrogen atmosphere and redfiltered light. The practice of assembling cells in this sheltered environment was adopted in order to protect them from moisture, oxygen, and energetic light during assembly, and is believed to be coincident with the onset of the low FF phenomenon. It is possible that mild exposure to one or more of those environmental hazards may hasten the aging process. It is worth noting that DSSCs are typically prepared in open lab environments. It would be of interest to positively identify the cause of the low FF, and determine what protections if any should be provided to cells during assembly to maximize long-term stability and efficiency.

Cells treated with PAs as sim-adsorbates at two very different concentrations showed significant improvement in $\mathrm{J}_{\mathrm{sc}}$ and efficiency, as well as modest improvement in $\mathrm{V}_{\mathrm{oc}}$ with the best results obtained at the higher concentration. It would be of interest to identify the optimum concentration for each sim-adsorbate. Additionally, linear alkyl PAs longer than C16PA should be investigated, since the best results were obtained from C16PA and 
the trend toward better performance as a function of longer chain length was still increasing at C16PA. 


\section{REFERENCES}

1. World Population Prospects: The 2015 Revision, Key Findings and Advance Tables; Working Paper No. ESA/P/WP.241; United Nations, Department of Economic and Social Affairs, Population Division: 2015.

2. Hofmann, D. J.; Butler, J. H.; Tans, P. P., A new look at atmospheric carbon dioxide. Atmos. Environ. 2009, 43, 2084-2086.

3. Lewis, N. S.; Crabtree, G., Basic Research Needs for Solar Energy Utilization. Office of Science, U. S. Department of Energy: 2005.

4. $\quad$ Feldt, S., M.; Gibson, E., A.; Gabrielsson, E.; Sun, L.; Boschloo, G.; Hagfeldt, A., Design of organic dyes and cobalt polypyridine redox mediators for high-efficiency dyesensitized solar cells. J. Amer. Chem. Soc. 2010, 132, (46), 16714-16724.

5. Sapp, S. A.; Elliott, C. M.; Contado, C.; Caramori, S.; Bignozzi, C. A., Substituted polypyridine complexes of cobalt(II/III) as efficient electron-transfer mediators in dye-sensitized solar cells. J. Amer. Chem. Soc. 2002, 124, (37), 1121511222.

6. Parkinson, B., On the efficiency and stability of photoelectrochemical devices. Acc. Chem. Res. 1984, 17, (12), 431-437.

7. O'Regan, B.; Grätzel, M., A low-cost, high-efficiency solar cell based on dyesensitized colloidal titanium dioxide films. Nature 1991, 353, (6346), 737-740.

8. Bessho, T.; Zakeeruddin, S. M.; Yeh, C.-Y.; Diau, E. W.-G.; Grätzel, M., Highly Efficient Mesoscopic Dye-Sensitized Solar Cells Based on Donor-Acceptor-Substituted Porphyrins. Angew. Chem., Int. Ed. 2010, 49, (37), 6646-6649.

9. $\quad$ Han, L.; Islam, A.; Chen, H.; Malapaka, C.; Chiranjeevi, B.; Zhang, S.; Yang, X.; Yanagida, M., High-efficiency dye-sensitized solar cell with a novel co-adsorbent. Energ. Environ. Sci. 2012, 5, 6057-6060.

10. Mathew, S.; Yella, A.; Gao, P.; Humphry-Baker, R.; Curchod, B. F. E.; AshariAstani, N.; Tavernelli, I.; Rothlisberger, U.; Nazeeruddin, M. K.; Grätzel, M., Dyesensitized solar cells with $13 \%$ efficiency achieved through the molecular engineering of porphyrin sensitizers. Nat. Chem. 2014, 6, 242-247.

11. Xie, Y.; Tang, Y.; Wu, W.; Wang, Y.; Liu, J.; Li, X.; Tian, H.; Zhu, W.-H., Porphyrin Cosensitization for a Photovoltaic Efficiency of 11.5\%: A Record for NonRuthenium Solar Cells Based on Iodine Electrolyte. J. Amer. Chem. Soc. 2015, 137 , 14055-14058. 
12. Nazeeruddin, M. K.; Kay, A.; Rodicio, I.; Humphry-Baker, R.; Mueller, E.; Liska, P.; Vlachopoulos, N.; Grätzel, M., Conversion of light to electricity by cis- $\mathrm{X}_{2}$ bis(2,2'bipyridyl-4,4'-dicarboxylate)ruthenium(II) charge-transfer sensitizers ( $\mathrm{X}=\mathrm{Cl}^{-}, \mathrm{Br}^{-}, \mathrm{I}^{-}$, $\mathrm{CN}^{-}$, and $\mathrm{SCN}^{-}$) on nanocrystalline titanium dioxide electrodes. J. Amer. Chem. Soc. 1993, 115, (14), 6382-6390.

13. Argazzi, R.; Bignozzi, C. A.; Heimer, T. A.; Castellano, F. N.; Meyer, G. J., Long-Lived Photoinduced Charge Separation across Nanocrystalline $\mathrm{TiO}_{2}$ Interfaces. J. Amer. Chem. Soc. 1995, 117, (47), 11815-11816.

14. Nazeeruddin, M. K.; Pechy, P.; Renouard, T.; Zakeeruddin, S. M.; HumphryBaker, R.; Comte, P.; Liska, P.; Cevey, L.; Costa, E.; Shklover, V.; Spiccia, L.; Deacon, G. B.; Bignozzi, C. A.; Grätzel, M., Engineering of Efficient Panchromatic Sensitizers for Nanocrystalline $\mathrm{TiO}_{2}$-Based Solar Cells. J. Amer. Chem. Soc. 2001, 123, (8), 1613-1624.

15. Nazeeruddin, M. K.; Bessho, T.; Cevey, L.; Ito, S.; Klein, C.; De Angelis, F.; Fantacci, S.; Comte, P.; Liska, P.; Imai, H.; Grätzel, M., A high molar extinction coefficient charge transfer sensitizer and its application in dye-sensitized solar cell. $J$. Photoch. Photobio. A 2007, 185, (2-3), 331-337.

16. Walter, M. G.; Rudine, A. B.; Wamser, C. C., Porphyrins and phthalocyanines in solar photovoltaic cells. J. Porphyrins Phthalocyanines 2010, 14, (9), 759-792.

17. Yella, A.; Lee, H.-W.; Tsao, H. N.; Yi, C.; Chandiran, A. K.; Nazeeruddin, M. K.; Diau, E. W.-G.; Yeh, C.-Y.; Zakeeruddin, S. M.; Grätzel, M., Porphyrin-Sensitized Solar Cells with Cobalt (II/III)-Based Redox Electrolyte Exceed 12\% Efficiency. Science 2011, 334, (6056), 629-634.

18. Klahr, B. M.; Hamann, T. W., Performance Enhancement and Limitations of Cobalt Bipyridyl Redox Shuttles in Dye-Sensitized Solar Cells. J. Phys. Chem. C 2009, 113, (31), 14040-14045.

19. Nusbaumer, H.; Moser, J.-E.; Zakeeruddin, S. M.; Nazeeruddin, M. K.; Grätzel, M., CoII(dbbip) ${ }_{2}{ }^{2+}$ Complex Rivals Tri-iodide/Iodide Redox Mediator in Dye-Sensitized Photovoltaic Cells. J. Phys. Chem. B 2001, 105, (43), 10461-10464.

20. Nusbaumer, H.; Zakeeruddin, S. M.; Moser, J.-E.; Grätzel, M., An alternative efficient redox couple for the dye-sensitized solar cell system. Chem.--Eur. J. 2003, 9, (16), 3756-3763.

21. Nelson, J. J.; Amick, T. J.; Elliott, C. M., Mass Transport of Polypyridyl Cobalt Complexes in Dye-Sensitized Solar Cells with Mesoporous $\mathrm{TiO}_{2}$ Photoanodes. J. Phys. Chem. C 2008, 112, (46), 18255-18263. 
22. DeVries, M. J.; Pellin, M. J.; Hupp, J. T., Dye-Sensitized Solar Cells: DrivingForce Effects on Electron Recombination Dynamics with Cobalt-Based Shuttles.

Langmuir 2010, 26, (11), 9082-9087.

23. Huang, S. Y.; Schlichthoerl, G.; Nozik, A. J.; Grätzel, M.; Frank, A. J., Charge Recombination in Dye-Sensitized Nanocrystalline $\mathrm{TiO}_{2}$ Solar Cells. J. Phys. Chem. B 1997, 101, (14), 2576-2582.

24. Schlichthoerl, G.; Huang, S. Y.; Sprague, J.; Frank, A. J., Band Edge Movement and Recombination Kinetics in Dye-Sensitized Nanocrystalline $\mathrm{TiO}_{2}$ Solar Cells: A Study by Intensity Modulated Photovoltage Spectroscopy. J. Phys. Chem. B 1997, 101, (41), 8141-8155.

25. Kay, A.; Grätzel, M., Artificial Photosynthesis. 1. Photosensitization of Titanium Dioxide Solar Cells with Chlorophyll Derivatives and Related Natural Porphyrins. J. Phys. Chem. 1993, 97, 6272-6277.

26. Wang, P.; Zakeeruddin, S. M.; Comte, P.; Charvet, R.; Humphry-Baker, R.; Grätzel, M., Enhance the performance of dye-sensitized photoelectrochemical cells by co-grafting amphiphilic sensitizer and hexadecyl malonic acid on $\mathrm{TiO}_{2}$ nanocrystals. $J$. Phys. Chem. B 2003, 107, (51), 14336-14341.

27. Neale, N. R.; Kopidakis, N.; van de Lagemaat, J.; Grätzel, M.; Frank, A. J., Effect of a Coadsorbent on the Performance of Dye-Sensitized $\mathrm{TiO}_{2}$ Solar Cells: Shielding versus Band-Edge Movement. J. Phys. Chem. B 2005, 109, (49), 23183-23189.

28. Yum, J.-H.; Jang, S.-r.; Humphry-Baker, R.; Grätzel, M.; Cid, J.-J.; Torres, T.; Nazeeruddin, M. K., Effect of Coadsorbent on the Photovoltaic Performance of Zinc Phthalocyanine-Sensitized Solar Cells. Langmuir 2008, 24, (10), 5636-5640.

29. Zhang, Z.; Zakeeruddin, S. M.; O'Regan, B. C.; Humphry-Baker, R.; Grätzel, M., Influence of 4-Guanidinobutyric Acid as Coadsorbent in Reducing Recombination in Dye-Sensitized Solar Cells. J. Phys. Chem. B 2005, 109, (46), 21818-21824.

30. Gregg, B. A.; Pichot, F.; Ferrere, S.; Fields, C. L., Interfacial Recombination Processes in Dye-Sensitized Solar Cells and Methods To Passivate the Interfaces. $J$. Phys. Chem. B 2001, 105, (7), 1422-1429.

31. Shockley, W.; Queisser, H. J., Detailed balance limit of efficiency of p-n junction solar cells. J. Appl. Phys. 1961, 32, 510-519.

32. Green, M. A.; Emery, K.; Hishikawa, Y.; Warta, W.; Dunlop, E. D., Solar cell efficiency tables (version 46). Prog. Photovoltaics 2011, 23, 805-812. 
33. O'Regan, B. C.; Scully, S.; Mayer, A. C.; Palomares, E.; Durrant, J., The Effect of $\mathrm{Al}_{2} \mathrm{O}_{3}$ Barrier Layers in $\mathrm{TiO}_{2} /$ Dye/CuSCN Photovoltaic Cells Explored by Recombination and DOS Characterization Using Transient Photovoltage Measurements. J. Phys. Chem. B 2005, 109, (10), 4616-4623.

34. Fabregat-Santiago, F.; Garcia-Canadas, J.; Palomares, E.; Clifford, J. N.; Haque, S. A.; Durrant, J. R.; Garcia-Belmonte, G.; Bisquert, J., The origin of slow electron recombination processes in dye-sensitized solar cells with alumina barrier coatings. $J$. Appl. Phys. 2004, 96, (11), 6903-6907.

35. Durrant, J. R.; Haque, S. A.; Palomares, E., Towards optimisation of electron transfer processes in dye sensitised solar cells. Coordin. Chem. Rev. 2004, 248, (13-14), $1247-1257$.

36. Palomares, E.; Clifford, J. N.; Haque, S. A.; Lutz, T.; Durrant, J. R., Control of Charge Recombination Dynamics in Dye Sensitized Solar Cells by the Use of Conformally Deposited Metal Oxide Blocking Layers. J. Amer. Chem. Soc. 2003, 125, (2), 475-482.

37. Bartelt, A. F.; Schutz, R.; Neubauer, A.; Hannappel, T.; Eichberger, R., Influence of $\mathrm{TiO}_{2} /$ Perylene Interface Modifications on Electron Injection and Recombination Dynamics. J. Phys. Chem. C 2009, 113, (50), 21233-21241.

38. Pawsey, S.; Yach, K.; Reven, L., Self-Assembly of Carboxyalkylphosphonic Acids on Metal Oxide Powders. Langmuir 2002, 18, (13), 5205-5212.

39. Pechy, P.; Rotzinger, F. P.; Nazeeruddin, M. K.; Kohle, O.; Zakeeruddin, S. M.; Humphry-Baker, R.; Grätzel, M., Preparation of phosphonated polypyridyl ligands to anchor transition-metal complexes on oxide surfaces: application for the conversion of light to electricity with nanocrystalline $\mathrm{TiO}_{2}$ films. J. Chem. Soc., Chem. Commun. 1995, (1), 65-66.

40. Wang, P.; Zakeeruddin, S. M.; Humphry-Baker, R.; Moser, J. E.; Grätzel, M., Molecular-scale interface engineering of $\mathrm{TiO}_{2}$ nanocrystals: Improving the efficiency and stability of dye-sensitized solar cells. Adv. Mater. 2003, 15, 2101-2104.

41. Zhang, L.; Cole, J. M., Anchoring Groups for Dye-Sensitized Solar Cells. ACS Appl. Mater. Interfaces 2015, 7, 3427-3455.

42. Goh, C.; Scully, S. R.; McGehee, M. D., Effects of molecular interface modification in hybrid organic-inorganic photovoltaic cells. J. Appl. Phys. 2007, 101, (11), 114503/1-114503/12.

43. Rivest, J. B.; Li, G.; Sharp, I. D.; Neaton, J. B.; Milliron, D. J., Phosphonic Acid Adsorbates Tune the Surface Potential of $\mathrm{TiO}_{2}$ in Gas and Liquid Environments. J. Phys. Chem. Lett. 2014, 5, 2450-2454. 
44. Kruger, J.; Bach, U.; Grätzel, M., Modification of $\mathrm{TiO}_{2}$ heterojunctions with benzoic acid derivatives in hybrid molecular solid-state devices. Adv. Mater. 2000, 12, (6), 447-451.

45. Ruehle, S.; Greenshtein, M.; Chen, S. G.; Merson, A.; Pizem, H.; Sukenik, C. S.; Cahen, D.; Zaban, A., Molecular Adjustment of the Electronic Properties of Nanoporous Electrodes in Dye-Sensitized Solar Cells. J. Phys. Chem. B 2005, 109, (40), 1890718913.

46. Nazeeruddin, M. K.; Humphry-Baker, R.; Officer, D. L.; Campbell, W. M.; Burrell, A. K.; Grätzel, M., Application of Metalloporphyrins in Nanocrystalline DyeSensitized Solar Cells for Conversion of Sunlight into Electricity. Langmuir 2004, 20, (15), 6514-6517.

47. Ambrosio, F.; Martsinovich, N.; Troisi, A., Effect of the Anchoring Group on Electron Injection: Theoretical Study of Phosphonated Dyes for Dye-Sensitized Solar Cells. J. Phys. Chem. C 2012, 116, (3), 2622-2629.

48. Ambrosio, F.; Martsinovich, N.; Troisi, A., What Is the Best Anchoring Group for a Dye in a Dye-Sensitized Solar Cell? J. Phys. Chem. Lett. 2012, 3, (11), 1531-1535.

49. Athanassov, Y.; Rotzinger, F. P.; Pechy, P.; Grätzel, M., Sensitized Electroluminescence on Mesoporous Oxide Semiconductor Films. J. Phys. Chem. B 1997, 101, (14), 2558-2563.

50. Bonhote, P.; Moser, J.-E.; Humphry-Baker, R.; Vlachopoulos, N.; Zakeeruddin, S. M.; Walder, L.; Grätzel, M., Long-Lived Photoinduced Charge Separation and RedoxType Photochromism on Mesoporous Oxide Films Sensitized by Molecular Dyads. $J$. Amer. Chem. Soc. 1999, 121, (6), 1324-1336.

51. Tosatti, S.; Michel, R.; Textor, M.; Spencer, N. D., Self-Assembled Monolayers of Dodecyl and Hydroxy-dodecyl Phosphates on Both Smooth and Rough Titanium and Titanium Oxide Surfaces. Langmuir 2002, 18, (9), 3537-3548.

52. Viornery, C.; Chevolot, Y.; Leonard, D.; Aronsson, B.-O.; Pechy, P.; Mathieu, H. J.; Descouts, P.; Grätzel, M., Surface Modification of Titanium with Phosphonic Acid To Improve Bone Bonding: Characterization by XPS and ToF-SIMS. Langmuir 2002, 18, (7), 2582-2589.

53. Adden, N.; Gamble, L. J.; Castner, D. G.; Hoffmann, A.; Gross, G.; Menzel, H., Phosphonic Acid Monolayers for Binding of Bioactive Molecules to Titanium Surfaces. Langmuir 2006, 22, (19), 8197-8204. 
54. Clifford, J. N.; Palomares, E.; Nazeeruddin, M. K.; Grätzel, M.; Durrant, J. R., Dye Dependent Regeneration Dynamics in Dye Sensitized Nanocrystalline Solar Cells: Evidence for the Formation of a Ruthenium Bipyridyl Cation/Iodide Intermediate. $J$. Phys. Chem. C 2007, 111, (17), 6561-6567.

55. Li, X. S.; Fryxell, G. E.; Birnbaum, J. C.; Wang, C., Effects of Template and Precursor Chemistry on Structure and Properties of Mesoporous $\mathrm{TiO}_{2}$ Thin Films. Langmuir 2004, 20, (21), 9095-9102.

56. Cherian, S.; Wamser, C. C., Adsorption and photoactivity of tetra(4carboxyphenyl)porphyrin (TCPP) on nanoparticulate TiO2. Journal of Physical Chemistry B 2000, 104, (15), 3624-3629.

57. Gouterman, M., Optical Spectra and Electronic Structure of Porphyrins and Related Rings. In The Porphyrins, Dolphin, D., Ed. Academic Press: New York, 1978; Vol. III, pp 1-165. 